\title{
Cell-type specific CD40-CD40L interactions in atherosclerosis
}

Citation for published version (APA):

Lievens, D. (2010). Cell-type specific CD40-CD40L interactions in atherosclerosis. [Doctoral Thesis, Maastricht University]. die Keure. https://doi.org/10.26481/dis.20100128dl

Document status and date:

Published: 01/01/2010

DOI:

$10.26481 /$ dis.20100128dl

Document Version:

Publisher's PDF, also known as Version of record

\section{Please check the document version of this publication:}

- A submitted manuscript is the version of the article upon submission and before peer-review. There can be important differences between the submitted version and the official published version of record.

People interested in the research are advised to contact the author for the final version of the publication, or visit the DOI to the publisher's website.

- The final author version and the galley proof are versions of the publication after peer review.

- The final published version features the final layout of the paper including the volume, issue and page numbers.

Link to publication

\footnotetext{
General rights rights.

- You may freely distribute the URL identifying the publication in the public portal. please follow below link for the End User Agreement:

www.umlib.nl/taverne-license

Take down policy

If you believe that this document breaches copyright please contact us at:

repository@maastrichtuniversity.nl

providing details and we will investigate your claim.
}

Copyright and moral rights for the publications made accessible in the public portal are retained by the authors and/or other copyright owners and it is a condition of accessing publications that users recognise and abide by the legal requirements associated with these

- Users may download and print one copy of any publication from the public portal for the purpose of private study or research.

- You may not further distribute the material or use it for any profit-making activity or commercial gain

If the publication is distributed under the terms of Article $25 \mathrm{fa}$ of the Dutch Copyright Act, indicated by the "Taverne" license above, 

CELL-TYPE SPECIFIC CD40-CD40L INTERACTIONS IN ATHEROSCLEROSIS

» layout: Tom Hoorens

» cover design: Jolyn Vanneste

" press: Die Keure, Bruges, Belgium

" (c) 2010 Dirk Lievens, Maastricht

»ISBN/EAN : 978-90-9025012-0 financial support:

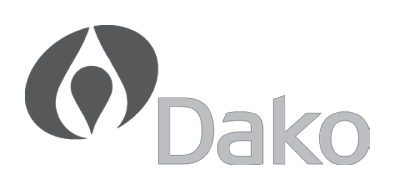


Gratitude is the best attitude

Aan mijn ouders, voor Jolyn 
Promotor

Prof. dr. E.A. Biessen

Prof. dr. M.J.A.P. Daemen

\section{Copromotor}

Dr. E. Lutgens

Beoordelingscommissie

Prof. dr. H. ten Cate (voorzitter)

Prof. dr. W.A. Buurman

dr. S. Heymans

Prof. dr. J. Borst (NKI Amsterdam)

Prof. dr. S. Massberg (TU Munich, Germany)
CELL-TYPE SPECIFIC CD40-CD40L INTERACTIONS IN ATHEROSCLEROSIS

\section{PROEFSCHRIFT}

Ter verkrijging van de graad van doctor aan de Universiteit Maastricht, op gezag van de Rector Magnificus, Prof. Mr. G.P.M.F. Mols

volgens het besluit van het College van Decanen,

in het openbaar te verdedigen

op donderdag 28 januari 2010 om 14 uur

doo

Dirk Lievens

geboren 4 augustus 1980 te Keulen.
Financial support by the Netherlands Heart Foundation for the publication of tis thesis is gratefully acknowledged.

The research described in this thesis was supported by a grant of the Netherlands Heart Foundation (NHF-2000T41/2000T4101) 


\section{CONTENTS}


2. The multi-functionality of $\mathrm{CD} 40 \mathrm{~L}$ and its receptor $\mathrm{CD} 40$ in atherosclerosis

Thromb Haemost. 2009 Aug; 102(2):206-14

3. $\mathrm{CD} 40$ and its ligand in atherosclerosis

Trends Cardiovasc Med. 2007 May; 17(4):118-23.

4. CD40L deficiency protects against aneurysm formation: a novel prevention strategy?

under revision

5. Deficiency of TGF- $\beta$ signaling in CD11c positive cells accelerates atherosclerosis by disrupting T-cell homeostasis

submitted

6. Platelet $\mathrm{CD} 40 \mathrm{~L}$ mediates thrombotic and inflammatory processes in atherosclerosis

submitted

7. The CD40-TRAF6 axis is the key regulator of the CD40-CD40L system in neointima formation and arterial remodeling

Blood. 2008 May 1; 111(9):4596-604.

8. Deficient CD40-TRAF6 signaling in leukocytes prevents atherosclerosis by skewing the immune response towards an anti-inflammatory profile accepted in the Journal of Experimental Medicine

9. Discussion

Summary/samenvatting

Curriculum vitae

Dankwoord 


\author{
GENERAL
}

INTRODUCTION 
Atherosclerosis, a disease of the large and middle sized arteries, is the primary underlying cause of cardiovascular disease (CVD) such as ischemic heart disease and stroke. ${ }^{1}$ In the US only, an estimated 80 million American adults (one out of three) have one or more types of CVD, of whom 38.1 million are age 60 or older. ${ }^{2}$ Mortality due to CVD (including congenital cardiovascular defects) accounted for $35.3 \%$ of all deaths in 2005, or one of every 2.8 deaths in the United States. ${ }^{2}$ In addition, data from World Health Organization (WHO) demonstrate that CVD is the principle cause of death worldwide : $30 \%$ of al deaths throughout the world are due to heart diseases. Furthermore, the future scenario pictured by the WHO predicts an increase in the rate of morbidity and mortality especially in emerging countries.

Atherosclerosis is characterized by the accumulation of lipids, cells and debris in the arterial wall : the atherosclerotic lesion or plaque. Atherosclerosis is an asymptomatic process that starts during childhood and progresses with age. The early, initial lesions consist of subendothelial accumulations of cholesterol-loaded macrophages (the foam cells) and are referred to as fatty streaks. Progression of atherosclerotic lesions is associated with haemodynamic and genetic factors as well as acquired risk factors including hypertension, tobacco smoking, diabetes mellitus, and obesity. The progression-pattern towards advanced lesions is characterized by the accumulation of a lipid-rich necrotic debris enclosed by a fibrous cap consisting of smooth muscle cells (SMC) and extracellular matrix. ${ }^{1}$ These advanced lesions are regarded as stable lesions. However, destruction of the extracellular matrix will weaken the fibrous cap and will lead to plaque instability. ${ }^{3}$ Vulnerable plaques generally have thin fibrous caps and increased numbers of inflammatory cells. Although advanced lesions can grow sufficiently large to block blood flow, the most important clinical complication is an acute occlusion due to rupture of a fibrous cap and the subsequent formation of a thrombus. ${ }^{4}$ Nevertheless, many plaque-ruptures are clinically silent and heal as can be detected on postmortem assessment. ${ }^{5}$

\section{Atherosclerosis, a historical perspective}

Pathologists identified atherosclerotic lesions well before establishing a causal relation between the histological observations found in arteries at autopsy and the clinical syndromes of coronary artery disease. ${ }^{6}$ Atherosclerosis has weighed down on mankind since ancient times. Atherosclerotic lesions were already apparent in pharaoh mummies more than 3500 years ago. ${ }^{7}$ In 1829, The French pathologist Jean Lobstein (1777-1835) first used the term "arteriosclerosis", which he defined as sclerotic changes of the arterial wall in his unfinished four-volume work titled "Traité d'anatomie pathologique", which was based on his personal experiences as a pathologist. The German pathologist Rudolf Ludwig Karl Virchow (1821-1902) was the first to identify the primary role of cellular inflammatory changes in the atherosclerotic lesions. He considered the atheroma as a chronic inflammatory disease of the intima; "chronic endarteritis deformans". ${ }^{8}$ By this he meant that the atheroma was a product of an inflammatory process within the intima and that the fibrous thickening evolved as a consequence of a reactive fibrosis induced by proliferating connective tissue cells. ${ }^{9}$ Virchow is best known for his theory "Omnis cellula e cellula" (every cell originates from another existing cell like it), which he published in 1858. In 1910, the German chemist Adolf Windaus (1876-1959) described that atherosclerotic plaques consist of calcified connective tissue and cholesterol. Finally, in 1904 Marchand first uses the term atherosclerosis from the Greek "athero", meaning gruel, and "sclerosis", meaning hardening, to describe the degenerative process of the intimal layer of the arteries. In 1914, Anitschkow described the role of cholesterol accumulation in the vessel wall for the development of atherosclerosis. He used a cholesterol-fed rabbit model and described the 'Cholesterinester-phagozyten', which today we commonly know as foam cells. ${ }^{10}$ In this context, a major contribution was the discovery of the LDL-receptor in the 1970s and its importance for the development of atherosclerosis by Brown and Goldstein. ${ }^{11}$ However, one of the most important theories was the 'response to injury hypothesis' by Ross and suggested that atherosclerosis is the result of endothelial denudation. ${ }^{12,}{ }^{13}$ More recent versions of this hypothesis emphasized endothelial dysfunction rather than denudation and in 1999 Ross wrote his renowned review entitled: "Atherosclerosis - An Inflammatory Disease". ${ }^{14}$ Today, the initiative that atherosclerosis is a chronic inflammatory disease is widely acknowledged.

\section{Atherosclerosis research today}

Over the past decade, the availability of new investigative tools, including genetically modified mouse models of disease, has resulted in an improved knowledge of the molecular mechanisms of atherosclerosis. These novel insights connect altered cholesterol metabolism, inflammatory cell influx and other risk factors to the development of atherosclerotic plaques. Today we recognize atherosclerosis not simply as an inevitable degenerative consequence of ageing, but as a chronic inflammatory condition that can be converted into an acute clinical event by plaque rupture and thrombosis. Several studies reported the presence of the most prominent cells of both the innate and adaptive immune system, such as macrophages, T-cells, dendritic cells (DC), neutrophils, natural killer (NK) cells, mast cells and B-cells in the atherosclerotic plaque. ${ }^{15,16}$ The inflammatory reaction and recruitment involves complex interactions between different cells of the immune system and cells of the vasculature. Recently, a prominent inflammatory and pro-atherogenic role was also attributed to platelets. ${ }^{17-19}$ 
A multiplicity of cytokines, chemokines and growth factors orchestrates the inflammatory component of atherogenesis and forms the basis of numerous intervention studies. ${ }^{8,20}$ However, the exact mediators and mechanisms that evoke these chronic inflammatory processes implicated in plaque formation and progression together with the formation of unstable lesions, still need to be fully elucidated. In the late 90 s, our lab and others discovered that CD40-CD40L interaction was a potent immune-modulator of atherosclerosis. Altough we found that inhibition of $\mathrm{CD} 40 \mathrm{~L}$ reduced atherosclerosis and induced plaque stability, the underlying mechanisms remain largely unidentified. Elucidation of the exact role of CD40-CD40L interactions in atherosclerosis forms the foundation of this thesis.

\section{The immunobiology of the CD40-CD40L co-stimulatory dyad in atherosclerosis}

CD40-CD40L co-stimulatory molecules are known as crucial regulators of immune responses. ${ }^{21,22} \mathrm{CD} 40$ is an integral membrane protein of the Tumor Necrosis Factor receptor (TNF-R) family. CD40 lacks intrinsic signaling activity, and upon activation, recruits adaptor molecules, TRAFs. TRAF proteins bind to the cytoplasmic tail of CD40 and subsequently mediate the activation of multiple signaling cascades (chapter $\mathbf{2}$ and $\mathbf{3}$ of this thesis). ${ }^{23}$ CD40 was originally thought to be restricted to B-cells, dendritic cells and basal epithelial cells, whereas CD40L, the ligand of CD40 and a member of the TNF family, was thought to be restricted to activated T-cells. Recent studies, however, identified CD40 and/or CD40L in the majority of the cell types present in the atherosclerotic plaques (macrophages, smooth muscle cells, T-cells and endothelial cells), as well as in the circulation (platelets). ${ }^{24,25}$

Intervention studies in mice clearly demonstrated that deficiency of CD40L significantly reduces atherosclerosis formation. ${ }^{26,27}$ Moreover, plaques of animals deficient in CD40L displayed a remarkable phenotype. Advanced atherosclerotic lesions contained increased amounts of collagen and smooth muscle cells, while plaque lipid levels and the number of inflammatory cells were strongly reduced. ${ }^{25,28,29}$ These plaques are the equivalent of clinically favourable, stable plaques in humans. Also, both early and delayed treatment with an anti-CD40L antibody did not affect atherosclerotic lesion initiation, but resulted in the development of a lipid-poor, collagen-rich stable plaque phenotype. ${ }^{30}$ One of the proposed mechanisms of this effect on plaque phenotype is the up-regulation of collagen-promoting factors and anti-inflammatory cytokines like transforming growth factor $\beta$ (TGF- $\beta$ ). TGF- $\beta$ is an immunosuppressive agent that is highly effective in suppressing a wide variety of cellmediated immune responses.

\section{Hypothesis and outline of the thesis}

The inflammatory competence of CD40-CD40L signaling in atherosclerosis has been an exciting subject of research for the last decade. Activation of CD40-signaling promotes the initiation, progression and destabilization of atherosclerotic plaques. Therefore, intervening in this co-stimulatory pathway could generate prospects for treatment of atherosclerosis. However, the mechanisms of CD40-CD40L signaling have been proven to be particularly complex. Virtually all cell types present in the atherosclerotic plaque and in the circulation express $\mathrm{CD} 40$ and/or CD40L although their relative contribution to atherogenesis remains to be elucidated. Therefore, the clarification of the individual contribution of each of the different $\mathrm{CD} 40$ (L) expressing cell types towards atherogenesis outlines the basis of this thesis. Furthermore, the recent discovery of the important CD40-signaling pathways in atherosclerosis offers a new challenge in the development of therapeutic agents.

Therefore we hypothesize that elucidating cell-type specific CD40-CD40L interactions together with the different CD40 downstream signaling cascades will reveal insight in the the mechanism of CD40-CD40L signaling in atherosclerosis.

In chapter 2 and $\mathbf{3}$ we review the multifunctionality of cell type specific CD40-CD40L signaling in atherosclerosis and shed light on the different CD40-CD40L signaling cascades. In addition we theorize on the therapeutic potential of $\mathrm{CD} 40(\mathrm{~L})$ inhibition. Considering the imperative role of $\mathrm{CD} 40-\mathrm{CD} 40 \mathrm{~L}$ signaling on both inflammation and extracellular matrix degradation, and its profound effects on atherosclerosis, we hypothesised in chapter 4 that CD4OL plays a pivotal role in aneurysm formation. Since inhibition of CD4OL increases TGF- $\beta$ levels, we address in chapter 5 cell type specific TGF- $\beta$ signaling. We analyze the effect of TGF- $\beta$ signaling in CD11c expressing cell-types. CD11c is mainly expressed in dendritic cells (DC) and natural killer (NK) cells. We developed a construct that contains a dominant negative TGF- $\beta$ receptor II and placed it under a CD11c promotor. Thereby we were able to analyze the effect of CD11c positive cells that lack TGF- $\beta$ signaling in atherosclerosis development. In chapter 6 we determine the effect of platelet CD40L in atherosclerosis. Platelets play a major role in the hemostatic process and in thrombus formation after endothelium injury. However, recent studies have provided insight into platelet function in inflammation and atherosclerosis. ${ }^{7,31-33}$ Today platelets are seen as true immune cells. By using a unique mouse model of Ley et al. ${ }^{19}$ we were able to investigate the effect of platelets and especially the effect of deficiency in platelet CD40L on both the initiation and the progression of atherosclerosis. In chapter 7 we investigate the role of CD40 and CD40L in neointima formation and vascular remodelling using a mouse model of carotid artery ligation and we identified which TRAF members were involved in these processes. In chapter 
8 we clarify the role of $\mathrm{CD} 40$ in primary atherosclerosis. By transplanting $\mathrm{CD} 40 \%$ bone marrow into $L D L^{\prime}{ }^{-}$recipients we were able to analyze the cell type specific effect of CD40 expressing bone marrow cells on atherosclerosis formation.

The second aim of this thesis was to identify which CD40 signaling cascade was important in atherosclerosis. Both in chapter $\mathbf{7}$ and $\mathbf{8}$ we elucidate the effect of the different CD40 dependent TRAF signaling cascades on atherosclerosis formation.

Finally, in chapter 9 the experimental results obtained in this thesis are discussed and further perspectives are given. 


\section{References}

1. Lusis, A.J. Atherosclerosis. Nature 407, 233-241 (2000)

2. Lloyd-Jones, D., et al. Heart disease and stroke statistics--2009 update : a report from the American Heart Association Statistics Committee and Stroke Statistics Subcommittee. Circulation 119, 480-486 (2009).

3. Newby, A.C. Metalloproteinase expression in monocytes and macrophages and its relationship to atherosclerotic plaque instability. Arterioscler Thromb Vasc Biol 28, 2108-2114 (2008).

4. Burke, A.P. \& Virmani, R. Pathophysiology of acute myocardial infarction. Med Clin North Am 91, 553-572; ix (2007).

5. Burke, A.P., et al. Healed plaque ruptures and sudden coronary death : evidence that subclinical rupture has a role in plaque progression. Circulation 103, 934-940 (2001).

6. Mayerl, C., et al. Atherosclerosis research from past to present--on the track of two pathologists with opposing views, Carl von Rokitansky and Rudolf Virchow. Virchows Arch 449, 96-103 (2006).

7. Cockburn, A., Barraco, R.A., Reyman, T.A. \& Peck, W.H. Autopsy of an Egyptian mummy. Science 187, 1155-1160 (1975).

8. Tedgui, A. \& Mallat, Z. Cytokines in atherosclerosis : pathogenic and regulatory pathways. Physiol Rev 86, 515-581 (2006).

9. Ventura, H.O. Profiles in cardiology. Rudolph Virchow and cellular pathology. Clin Cardiol 23, 550-552 (2000).

10. Hanke, H., Lenz, C. \& Finking, G. The discovery of the pathophysiological aspects of atherosclerosis--a review. Acta Chir Belg 101, 162-169 (2001).

11. Goldstein, J.L. \& Brown, M.S. The LDL receptor. Arterioscler Thromb Vasc Biol 29, 431-438 (2009).

12. Ross, R., Glomset, J. \& Harker, L. Response to injury and atherogenesis. Am J Pathol 86, 675-684 (1977).

13. Ross, R. \& Glomset, J.A. Atherosclerosis and the arterial smooth muscle cell : Proliferation of smooth muscle is a key event in the genesis of the lesions of atherosclerosis. Science 180, 1332-1339 (1973).

14. Ross, R. Atherosclerosis--an inflammatory disease. N Engl J Med 340, 115-126 (1999).

15. Weber, C., Zernecke, A. \& Libby, P. The multifaceted contributions of leukocyte subsets to atherosclerosis: lessons from mouse models. Nat Rev Immunol 8, 802-815 (2008).

16. Galkina, E. \& Ley, K. Immune and inflammatory mechanisms of atherosclerosis (*). Annu Rev Immunol 27, 165-197 (2009).

17. Massberg, S., et al. A Critical Role of Platelet Adhesion in the Initiation of Atherosclerotic Lesion Formation. J. Exp. Med. 196, 887-896 (2002).

18. van Gils, J.M., da Costa Martins, P.A., Mol, A., Hordijk, P.L. \& Zwaginga, J.J. Transendothelial migration drives dissociation of plateletmonocyte complexes. Thromb Haemost 100, 271-279 (2008).

19. Huo, Y., et al. Circulating activated platelets exacerbate atherosclerosis in mice deficient in apolipoprotein E. Nat Med 9, 61 (2003).

20. Weber, C., Schober, A. \& Zernecke, A. Chemokines: key regulators of mononuclear cell recruitment in atherosclerotic vascular disease. Arterioscler Thromb Vasc Biol 24, 1997-2008 (2004).

21. Grewal, I.S. \& Flavell, R.A. CD40 and CD154 in cell-mediated immunity. Annu Rev Immunol 16, 111-135 (1998).

22. Noelle, R.J., Ledbetter, J.A. \& Aruffo, A. CD40 and its ligand, an essential ligand-receptor pair for thymusdependent B-cell activation. Immunol Today 13, 431-433 (1992).
23. Zapata, J.M. TNF-receptor-associated factors as targets for drug development. Expert Opin Ther Targets 7, 411-425 (2003).

24. Henn, V., et al. CD40 ligand on activated platelets triggers an inflammatory reaction of endothelial cells. Nature 391, 591 (1998).

25. Schonbeck, U. \& Libby, P. CD40 signaling and plaque instability. Circ Res 89, 1092-1103 (2001).

26. Mach, F., Schonbeck, U., Sukhova, G.K., Atkinson, E. \& Libby, P. Reduction of atherosclerosis in mice by inhibition of CD40 signaling. Nature 394, 200-203 (1998).

27. Lutgens, E., et al. Requirement for CD154 in the progression of atherosclerosis. Nat Med 5, 1313-1316 (1999).

28. Schonbeck, U., Sukhova, G.K., Shimizu, K., Mach, F. \& Libby, P. Inhibition of CD40 signaling limits evolution of established atherosclerosis in mice. Proc Natl Acad Sci U S A 97, 7458-7463 (2000).

29. Lutgens, E., Lievens, D., Beckers, L., Donners, M. \& Daemen, M. CD40 and its ligand in atherosclerosis. Trends Cardiovasc Med 17, 118-123 (2007).

30. Lutgens, E., et al. Both early and delayed anti-CD40L antibody treatment induces a stable plaque phenotype. Proc Natl Acad Sci U S A 97, 7464-7469 (2000).

31. Huo, Y. \& Ley, K.F. Role of Platelets in the Development of Atherosclerosis. Trends in Cardiovascular Medicine 14, 18 (2004).

32. von Hundelshausen, P. \& Weber, C. Platelets as immune cells: bridging inflammation and cardiovascular disease. Circ Res 100, 27-40 (2007).

33. Gawaz, M., Langer, H. \& May, A.E. Platelets in inflammation and atherogenesis. J. Clin. Invest. 115, 33783384 (2005). 
THE MULTI-FUNCTIONALITY OF CD40L AND ITS RECEPTOR CD40 IN ATHEROSCLEROSIS 


\section{Summary}

Disrupting the CD40-CD40L co-stimulatory pathway reduces atherosclerosis and induces a stable atherosclerotic plaque phenotype that is low in inflammation and high in fibrosis. Therefore, inhibition of the CD40-CD40L pathway is an attractive therapeutic target to reduce clinical complications of atherosclerosis. The CD40-CD40L dyad is known to interact with other co-stimulatory molecules, to activate antigen-presenting cells (APC) and to contribute to T-cell priming and B-cell isotype switching. Besides their presence on Tcells and APCs, CD40 and CD40L are also present on macrophages, endothelial cells and vascular smooth muscle cells in the plaque, where they can exert pro-atherogenic functions. Moreover, recent progress indicates the involvement of neutrophil CD40, platelet CD40L and dendritic cell CD40 in atherogenesis. Since systemic CD40-CD40L modulation compromises host defense, more targeted interventions are needed to develop superior treatment strategies for atherosclerosis. We believe that by unraveling the cell-cell CD40$\mathrm{CD} 40 \mathrm{~L}$ interactions, inhibition of cell-type specific (signaling components of) $\mathrm{CD} 40(\mathrm{~L})$ that do not compromise the patient's immune system, will become possible. In this review, we highlight the cell-type specific multi-functionality of CD40-CD40L signaling in atherosclerosis.

\section{Introduction}

In the late 1990s it became clear that atherosclerosis is a chronic inflammatory disorder of the arterial wall. ${ }^{1-3}$ Today we know that the process of atherosclerosis is a complex interplay between modified lipids, different cells of the immune system, endothelial cells and smooth muscle cells. Even more, the understanding of the pathophysiology of atherosclerosis entered a new era. Elegant new studies describe the diversity of cell types involved in atherogenesis. ${ }^{4}$ Besides the well known cell-types like monocytes, T-cells and B-cells, different monocyte subsets (e.g. Ly- $6 \mathrm{C}^{\text {hi }}$, Ly- $\left.6 \mathrm{C}^{10}\right)^{5-8}$ and T-cell subsets (e.g. CD4+ T-helper cells [Th1, Th2, Th17], CD8+ cytotoxic T-cells, regulatory T-cells) ${ }^{9}$ have been described to be present in plaques and to be causally implicated in the disease process. Furthermore, unexpected roles for neutrophils, ${ }^{10,11}$ mast cells, ${ }^{12,13}$ dendritic cells ${ }^{14}$ and platelets ${ }^{15,16}$ in atherosclerosis were recently discovered.

A receptor-ligand pair that has been shown to play an important role in atherosclerosis is the CD40-CD40L dyad. CD40 is a member of the tumor necrosis factor receptor (TNF-R) superfamily ${ }^{17}$ that is activated by CD40 ligand (CD40L, also known as CD154), a 39 kD transmembrane glycoprotein and member of the Tumor Necrosis Factor $\alpha$ (TNF- $\alpha$ ) family. CD40L can also be shedded into a soluble (s)CD40L form. $\mathrm{SCD} 40 \mathrm{~L}$ is a truncated form (18kDa) of the $\mathrm{CD} 40 \mathrm{~L}$ protein. ${ }^{18} \mathrm{SCD} 40 \mathrm{~L}$ retains the ability to bind the $\mathrm{CD} 40$ receptor as a trimeric ligand and is believed to be biologically active. However, its repertoire of functional activities and potential differences between $\mathrm{CD} 40 \mathrm{~L}$ and $\mathrm{SCD} 40 \mathrm{~L}$ remain to be further elucidated. CD40-CD40L interactions are originally known as co-stimulatory molecules indispensable for the function of antigen presenting cells and activated CD4+ T-cells. Nevertheless, CD40 and CD40L are both expressed on the vast majority of immune cells (lymphocytes, monocytes, dendritic cells, neutrophils and mast cells) and non-immune cells (e.g. endothelial cells and vascular smooth muscle cells) and epithelial cells. ${ }^{19}$ In addition, platelets have been shown to be the main source of circulating CD4OL and SCD4OL.

CD40-CD40L signaling induces cell-proliferation, -differentiation and -activation, which is characterized by the release of a wide range of cytokines (e.g. IL-1 $\beta$, IL-2, TNF- $\alpha$, IFN- $\gamma$ ) and growth factors (VEGF) that exert many pro- and anti-inflammatory effects. ${ }^{20,21}$ Furthermore, CD40-CD40L signaling results in the expression of chemokines (e.g. MCP-1, RANTES) and endothelial adhesion molecules (e.g. ICAM-1, VCAM-1, P-selectin) that stimulate trafficking of leukocytes and regulate the migration of different cell types. ${ }^{22,23}$

Both CD40 and CD40L are present in human atherosclerotic lesions. Macrophages, smooth muscle cells, endothelial cells and T-cells express CD40 and CD40L in fatty streaks and the expression increases in advanced human atherosclerotic lesions. ${ }^{24-26}$ CD40-CD40L interactions mediate several of the processes that set the stage for plaque rupture, like degradation of the extracellular matrix and formation of the necrotic core. ${ }^{19}$ Moreover, we, and others showed that mice deficient in CD40L have less atherosclerosis and develop plaques that are low in inflammation and high in fibrosis, generally referred to as a stable plaque phenotype. ${ }^{27-30}$ This review will focus on the potential atherogenic effects of CD40-CD40L signaling in the individual cell types relevant to atherosclerosis and their impact on the overall effect of CD40 signaling on plaque formation and stability.

\section{CD40-CD40L inhibition in atherosclerosis}

Multiple intervention studies have revealed the pro-atherogenic effects of CD40-CD40L signaling. In 1998, Mach et al showed that hyperlipidemic LDLR ${ }^{-/}$mice treated with an anti-CD4OL antibody significantly reduced the size and lipid content of aortic atherosclerotic lesions. ${ }^{30}$ In 1999, we showed that $\mathrm{CD} 4 \mathrm{~L}^{-/} \mathrm{ApoE} \mathrm{E}^{-/}$mice exhibited a 5.5 fold decrease in plaque area. ${ }^{27}$ Moreover, $\mathrm{CD}^{2} \mathrm{LL}^{-/-} \mathrm{ApoE}-\mathrm{E}^{-/}$animals contained pronounced collagen-rich, lipid-poor advanced plaques with a decreased macrophage and T-cell content. In a followup study, we used an anti-CD40L antibody (MR-1) to block CD40L signaling. ${ }^{29}$ Anti-CD40L was administered in $\mathrm{ApoE}^{-/}$mice on normal chow diet, either at the onset of atherosclerosis or when established atherosclerotic lesions were already present. In both the early and delayed treatment groups, anti-CD4OL antibody treatment did not result in a decrease 
in plaque area but resulted in the development of a lipid-poor, collagen-rich stable plaque phenotype. Schonbeck et al. showed similar results with an anti-CD40L antibody (M158, Immunex) treatment in LDLR ${ }^{-/}$mice that were on high fat diet. ${ }^{30-32}$

These findings provided novel insights in the inflammatory pathway of atherosclerosis and identified CD40-CD40L interactions as a promising therapeutic target to improve plaque stability, even when established atherosclerotic lesions are present. Thus, inhibition of CD40-CD40L interactions is expected to prevent clinical complications of atherosclerosis, thereby reducing (atherosclerosis)-related morbidity and mortality. It has been suggested that, long-term inhibition of the CD40-CD40L axis might severely compromise the immune system of the patient, thereby hampering the therapeutic potential of this target. However, in a phase I trial, using a monoclonal anti-CD40L antibody (IDEC-131) for patients suffering from systemic lupus erythematosus (SLE), no side effects were observed. ${ }^{33}$ Patients received a single intravenous injection. However, no further development for this indication has been reported. ${ }^{34}$ In addition, Schuler et al. tested a humanized CD40L monoclonal antibody (ABI793) in renal allotransplantations. ${ }^{35} \mathrm{ABI} 793$ treatment indeed effectively prevented graft rejection in cynomolgus monkeys. Since treatment was accompanied by thromboembolic events, all clinical trials were put on hold. In these studies, only a single or a couple of doses were administered. In order to contribute to plaque stabilization, long term treatment will be necessary, which may even lead to more severe and frequent adverse side effects. However, as a potential alternative to CD40L therapy targeting of CD40, the receptor for $\mathrm{CD} 40 \mathrm{~L}$ would be feasible. In allotransplantation research, two promising anti-CD40 antibodies were developed: Chi220 in 2002 and 4D11 in 2007. ${ }^{36,37}$ Both antibodies appear to be an encouraging agent for anti-rejection treatment in clinical organ transplantation. Satisfying prolonged allograft survivals in monkeys were obtained without thromboembolic complications. Both antibodies open a new perspective for inhibition of the CD40-CD40L system in atherosclerosis.

Given the complex, cell specific mode of action of CD40 signaling, we believe it is necessary to study cell-type specific CD40-CD40L signaling. This will enable us to identify the cell-cell CD40-CD40L interactions that are responsible for the destabilization of the atherosclerotic lesion and thus to target CD40-CD40L signaling in a cell-specific manner with minimal side effects. In addition, it will be essential to elucidate the cell-type specific CD40-CD40L signaling cascade in order to find downstream targetable molecules that will allow targeted blockage of CD40 signaling in an atherosclerosis-specific way.

\section{The CD40-CD40L system}

CD40 lacks intrinsic signaling activity and needs to recruit adaptor molecules upon activation. Ligation of $\mathrm{CD} 40 \mathrm{~L}$ to $\mathrm{CD} 40$ results in trimerization of $\mathrm{CD} 40$ receptor molecules and subsequent association of adaptor proteins (TNF receptor-associated factors, or TRAFs) to its cytoplasmic domain.

The TRAF protein family is composed of six members (TRAF 1,2,3,4,5 and 6). CD40 can bind five of the six TRAF members (TRAF 1,2,3,5 and 6), depending on cell type and function. CD40 has 3 TRAF binding domains, one for TRAF6 and one for TRAF2\&3 and, indirectly, TRAF5. Recently, Lu et al. identified a new functional domain within the cytoplasmic tail of CD40 that contains an alternative TRAF2 binding-site. ${ }^{38}$ These binding sites can initiate different downstream signaling pathways resulting in a broad range of cell-type specific actions of CD40-CD40L. For example, in B-lymphocytes, CD40-TRAF6 interactions are required for CD40-mediated IgM production, isotype switching and B-cell induced IL- 6 secretion, whereas the TRAF2/3/5 binding site is required for CD40-mediated upregulation of the co-stimulatory molecules B7-1 and B7-2. ${ }^{39,40}$ Signaling results in the activation and nuclear translocation of different transcription factors, e.g. NF-kB, NFAT and AP-1 leading to the production of pro-inflammatory and pro-atherogenic cytokines/chemokines, growth factors (e.g. VEGF), matrix metalloproteinases (MMPs), and adhesion molecules, depending on the cell-type and CD40-TRAF binding site involved. ${ }^{19}$

Only scattered information exists on CD40-TRAF signaling that is induced by SCD40L. ${ }^{41}$ When CD40L binds to CD40 on endothelial cells, CD40 is internalized into the membrane associated lipid raft fraction, where binding of TRAF1/2/3/5 and/or TRAF6 occurs, followed by activation of NFkB and subsequent induction of inflammation, However, when SCD40L binds to CD40 rapid endocytosis of the CD40 receptor is induced independently of TRAF2/3/5/6 binding. Upon binding of SCD40L to CD40, CD40 translocates to the early, rab5+ endosome, activates NFkB but fails to induce expression of pro-inflammatory cytokines and adhesion molecules. Since only scattered, but important information on this subject is available, further characterization of the signaling network of the different forms of CD40L, as well as of the different CD40-expressing cell-types is needed.

The discovery of this complex signaling pathway heralds a new area in the development of therapeutic agents with limited side effects. Different cell types have their own specific TRAF mediated CD40-CD40L signaling pathway. Therefore, we need to find the CD40-TRAF interactions important in atherosclerosis as well as the cell-type specific CD40-TRAF signaling. 
In a recent study we induced neointima formation in mice that express a human/mouse chimeric CD40 transgene (human CD40 extracellular domain; mouse CD40 transmembrane and cytoplasmic domain) under a major histocompatability complex (MHC) II promoter and contains mutations at the TRAF2,3\&5 (CD40-T2/3/5), TRAF6 (CD40-T6), or both the TRAF2/3/5 and TRAF6 (CD40-T2/3/5\&6) binding site. Using these unique mouse models we were able to determine the leukocyte specific CD40L signaling in relationship with neointima formation. ${ }^{42}$ In this study we identified TRAF6 as the key player in CD40L signaling in leukocytes in neointima formation. Moreover, CD40-TRAF6 signaling was required for inflammatory cell infiltration and collagen turnover in the neointima. ${ }^{42}$

Even though we have identified the key factors in CD40 signaling, the exact mechanisms still need to be unraveled. Elucidating the exact mechanisms will open opportunities to develop more specialized treatment with fewer side effects.

\section{Cell-type specific CD40-CD40L signaling}

It has become evident that CD40 and/or CD40L are expressed on the majority of cell types involved in atherosclerosis (table 2.1). In these paragraphs we will elaborate on the (proatherogenic) consequences of CD40-CD40L signaling of the distinct cell-types that have a role in plaque progression and destabilization.

Table 2.1

\begin{tabular}{|c|c|c|c|c|c|}
\hline \multirow{2}{*}{ Cell type } & \multicolumn{2}{|c|}{ CD40 } & \multicolumn{2}{|c|}{ CD40L } & \multirow{2}{*}{ Forms of CD40L } \\
\hline & Resting & Activated & Resting & Activated & \\
\hline CD4+ T-cells & - & +++ & - & +++ & Membrane, soluble \\
\hline B-cells & +++ & +++ & ++ & +++ & Membrane \\
\hline Macrophages & + & +++ & + & +++ & Membrane \\
\hline Platelets & ++ & +++ & - & +++ & Membrane, soluble \\
\hline Dendritic cells & _- & +++ & + & + & Membrane \\
\hline Neutrophils & + & +++ & + & + & Membrane \\
\hline Endothelial cells & + & +++ & + & + & Membrane \\
\hline SMCs & \multicolumn{2}{|c|}{ +++ } & \multicolumn{2}{|c|}{+} & Membrane \\
\hline
\end{tabular}

Cell Types Expressing CD40 and CD4OL.

-, no expression; + weak expression; ++, average expression; +++, strong expression. SMC, smooth muscle cells.
T-cells

Activated CD4+ T-cells express CD40L, which serves as a co-stimulatory molecule. To become activated, T-cells require two signals. A first antigen-specific signal is provided through the T-cell receptor (TCR), which interacts with peptide-MHC molecules exposed by antigen presenting cells (APC). A second antigen non-specific signal is provided by the interaction between co-stimulatory molecules. The best-characterized co-stimulatory mechanisms in T-cell activation are CD28-B7 interactions and CD40-CD40L interactions. T-cell co-stimulation is necessary for T-cell proliferation, differentiation and survival. Activation of T-cells without co-stimulation may lead to T-cell anergy, T-cell deletion or the development of immune tolerance. Ligation of T-cell CD40L to the receptor CD40 on APCs like $B$-cells, macrophages and dendritic cells leads to the up-regulation of co-stimulatory activity (ICAM-1, VCAM-1, E-selectin, LFA-3, B7-1, B7-2, class II MHC, and CD40) and the production of the pro-inflammatory cytokines IL-12, IL-1, IL-6, and TNF- $\alpha$, all of which are atherogenic. 9, 43, 44 In lymphoid tissues, naïve T-cells will be activated by APCs that present antigens leading to the differentiation and proliferation of the naïve T-cell into an effector T-cell phenotype. CD40 signaling is also important for the induction of regulatory T-cells (Tregs) by interacting with APCs. ${ }^{45}, 46$ In CD40-deficient mice, the amount of Tregs was markedly reduced since CD40-deficient APCs failed to induce T regulatory cells and resulted in T-cell autoreactivity. T-cell co-stimulation is an important link between innate immunity and adaptive immune responses. ${ }^{47}$

Additionally, T-cell CD40L can be shedded into SCD40L. Limited information is available regarding the mechanism that controls the production of SCD40L. Recently, Matthies et al. showed that CD40L and SCD40L are differentially regulated. ${ }^{48}$ In T-cell receptor (TCR) activated cells, calcium was sufficient to induce membrane CD40L expression, but insufficient for the production of SCD40L. Furthermore, the study showed that CD40L shedding is protein kinase $C$ (PKC) dependent, involving the activity of a $\mathrm{Zn}^{2+}$-dependent matrix metalloproteinase. They further suggest that cleavage by the ADAM-10 protease, which belongs to a superfamily of $\mathrm{Zn}^{2+}$-dependent metalloproteinases, may represent an important mechanism for $\mathrm{SCD} 40 \mathrm{~L}$ generation. However, we have to state that the biological effects of T-cell derived SCD40L remain to be determined and we have to take into account that SCD40L is mainly shed from platelets and not from T-cells.

Interestingly, T-cells can also express CD40. ${ }^{49}$ However, the mechanisms of T-cell CD40 function have not been clearly defined. In 2002, Bourgeois et al. demonstrated that in addition to CD40L, both activated CD4+ and CD8+ T-cells also expressed its receptor CD40. ${ }^{50}$ In the absence of CD40, CD8+ T-cells were unable to differentiate into memory cells or receive CD4 help. These results suggest that, like B-cells, CD8+ T-cells receive CD4 help directly through CD40 and that this interaction is fundamental for CD8+ memory T-cell generation. 
We, and others, investigated the effects of leukocyte CD40L on atherosclerosis by transplanting $\mathrm{CD} 4 \mathrm{LL}^{-1}$ bone marrow into $\mathrm{LDLR}^{-/}$recipients. ${ }^{46,51}$ Surprisingly, no effect on plaque progression or phenotype could be found. These data reveal that bone marrow derived CD40L-expressing cells alone are not responsible for the stable plaque phenotype observed in $\mathrm{CD}^{2} \mathrm{LL}^{-} / \mathrm{ApoE}^{-/}$mice. However, bone-marrow transplantation cannot address the function of individual hematopoietic lineages and more precise studies have to be performed to elucidate the specific role of T-cell CD40L in atherosclerosis.

\section{B-cells}

CD40-CD40L interactions play a crucial role in humoral, adaptive, immune responses. Thelper cells that are activated by antigens and co-stimulatory molecules (B7-CD28), express $\mathrm{CD} 40 \mathrm{~L}$ that binds to $\mathrm{CD} 40$ on B-cells where it is constitutively expressed. This interaction, together with cytokines produced by the T-helper cell, will stimulate B-cell proliferation and differentiation into plasma cells. Consequently, B-cells will undergo Ig isotype switching. In the absence of signals from T-helper cells (CD40L, cytokines), B-cells will only produce IgM (fig. 2.1). However, in the presence of signals from T-helper cell CD40L, B-cells will undergo isotype switching to other Igs (IgG subclasses, IgE and IgA). 52,53
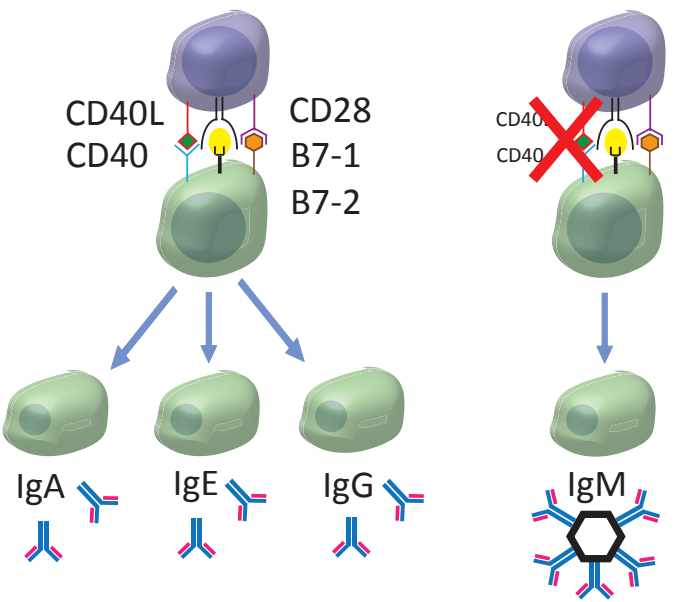

T-Cell

CD28

B7-2 B-Cell

Figure 2.1

Ig heavy chain class isotype switching is initiated by CD4O-CD4OL signals. In the absence of CD40 or CD4OL, Bcells secrete only lgM and fail to switch to other isotypes.

In humans, mutations in the CD40L gene are associated with the X-linked hyper IgM syndrome, characterized by low or absent levels of IgG, IgE and IgA in serum, but normal or elevated serum-levels of $\operatorname{lgM} .{ }^{54}$
B-cells play a significant role in atherosclerosis. They are not commonly found in lesions, but are present in the adjacent adventitia of established lesions and are thought to have an atheroprotective function. Caligiuri et al. showed that splenectomy dramatically aggravated atherosclerosis in hypercholesterolemic $\mathrm{ApoE}^{-/}$mice and decreased titers of IgM anti-OXLDL antibodies, effects that could be rescued by infusion of $\mathrm{B}$-cells from aged apo $\mathrm{E}^{-1-}$ mice. ${ }^{55}$ In addition, Binder et al. demonstrated that Th2 cells produce, during atherogenesis, large amounts of IL-5, which in turn stimulates B-1 cells to secrete T15/E06 (oxLDL specific) IgM antibodies. ${ }^{56}$ Despite the fact that $\mathrm{B}$ cells are important in atherosclerosis, the exact role of B-cell specific CD40 signaling in atherosclerosis remains to be determined.

\section{Monocytes/macrophages}

A myriad of monocyte and macrophage subsets are currently subject of numerous studies. However, their functional significance in atherosclerosis is still under debate and the exact role of $\mathrm{CD} 40-\mathrm{CD} 40 \mathrm{~L}$ signaling in monocyte and macrophage differentiation into the different subsets still needs to be elucidated. Therefore we will focus in this paragraph on general CD40-CD40L signaling in monocytes and macrophages rather then the effect on the different subsets. Several reports describe functional CD40-CD40L interactions between T-cells and monocytes. ${ }^{57}$ CD40 is constitutively expressed on monocytes and activated T-cells are able to activate monocytes through CD40-CD40L signaling. ${ }^{58}$ This interaction is bidirectional and activated monocytes are capable of activating other T-cells. Ligation of CD40 on monocytes will induce IL-12 secretion, which induces CD40L expression on T-cells ${ }^{59}$ and IL1- $\beta$, a pro-inflammatory cytokine, abundantly expressed in the atherosclerotic lesion. Most biological functions of $\mathrm{CD} 40 \mathrm{~L}$ have been attributed to direct interaction with CD40, the classical receptor for CD40L. However, alternative receptors have been described in recent years. Mehlhop et al. showed that the development of bronchial hyperresponsiveness could be prevented in $\mathrm{CD}_{40 \mathrm{~L}} \%$ mice but not in $\mathrm{CD} 40 \%$ mice, indicating for the first time that $\mathrm{CD} 40 \mathrm{~L}$ can bind other receptors then $\mathrm{CD} 40 .{ }^{60}$ More recently, Zirlik et al showed that CD40L can also interact with Mac-1 present on monocytes, and that CD40L improves monocyte adhesion and migration as well as myeloperoxidase release in vitro in a Mac-1-dependent way. ${ }^{61}$

CD40L on T-cells also binds to CD40 on macrophages, which in turn become activated. Activated macrophages are able to synthesize and secrete matrix metalloproteinases (e.g. MMP-1, MMP-2, MMP-3, MMP-9), ${ }^{62}$ which are known to degrade extra-cellular collagen matrix, thereby weakening the cap of the plaque. ${ }^{63}$ Even more, ligation of $\mathrm{CD} 40$ on macrophages evokes the release of pro-inflammatory cytokines (II- -12 , TNF- $\alpha$, IL-1 $\beta$, IL- 6 , and IL-8). The CD40L-CD40 system also affects thrombosis as it induces macrophages to secrete Tissue factor. ${ }^{62}$ 


\section{Platelets}

Several lines of evidence suggest that platelets not only promote thrombus formation, but also propagate inflammatory processes. Platelets, upon activation, can induce inflammation directly by autocrine and paracrine mechanisms. Activated platelets release their $\alpha$-granules, which contain, besides clotting proteins, a plethora of cytokines, chemokines and growth factors.

Detection of activated platelets, as defined by P-selectin surface expression, in peripheral blood of patients with unstable angina pectoris was first reported by Fitzgerald et al. ${ }^{64}$ Multiple studies were recently published that presented insights into the inflammatory function of activated platelets in the process of atherosclerosis. ${ }^{15,65,66}$ Huo et al showed that circulating activated platelets promote monocyte recruitment to atherosclerotic arteries and accelerate atherosclerosis in ApoE-deficient mice. ${ }^{16}$ The increase in lesion area was halted when the activated platelets were P-selectin negative. Moreover, platelets that transiently interact with the atherosclerotic endothelium are able to deliver and deposit the chemokines RANTES (CCL5) and PF4 (CXCL4). Both RANTES and PF4 deposition by platelets promotes atherosclerosis by triggering monocyte arrest on the endothelium of atherosclerotic lesions. ${ }^{67,68}$

Besides the direct effect, platelets induce inflammation by indirect interactions with other cell types, especially endothelial cells and monocytes. Henn et al proved that platelets, through CD40-CD40L interactions, are capable to initiate various inflammatory responses on endothelial cells (fig. 2.2) such as the expression of inflammatory adhesion receptors (e.g., E-selectin, vascular adhesion molecule-1 [VCAM-1], intercellular adhesion molecule-1 [ICAM-1]) the production of chemokines (e.g., monocyte chemoattractant protein-1 [MCP-1], interleukin- 6 and interleukin-8) and the production of matrix metalloproteinase 9 (MMP-9). ${ }^{66,69}$ Dole et al showed that activated platelets promote the secretion of WeibelPalade bodies and leukocyte rolling, which is mediated by platelet P-selectin and not by CD40L. ${ }^{70}$

\section{MMPs}

Tissue Factor

V-CAM1

I-CAM1

MCP-1

SCD40L

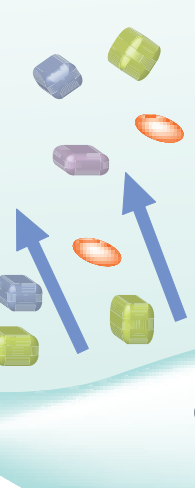

Platelets

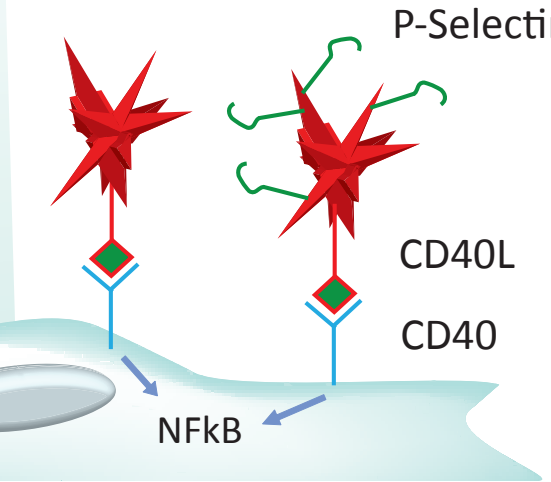

Endothelial cell

Figure 2.2

Platelet-endothelium adhesion through CD40-CD4OL induces the release of pro-inflammatory mediators and Tissue Factor and the expression of adhesion molecules.

Another important feature of activated platelets is the capability of binding monocytes to form platelet-monocyte aggregates. ${ }^{71}$ Platelets will hereby stimulate monocytes to differentiate into a more pro-adhesion and pro-migratory phenotype and promote monocyte recruitment to the lesion. ${ }^{72}$ Since more than $95 \%$ of circulating CD40L exists in platelets, we believe that platelet $\mathrm{CD} 40 \mathrm{~L}$ could play a decisive role in the pathogenesis of atherosclerosis (fig. 2.3). CD4OL is stored in the cytoplasm of resting platelets and rapidly presented at the surface after activation. CD40L on platelets can interact with CD40 that is present on leukocytes (preferentially monocytes), and form platelet-leukocyte-aggregates (PLA). In humans with profound atherosclerosis, elevated numbers of PLA are found in the blood, which result in more cytokine production. ${ }^{73}$ 


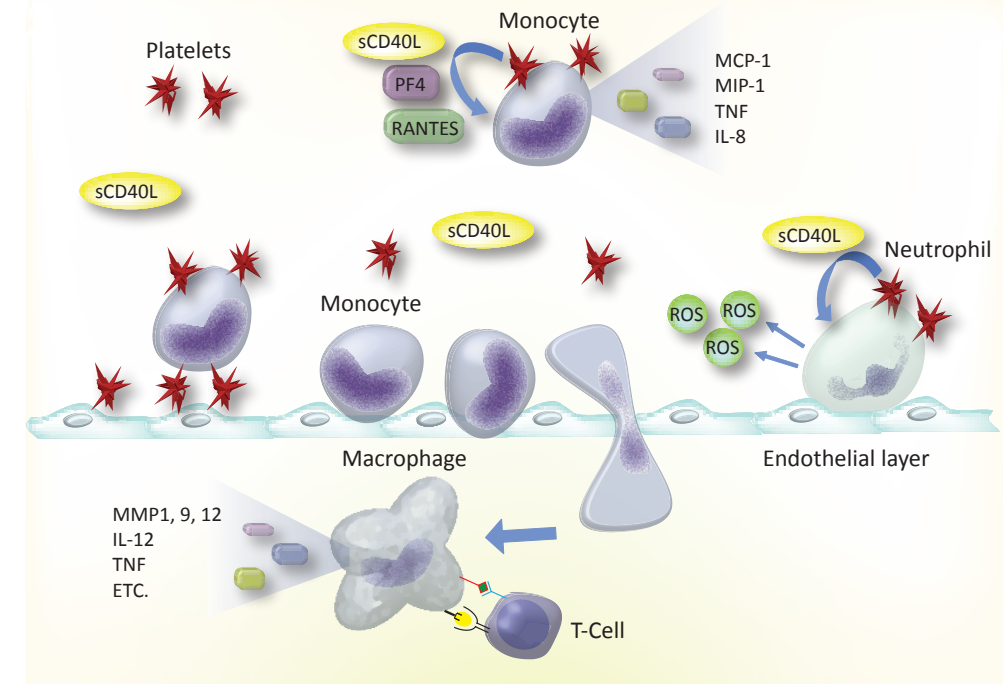

Figure 2.3

Potential pro-atherogenic functions of CD40-CD4OL signaling during atherogenesis. Adherent platelets to the activated endothelium recruit and inflame monocytes. Circulating platelets form platelet-leukocyte aggregates in the circulation, which recruit and activate the leukocyte. T-cells interact with monocytes and macrophages through CD4O-CD4OL signaling leading to the release of pro-inflammatory mediators. Finally, neutrophils also express $C D 40$, which interacts with platelet $C D 40 \mathrm{~L}$ and $S C D 40 \mathrm{~L}$ resulting in ROS production.

Upon platelet activation, $\mathrm{CD} 40 \mathrm{~L}$ is cleaved from the platelet surface over a period of minutes to hours to generate a $18 \mathrm{kDa}$ SCD40L molecule, which is similar to the T-cell released SCD40L. The release of SCD40L is much slower then $\alpha$-granule release and therefore not a direct result of $\alpha$-granule release. Clinical studies were carried out to evaluate the value of SCD40L levels as biomarker for cardiovascular risk. Elevation of SCD40L indicated an increased risk of cardiovascular events. ${ }^{74} \mathrm{SCD} 40 \mathrm{~L}$ is known to be pro-thrombotic via stabilization of arterial thrombi in a $\alpha 3$-integrin dependent mechanism and it has been reported that $\alpha \mathrm{llb} \beta 3$ (GP IIb/IIla) antagonists inhibit the release of sCD40L from activated platelets. ${ }^{76}$ In addition, Henn et al. reported that CD40 is constitutively expressed on platelets, and that the interaction between $\mathrm{CD} 40$ and $\mathrm{CD} 40 \mathrm{~L}$ is needed for the shedding of SCD40L. ${ }^{77}$ Unfortunately, it is not known if platelet derived SCD40L is cleaved in the same way as Tcell derived SCD40L. However, recently, in Crohn disease patients, a specific inhibitor of MMP-9 was able to significantly reduce platelet CD40L shedding, suggesting a Zn2+ cleavage site. ${ }^{78}$ Interestingly, in endothelial cells, only membrane-bound CD40L is able to induce expression of pro-inflammatory cytokines and adhesion molecules, whereas SCD40L is not. ${ }^{41}$ However, Chen et al showed in 2008 that SCD40L could induce endothelial dys- function by significantly decreasing eNOS expression and NO production. ${ }^{79}$ Although there is still some controversy on the function of $\mathrm{SCD} 40 \mathrm{~L}$, we have to consider the potential of SCD40L to mediate inflammatory events within the vasculature. ${ }^{76}$

Besides CD40L and SCD40L, platelets are also shown to express the receptor CD40. The role of this platelet CD40 is still under debate. However, Danese et al showed that CD40Lpositive T-cells induced platelet activation through a contact-mediated, CD40-dependent pathway. This resulted in RANTES release, which bound to endothelial cells and mediated T-cell recruitment. ${ }^{80}$ Soluble CD40L induced the same events.

Finally, Crist et al showed that CD40L is also abundantly expressed on the membrane of megakaryocytes and found that NFAT, a calcium-dependent transcriptional regulator associated with activated T-cells, mediated both differentiation-dependent and inducible megakaryocyte-specific CD40L expression. ${ }^{81}$

\section{Neutrophils}

The concept of neutrophils as strong mediators of atherosclerosis development is emerging. The presence of neutrophils and myeloperoxidase in murine lesions was described by van Leeuwen et al. ${ }^{10}$ Even more, Soehnlein et al described that neutrophils, through their secretory products, pave the way for inflammatory monocytes in the progress of atherogenesis. ${ }^{11}$ Zernecke et al showed that the CXC ligand (CXCL)12/CXC receptor (CXCR)4 chemokine-receptor axis controls the important contribution of neutrophils to atherogenesis in mice. ${ }^{82}$ These studies illustrate that as a cell type with a major role in mediating inflammatory responses, the neutrophil could be an important mediator in the development of atherosclerosis.

CD40 was reported to be present on neutrophils, its precise role remains to be determined. Neutrophils are able to interact with platelets through CD40-CD40L interactions. These interactions appear to influence both cell-types. Vanichakarn et al demonstrated that stimulated platelets activate neutrophils through the release of soluble CD40L. ${ }^{83}$ This SCD40L will stimulate neutrophils, via CD40, to release reactive oxygen species (ROS), which subsequently will stimulate more platelets. In another elegant study, by Li et al, incubation of mouse neutrophils with activated platelets led to enhanced MAC-1 expression on neutrophils. ${ }^{84} \mathrm{Anti}-\mathrm{CD} 40 \mathrm{~L}$ and anti-P-selectin antibodies inhibited this effect. The same study showed that elevated levels of SCD40L promoted platelet-leukocyte activation and recruitment, as well as neointima formation after arterial injury. These findings suggest a novel mechanism in the recruitment of leukocytes and the formation of platelet-leukocyte aggregates through CD40-CD40L signaling. 


\section{Dendritic cells}

Antigen-presenting cells (APC), especially dendritic cells, the central cell type of the immune system, immediately sense potential pathogens and provide the first link to an adaptive immune response by activating T-cells. CD40-CD40L co-stimulatory signaling plays a crucial role in dendritic cell (DC) function. Immature DCs in the periphery take up antigens efficiently but express low levels of MHC and co-stimulatory molecules like CD40, resulting in a poor capacity to stimulate T-cells. However, upon maturation, DCs significantly augment their ability to stimulate naïve T-cells by surface exposure of antigen/MHC complexes and by upregulation of CD40 and other co-stimulatory (e.g. B7-1, B7-2) molecules. DCs consist of numerous distinctive subsets, with diverse immunological functions, unique markers and different tissue distributions. Several dendritic-cell-classifications have been described. The commonly used DC phenotypes are the CD11 $\mathrm{c}^{\text {hi }} \mathrm{MHCll}+$ conventional DCs (CDCs), which are subdivided into migratory and lymphoid-tissue-resident DCs, and the type I interferon-producing plasmacytoid DCs (pDCs). It has been shown that DCs, upon constant CD40L stimulation, provide long-lasting IL-12 responses, important for driving a potent Th1 response. ${ }^{85}$ It has also been revealed that TRAF6 is important for DC maturation, cytokine production, and T-cell stimulatory capacity of DCs in response to CD40 ligand, but also for the homeostasis of splenic DC subsets. ${ }^{86}$ In addition, Kuwajima and colleagues demonstrated recently that CD40 on CDCs could interact with CD40L on pDCs, resulting in IL-12 production by $\mathrm{CDCs} .{ }^{87}$ This study demonstrates the importance and the difference of CD40-CD40L signalling between different subsets of DCs.

In atherosclerosis, the function and distribution of DC (subsets) still remains to be elucidated. ${ }^{4,88}$ Together with the fact that naive T-cells require priming by DCs in secondary lymph nodes in order to enter peripheral tissues like atherosclerotic plaques, CD40-CD40L interactions between dendritic cells and T-cells could be an interesting target to study in atherosclerosis.

\section{Endothelial cells and vascular smooth muscle cells}

CD40-CD40L interactions play a significant role in the activation of vascular endothelium. ${ }^{89}$ Endothelial cells, as well as vascular smooth muscle cells (vSMC) express both CD40L and its receptor CD40. Enhanced adhesion of immuno-competent cells to the endothelium may be among the earliest pro-atherogenic functions mediated by the CD40-CD40L dyad. Ligation of CD40 on endothelial cells induces the expression of several cell adhesion molecules (VCAM-1, E-Selectin, ICAM-1) and chemokines (IL-8, MCP-1 and MIP-1 $\alpha$ ). ${ }^{90,91}$ This will lead to the recruitment of monocytes and lymphocytes to the site of injury. IL-1, IL-6 and TNF- $\alpha$ also play a part in this process along with CD40L. ${ }^{92}$ Other elements involved are macrophage inflammatory protein-1 (MIP-1), RANTES and chemoattractant protein-1
(MCP-1). Soluble CD40L may also contribute to endothelial dysfunction by reducing NO through an increased generation of reactive oxygen species (ROS) and promote atherogenesis. ${ }^{93,94}$ Bavendiek et al showed that ligation of CD40 on endothelial cells induces Tissue Factor expression. ${ }^{95}$ On the subject of signaling, Zirlik recently showed that CD40L enhances endothelial expression of TRAF-1,-2,-3 and 6 but not TRAF- $5 .{ }^{96}$ Furthermore, TRAFassociated signaling induced by $\mathrm{CD} 40 \mathrm{~L}$ differs from activation pathways used by other proinflammatory cytokines like TNF- $\alpha$ or IL-1 $\beta$.

In relation to $\mathrm{CD} 40-\mathrm{CD} 40 \mathrm{~L}$ interactions in vascular smooth muscle cells, Hermann et al showed that CD4OL can activate mitogenic signaling and DNA synthesis in vascular smooth muscle cells but does not contribute to proliferation or migration of vascular SMC. ${ }^{97}$ CD40 signaling in vascular SMC activates a Src family kinase-initiated pathway that results in the induction of MAPK activities like the chemokines MCP-1 and IL-8. ${ }^{98}$ In addition, Schonbeck showed already in 1997 that ligation of CD40 on VSMC activates IL-1beta converting enzyme (caspase-1) that promotes IL-1 $\beta$ production. ${ }^{99}$ In another publication by the same group, ligation of CD40 on VSMC was found to mediate the loss of interstitial collagen by the production of several metalloproteinases (MMP). ${ }^{100}$ These MMPs weaken the plaque cap and promote plaque rupture. ${ }^{101}$ Finally, the CD40-CD40L signaling pathway also regulates Tissue Factor (TF) activity in vascular smooth muscle cells. ${ }^{31}$

\section{Concluding remarks}

Given the plaque-stabilizing capacity of CD40L blockage, CD40-CD40L interactions have been appreciated as a promising therapeutic target to reduce clinical manifestations of atherosclerosis, and thus thereby morbidity and mortality. However, long-term systemic inhibition of total CD40(L) can result in immune-suppression.

This review highlighted the potential contribution of each of the different $\mathrm{CD} 40(\mathrm{~L})$ expressing cell types, as well as the most important circulating source of CD40L: platelets, to atherosclerosis. Important functions in the context of atherosclerosis have been established for CD40-CD40L signaling in monocytes, T-cells and B-cells. We believe that platelet $\mathrm{CD} 40 \mathrm{~L}$ and $\mathrm{SCD} 40 \mathrm{~L}$ could play a decisive and central role in the inflammatory process of atherosclerosis by orchestrating both the activation and recruitment of different leukocyte subsets to the vessel wall. In addition, neutrophils, constitutively expressing CD40, present an attractive new approach in understanding the mechanisms of atherosclerosis. However, further research is needed to determine the exact role of neutrophils and especially neutrophil CD40. It will be particularly important to extrapolate these findings to human disease, where the contribution of neutrophils is unclear. Finally, the understanding of CD40 in dendritic cell function in atherosclerosis is still under investigation. ${ }^{102}$ Different 
subsets of dendrtic cells with distinct functions have been described, but their specific role in atherosclerosis is yet to be determined. ${ }^{102}$ Therefore, we believe that dendritic cell CD40 in relation to atherosclerosis could be a promising target to study.

In order to develop a targeted, cell-type based, therapeutic agent with limited side effects the complex equilibrium between the $\mathrm{CD} 40(\mathrm{~L})$ expressing cell types has to be further elucidated. 


\section{References}

1. Lusis, A.J. Atherosclerosis. Nature 407, 233-241 (2000)

2. Hansson, G.K. \& Libby, P. The immune response in atherosclerosis: a double-edged sword. Nat Rev Immunol 6, 508-519 (2006).

3. Ross, R. Atherosclerosis--an inflammatory disease. N Engl J Med 340, 115-126 (1999).

4. Weber, C., Zernecke, A. \& Libby, P. The multifaceted contributions of leukocyte subsets to atherosclerosis: lessons from mouse models. Nat Rev Immunol 8, 802-815 (2008).

5. Passlick, B., Flieger, D. \& Ziegler-Heitbrock, H.W. Identification and characterization of a novel monocyte subpopulation in human peripheral blood. Blood 74, 2527-2534 (1989).

6. Swirski, F.K., et al. Ly-6Chi monocytes dominate hypercholesterolemia-associated monocytosis and give rise to macrophages in atheromata. J Clin Invest 117, 195-205 (2007).

7. Weber, C., et al. Differential chemokine receptor expression and function in human monocyte subpopulations. J Leukoc Biol 67, 699-704 (2000).

8. Gordon, S. \& Taylor, P.R. Monocyte and macrophage heterogeneity. Nat Rev Immunol 5, 953-964 (2005).

9. Robertson, A.K. \& Hansson, G.K. T cells in atherogenesis: for better or for worse? Arterioscler Thromb Vasc Biol 26, 2421-2432 (2006)

10. van Leeuwen, M., et al. Accumulation of myeloperoxidase-positive neutrophils in atherosclerotic lesions in LDLR-/- mice. Arterioscler Thromb Vasc Biol 28, 84-89 (2008).

11. Soehnlein, O., et al. Neutrophil secretion products pave the way for inflammatory monocytes. Blood 112, 1461-1471 (2008)

12. Bot, l., et al. Perivascular mast cells promote atherogenesis and induce plaque destabilization in apolipoprotein E-deficient mice. Circulation 115, 2516-2525 (2007).

13. Sun, J., et al. Mast cells promote atherosclerosis by releasing proinflammatory cytokines. Nat Med 13, 719-724 (2007).

14. Bobryshev, Y.V. Dendritic cells in atherosclerosis: current status of the problem and clinical relevance. Eur Heart J 26, 1700-1704 (2005)

15. Massberg, S., et al. A critical role of platelet adhesion in the initiation of atherosclerotic lesion formation. $J$ Exp Med 196, 887-896 (2002).

16. Huo, Y., et al. Circulating activated platelets exacerbate atherosclerosis in mice deficient in apolipoprotein E. Nat Med 9, 61-67 (2003).

17. Noelle, R.J., Ledbetter, J.A. \& Aruffo, A. CD40 and its ligand, an essential ligand-receptor pair for thymusdependent B-cell activation. Immunol Today 13, 431-433 (1992).

18. Ludewig, B., Henn, V., Schroder, J.M., Graf, D. \& Kroczek, R.A. Induction, regulation, and function of soluble TRAP (CD40 ligand) during interaction of primary CD4+ CD45RA+ T cells with dendritic cells. Eur J Immunol 26, 3137-3143 (1996).

19. Schonbeck, U. \& Libby, P. CD40 signaling and plaque instability. Circ Res 89, 1092-1103 (2001).

20. Tedgui, A. \& Mallat, Z. Cytokines in atherosclerosis: pathogenic and regulatory pathways. Physiol Rev 86, 515-581 (2006).

21. Kleemann, R., Zadelaar, S. \& Kooistra, T. Cytokines and atherosclerosis: a comprehensive review of studies in mice. Cardiovasc Res 79, 360-376 (2008).

22. Charo, I.F. \& Ransohoff, R.M. The many roles of chemokines and chemokine receptors in inflammation. N Engl J Med 354, 610-621 (2006)
23. Zernecke, A., Shagdarsuren, E. \& Weber, C. Chemokines in Atherosclerosis. An Update. Arterioscler Thromb Vasc Biol (2008).

24. Bruemmer, D., et al. Expression of CD40 in vascular smooth muscle cells and macrophages is associated with early development of human atherosclerotic lesions. Am J Cardiol 87, 21-27 (2001).

25. Hakkinen, T., Karkola, K. \& Yla-Herttuala, S. Macrophages, smooth muscle cells, endothelial cells, and Tcells express $\mathrm{CD} 40$ and $\mathrm{CD} 40 \mathrm{~L}$ in fatty streaks and more advanced human atherosclerotic lesions. Colocalization with epitopes of oxidized low-density lipoprotein, scavenger receptor, and CD16 (Fc gammaRIII). Virchows Arch 437, 396-405 (2000).

26. Mach, $\mathrm{F}$, et al. Functional $\mathrm{CD} 40$ ligand is expressed on human vascular endothelial cells, smooth muscle cells, and macrophages: implications for CD40-CD40 ligand signaling in atherosclerosis. Proc Natl Acad Sci U S A 94, 1931-1936 (1997).

27. Lutgens, E., et al. Requirement for CD154 in the progression of atherosclerosis. Nat Med 5, 1313-1316 (1999).

28. Lutgens, E. \& Daemen, M.J. CD40-CD40L interactions in atherosclerosis. Trends Cardiovasc Med 12, 27-32 (2002).

29. Lutgens, E., et al. Both early and delayed anti-CD40L antibody treatment induces a stable plaque phenotype. Proc Natl Acad Sci U S A 97, 7464-7469 (2000).

30. Mach, F., Schonbeck, U., Sukhova, G.K., Atkinson, E. \& Libby, P. Reduction of atherosclerosis in mice by inhibition of CD40 signalling. Nature 394, 200-203 (1998).

31. Schonbeck, U., et al. CD40 ligation induces tissue factor expression in human vascular smooth muscle cells. Am J Pathol 156, 7-14 (2000).

32. Schonbeck, U., Sukhova, G.K., Shimizu, K., Mach, F. \& Libby, P. Inhibition of CD40 signaling limits evolution of established atherosclerosis in mice. Proc Natl Acad Sci U S A 97, 7458-7463 (2000).

33. Davis, J.C., Jr., Totoritis, M.C., Rosenberg, J., Sklenar, T.A. \& Wofsy, D. Phase I clinical trial of a monoclonal antibody against CD40-ligand (IDEC-131) in patients with systemic lupus erythematosus. J Rheumatol 28, 95-101 (2001)

34. Dumont, F.J. IDEC-131. IDEC/Eisai. Curr Opin Investig Drugs 3, $725-734$ (2002)

35. Schuler, W., et al. Efficacy and safety of ABI793, a novel human anti-human CD154 monoclonal antibody, in cynomolgus monkey renal allotransplantation. Transplantation 77, 717-726 (2004).

36. Pearson, T.C., et al. Anti-CD40 therapy extends renal allograft survival in rhesus macaques. Transplantation 74, 933-940 (2002).

37. Imai, A., et al. A novel fully human anti-CD40 monoclonal antibody, 4D11, for kidney transplantation in cynomolgus monkeys. Transplantation 84, 1020-1028 (2007).

38. Lu, L.F., et al. The in vivo function of a noncanonical TRAF2-binding domain in the C-terminus of CD40 in driving B-cell growth and differentiation. Blood 110, 193-200 (2007).

39. Ahonen, C., et al. The CD40-TRAF6 axis controls affinity maturation and the generation of long-lived plasma cells. Nat Immunol 3, 451-456 (2002).

40. Lutgens, E., Lievens, D., Beckers, L., Donners, M. \& Daemen, M. CD40 and its ligand in atherosclerosis. Trends Cardiovasc Med 17, 118-123 (2007).

41. Chen, Y., et al. Internalization of CD40 regulates its signal transduction in vascular endothelial cells. Biochem Biophys Res Commun 345, 106-117 (2006).

42. Donners, M.M., et al. The CD40-TRAF6 axis is the key regulator of the CD40/CD40L system in neointima formation and arterial remodeling. Blood 111, 4596-4604 (2008). 
43. Grewal, I.S. \& Flavell, R.A. CD40 and CD154 in cell-mediated immunity. Annu Rev Immunol 16, 111-135 (1998).

44. Gotsman, I., Sharpe, A.H. \& Lichtman, A.H. T-cell costimulation and coinhibition in atherosclerosis. Circ Res 103, 1220-1231 (2008).

45. Kumanogoh, A., et al. Increased T cell autoreactivity in the absence of CD40-CD40 ligand interactions: a role of CD40 in regulatory T cell development. J Immunol 166, 353-360 (2001).

46. Smook, M.L., et al. Leukocyte CD40L deficiency affects the CD25(+) CD4 T cell population but does not affect atherosclerosis. Atherosclerosis 183, 275-282 (2005).

47. Buono, C. \& Lichtman, A.H. Co-stimulation and plaque-antigen-specific T-cell responses in atherosclerosis. Trends Cardiovasc Med 14, 166-172 (2004).

48. Matthies, K.M., Newman, J.L., Hodzic, A. \& Wingett, D.G. Differential regulation of soluble and membrane CD40L proteins in T cells. Cell Immunol 241, 47-58 (2006).

49. Munroe, M.E. \& Bishop, G.A. A costimulatory function for T cell CD40. J Immunol 178, 671-682 (2007).

50. Bourgeois, C., Rocha, B. \& Tanchot, C. A role for CD40 expression on CD8+ T cells in the generation of CD8+ T cell memory. Science 297, 2060-2063 (2002).

51. Bavendiek, U., et al. Atherogenesis in mice does not require CD40 ligand from bone marrow-derived cells. Arterioscler Thromb Vasc Biol 25, 1244-1249 (2005).

52. Aruffo, A., et al. The CD40 ligand, gp39, is defective in activated T cells from patients with X-linked hyperIgM syndrome. Cell 72, 291-300 (1993).

53. Smook, M.L., et al. Anti-oxLDL antibody isotype levels, as potential markers for progressive atherosclerosis in APOE and APOECD4OL mice. Clin Exp Immunol (2008).

54. Hill, A. \& Chapel, H. X-linked immunodeficiency. The fruits of cooperation. Nature 361, 494 (1993).

55. Caligiuri, G., Nicoletti, A., Poirier, B. \& Hansson, G.K. Protective immunity against atherosclerosis carried by B cells of hypercholesterolemic mice. J Clin Invest 109, 745-753 (2002).

56. Binder, C.J., et al. IL-5 links adaptive and natural immunity specific for epitopes of oxidized LDL and protects from atherosclerosis. J Clin Invest 114, 427-437 (2004).

57. Cella, M., et al. Ligation of CD40 on dendritic cells triggers production of high levels of interleukin-12 and enhances T cell stimulatory capacity: T-T help via APC activation. J Exp Med 184, 747-752 (1996).

58. Schonbeck, U. \& Libby, P. The CD40/CD154 receptor/ligand dyad. Cell Mol Life Sci 58, 4-43 (2001).

59. Peng, X., Remacle, J.E., Kasran, A., Huylebroeck, D. \& Ceuppens, J.L. IL-12 up-regulates CD40 ligand (CD154) expression on human T cells. J Immunol 160, 1166-1172 (1998).

60. Mehlhop, P.D., et al. CD40L, but not $\mathrm{CD} 40$, is required for allergen-induced bronchial hyperresponsiveness in mice. Am J Respir Cell Mol Biol 23, 646-651 (2000).

61. Zirlik, A., et al. CD40 ligand mediates inflammation independently of CD40 by interaction with Mac-1. Circulation 115, 1571-1580 (2007)

62. Mach, F., Schonbeck, U., Bonnefoy, J.Y., Pober, J.S. \& Libby, P. Activation of monocyte/macrophage functions related to acute atheroma complication by ligation of CD40: induction of collagenase, stromelysin, and tissue factor. Circulation 96, 396-399 (1997).

63. Thim, T., Hagensen, M.K., Bentzon, J.F. \& Falk, E. From vulnerable plaque to atherothrombosis. J Intern Med 263, 506-516 (2008).

64. Fitzgerald, D.J., Roy, L., Catella, F. \& FitzGerald, G.A. Platelet activation in unstable coronary disease. N Engl J Med 315, 983-989 (1986).

65. May, A.E., Seizer, P. \& Gawaz, M. Platelets: inflammatory firebugs of vascular walls. Arterioscler Thromb Vasc Biol 28, s5-10 (2008).
66. Gawaz, M., Langer, H. \& May, A.E. Platelets in inflammation and atherogenesis. J Clin Invest 115, 33783384 (2005).

67. von Hundelshausen, P., et al. RANTES deposition by platelets triggers monocyte arrest on inflamed and atherosclerotic endothelium. Circulation 103, 1772-1777 (2001).

68. von Hundelshausen, P., et al. Heterophilic interactions of platelet factor 4 and RANTES promote monocyte arrest on endothelium. Blood 105, 924-930 (2005).

69. Henn, $\mathrm{V}$., et al. CD40 ligand on activated platelets triggers an inflammatory reaction of endothelial cells. Nature 391, 591-594 (1998)

70. Dole, V.S., Bergmeier, W., Mitchell, H.A., Eichenberger, S.C. \& Wagner, D.D. Activated platelets induce Weibel-Palade-body secretion and leukocyte rolling in vivo: role of P-selectin. Blood 106, 2334-2339 (2005).

71. Furman, M.I., et al. Increased platelet reactivity and circulating monocyte-platelet aggregates in patients with stable coronary artery disease. J Am Coll Cardiol 31, 352-358 (1998).

72. van Gils, J.M., da Costa Martins, P.A., Mol, A., Hordijk, P.L. \& Zwaginga, J.J. Transendothelial migration drives dissociation of plateletmonocyte complexes. Thromb Haemost 100, 271-279 (2008).

73. Marx, N., et al. Induction of cytokine expression in leukocytes in acute myocardial infarction. J Am Coll Cardiol 30, 165-170 (1997).

74. Heeschen, C., et al. Soluble CD40 ligand in acute coronary syndromes. N Engl J Med 348, 1104-1111 (2003).

75. Andre, P., et al. CD40L stabilizes arterial thrombi by a beta3 integrin--dependent mechanism. Nat Med 8 , 247-252 (2002).

76. Andre, P., Nannizzi-Alaimo, L., Prasad, S.K. \& Phillips, D.R. Platelet-derived CD40L: the switch-hitting player of cardiovascular disease. Circulation 106, 896-899 (2002).

77. Henn, V., Steinbach, S., Buchner, K., Presek, P. \& Kroczek, R.A. The inflammatory action of CD40 ligand (CD154) expressed on activated human platelets is temporally limited by coexpressed CD40. Blood 98, 1047-1054 (2001).

78. Menchen, L., et al. Matrix metalloproteinase 9 is involved in Crohn's disease-associated platelet hyperactivation through the release of soluble CD40 ligand. Gut (2008).

79. Chen, $\mathrm{C}$., et al. Soluble CD40 ligand induces endothelial dysfunction in human and porcine coronary artery endothelial cells. Blood 112, 3205-3216 (2008).

80. Danese, $\mathrm{S}$., et al. Cutting edge: T cells trigger CD40-dependent platelet activation and granular RANTES release: a novel pathway for immune response amplification. J Immunol 172, 2011-2015 (2004).

81. Crist, S.A., Sprague, D.L. \& Ratliff, T.L. Nuclear factor of activated T cells (NFAT) mediates CD154 expression in megakaryocytes. Blood 111, 3553-3561 (2008).

82. Zernecke, A., et al. Protective role of $C X C$ receptor $4 / C X C$ ligand 12 unveils the importance of neutrophils in atherosclerosis. Circ Res 102, 209-217 (2008).

83. Vanichakarn, P., Blair, P., Wu, C., Freedman, J.E. \& Chakrabarti, S. Neutrophil CD40 enhances plateletmediated inflammation. Thromb Res 122, 346-358 (2008).

84. Li, G., et al. CD40 ligand promotes Mac-1 expression, leukocyte recruitment, and neointima formation after vascular injury. Am J Pathol 172, 1141-1152 (2008).

85. Loskog, A., Ninalga, C. \& Totterman, T.H. Dendritic cells engineered to express CD40L continuously produce IL12 and resist negative signals from Tr1/Th3 dominated tumors. Cancer Immunol Immunother 55, 588-597 (2006).

86. Kobayashi, T., Walsh, M.C. \& Choi, Y. The role of TRAF6 in signal transduction and the immune response. Microbes Infect 6, 1333-1338 (2004). 
87. Kuwajima, S., et al. Interleukin 15 -dependent crosstalk between conventional and plasmacytoid dendritic cells is essential for CpG-induced immune activation. Nat Immunol 7, 740-746 (2006).

88. Auffray, C., Sieweke, M.H. \& Geissmann, F. Blood Monocytes: Development, Heterogeneity, and Relationship with Dendritic Cells. Annu Rev Immunol (2009).

89. Karmann, K., Hughes, C.C., Schechner, J., Fanslow, W.C. \& Pober, J.S. CD40 on human endothelial cells: inducibility by cytokines and functional regulation of adhesion molecule expression. Proc Natl Acad Sci U S A 92, $4342-4346$ (1995).

90. Wagner, A.H., Guldenzoph, B., Lienenluke, B. \& Hecker, M. CD154/CD40-mediated expression of CD154 in endothelial cells: consequences for endothelial cell-monocyte interaction. Arterioscler Thromb Vasc Biol 24, 715-720 (2004).

91. Stout, R.D. \& Suttles, J. The many roles of CD40 in cell-mediated inflammatory responses. Immunol Today 17, 487-492 (1996)

92. Rizvi, M., Pathak, D., Freedman, J.E. \& Chakrabarti, S. CD40-CD40 ligand interactions in oxidative stress, inflammation and vascular disease. Trends Mol Med 14, 530-538 (2008)

93. Urbich, C., Dernbach, E., Aicher, A.,Zeiher, A.M. \& Dimmeler, S. CD40 ligand inhibits endothelial cell migration by increasing production of endothelial reactive oxygen species. Circulation 106, 981-986 (2002).

94. Cipollone, F., et al. Enhanced soluble CD40 ligand contributes to endothelial cell dysfunction in vitro and monocyte activation in patients with diabetes mellitus: effect of improved metabolic control. Diabetologia 48, 1216-1224 (2005).

95. Bavendiek, U., et al. Induction of tissue factor expression in human endothelial cells by CD40 ligand is mediated via activator protein 1, nuclear factor kappa B, and Egr-1. J Biol Chem 277, $25032-25039$ (2002).

96. Zirlik, A., et al. TRAF-1, $-2,-3,-5$, and -6 are induced in atherosclerotic plaques and differentially mediate proinflammatory functions of CD40L in endothelial cells. Arterioscler Thromb Vasc Biol 27, 1101-1107 (2007).

97. Hermann, A., Schror, K. \& Weber, A.A. CD40 ligand (CD40L) does not stimulate proliferation of vascular smooth muscle cells. Eur J Cell Biol 81, 213-221 (2002).

98. Mukundan, L., Milhorn, D.M., Matta, B. \& Suttles, J. CD40-mediated activation of vascular smooth muscle cell chemokine production through a Src-initiated, MAPK-dependent pathway. Cell Signal 16, 375-384 (2004).

99. Schonbeck, $\mathrm{U}$., et al. Ligation of CD40 activates interleukin 1beta-converting enzyme (caspase-1) activity in vascular smooth muscle and endothelial cells and promotes elaboration of active interleukin 1 beta. J Biol Chem 272, 19569-19574 (1997).

100. Horton, D.B., Libby, P. \& Schonbeck, U. Ligation of CD 40 onvascular smooth muscle cells mediates loss of interstitial collagen via matrix metalloproteinase activity. Ann N Y Acad Sci 947, 329-336 (2001).

101. Newby, A.C. Metalloproteinases and vulnerable atherosclerotic plaques. Trends Cardiovasc Med 17, 253258 (2007).

102. Packard, R.R., et al. CD11c(+) dendritic cells maintain antigen processing, presentation capabilities, and CD4(+) T-cell priming efficacy under hypercholesterolemic conditions associated with atherosclerosis. Circ Res 103, 965-973 (2008).

103. Leveille, C., et al. CD40 ligand binds to alpha5beta1 integrin and triggers cell signaling. J Biol Chem 282, 5143-5151 (2007). 
CD40 AND ITS LIGAND IN ATHEROSCLEROSIS

Esther Lutgens, Dirk Lievens, Linda Beckers, Marjo Donners and Mat Daemen.

Trends Cardiovasc Med. 2007 May; 17(4):118-23. 


\section{Abstract}

CD40-CD40 ligand (CD40L) interactions play a central role in the development and progression of atherosclerosis. In the late $90 \mathrm{~s}$, we and others showed that complete inhibition of the CD40L signaling pathway resulted in a decrease in atherosclerosis and in the induction of a stable atherosclerotic plaque phenotype. These stable plaques contained high amounts of collagen and vascular smooth muscle cells, while the amount of macrophages and T-lymphocytes was low.

Since clinical complications of atherosclerosis are mostly the result of plaque rupture, induction of plaque stability would significantly reduce the morbidity and mortality of atherosclerosis and thus validates inhibition of the CD40L system as a therapeutic target for atherosclerosis. However, long-term inhibition of this system probably compromises the immune system of the patient. Therefore, it is desirable to target either the downstream signaling modulators of the CD40-CD40L system that are associated with atherosclerosis, or target the CD40-CD40L system in a local, cell type-specific way. This is likely to induce plaque stabilization with limited systemic side effects, and a significant reduction of cardiovascular disease.

\section{Introduction}

In the past decade, the CD40-CD40 ligand (CD40L) system has gained increased interest in the medical community as a major player in a wide array of chronic inflammatory and auto-immune diseases, among them atherosclerosis. ${ }^{1}$ In murine models, absence of CD40-CD40L signaling reduced the severity of arthritis, ${ }^{2}$ allergic encephalomyelitis, ${ }^{3}$ and atherosclerosis. ${ }^{4-7}$ However, the use of anti-CD40L as therapeutic treatment and exploration of its beneficial and adverse effects is only just beginning.

From 1999, the first phase I and II trials started using either IDEC131 or BCG9588, both humanized anti-CD40L antibodies, for treatment of psoriasis, multiple sclerosis, idiopathic thrombocytopenic purpura (ITP), ${ }^{8}$ Crohn's disease, systemic lupus erythematosus (SLE) ${ }^{9}$, ${ }^{10}$ and proliferative lupus nephritis. ${ }^{11}$ Most of these studies (ITP, SLE) showed promising results with only limited adverse effects. Unfortunately, trials were discontinued after a study in which twenty-eight patients suffering from proliferative lupus nephritis received 1-5 doses of antibody. Treatment was effective, as shown by a reduction of anti-dsDNA antibody titers, an increased serum C3 concentration and a decrease in hematuria. However, the study was terminated prematurely because of thromboembolic events. ${ }^{11}$ The thrombo-embolic events can be explained by the function of CD40L in thrombus stabilization. $\mathrm{CD} 40 \mathrm{~L}$ stabilizes thrombi by interaction with the integrin $\alpha$ llb $\beta 3 .{ }^{12}$ By inhibiting CD40L, thrombi will be less stable and will more easily shed emboli. In 2005, the first study using an anti-CD40 antibody was initiated. A single dose of antagonist chimeric monoclonal antiCD40 antibody (ch5D12) was administrated to 18 patients with moderate to severe Crohn's disease. Biopies showed reduced microscopic disease activity. ${ }^{11}$ By now, novel anti-CD40 and anti-CD40L antibodies are being developed, and new clinical trials are emerging.

Application of anti-CD40L antibodies as a treatment for atherosclerosis will be a challenge. Atherosclerosis is a slowly progressive, multi-factorial chronic inflammatory disease. To limit disease progression by anti-CD40L or anti-CD40 antibodies, the antibodies should be given during many years, which increases the risk of immune suppression, and for antiCD40L, the risk of thrombo-embolic events. Moreover, the CD40-CD40L system has many different functions in atherogenesis and is capable of exerting cell type-specific signaling pathways in the atherosclerotic plaque. Therefore, we feel that atherosclerosis-associated downstream intermediate of the CD40-system or a local, cell type-specific approach that blocks CD40/CD40L signaling should be explored as therapy once they are available.

This paper will review the cell type-specific functions and signaling events in atherosclerosis and will discuss the therapeutic possibilities of CD40 in atherosclerosis.

\section{CD40-CD40L signaling}

$\mathrm{CD} 40$ is a $50-\mathrm{kDa}$ integral membrane protein of the tumor necrosis factor receptor (TNF-R) family. It is constitutively expressed as a homotrimer on professional antigen presenting cells (APCs) such as B-cells, monocytes/macrophages, and dendritic cells, but also on nonprofessional APCs like endothelial cells, vascular smooth muscle cells (VSMCs), fibroblasts, platelets and several types of epithelial cells. ${ }^{13}$

Its ligand, CD40L, is a 39-kDa protein that belongs to the TNF family. CD40 forms a trimer that binds CD40L at the interface of the 3 monomers. CD40L is expressed on activated T-lymphocytes, platelets, as well as on VSMCs and endothelial cells, monocytes and on some macrophages. Besides surface-expressed CD40L, CD40L can also exist in a soluble, biologically active form ( $\mathrm{SCD} 40 \mathrm{~L})$ that is shed after activation. The main source of SCD40L are platelets. ${ }^{13}$

\section{TNF-receptor associated factors (TRAFs)}

After binding of CD40L to CD40, signaling is elicited. Interestingly, CD40 lacks intrinsic signaling activity, and needs to recruit adaptor molecules. These adaptor molecules are the TNF-receptor associated factors (TRAFs) that bind to the cytoplasmic tail of CD40 and subsequently recruit kinases and other effector proteins ${ }^{14}$ (fig. 3.1). 


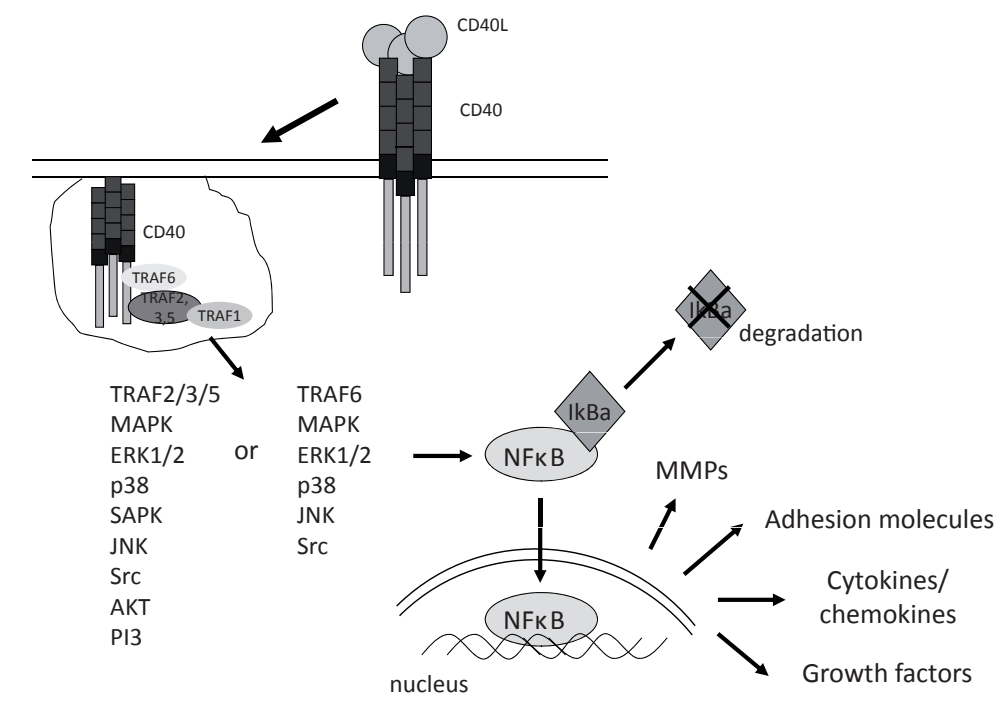

Figure 3.1: Downstream signaling of $C D 40$

CD40 exists as a homotrimer. After binding of CD4OL, CD4O becomes activated and is internalized into the cell in membrane-derived vesicles. However, whether CD40 remains a homotrimer after internalization is not sure. CD40 cannot elicit signaling by itself, and needs adaptor molecules, the TRAFs. CD4O has 2 TRAF binding domains, one for TRAF2, 3 and 5 (a binding domain which can also bind TRAF1 after TRAF2/3/5 have bound), and one for TRAF6. After binding of TRAF1, 2, 3, 5 or 6, further downstream signaling is elicited. The signaling pathway that is elicited depends on the TRAF binding domain that has been occupied, and on the cell type that is activated. Figure 3.1 shows the possible downstream signaling intermediates that are involved. The most important transcription factor that is activated by CD4O-signaling is NFKB. NFKB translocation into the nucleus results in the expression of pathways of inflammation, thrombosis proteolysis etc.

The TRAF-protein family is composed of six members and is characterized by a conserved 180 amino acid fold, the TRAF domain (TD), which supports the interaction between the TNF-R and its downstream signaling intermediates. The TRAF domain is further divided into two subregions. The C-terminus of the TRAF-domain mediates homo- and hetero-dimerization with other TRAF-proteins and the receptor that recruits them. The N-terminus contains a RING finger (except TRAF1) and a variable number (5-6) of zinc-finger domains, which are required for TRAF-mediated downstream signal transduction. ${ }^{15}$ TNF-Rs usually use more than one TRAF family member for signaling, activating specific, but also similar downstream pathways within the same or within different cell-types.

CD40 can bind 5 of the 6 TRAF family members (TRAF1,2,3,5,6), depending on cell type or function. The cytoplasmic domain of CD40 has a proximal TRAF6 binding site and a more distal TRAF 2/3/5 binding-site. The TRAF2/3/5 binding site is most often occupied by TRAF2 and TRAF3. TRAF1 only binds to CD 40 when CD40-signaling is already active. It can bind to the TRAF $2 / 3 / 5$ binding site and replaces or hetero-dimerizes with TRAF2 and acts as a regulator rather than an activator of CD40 signaling. ${ }^{16}$ Whether TRAF5 directly or indirectly binds to the TRAF2/3/5 binding domain is still under debate. TRAF5 was found to bind CD40 directly in a yeast 2 hybrid study. ${ }^{17}$ However, more recent studies show that TRAF5 is only able to bind to CD40 via TRAF3/TRAF5 hetero-dimers. ${ }^{15}$ Until now, TRAF6 is the only protein able to bind the TRAF6 binding site of CD40. ${ }^{15}$

As in other TNF-R family members, both TRAF binding-sites can initiate different CD40 downstream mediators and effectors. For example, in B-lymphocytes, CD40-TRAF6 interactions are required for CD40-mediated IgM production, B-cell induced IL-6 secretion and isotype switching, whereas the TRAF2/3/5 binding site is required for CD40-mediated upregulation of CD80/CD86 (a co-stimularory molecule) and protection from B-cell antigenreceptor mediated growth arrest. ${ }^{18}$ Moreover, both binding domains also seem to exert cell type-specific actions.

This is also true for the cell types present in atherosclerotic plaques. In monocytes and macrophages, the interaction between CD40 and TRAF6 is crucial for the activation of Src/ ERK1/2 and IKK/NF-KB pro-inflammatory pathways, while CD40-TRAF2/3/5 interactions are not required for induction of inflammation. ${ }^{19}$ However, in endothelial cells and VSMCs, TRAF2 seems to mediate the activation of pro-inflammatory pathways. ${ }^{20}$ Interestingly, during shear stress, TRAF3 inhibits CD40-signaling, thereby preventing recruitment of inflammatory cells into the arterial wall. ${ }^{21}$

\section{Internalization of the receptor}

The specificity of CD40-signaling, as it is for other TNF-R family members, depends not only on its interaction with the different TRAF family members, but also on whether activated receptors remain at the cell membrane, or become internalized. After internalization, the endocytic pathway can either activate or switch off receptor signaling, depending on which cytoplasmic complex the receptor recruits, and to which intracellular compartment the complex is targeted. ${ }^{22}$

Until now, insights into how the CD40L-CD40 complex enters the cell membrane and how CD40 travels into and throughout the cell are limited. What is known is that CD40 can induce internalization of $\mathrm{CD} 40 \mathrm{~L}$, thereby down-regulating $\mathrm{CD} 40 \mathrm{~L}$ signaling in T-cells, ${ }^{23}$ and that $\mathrm{CD} 40 \mathrm{~L}$ on fibroblast cells can induce endocytosis of $\mathrm{CD} 40$, and consequently CD40signaling, in B-cells. ${ }^{24}$

Internalization of CD40 into specific cellular compartments seems to differ somewhat between the different cell types. However, most reports show that CD40 clusters and forms a signalosome complex within (different parts of) detergent-insoluble membrane microdomains, the lipid rafts. 
In resting conditions, a small part of CD40 is already located in the lipid raft compartment. When stimulated, the majority of CD40 translocates into the lipid raft compartment. In Blymphocytes, HEK-293 cells and dendritic cells, translocation to lipid rafts is TRAF2 dependent. ${ }^{16,25-28}$ Within the lipid raft, CD40 associates with TRAF2 and TRAF3, as well as with its downstream signaling molecules. In dendritic cells, it is also postulated that TRAF2 and TRAF3 are subsequently degraded, and that further signaling is regulated via TRAF1 and TRAF6. ${ }^{16}$ In dendritic cells, CD40 also colocalizes with TRAF2 and -3 in lipid rafts, and CD40 signaling is not elicited when lipid rafts are destroyed by methylcyclodextrin, suggesting that lipid rafts are a crucial element for the CD40-signaling cascade. ${ }^{26}$

Interestingly, in human renal proximal tubular cells, CD40 as well as its downstream signaling intermediates SAPK/JNK, p38 and ERK1/2 MAPKs, were found to reside within caveolae, which are specialized structures within the lipid raft. When CD40L binds to CD40, CD40 and its downstream signaling intermediates dissociate from caveolae, followed by binding of CD40 to TRAF6 in the cytoplasmic compartment, and propagation of CD40-signaling. ${ }^{29}$

In endothelial cells, the localization of the CD40-signaling complex seems to depend on the way the receptor is activated. When surface CD40L binds to CD40, the complex translocates into the lipid rafts where it subsequently binds TRAF3 and induces pro-inflammatory cytokines via AKT and NFKB signaling. However, when SCD40L binds CD40, CD40 enters the cell in early endosomes via Rab5, a small GTPase. TRAF2/3 colocalizes with CD40 in these early endosomes, phosphorylates AKT and also activates NFKB, but fails to induce the production of pro-inflammatory cytokines. ${ }^{30}$

These data suggest that the specificity of CD40-signaling is not only determined by the different CD40-TRAF interactions, but also by the cellular compartments in which CD40 resides (fig. 3.2).

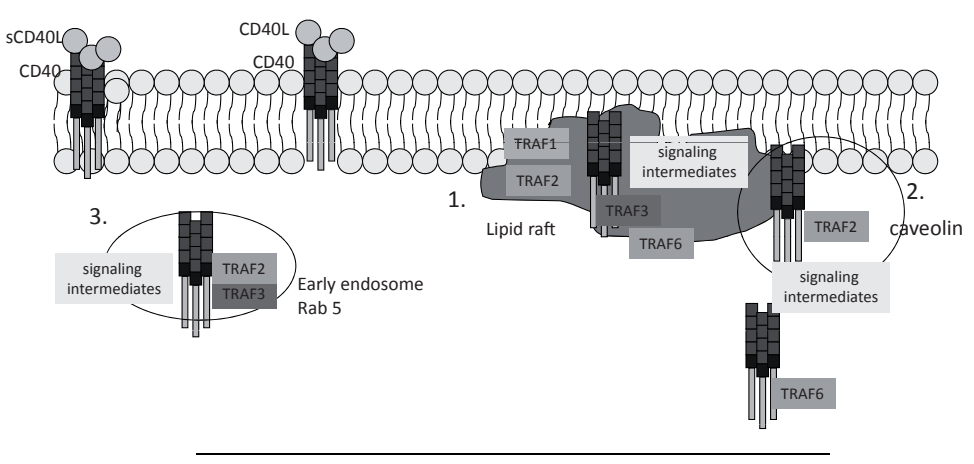

NFKB

Figure 3.2: Internalization of $\mathrm{CD} 40$ : postulated mechanisms

1. The first mechanism, which has been described in B-lymphocytes, HEK293 cells and dendritic cells, is that CD40 translocates into the lipid rafts after binding to CD4OL. This is TRAF2 dependent. Within the lipid rafts, CD40 associates with TRAF2, 3, 1 or 6 and several downstream signaling molecules.

2. In renal proximal tubular cells, CD40 translocates into caveolae, specialized structures within the lipid rafts, where it binds to TRAF2 and its downstream signaling intermediates. Subsequently, these signaling intermediates dissociate from caveolae, and CD4O binds to TRAFG in the cytoplasmic compartment.

3. A third mechanism has been described in endothelial cells. When SCD4OL binds to CD40, CD40 does not go to lipid rafts, but enters the early endosome via rab5, a small GTPase, where it binds to TRAF2/3 and associates with its downstream signaling intermediates.

\section{Downstream signaling intermediates and effector molecules}

As described above, the various TRAF-binding domains, as well as the intra-cellular compartments, play a role in the signaling that can be elicited through CD40L. Most CD40signaling pathways result in the activation of NFKB, followed by upregulation of pro-inflammatory pathways, but the pathway from membrane to transcription factor varies.

In B-cells, CD40 signals via src family protein tyrosine kinases, serine/threonine kinases, Jak3 and MAPK family members (JNK, p38,ERK1/2), followed by activation of NFKB. ${ }^{31}$ In endothelial cells, CD40-signaling goes via janus kinase (JNK), phosphoinositide 3-kinase (PI3)/Akt, mitogen-activated protein kinase (MAPK) to activation of NFKB. In monocytes and macrophages, CD40 signaling is also elicited via Src kinases and activation of the MAPK family members. ${ }^{19}$ However, only ERK $1 / 2$ seems to be activated, but not $\mathrm{p} 38$ or JNK, ${ }^{32}$ while smooth muscle cells and endothelial cells do show activation of JNK and p38 as well. ${ }^{20}$

Although CD40-signaling in general activates NFKB signaling, the final activation of NFKB can occur via two different pathways, a canonical and a non-canonical pathway. The canonical pathway operates via the kinase IKK $\beta$ and subsequently in the nuclear transcription of p50/RelA heteromers. The non-canonical pathway is activated by IKK $\alpha$, and results in the degradation of NFKB2 (p100) and the translocation of p52/RelB. CD40 is able to acti- 
vate NFkB via these pathways. Interestingly, CD40-TRAF6 interactions are only capable of activating the canonical NFKB pathway, while CD40-TRAF2/5 interactions activate both. ${ }^{33}$ TRAF3 plays a regulatory role in this process: TRAF3 is able to inhibit CD40-TRAF2/5 mediated NFKB signaling, thereby upregulating CD40-TRAF6 NFKB signaling. ${ }^{33}$

\section{Cell type-specific CD40-CD40L effects in atherosclerosis}

Both CD40 and CD40L are expressed on almost all cell types present in human and experimental atherosclerotic lesions. T-lymphocytes, platelets, endothelial cells and VSMCs, macrophages and dendritic cells are considered to express CD40L whereas CD40 is found on macrophages, endothelial cells, VSMCs and on the small number of B-cells found in plaques. ${ }^{14}$

In general, stimulation of all CD40-expressing cell types induces cell functions that contribute to inflammation, such as activation of chemokine and cytokine synthesis, enhancement of co-stimulatory and adhesion molecules, as well as upregulation of proteolytic enzymes. ${ }^{34}$

Almost a decade ago, we and others showed that total absence of CD40L (knockout mice) or inhibition of CD40L by antibody treatment not only reduced atherosclerosis extent, but also induced a plaque phenotype that was high in fibrosis (ie collagen-rich) and low in inflammation (low macrophage and T-lymphocyte content): a stable plaque phenotype (fig. 3.3). ${ }^{4-7}$ Interestingly when $\mathrm{CD} 40 \mathrm{~L}$ is only absent from bone marrow-derived plaque cells in $\mathrm{LDLR}^{-/}$mice, plaque area as well as atherosclerotic plaque phenotype were not affected. ${ }^{35}$,
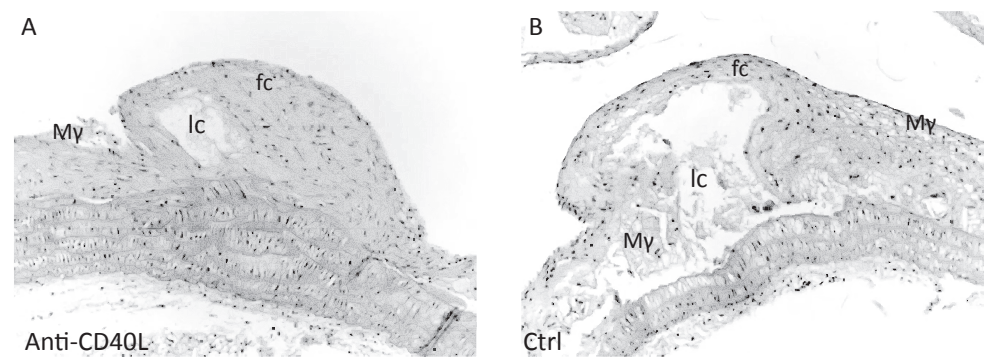

Figure 3.3

(a) atherosclerotic plaque of an $A p o E$ mouse (29 wks old) that was treated from week 17-29 with an anti-CD40L antibody. The atherosclerotic plaque contains a thick fibrous cap (fc), and has a fibrotic appearance. The lipid core (Ic) is very small, and only a few macrophages $(m \boldsymbol{l})$ are present. This atherosclerotic plaque has a stable plaque phenotype. Compare these features with a normal plaque of an ApoE $\%$ mouse (b) that was treated with a control lgG (ctrl).

The expression of CD40 on many cell-types present in atherosclerotic plaques and in the circulation creates many possible cell-cell CD40-CD40L interactions, some of which are more crucial than others. This, combined with the accumulating data demonstrating the divergence of signaling outcomes of CD40 ligation in the various cell types, underscores the importance of examining CD40-signaling as a cell-specific event.

\section{T-lymphocytes}

Interaction between CD40 on APCs and CD40L on T-cells results in upregulation of costimulatory molecule complexes CD80/CD86 on the APCs and consequently of CD28 on the T-cells. Interaction between the different co-stimulatory molecules results in expansion of the number of CD4+ T-lymphocytes and drives the T-cell response towards Th1, Th2 or Th3. The Th1 response is characterized by upregulation of interferon (IFN) $v$, tumor necrosis factor (TNF) $\alpha$, IL-1 and IL-18, all pro-atherogenic factors, while upregulation of Th2 (IL-4, IL-5, IL-10) is considered mostly anti-atherogenic. The Th3 response is a regulatory response, characterized by expression of transforming growth factor (TGF) $\beta$ and IL-10. ${ }^{37}$

\section{Macrophages}

In addition to activation of the T-cell, the CD40-bearing macrophage is also activated after binding of CD4OL. This results in the induction of a plethora of pro-inflammatory, proteolytic and prothrombotic mediators. CD40 ligation induces for example the expression of the chemokines MCP-1, MIP1 $\alpha$, MIP1 $\beta$, RANTES and IL8, and of the cytokines IL1, IL6, IFN $Y$ and TNF $\alpha$. Moreover, a series of MMPs like MMP-1, -2, -3, -9, -11 and -13 are being produced, as well as the pro-thrombotic tissue factor. ${ }^{38}$ 


\section{Vascular smooth muscle cells and endothelial cells}

VSMCs and endothelial cells express both CD40 and CD40L, and activation of CD40L even further activates the system in an autocrine manner. Activation of CD40 signaling results in the expression of comparable effector molecules as in the macrophage. ${ }^{39}$ In addition, endothelial cells show enhanced expression of the leukocyte adhesion molecules VCAM, ICAM and E-selectin. ${ }^{40}$

\section{Platelets}

Besides T-lymphocytes, platelets are the main source of CD40L in the body. Upon platelet activation, $\mathrm{CD} 40 \mathrm{~L}$ is actively released form the platelet by proteolytic cleavage and released as SCD40L. Both membrane-bound CD40L and SCD40L are biologically active, and they can induce TF expression on monocytes, endothelial cells and VSMCs and are crucial in the stabilization of thrombi, which is mediated via $\alpha$ ll $\beta 3$ integrin. ${ }^{12}$ However, the effects of SCD40L versus CD40L on the different cell types are not known. Interestingly, in endothelial cells, only membrane bound CD4OL is able to induce expression of pro-inflammatory cytokines and adhesion molecules, while $\mathrm{SCD} 40 \mathrm{~L}$ is not. ${ }^{30}$

Platelet CD40L also acts as a pro-inflammatory mediator since it induces leukocyte adhesion molecules on the endothelium, and can activate monocytes and macrophages to induced inflammatory mediators. ${ }^{41}$

Interestingly, the cleaved form of $\mathrm{CD} 40 \mathrm{~L}, \mathrm{SCD} 40 \mathrm{~L}$ was found to be a predictive biomarker for (recurrent) cardiovascular events such as myocardial infarction and stroke. ${ }^{42}$

\section{Inhibition of CD40-CD40L interactions: a therapy for atherosclerosis?}

Although inhibition of CD40-CD40L interactions has been proven successful in atherosclerosis prevention and regression in a laboratory setting, interruption of the CD40-CD40L system in humans for prolonged periods of time would induce severe immune-suppression. Therefore, we feel that cell type-specific targeting or targeting of a downstream intermediate of the CD40-signaling cascade that is/are associated with atherosclerosis is recommended.

As described in this review, CD40-signaling and activation of the different CD40-effector molecules is complex, since the different $C D 40$-signaling cascades are highly cell type specific and even differ within one cell type, depending on the local requirements of that specific cell type.
Because data on CD40-signaling in atherosclerosis-associated cell-types are limited, more detailed studies dissecting the molecular mechanisms of the possible cell type-specific pro-atherogenic actions of $\mathrm{CD} 40 \mathrm{~L}$ are required. Knowledge of and subsequent targeting of different cell type-specific signal transduction pathways in cell types present in atherosclerotic plaques could provide more specific treatment targets of atherosclerosis, thereby obviating the undesired effects of global interruption of CD40 signaling. 


\section{References}

1. Lutgens, E. \& Daemen, M.J. CD40-CD40L Interactions in Atherosclerosis. Trends Cardiovasc.Med. 12, 2732 (2002).

2. Durie, F.H., et al. Prevention of collagen-induced arthritis with an antibody to gp39, the ligand for CD40. Science 261, 1328-1330 (1993).

3. Grewal, I.S., et al. Requirement for CD40 ligand in costimulation induction, $\mathrm{T}$ cell activation, and experimental allergic encephalomyelitis. Science 273, 1864-1867 (1996).

4. Lutgens, E., et al. Requirement for CD154 in the progression of atherosclerosis. Nat.Med. 5, 1313-1316 (1999).

5. Lutgens, E., et al. Both early and delayed anti-CD40L antibody treatment induces a stable plaque phenotype. Proc.Natl.Acad.Sci.U.S.A 97, 7464-7469 (2000).

6. Mach, F., Schonbeck, U., Sukhova, G.K., Atkinson, E. \& Libby, P. Reduction of atherosclerosis in mice by inhibition of CD40 signaling. Nature 394, 200-203 (1998).

7. Schonbeck, U., Sukhova, G.K., Shimizu, K., Mach, F. \& Libby, P. Inhibition of CD40 signaling limits evolution of established atherosclerosis in mice. Proc.Natl.Acad.Sci.U.S.A 97, 7458-7463 (2000).

8. Kuwana, M., et al. Effect of a single injection of humanized anti-CD154 monoclonal antibody on the platelet-specific autoimmune response in patients with immune thrombocytopenic purpura. Blood 103, 12291236 (2004).

9. Kalunian, K.C., Davis, J.C., Jr., Merrill, J.T., Totoritis, M.C. \& Wofsy, D. Treatment of systemic lupus erythematosus by inhibition of $\mathrm{T}$ cell costimulation with anti-CD154: a randomized, double-blind, placebocontrolled trial. Arthritis Rheum 46, 3251-3258 (2002).

10. Davis, J.C., Jr., Totoritis, M.C., Rosenberg, J., Sklenar, T.A. \& Wofsy, D. Phase I clinical trial of a monoclonal antibody against CD40-ligand (IDEC-131) in patients with systemic lupus erythematosus. J Rheumatol 28, 95-101 (2001)

11. Boumpas, D.T., et al. A short course of BG9588 (anti-CD40 ligand antibody) improves serologic activity and decreases hematuria in patients with proliferative lupus glomerulonephritis. Arthritis Rheum 48, 719-727 (2003).

12. Andre, P., et al. CD40L stabilizes arterial thrombi by a beta3 integrin--dependent mechanism. Nat Med 8 , 247-252 (2002).

13. Foy, T.M., Aruffo, A., Bajorath, J., Buhlmann, J.E. \& Noelle, R.J. Immune regulation by CD40 and its ligand GP39. Annu.Rev.Immunol. 14, 591-617 (1996).

14. Schonbeck, U. \& Libby, P. CD40 signaling and plaque instability. Circ. Res. 89, 1092-1103 (2001).

15. Zapata, J.M. TNF-receptor-associated factors as targets for drug development. Expert Opin Ther Targets 7, 411-425 (2003).

16. Arron, J.R., Pewzner-Jung, Y., Walsh, M.C., Kobayashi, T. \& Choi, Y. Regulation of the subcellular localization of tumor necrosis factor receptor-associated factor (TRAF)2 by TRAF1 reveals mechanisms of TRAF2 signaling. J Exp Med 196, 923-934 (2002).

17. Ishida, T.K., et al. TRAF5, a novel tumor necrosis factor receptor-associated factor family protein, mediates CD40 signaling. Proc Natl Acad Sci U S A 93, 9437-9442 (1996).

18. Ahonen, C., et al. The CD40-TRAF6 axis controls affinity maturation and the generation of long-lived plasma cells. Nat.Immunol. 3, 451-456 (2002).

19. Mukundan, L., et al. TNF receptor-associated factor 6 is an essential mediator of CD40-activated proinflammatory pathways in monocytes and macrophages. J Immunol 174, 1081-1090 (2005).
20. Mukundan, L., Milhorn, D.M., Matta, B. \& Suttles, J. CD40-mediated activation of vascular smooth muscle cell chemokine production through a Src-initiated, MAPK-dependent pathway. Cell Signal 16, 375-384 (2004).

21. Urbich, C., et al. Upregulation of TRAF-3 by shear stress blocks CD40-mediated endothelial activation. J.Clin.Invest 108, 1451-1458 (2001)

22. McPherson, P.S., Kay, B.K. \& Hussain, N.K. Signaling on the endocytic pathway. Traffic 2, 375-384 (2001).

23. Yellin, M.J., et al. CD40 molecules induce down-modulation and endocytosis of $\mathrm{T}$ cell surface $\mathrm{T}$ cell-B cell activating molecule/CD40-L. Potential role in regulating helper effector function. J Immunol 152, 598-608 (1994).

24. Anolik, J., Looney, R.J., Bottaro, A., Sanz, I. \& Young, F. Down-regulation of CD20 on B cells upon CD40 activation. Eur J Immunol 33, 2398-2409 (2003).

25. Hostager, B.S., Catlett, I.M. \& Bishop, G.A. Recruitment of CD 40 and tumor necrosis factor receptor-associated factors 2 and 3 to membrane microdomains during CD40 signaling. J Biol Chem 275, 15392-15398 (2000).

26. Vidalain, P.O., et al. CD40 signaling in human dendritic cells is initiated within membrane rafts. EMBO J. 19, 3304-3313 (2000)

27. Malapati, S. \& Pierce, S.K. The influence of $C D 40$ on the association of the $B$ cell antigen receptor with lipid rafts in mature and immature cells. Eur J Immunol 31, 3789-3797 (2001).

28. Xie, P., Hostager, B.S., Munroe, M.E., Moore, C.R. \& Bishop, G.A. Cooperation between TNF receptorassociated factors 1 and 2 in CD40 signaling. J Immunol 176, 5388-5400 (2006).

29. Li, H. \& Nord, E.P. Functional caveolae are a prerequisite for $C D 40$ signaling in human renal proximal tubule cells. Am J Physiol Renal Physiol 286, F711-719 (2004).

30. Chen, Y., et al. Internalization of CD40 regulates its signal transduction in vascular endothelial cells. Biochem Biophys Res Commun 345, 106-117 (2006).

31. Manning, E., Pullen, S.S., Souza, D.J., Kehry, M. \& Noelle, R.J. Cellular responses to murine CD40 in a mouse B cell line may be TRAF dependent or independent. Eur.J.Immunol. 32, 39-49 (2002).

32. Suttles, J., et al. CD40 signaling of monocyte inflammatory cytokine synthesis through an ERK1/2-dependent pathway. A target of interleukin (il)-4 and il-10 anti-inflammatory action. J Biol Chem 274, 5835-5842 (1999).

33. Hauer, J., et al. TNF receptor (TNFR)-associated factor (TRAF) 3 serves as an inhibitor of TRAF2/5-mediated activation of the noncanonical NF-kappaB pathway by TRAF-binding TNFRs. Proc Natl Acad Sci U S A 102, 2874-2879 (2005).

34. Mach, F., Schonbeck, U. \& Libby, P. CD40 signaling in vascular cells: a key role in atherosclerosis? Atherosclerosis 137 Suppl, S89-S95 (1998).

35. Smook, M.L., et al. Leukocyte CD40L deficiency affects the CD25(+) CD4 $\mathrm{T}$ cell population but does not affect atherosclerosis. Atherosclerosis 183, 275-282 (2005).

36. Bavendiek, U., et al. Atherogenesis in mice does not require CD40 ligand from bone marrow-derived cells. Arterioscler Thromb Vasc Biol 25, 1244-1249 (2005).

37. Robertson, A.K. \& Hansson, G.K. T cells in atherogenesis: for better or for worse? Arterioscler Thromb Vasc Biol 26, 2421-2432 (2006)

38. Mach, F., Schonbeck, U., Bonnefoy, JY, Pober, J.S. \& Libby, P. Activation of monocyte/macrophage functions related to acute atheroma complication by ligation of CD40: induction of collagenase, stromelysin, and tissue factor. Circulation 96, 396-399 (1997).

39. Bavendiek, U., et al. Induction of tissue factor expression in human endothelial cells by CD40 ligand is mediated via activator protein 1, nuclear factor kappa B, and Egr-1. J Biol Chem 277, 25032-25039 (2002). 
40. Rook AH, Kehrl JH, Wakefield LM, Roberts AB, Sporn MB. Effects of transforming growth factor on the functions of natural killer cells: depressed cytolytic activity and blunting of interferon responsiveness. J. Immunol. 1986;136:3916

41. Bellone G, Aste-Amezaga M, Trinchieri G, Rodeck U. Regulation of NK cell functions by TGF- 1. J. Immunol. 1995;155:1066.

42. Gautier EL, Huby T, Saint-Charles F, Ouzilleau B, Pirault J, Deswaerte V, Ginhoux F, Miller ER, Witztum JL, Chapman MJ, Lesnik P. Conventional dendritic cells at the crossroads between immunity and cholesterol homeostasis in atherosclerosis. Circulation. 2009;119(17):2367-2375.

43. Choi JH, Do Y, Cheong C, Koh H, Boscardin SB, Oh YS, Bozzacco L, Trumpfheller C, Park CG, Steinman RM. Identification of antigen-presenting dendritic cells in mouse aorta and cardiac valves. J Exp Med. 2009;206(3):497-505.

44. Laouar Y, Town T, Jeng D, Tran E, Wan Y, Kuchroo VK, Flavell RA. TGF-beta signaling in dendritic cells is a prerequisite for the control of autoimmune encephalomyelitis. Proc Natl Acad Sci U S A. 2008;105(31):1086510870. 
CD40L DEFICIENCY PROTECTS AGAINST ANEURYSM FORMATION:

A NOVEL PREVENTION STRATEGY?

Linda Beckers, Dirk Lievens, Erwin Wijnands, Ulrike Benbow, Richard Flavell, Alan

Daugherty, Andrew Newby, Mat JAP Daemen and Esther Lutgens

under revision 


\section{Abstract}

\section{Objective}

To study the role of CD40L on aneurysm formation.

\section{Methods and results}

$\mathrm{CD} 40 \mathrm{~L}^{+/+} / \mathrm{ApoE}^{-/-}(\mathrm{n}=27)$ and $\mathrm{CD} 40 \mathrm{~L}^{-/} / \mathrm{ApoE}^{-/-}(\mathrm{n}=26)$ mice were infused with angiotensin II (Angll, $1000 \mathrm{ng} / \mathrm{kg} / \mathrm{min}, 4 \mathrm{wks}$ ) to induce suprarenal aortic aneurysms (AAA). Only $18 \%$ of the $\mathrm{CD} 40 \mathrm{~L}^{-/} / \mathrm{ApoE}^{-/-}$mice developed an AAA during Angll infusion vs $67 \%$ of the $\mathrm{CD}^{-10 \mathrm{~L}^{++} /}$ ApoE $\mathrm{E}^{-/}$mice. Total vessel area at the level of the suprarenal aorta in $\mathrm{CD}^{2} 0 \mathrm{~L}^{-1 /} / \mathrm{ApoE}^{-1-}$ was only $47.6 \%$ of that in $\mathrm{CD}_{40 \mathrm{~L}^{++} / \mathrm{ApoE}}-/$ mice. $\mathrm{CD} 40 \mathrm{~L}$ deficiency was also protective against fatal AAA rupture.

Macrophage and CD45+ cell accumulations in the aneurysms were reduced in $\mathrm{CD}^{2} 0 \mathrm{~L}^{-1} /$ ApoE ${ }^{-1}$ mice. Expression of MCP-1, -5, MIP-1 $\alpha$, MIP-2, IL-1 $1 \beta$, IL- 6 and TNF $\alpha$ had decreased in AAA in absence of CD40L. CD40L efficiency decreased the expression of the Th1 cytokines, whereas the Th2 cytokines were not affected in the AAA tissues. Interestingly, in the non-aneurysmatic arterial wall, the Th1 response had decreased while Th2 and Treg responses had increased in absence of $\mathrm{CD} 40 \mathrm{~L}$. In addition, $\mathrm{AAA}$ of $\mathrm{CD} 40 \mathrm{~L}^{-/} / \mathrm{ApoE}^{--}$mice had decreased activities of MMP-2, pro-MMP-9 and MMP-9.

\section{Conclusions}

Deficiency of CD40L protects against AAA formation and reduces the incidence of aortic rupture, by decreasing influx and activity of inflammatory cells, and protease activity in the arterial wall.

\section{Introduction}

Aortic abdominal aneurysms (AAAs) are defined as a permanent dilation of $>50 \%$ of the abdominal aorta, and occur in about $5 \%$ of the elderly population. Because of ageing of the population, the incidence of AAAs raises which is of increasing health concern. Complications of AAA, such as rupture or dissection cause substantial morbidity and mortality. ${ }^{1-2}$ Histo-pathological characteristics of AAAs are degeneration of medial elastin fibers, medial thinning, adventitial hypertrophy with accumulation of macrophages, $T$ and $B$ lymphocytes, as well as the presence of atherosclerosis and thrombi. ${ }^{3}$ Since human samples mostly reflect end-stage aneurysmal disease, and are therefore not suitable for studying etiologic factors of AAA formation, mouse models are often used.

One of the most frequently used mouse models of AAA is based on the infusion angiotensin II (AngII). In this model, Angll is infused into hyperlipidemic mice and within 2-4 wks, an AAA develops in the suprarenal area of the aorta. ${ }^{4}$ This model has many characteristics of human aneurysm formation, including lumen dilatation, medial degeneration, inflammation, thrombus formation and rupture. AAAs in this mouse model are frequently characterized by dissections, ${ }^{5}$ which is not often seen in human AAAs.

Most etiological studies of AAA point to an important role for excessive matrix degeneration and inflammation. ${ }^{1,3}$ Excessive matrix degeneration in the arterial wall is attributed to the families of matrix metalloproteinases (MMPs) and cysteine proteases. ${ }^{6}$ Increased MMP-1, $-2,-3,-7,-8,-9,-12,-13$ and -14 levels and activity have been noted in $A A A s^{6-8}$ and especially deficiency in MMP- $9,{ }^{9}$ or inhibition with broad spectrum MMP-inhibitors like doxycycline ${ }^{10}$ have been shown to reduce aneurysms.

Besides MMPs, the cysteine proteases such as cathepsin $\mathrm{K}, \mathrm{L}$ and $\mathrm{S}$, have been implicated in AAA development and rupture. High expression levels of cathepsin $\mathrm{K}, \mathrm{L}$ and $\mathrm{S}$ have been observed in human AAAs, ${ }^{6}$ and animal models have demonstrated a protective effect of cathepsin $\mathrm{S}$ deficiency in AAA development. ${ }^{11}$

Inflammation is also of major importance in aneurysm formation with lymphocytes being the largest population of inflammatory infiltrate in AAAs. ${ }^{12}$ Patients suffering from AAA show increased serum concentrations of inflammatory mediators such as IL-1 13 , IL-6, TNF $\alpha$ and IFN $Y^{13}$, and several pro- and anti-inflammatory mediators were reported to affect AAA development in mice.

A TNF-related signaling pathway, known to have profound effects on both inflammation and matrix turnover, is the $\mathrm{CD} 40-\mathrm{CD} 40 \mathrm{~L}$ signaling pathway. ${ }^{14} \mathrm{CD} 40-\mathrm{CD} 40 \mathrm{~L}$ interactions have proven to be crucial players in inflammatory and auto-immune related diseases like atherosclerosis, Crohn's disease, allergic encephalitis, and arthritis. ${ }^{14}$ 
In atherosclerosis, inhibition of CD40-CD40L signaling decreases plaque size and results in a stable plaque phenotype, with high amounts of vascular smooth muscle cells and collagen and decreased amounts of inflammatory cells such as macrophages and T-cells. ${ }^{15-17}$

Considering the important role of $\mathrm{CD} 40 \mathrm{~L}$ on both inflammation and extracellular matrix degradation, and its profound effect on atherosclerosis, we hypothesized that CD40L plays a pivotal role in AAA development. Here, we show that deficiency of CD40L dramatically reduces the incidence of AAA in Ang II-infused $\mathrm{ApoE}^{-/-}$mice. This was caused by a low inflammatory cell influx, a low abundance of chemokines and cytokines, and reduced MMPactivity in the (aneurysmatic) aorta.

\section{Methods}

\section{Mice}

$\mathrm{CD} 40 \mathrm{~L}^{-/} / \mathrm{ApoE}^{-/-}(\mathrm{n}=26)$ and $\mathrm{CD} 40 \mathrm{~L}+/+/ \mathrm{ApoE}-/-(\mathrm{n}=27)$ mice on a C57BI6 background were bred in our animal facility. All mice were fed a normal chow diet throughout the experiment. At 10 weeks of age, Alzet osmotic minipumps (Model 2004; Durect Corporation, Cupertino, California, USA), containing Angiotensin II (Sigma A9525) were implanted subcutaneously into both the $\mathrm{CD} 4 \mathrm{~L}^{+/+} / \mathrm{ApoE}^{-/}$and $\mathrm{CD} 4 \mathrm{~L}^{-/} / \mathrm{ApoE}^{-/}$mice. Angiotensin II was delivered at a dose of $1000 \mathrm{ng} / \mathrm{kg} / \mathrm{min}$ for 28 days. ${ }^{4}$ After 28 days of Ang II infusion, all mice were euthanized after an overnight fast. Blood was collected from the right ventricular apex for lipoprotein analysis. Presence of macroscopic AAA or TAA was noted. Mice were

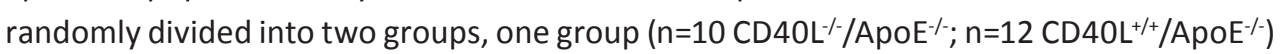
was used for histological and morphometric analysis and the second group $\left(n=16 \mathrm{CD}^{2} \mathrm{~L}^{-1}\right.$ ) ApoE $E^{-/} ; \mathrm{n}=15 \mathrm{CD} \mathrm{OL}^{+/+} / \mathrm{ApoE}^{-/}$) for mRNA and protein analysis. All animal experiments were approved by the institutional committee for the welfare of laboratory animals of the University of Maastricht.

\section{Histological analysis}

For morphometric analysis the entire arterial tree was perfused with PBS containing $0.1 \mathrm{mg} /$ $\mathrm{ml}$ nitroprusside and then with $1 \%$ paraformaldehyde via a catheter inserted into the left ventricle. The arterial tree was excised and fixed overnight in $1 \%$ paraformaldehyde and embedded in paraffin. Cross sections $(4 \mu \mathrm{m})$ of the suprarenal area of the abdominal aorta (with or without AAA) were made at 12 different levels at $200 \mu \mathrm{m}$ intervals. Cross sections from each level were stained with H\&E and Elastica von Gieson. Total vessel area on all 12 levels was quantified using the Leica Qwin V3.2.1 system and DM 500B microscope. Morphometric analysis was performed by one investigator (LB) who was blinded for genotype. The intra-observer variability was $<9 \%$.

\section{Immunohistochemistry}

To characterize accumulation of inflammatory cells in aneurismal tissue and the tissue surrounding the AAA, cross sections were immunostained with MAC-3 (1:30, Beckton \&Dickenson) for presence of macrophages, CD45 (1:5000, Becton \& Dickenson) for leukocyte infiltration and CD3 (Dako) for T-cell infiltration. MAC-3, CD45 and CD3 immunostainings were quantified using a scoring system where no chromagen corresponded with a score of 0 and maximum color corresponded with a score of 5 . Scoring was performed by 1 investigator, who was blinded to the indentity of the sections. The intra-observer variability was $<10 \%$.

\section{RNA and protein analyses}

Abdominal aortas of mice for RNA or protein analysis were excised and immediately snap frozen in liquid nitrogen and stored at $-80^{\circ} \mathrm{C}$ until further use. The presence of a macroscopic visible aneurysm was documented.

\section{RNA isolation and quantitative real time PCR}

Aortic tissues were homogenized and RNA was isolated using the Qiagen Rneasy mini kit (Qiagen) and eluted with $30 \mathrm{ul}$ of ddH2O. For the preparation of cDNA the iScriptTMcDNA Synthesis Kit (BIORAD) was used according to manufacturers protocols. Quantitative PCR was done using the SYBR Green method. 10ng of CDNA was used with the 2x qPCR master mix (BIORAD). Expression of matrix metalloproteinases and their inhibitor genes (MMP-2, MMP-9, MMP-3, MMP-13, MMP-14, TIMP-1, TIMP-2 and TIMP-3), inflammatory genes (MCP-1, MCP-5, MIP-1 $\alpha$, MIP-2, IL-1 $\beta$, IL6 and TNF $\alpha$ ), Th1 specific cytokines (IL-12, IL-18, IFN ү) Th2 specific cytokines (IL-4, IL-5, IL-10) and the regulatory T-cell specific gene Foxp3 were analyzed. The housekeeping gene cyclophilin A was used to normalilze RNA abundance.

\section{Gelatin zymography}

MMP-2 and MMP-9 activity was determined in aortic/aneurysm tissues of $\mathrm{CD} 4 \mathrm{~L}^{+/+} / \mathrm{ApoE}^{-/}$ and $\mathrm{CD} \mathrm{LL}^{-1} / \mathrm{ApoE}^{-/-}$mice. Tissue samples were extracted in $150 \mu \mathrm{l} \mathrm{SDS-lysis} \mathrm{(10 \%} \mathrm{glycerol,}$ $20 \%$ SDS, $10 \% 1.5 \mathrm{M}$ Tris $\mathrm{pH}$ 6.8) buffer by cutting the tissue into small pieces. MMP-2 and MMP-9 activity in extracts were detected as decribed previously. ${ }^{18}$ Briefly, $4 \mu \mathrm{l}$ of tissue extracts was diluted (1:5) with distilled water. Samples were electrophoresed in the pres- 
ence of non-reducing buffer at $4^{\circ} \mathrm{C}$ in $7.5 \%$ SDS-polyacrylamide gels containing $2 \mathrm{mg} / \mathrm{mL}$ gelatin. After the removal of SDS, gelatinase activity was revealed by overnight incubation at $37^{\circ} \mathrm{C}$ and staining with $0.1 \%$ Coomassie brilliant blue. Zymograms were quantified in the linear range by densitometry with Quantity One 1-D Image Analysis software system (Bio-Rad).

\section{Lipoprotein analysis}

Plasma cholesterol concentrations were measured enzymatically using commercially available kits (Roche Diagnostics GmbH, Mannheim, Germany).

\section{Statistical analysis}

Data are expressed as mean \pm SEM. The Mann-Whitney non-parametrical test was used to compare the $\mathrm{CD} 4 \mathrm{~L}^{-/} / \mathrm{ApoE}^{-/}$and $\mathrm{CD} 40 \mathrm{~L}^{+/+} / \mathrm{ApoE}^{-/}$groups. When analyzing incidence of aneurysm formation and incidence of death before end of the experiment the Pearsons Chi-Squared test was used. Data with probability values $<0.05$ were considered statistically significant.

\section{Results}

\section{General}

No differences in body weight were observed between $\mathrm{CD} 4 \mathrm{~L}^{+/+} / \mathrm{ApoE}^{---}$and $\mathrm{CD}^{-10 \mathrm{~L}^{-1} /}$ ApoE ${ }^{-/-}$mice at the beginning or at the end of the study (body weight start $24.6 \mathrm{~g} \mathrm{CD}^{-10 \mathrm{~L}^{++} /}$ ApoE $E^{-/}$vs $24.1 \mathrm{~g} \mathrm{CD} 40 \mathrm{~L}^{-1 /} / \mathrm{ApoE}^{-1} ; \mathrm{P}>0.05$ and body weight end $27.2 \mathrm{~g} \mathrm{CD} 40 \mathrm{~L}^{+/+} / \mathrm{ApoE}^{-/}$vs

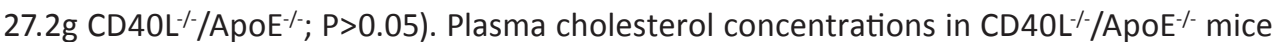
did not differ compared to the $\mathrm{CD} 4 \mathrm{~L}^{+++} / \mathrm{ApoE}^{-/-}$mice $\left(331 \mathrm{mg} / \mathrm{dl} \mathrm{CD} 40 \mathrm{~L}^{+/+} / \mathrm{ApoE}^{-/-}\right.$vs $299 \mathrm{mg} /$ dl $\mathrm{CD} 40 \mathrm{~L}^{-1 /} / \mathrm{ApoE}^{-1} ; \mathrm{P}=0.06$ )

\section{CD4OL deficiency protects against Angll-induced AAA formation in $\mathrm{ApoE}^{-/}$mice}

CD40L deficiency was largely protective against Angll-induced AAA formation. In $\mathrm{CD}^{2} \mathrm{LL}^{-1} /$ ApoE ${ }^{-1-}$ mice, the incidence of AAA was only $19 \%$ compared to $67 \%$ in $\mathrm{CD}^{2} 40 \mathrm{~L}^{+/+} / \mathrm{ApoE}^{-1-}$ mice, rendering a large group of non-responders in the $\mathrm{CD} 4 \mathrm{LL}^{-1} / \mathrm{ApoE}^{-/}$group (table 1 ). The protective effect of $\mathrm{CD} 40 \mathrm{~L}$-deficiency on Angll-induced AAA formation is reflected in the total vessel area (EEL area), which was decreased in $\mathrm{CD}^{2} 0 \mathrm{~L}^{-1} / \mathrm{ApoE}^{-1-}$ mice $\left(172,443 \mu \mathrm{m}^{2}\right.$ $\pm 68,760 \mu \mathrm{m}^{2}$ in $\mathrm{CD} 40 \mathrm{~L}^{-/} / \mathrm{ApoE}^{-/}$vs $360,767 \mu \mathrm{m}^{2} \pm 86,256 \mu \mathrm{m}^{2}$ in $\mathrm{CD}^{2} \mathrm{LL}^{+/+} / \mathrm{ApoE}^{-/-}$mice) (fig.
4.1). $\mathrm{CD} 40 \mathrm{~L}$ deficiency was also protective against fatal AAA rupture, which occurred in only $3.8 \%$ of all Angll treated $\mathrm{CD}^{2} 0 \mathrm{~L}^{-1 /} / \mathrm{ApoE}^{--}$mice and in $18.5 \%$ of all Angll treated $\mathrm{CD} 4 \mathrm{~L}^{+/+} / \mathrm{ApoE}^{-/}$.

However, once an aneurysm had developed (that is in the subgroup of responders), no differences were found between total AAA areas (EEL area) $\left(458,913 \mu \mathrm{m}^{2} \pm 110,029 \mu \mathrm{m}^{2}\right.$ in the $\mathrm{CD}^{2} \mathrm{LL}^{-1 /} / \mathrm{ApoE}^{-1-}$ mice and $513,714 \mu \mathrm{m}^{2} \pm 86,096 \mu \mathrm{m}^{2}$ in the $\mathrm{CD}^{2} \mathrm{~L}^{+/+} / \mathrm{ApoE}-1-$ mice (fig. 4.1). Also in the two groups of non-responders total vessel areas were not different.

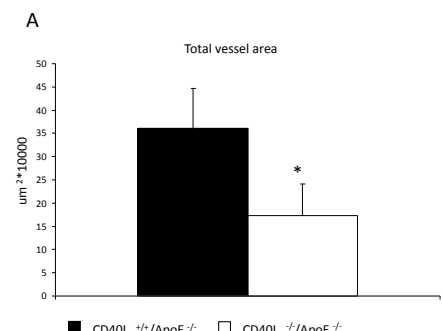

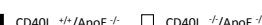

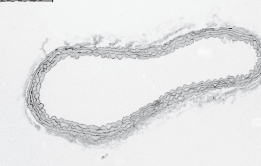

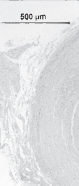

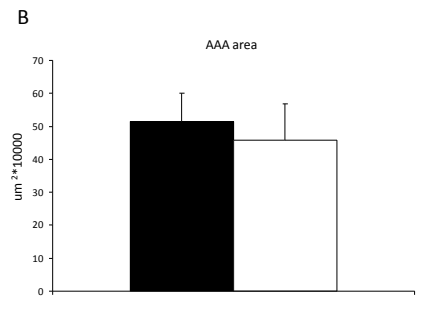

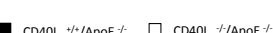

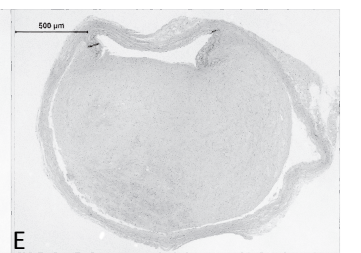

Figure 4.1

Total vessel area of the abdominal aorta of $\mathrm{CD} \mathrm{OL} \mathrm{L}^{++} / \mathrm{ApoE} \%$ and $\mathrm{CD} 40 \mathrm{OL} / \mathrm{ApOE} /$ mice has significantly decreased in $\mathrm{CD}^{2} \mathrm{OL} \% / \mathrm{ApoE} \%$ mice (a). Aortic aneurismal area of ApoE $\% / \mathrm{CD}^{2} \mathrm{~L}^{++}$compared to aneurismal area of ApoE $\%$ CD40L $\%$ mice is not different (b). EVG staining of a non-responder $A p O E \% / C D 40 \mathrm{~L} \%$ abdominal aorta (c). EVG stain-

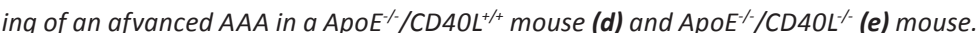

\section{The decrease in incidence of AAAs upon CD4OL deficiency is due to a reduction in vascular} inflammation and proteolytic activity

Deficiency of CD40L significantly reduced the infiltration of inflammatory cells in the vascular wall and its surrounding tissue upon Angll infusion. Both the number of CD45+ leukocytes and Mac3+ macrophages was significantly reduced in absence of CD40L (fig. 4.2). The decrease in inflammatory cells in the aortas from $\mathrm{CD}^{2} \mathrm{LL}^{-\%} / \mathrm{ApoE}^{-/}$mice upon Angllinfusion was reflected by the mRNA expression in the abdominal aorta of a plethora of chemokines and cytokines. 

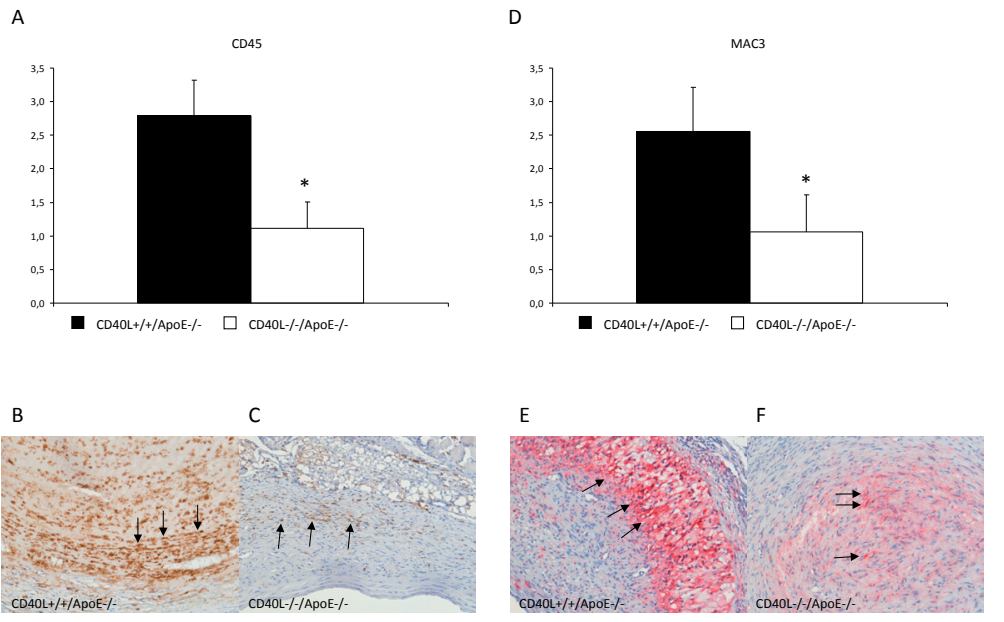

Figure 4.2

Accumulation of inflammatory cells in the AAA. Accumulation of CD45+cells and Mac3+ cells in AAA has signifi-

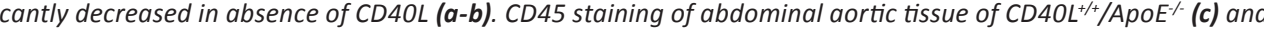

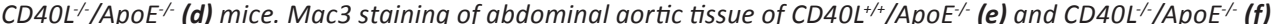
mice.

In absence of CD40L, abdominal aortas exhibited a decreased mRNA expression of the chemokines MCP-1, MCP-5, MIP-1 $\alpha$ and MIP-2, and the cytokines TNF $\alpha$, IL-1 $\beta$ and IL- 6 (fig. 4.3 a). Interestingly, CD40L-deficiency particularly reduced the expression of the Th1 cytokines IFNY, TNF $\alpha$, IL-12 and IL-18, while the expression of the Th2 cytokines IL-4, IL-5 and IL-10 was not affected. Surprisingly, the regulatory T-cell component, reflected by Foxp3 levels was also reduced in AAAs of $\mathrm{CD} 4 \mathrm{~L}^{-1 /} / \mathrm{ApOE}^{-1 /}$ mice (fig. 4.3 b).

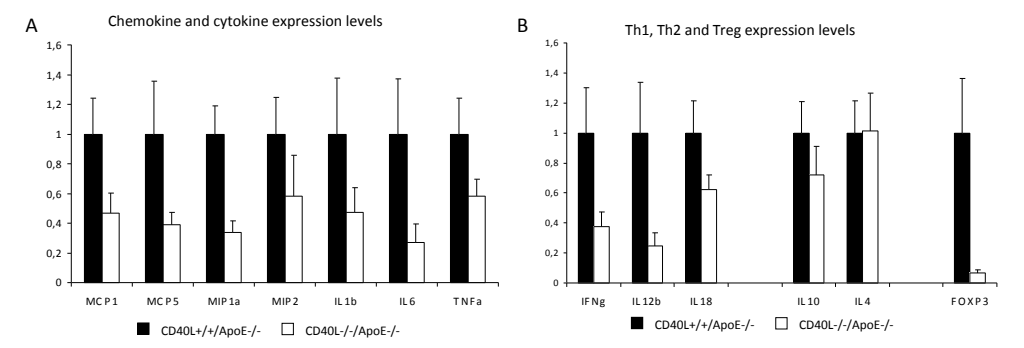

Figure 4.3

Quantitative real time PCR reveals a decrease in relative chemokine and cytokine gene expression levels in absence of CD4OL (a). Th1, Th2 and Treg responses are affected in absence of CD4OL (b).
Since Angll-infusion of mice had profound matrix degrading effects, MMP expression and activities were measured in the abdominal aorta of $\mathrm{CD}^{2} 0 \mathrm{~L}^{-/} / \mathrm{ApoE}^{-/-}$and $\mathrm{CD} 40 \mathrm{~L}^{+/+} / \mathrm{ApoE}^{-/-}$ mice. Real time analysis revealed a decrease in MMP-9, -13 and -14 mRNA levels after AngII infusion in abdominal aorta's of $\mathrm{CD}^{2} \mathrm{LL}^{-} / \mathrm{ApoE}-\%$ mice (fig. 4.4 a). In addition, gelatin zymographies revealed a significant decrease in both MMP-2 and MMP-9 activity, as well as in pro-MMP-9 in abdominal aorta's of $\mathrm{CD}^{2} \mathrm{LL}^{-1 /} / \mathrm{ApoE}^{-1}$ mice (fig. $4.4 \boldsymbol{b}$-c). Also the expression of the tissue inhibitors of MMPs (TIMPS), TIMP-1, TIMP-2 and TIMP-3 were analyzed. We found that only TIMP-3 mRNA expression was increased in the abdominal aorta of $\mathrm{CD}_{40 \mathrm{~L}^{-1} / \mathrm{ApoE}}{ }^{-1 /}$ mice (fig. 4.4 a)
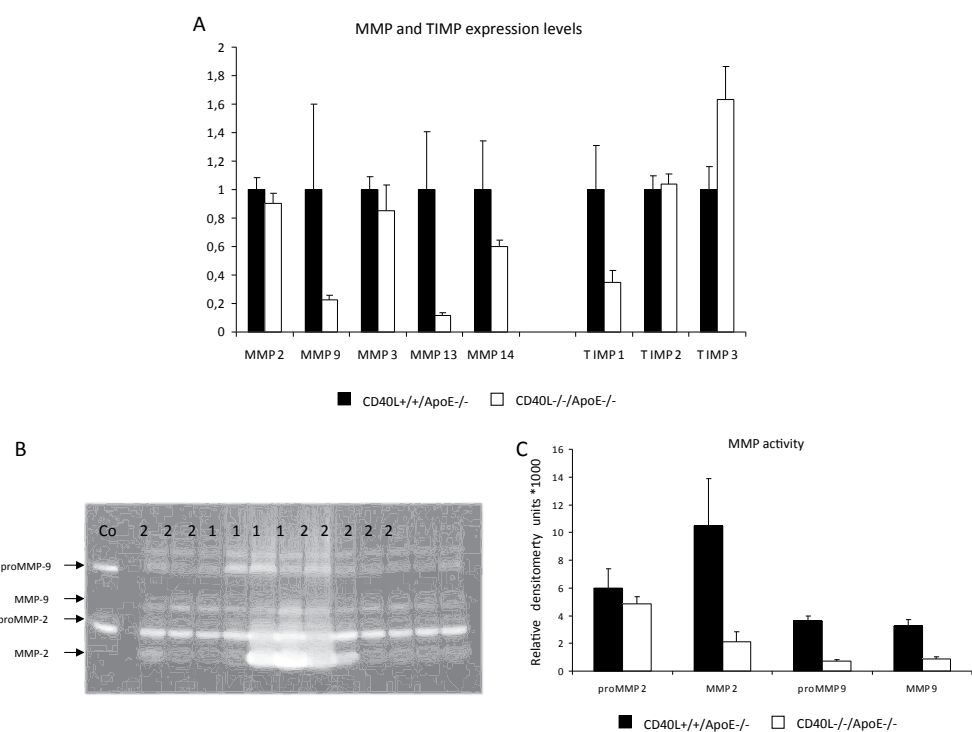

Figure 4.4

MMP and TIMP analysis, Quantitative real time PCR results for abdominal aortic tissue of $C D 40 L^{++/} / A p O E^{-}-$and CD4OL $\%$ ApoE $\%$ mice (a). MMP activity was decreased in absence of CD4OL (gelatine typografie) (b). $\mathrm{mVSMC}$ media, treated with TNF-a+PDGF was used as control (Co). Samples were aneurysm and non responder abdominal aortic tissue from ApoE $\% / \mathrm{CD} 4 \mathrm{~L}^{++}$(1) and $\mathrm{ApoE} \% / \mathrm{CD} 40 \mathrm{~L}^{\%}$ (2) mice. Quantification of MMP and proMMP activity of $A D O E \% / C D 4 O L^{+/+}$and $A p O E \% / C D 40 L \%$ mice (c). 
In absence of CD40L, the incidence of AAA was only $19 \%$ compared to $67 \%$ in wild type

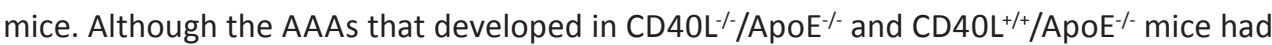
the same size, their inflammatory and proteolytic profile tend to be different. When CD40L was absent, the level of pro-inflammatory chemokines and cytokines like MCP-1, MIP-1, TNF $\alpha$ as well as the Th1 response was decreased in the AAA (suppl. fig. 4.1). However, the Th2 and Treg responses were also decreased.

Interestingly, this was also the case in mice that did not develop an AAAs upon Angllinfusion. In these non-responders, levels of MCP-1, MIP-1 $\alpha$, MIP2, IL1 $\beta$ and IL- 6 were lower in the aortas from $\mathrm{CD} 40 \mathrm{~L}^{-/} / \mathrm{ApoE}-/$ mice after $4 \mathrm{wks}$ of Angll infusion compared to aortas of $\mathrm{CD} 4 \mathrm{LL}^{+/+} / \mathrm{ApoE}^{-1}$. The Th1-cytokines IFN $\gamma$, TNF $\alpha$ and IL-18 were slightly decreased, whereas the Th-2 cytokines IL4 and IL10, as well as the regulatory T-cell marker FoxP3 had increased in the arterial wall in absence of CD40L. These data show that CD40L deficient aortas are protected against the pro-inflammatory actions of angiotensin II due to downregulation of pro-inflammatory chemokines and cytokines and Th1 responses, and activation of Th2 and Treg responses. However, once an AAA develops, CD40L-deficiency cannot prevent progression of the AAA due to decreased Th2 and Treg responses.

A similar phenomenon was observed for the proteolytic enzymes. AAAs of $\mathrm{CD} 40 \mathrm{~L}^{-1 /} / \mathrm{ApoE}^{-1 /}$ mice showed a decreased activity and/or expression of MMP-2, MMP-9, -13 and -14 and an increased expression of TIMP-3. In the non-responders, $\mathrm{CD}^{2} \mathrm{~L}^{-1} / \mathrm{ApoE}^{-/}$aortas showed less expression and/or activity of MMP-2, -9 and -13 , and higher expression of TIMP-3 than aortas of $\mathrm{CD}_{40 \mathrm{~L}^{++} / \mathrm{ApoE}}^{-/-}$mice, rendering $\mathrm{CD} 40 \mathrm{~L}-$ deficient aortas protected against Angll induced proteolysis and hence AAA formation (suppl. fig. 4.2).

\section{Discussion}

Here we show that inhibition of CD40L can attenuate the development of Angll induced $A A A$, although it is not capable of limiting the size of the AAA once it develops, but is protective against fatal AAA rupture. $C D 40 \mathrm{~L}$ deficiency prevents the occurrence of AAA by reducing inflammation and extra-cellular matrix degradation in the arterial wall, factors shown before to affect AAA initiation and development. ${ }^{3}$

In our study, deficiency of CD40L reduced accumulation of leukocytes and macrophages into the arterial wall during Angll-infusion. This was accompanied by a decreased mRNA expression of chemokines and cytokines involved in monocyte and leukocyte infiltration and activation, like MCP-1 and -5, MIP-1 $\alpha$ and MIP-2, as well as TNF $\alpha$, IL-1 $\beta$ and IL-6. These data are comparable to other disease models, like in atherosclerosis and allergic encephalitis, were CD40L also dramatically affected the level of inflammation. ${ }^{14}$

Some of the inflammatory mediators that are regulated by CD40L have been shown to affect AAA formation. For example, deficiency of CCR-2, the receptor for MCP-1, reduces the incidence of AAAs by $80 \% .{ }^{19}$ Treatment with simvastatin, a HMG-coA reductase with also anti-inflammatory properties, or pyrrolidine dithiocarbamate, an inhibitor of NFKB, both resulted in a $33 \%$ reduction in the incidence of AAA. ${ }^{20,21}$ Moreover, 5 -lipoxygenase, a key enzyme in leukotriene biosynthesis, aggravates AAA induced by an atherogenic $\operatorname{diet}^{22}$, and deficiency of $B L T-1$, the most important leukotriene $B 4$ receptor prevents $A A A^{23}$, while no effect was reported in the Angll-induced AAA model. ${ }^{24}$

In atherosclerosis it is clear that the driving inflammatory force is predominantly mediated by the Th1 cytokines IFNy, IL-2, II-12, and IL-18, while the Th2 cytokines like IL-5 and IL-10 are considered to have a protective effect, while IL-4 does not play a role. ${ }^{25,26}$ In AAA, it is still under debate whether the disease is Th1- or Th2-driven. Most of the T-lymphocytes present in the AAA are of the Th2 phenotype ${ }^{12}$, which can either mean that they compensate for the profound Th1 response, or that aneurysms are a Th2-driven disease. In an aortic interposition allograft model, Shimizu et al. showed that when mismatched wild type aortic allografts were transplanted into IFN $\gamma$ deficient mice, which harbor a Th2-skewed cytokine environment, AAA formation was induced. ${ }^{27}$ In the same study, the authors showed that AAA formation could be prevented by blocking IL-4. ${ }^{27}$ These results indicate that a Th2skewed cytokine environment promotes AAA formation. On the other side, studies have shown that disruption of IL- 4 and IL-10 results in an increase in AAAs, whereas CD4\% mice had a decrease in AAA formation, which could be rescued by IFN $\gamma .{ }^{28}$ These data suggest the opposite: Th1 promotes AAA formation while Th2 suppresses AAA formation. 
In the present study, $\mathrm{CD} 40 \mathrm{~L}$ deficiency was shown to particularly dampen the Th1 response in AAAs. This shows that CD40L promotes AAAs by aggravating a Th1 response. Interestingly, in $\mathrm{CD} 4 \mathrm{~L}^{-1} / \mathrm{ApoE}^{-/}$mice that did not develop AAAs upon angiotensin II treatment, we observed a reduced Th1-response, whereas the Th2-response was elevated. However, once an AAA develops, CD40L-deficiency could not maintain the elevated Th2 response.

In atherosclerosis, regulatory T-lymphocytes (Treg), characterized by the expression of $\mathrm{CD} 4 / \mathrm{CD} 25$ and FoxP3, have an anti-atherogenic propensity, particularly by dampening the Th1 response and by inducing Th2 cytokines. ${ }^{29}$ In AAA, the role of Tregs is not known. One would suggest a protective role for Treg cells in AAA formation as well. However, here we show that deficiency of $\mathrm{CD} 40 \mathrm{~L}$ decreases FoxP3 expression, despite the protection against AAA. However, this does not exclude a protective role for Treg cells in AAA development. Interestingly, in aortas of $\mathrm{CD} \mathrm{L}^{-1} / \mathrm{ApoE}^{-/}$mice that did not develop AAAs upon angiotensin II treatment, we observed an increase in arterial FoxP3 expression, indicating that Tregs protect against AAA formation.

Besides inflammation, CD40L is known to be a potent inducer of MMPs. ${ }^{30}$ Also in the present study, CD40L deficiency decreased MMP-2 and -9 activity, as well as MMP-9, -13 and -14 mRNA expression in AAA tissue. That modulation of MMP-activity, and other proteolytic mediators is an important mechanism in reducing the incidence of AAA formation has been shown in many studies. MMP-1, $-2,-3,-7,-8,-9,-12,-13$ and -14 are reported to be present in human and mouse AAAs..$^{1-2,6}$ Mice deficient in MMP-2, MMP-3 and/or $-9,9$, ${ }^{31-32}$ as well as mice treated with the broad spectrum MMP-inhibitor doxycycline, ${ }^{10} \mathrm{dem}$ onstrated resistance against AAA development. Moreover, ApoE-/ mice lacking the urokinase plasminogen activator reduced the frequency of micro-AAAs, that was attributed to a decreased MMP-12 activity. ${ }^{33}$ Interestingly, mice in which the MMP-1 gene was overexpressed showed no effect on AAA. ${ }^{34}$ The natural inhibitors of MMPs are also involved in the pathogenesis of AAA. Inactivation of TIMP-1 ${ }^{35}$ resulted in an enhanced AAA formation, while inactivation of TIMP-2 attenuated AAA development. ${ }^{36}$ Surprisingly, deficiency of CD40L only affected TIMP-3 levels.

A different group of proteases involved in degradation of collagen and elastin in the arterial wall is the family of cysteine proteases. Cathepsin $\mathrm{K}, \mathrm{L}$ and $\mathrm{S}$ are all expressed in AAA. ${ }^{6}$, ${ }^{37}$ Cathepsin $S$ deficiency prevented aortic dilation and resulted in better preserved elastic lamina, ${ }^{11}$ whereas deficiency of cystatin $\mathrm{C}$, a cysteine protease inhibitor, augmented loss of elastic laminae, resulting in profound ectasia of atherosclerotic aortas. ${ }^{38}$ Also dipeptidyl peptidase I (DPPI), a granule associated cysteine protease, is crucial in AAA development, by recruiting neutrophils to the aneurysm wall. ${ }^{39}$ Recently, promising results of inhibiting extracellular matrix degradation for the treatment of AAA were reported. Periadventitial administration of pentagalloyl glucose, an elastin binding phenol, was able to stablize elastin and to prevent AAA development in a rat model. ${ }^{40}$
When compared to other studies, deficiency of CD40L is one of the most powerful strategies to prevent aneurysm formation, rendering CD40L as a key component in AAA etiology, having very potent effects on both (Th-1 driven) inflammation and extracellular matrix degradation. Therefore, inhibition of $\mathrm{CD} 40 \mathrm{~L}$ can be considered as a novel strategy for the prevention of AAA formation, especially since it reduces and stabilizes atherosclerotic plaques as well. However, since $\mathrm{CD} 40 \mathrm{~L}$ is also an important co-stimulatory molecule, and its long-term inhibition would induce immune-suppression, novel, vascular associated CD40L-specific targets are needed to successfully apply inhibition of the CD40L-system as therapy for prevention of AAA. 


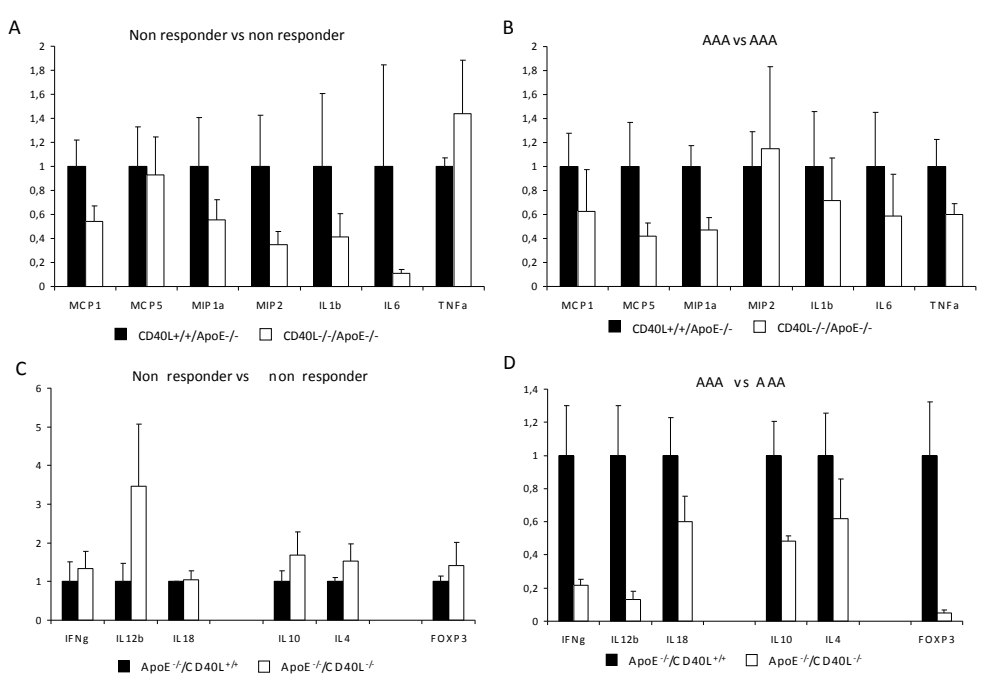

Supplementary figure 4.1

Relative chemokine and cytokine gene expression levels of non responsive ApoE $\% / C D 40 L^{++/}$mice compared to non responsive APOE $\% / C D 4 O L$ mice show a decrease in absence of $\mathrm{CD} 40 \mathrm{~L}$ (a). Relative chemokine and cytokine gene expression levels of the aneurysmal $A p o E^{-} / C_{C D} 4 L^{+*+}$ mice compared to the aneurysmal ApoE $\% / C D 4 O L^{-}$mice show a decrease in absence of $C D 4 O L$ (b). Relative Th1, Th2 and Treg gene expression levels of the non responsive Apo $\% / C D 4 O \mathrm{~L}^{+*}$ mice compared to the non responsive $\mathrm{ApOF} \% / \mathrm{CD} 40 \mathrm{~L} \%$ mice (c). Relative Th1, Th2 and Treg gene

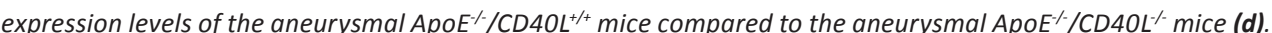

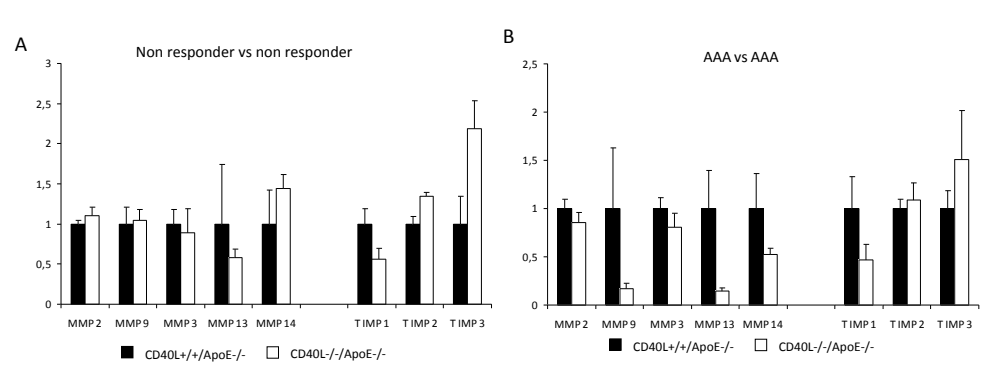

Supplementary figure 4.2

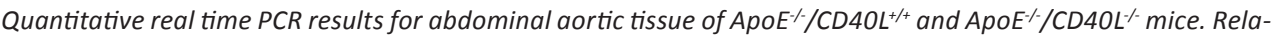
tive MMP and TIMP expression levels of the non responsive ApOF $\% / C D 40 \mathrm{O}^{+/+}$mice compared to the non responsive ApoE $\% / C D 4 O L^{-}$mice (a). Relative MMP and TIMP expression levels of the aneurysmal ApoE $\% / C D 40 L^{+*+}$ mice compared to the aneurysmal ApoE $\% / C D 40 L^{-1}$ mice (b). 


\section{References}

1. Thompson RW, Geraghty PJ, Lee JK. Abdominal aortic aneurysms: basic mechanisms and clinical implications. Curr Probl Surg. 2002;39: 110-230.

2. Wassef M, Baxter BT, Chisholm RL, Dalman RL, Fillinger MF, Heinecke J, Humphrey JD, Kuivaniemi H, Parks WC, Pearce WH, Platsoucas CD, Sukhova GK, Thompson RW, Tilson MD, Zarins CK. Pathogenesis of abdominal aortic aneurysms: a multidisciplinary research program supported by the National Heart, Lung, and Blood Institute. J Vasc Surg. 2001;34: 730-738.

3. Shimizu K, Mitchell RN, Libby P. Inflammation and cellular immune responses in abdominal aortic aneurysms. Arterioscler Thromb Vasc Biol. 2006;26: 987-994.

4. Daugherty A, Manning MW, Cassis LA. Angiotensin II promotes atherosclerotic lesions and aneurysms in apolipoprotein E-deficient mice. J.Clin.Invest. 2000;105: 1605-1612.

5. Saraff K, Babamusta F, Cassis LA, Daugherty A. Aortic dissection precedes formation of aneurysms and atherosclerosis in angiotensin II-infused, apolipoprotein E-deficient mice. Arterioscler Thromb Vasc Biol. 2003;23: 1621-1626.

6. Abdul-Hussien H, Soekhoe RG, Weber E, von der Thusen JH, Kleemann R, Mulder A, van Bockel JH, Hanemaaijer $\mathrm{R}$, Lindeman JH. Collagen degradation in the abdominal aneurysm: a conspiracy of matrix metalloproteinase and cysteine collagenases. Am J Pathol. 2007;170: 809-817.

7. Thompson RW, Holmes DR, Mertens RA, Liao S, Botney MD, Mecham RP, Welgus HG, Parks WC. Production and localization of 92 -kilodalton gelatinase in abdominal aortic aneurysms. An elastolytic metalloproteinase expressed by aneurysm-infiltrating macrophages. J Clin Invest. 1995;96: 318-326.

8. Eagleton MJ, Ballard N, Lynch E, Srivastava SD, Upchurch GR, Jr., Stanley JC. Early increased MT1-MMP expression and late MMP-2 and MMP-9 activity during Angiotensin II induced aneurysm formation. J Surg Res. 2006;135: 345-351.

9. Pyo R, Lee JK, Shipley JM, Curci JA, Mao D, Ziporin SJ, Ennis TL, Shapiro SD, Senior RM, Thompson RW. Targeted gene disruption of matrix metalloproteinase-9 (gelatinase B) suppresses development of experimental abdominal aortic aneurysms. J Clin Invest. 2000;105: 1641-1649.

10. Manning MW, Cassis LA, Daugherty A. Differential effects of doxycycline, a broad-spectrum matrix metalloproteinase inhibitor, on angiotensin II-induced atherosclerosis and abdominal aortic aneurysms. Arterioscler Thromb Vasc Biol. 2003;23: 483-488.

11. Sukhova GK, Zhang Y, Pan JH, Wada Y, Yamamoto T, Naito M, Kodama T, Tsimikas S, Witztum JL, Lu ML, Sakara Y, Chin MT, Libby P, Shi GP. Deficiency of cathepsin S reduces atherosclerosis in LDL receptor- deficient mice. J.Clin.Invest. 2003;111: 897-906.

12. Schonbeck U, Sukhova GK, Gerdes N, Libby P. $T(H) 2$ predominant immune responses prevail in human abdominal aortic aneurysm. Am J Pathol. 2002;161: 499-506.

13. Juvonen J, Surcel HM, Satta J, Teppo AM, Bloigu A, Syrjala H, Airaksinen J, Leinonen M, Saikku P, Juvonen T. Elevated circulating levels of inflammatory cytokines in patients with abdominal aortic aneurysm. Arterioscler Thromb Vasc Biol. 1997;17: 2843-2847.

14. Lutgens E, Lievens D, Beckers L, Donners M, Daemen M. CD40 and its ligand in atherosclerosis. Trends Cardiovasc Med. 2007;17: 118-123.

15. Lutgens E, Gorelik L, Daemen MJ, de Muinck ED, Grewal IS, Koteliansky VE, Flavell RA. Requirement for CD154 in the progression of atherosclerosis. Nat.Med. 1999;5: 1313-1316.

16. Lutgens E, Cleutjens KB, Heeneman S, Koteliansky VE, Burkly LC, Daemen MJ. Both early and delayed anti-CD40L antibody treatment induces a stable plaque phenotype. Proc.Natl.Acad.Sci.U.S.A. 2000;97: 7464-7469.
17. Mach F, Schonbeck U, Sukhova GK, Atkinson E, Libby P. Reduction of atherosclerosis in mice by inhibition of CD40 signalling. Nature. 1998;394: 200-203.

18. Southgate KM, Davies M, Booth RF, Newby AC. Involvement of extracellular-matrix-degrading metalloproteinases in rabbit aortic smooth-muscle cell proliferation. Biochem J. 1992;288 (Pt 1): 93-99.

19. Ishibashi M, Egashira K, Zhao Q, Hiasa K, Ohtani K, Ihara Y, Charo IF, Kura S, Tsuzuki T, Takeshita A, Sunagawa K. Bone marrow-derived monocyte chemoattractant protein-1 receptor CCR2 is critical in angiotensin II-induced acceleration of atherosclerosis and aneurysm formation in hypercholesterolemic mice. Arterioscler Thromb Vasc Biol. 2004;24: e174-178.

20. Steinmetz EF, Buckley C, Shames ML, Ennis TL, Vanvickle-Chavez SJ, Mao D, Goeddel LA, Hawkins CI, Thompson RW. Treatment with simvastatin suppresses the development of experimental abdominal aortic aneurysms in normal and hypercholesterolemic mice. Ann Surg. 2005;241: 92-101.

21. Parodi FE, Mao D, Ennis TL, Bartoli MA, Thompson RW. Suppression of experimental abdominal aortic aneurysms in mice by treatment with pyrrolidine dithiocarbamate, an antioxidant inhibitor of nuclear factor-kappaB. J Vasc Surg. 2005;41: 479-489.

22. Zhao L, Moos MP, Grabner R, Pedrono F, Fan J, Kaiser B, John N, Schmidt S, Spanbroek R, Lotzer K, Huang L, Cui J, Rader DJ, Evans JF, Habenicht AJ, Funk CD. The 5-lipoxygenase pathway promotes pathogenesis of hyperlipidemia-dependent aortic aneurysm. Nat Med. 2004;10: 966-973.

23. Ahluwalia N, Lin AY, Tager AM, Pruitt IE, Anderson TJ, Kristo F, Shen D, Cruz AR, Aikawa M, Luster AD, Gerszten RE. Inhibited aortic aneurysm formation in BLT1-deficient mice. J Immunol. 2007;179: 691-697.

24. Cao RY, Adams MA, Habenicht AJ, Funk CD. Angiotensin II-induced abdominal aortic aneurysm occurs independently of the 5-lipoxygenase pathway in apolipoprotein E-deficient mice. Prostaglandins Other Lipid Mediat. 2007;84: 34-42.

25. Tedgui A, Mallat Z. Cytokines in atherosclerosis: pathogenic and regulatory pathways. Physiol Rev. 2006;86: 515-581.

26. King VL, Cassis LA, Daugherty A. Interleukin-4 does not influence development of hypercholesterolemia or angiotensin II-induced atherosclerotic lesions in mice. Am J Pathol. 2007;171: 2040-2047.

27. Shimizu K, Shichiri M, Libby P, Lee RT, Mitchell RN. Th2-predominant inflammation and blockade of IFNgamma signaling induce aneurysms in allografted aortas. J Clin Invest. 2004;114: 300-308.

28. Curci JA, Thompson RW. Adaptive cellular immunity in aortic aneurysms: cause, consequence, or context? J Clin Invest. 2004;114: 168-171.

29. Ait-Oufella H, Salomon BL, Potteaux S, Robertson AK, Gourdy P, Zoll J, Merval R, Esposito B, Cohen JL, Fisson S, Flavell RA, Hansson GK, Klatzmann D, Tedgui A, Mallat Z. Natural regulatory T cells control the development of atherosclerosis in mice. Nat Med. 2006;12: 178-180.

30. Schonbeck U, Mach F, Sukhova GK, Murphy C, Bonnefoy JY, Fabunmi RP, Libby P. Regulation of matrix metalloproteinase expression in human vascular smooth muscle cells by $\mathrm{T}$ lymphocytes: a role for CD 40 signaling in plaque rupture? Circ.Res. 1997;81: 448-454.

31. Longo GM, Xiong W, Greiner TC, Zhao Y, Fiotti N, Baxter BT. Matrix metalloproteinases 2 and 9 work in concert to produce aortic aneurysms. J Clin Invest. 2002;110: 625-632.

32. Silence J, Lupu F, Collen D, Lijnen HR. Persistence of atherosclerotic plaque but reduced aneurysm formation in mice with stromelysin-1 (MMP-3) gene inactivation. Arterioscler.Thromb.Vasc.Biol. 2001;21: 14401445.

33. Carmeliet P, Stassen JM, Schoonjans L, Ream B, van den Oord JJ, De Mol M, Mulligan RC, Collen D. Plasminogen activator inhibitor-1 gene-deficient mice. II. Effects on hemostasis, thrombosis, and thrombolysis. J.Clin.Invest. 1993;92: 2756-2760 
34. Lemaitre V, O'Byrne TK, Borczuk AC, Okada Y, Tall AR, D'Armiento J. ApoE knockout mice expressing human matrix metalloproteinase-1 in macrophages have less advanced atherosclerosis. J.Clin.Invest. 2001;107: 1227-1234.

35. Silence J, Collen D, Lijnen HR. Reduced atherosclerotic plaque but enhanced aneurysm formation in mice with inactivation of the tissue inhibitor of metalloproteinase-1 (TIMP- 1) gene. Circ.Res. 2002;90: 897903.

36. Xiong W, Knispel R, Mactaggart J, Baxter BT. Effects of tissue inhibitor of metalloproteinase 2 deficiency on aneurysm formation. J Vasc Surg. 2006;44: 1061-1066.

37. Sukhova GK, Shi GP, Simon DI, Chapman HA, Libby P. Expression of the elastolytic cathepsins S and K in human atheroma and regulation of their production in smooth muscle cells. J.Clin. Invest. 1998;102: 576583.

38. Sukhova GK, Wang B, Libby P, Pan JH, Zhang Y, Grubb A, Fang K, Chapman HA, Shi GP. Cystatin C deficiency increases elastic lamina degradation and aortic dilatation in apolipoprotein E-null mice. Circ Res. 2005:96: 368-375.

39. Pagano MB, Bartoli MA, Ennis TL, Mao D, Simmons PM, Thompson RW, Pham CT. Critical role of dipeptidyl peptidase I in neutrophil recruitment during the development of experimental abdominal aortic aneurysms. Proc Natl Acad Sci U S A. 2007;104: 2855-2860.

40. Isenburg JC, Simionescu DT, Starcher BC, Vyavahare NR. Elastin stabilization for treatment of abdominal aortic aneurysms. Circulation. 2007;115: 1729-1737. 
DEFICIENCY OF TGF- $\beta$ SIGNALING IN CD11C POSITIVE CELLS ACCELERATES ATHEROSCLEROSIS BY DISRUPTING T-CELL HOMEOSTASIS 


\section{Background}

TGF- $\beta$ is an anti-inflammatory and pro-fibrotic cytokine that plays a bridging role between the innate and adaptive immune system. However, the exact liaison between TGF- $\beta$, the innate and the adaptive immune system in atherosclerosis is still unclear.

\section{Methods and results}

Here we investigate the effect of deficiency of TGF $\beta$-signaling in cells of the innate immune system (i.e. CD11 $\mathrm{c}^{+} \mathrm{DCs}$, NK cells and macrophages) in atherosclerosis, by using transgenic mice with a targeted functional inactivation of TGF- $\beta$ Receptor II (TGF $\beta$ RII) signaling in CD11c cells (ApoE ${ }^{-1} \mathrm{CD} 11 \mathrm{cDNR}$ ). ApoE ${ }^{-/} \mathrm{CD} 11 \mathrm{cDNR}$ mice were sacrificed at 20 wks of age and plaques in the aortic root were analyzed. ApoE $-\mathrm{CD}^{-} 11 \mathrm{CDNR}$ mice exhibited a 2 -fold increase in plaque area. Plaques of ApoE-/-CD11CDNR mice showed a substantial increase in the amount of $\mathrm{CD} 45+$ leukocytes and $\mathrm{CD}^{+}, \mathrm{CD}^{+}$and $\mathrm{CD} 8^{+} \mathrm{T}$-cells, while macrophage content and number of Tregs were not affected. Moreover, plaques of ApoE ${ }^{-1-C D 11 c D N R}$ mice showed a significant reduction in $\alpha$-smooth muscle cell actin (ASMA) and collagen content. FACS analysis of lymphoid organs of ApoE- ${ }^{-C D} 11 \mathrm{CDNR}$ mice revealed an increase in both $\mathrm{CD}^{+}$and $\mathrm{CD} 8{ }^{+} \mathrm{CD} 44^{\text {high }} \mathrm{CD} 2 \mathrm{~L}^{\text {low }}$ effector memory $\mathrm{T}$-cells, whereas in contrast to the plaques the number of $\mathrm{CD} 4^{+} \mathrm{CD} 25^{+} \mathrm{FoxP} 3^{+}$regulatory T-cells had increased. In the supernatant of $\mathrm{CD} 3 / \mathrm{CD} 28$ stimulated splenocytes from ApoE- ${ }^{-C D} 11 \mathrm{cDNR}$ mice, elevated levels of Th1 (IFN- $\gamma$ ), Th2 (IL-4, IL-10) and Th17 (IL-17) cytokines were detected.

\section{Conclusion}

Deficient TGF- $\beta$ signaling in CD11 $\mathrm{c}^{+}$cells results in a disturbed T-cell homeostasis, thereby accelerating atherosclerosis and inducing a pro-inflammatory plaque phenotype.

\section{Introduction}

Atherosclerosis is a chronic inflammatory disease of the arterial wall..$^{1-3}$ Immune cells from both the innate and the adaptive immune system orchestrate the formation and progression of atherosclerotic plaques by controlling their structure, composition and expansion. ${ }^{3}$ This complex interplay between different cells and cell types of the immune system is coordinated by a broad array of pro- and anti-inflammatory chemokines and cytokines. The balance between pro- and anti-inflammatory modulators is decisive in the degree of atherosclerosis progression and the plaque phenotype that will develop. ${ }^{4-7}$

One of the central regulators of the immune response is transforming growth factor beta (TGF- $\beta$ ). ${ }^{8,9}$ Three highly conserved isoforms of TGF- $\beta$ have been described: TGF- $\beta 1$, TGF- $\beta 2$ and TGF- $\beta 3$. TGF- $\beta 1$ is present in healthy blood vessels. Interestingly, higher levels of TGF$\beta 1$ are present in human asymptomatic lesions compared to lesions from symptomatic patients. ${ }^{10}$ The closely related TGF- $\beta 2$ and TGF- $\beta 3$ isoforms are either absent or present at low levels. ${ }^{11}$ The classical signaling receptors for TGF- $\beta$ are the TGF- $\beta$ receptor I (TGF $\beta$ RI), also known as activin-like kinase (ALK), and the constitutively active type II receptor (TGF $\beta R I I)$. Access of TGF- $\beta$ to the type I en type II receptors is regulated by soluble ligand binding proteins and by the accessory type III receptor, also known as betaglycan. ${ }^{12,13}$ TGF- $\beta$ signals via TGF- $\beta$ type II receptor and ALK5 in most cells. TGF- $\beta$ binding to type II receptor leads to heteromerization with and phosphorylation of ALK5. Activated ALK5 phosphorylates Smad2 and Smad3, which translocate into the nucleus in a complex with Smad4. ${ }^{13-17}$

A wide range of cell types important in atherosclerosis expresses TGF- $\beta .{ }^{11,18,19}$ TGF- $\beta$ exerts crucial anti-inflammatory functions by inhibiting the proliferation and differentiation of T-cells and the activation of macrophages. ${ }^{11,19}$ In endothelial cells, TGF- $\beta$ inhibits the expression of adhesion molecules and chemokines required for the recruitment of leukocytes. ${ }^{20,21}$ Moreover, TGF- $\beta$ is also known to stimulate collagen production in smooth muscle cells (SMC). ${ }^{22,23}$

In 2002 we showed that treatment of $A$ poE $^{-1}$ mice with a soluble TGF- $\beta$-receptor II protein (TGF $\beta-$ RII:FC) that prevents TGF- $\beta$ signaling, accelerated atherosclerosis. Plaques exhibited an unstable phenotype that contained low amounts of fibrosis, an increased amount of inflammatory cells, and even intraplaque hemorrhages. ${ }^{24}$ Mallat et al, who injected neutralizing antibodies against TGF- $\beta 1$ into ApoE-/- mice, obtained similar results. ${ }^{25}$ Recently, Frutkin et al. showed that mice with cardiac over-expression of TGF- $\beta$ reduced atherosclerosis formation in the aortic roots and prevented aortic dillatation. ${ }^{26}$ These effects could be attributed to TGF- $\beta$ signaling in T-cells. Mice, with deficient TGF- $\beta$ signaling in CD4 ${ }^{+}$ T-cells (CD4-dnTGFBRII), also showed accelerated plaque progression, and a shift towards an unstable atherosclerotic plaque phenotype. ${ }^{27}$ This was accompanied by an increased 
differentiation of T-cells towards both Th1 and Th2 phenotype. Increased levels of IFN- $\gamma$, IL-10 and IL-4 were found in cultured splenocytes. ${ }^{28}$ Gojova et al. who transplanted bone marrow from CD2-dnTGF $\beta R$ II mice into $L D L r^{1 /}$ recipients obtained similar results. ${ }^{29}$

Although the effects of TGF- $\beta$ signaling of the adaptive immune system in atherosclerosis have been described, limited data are available on the effect of TGF- $\beta$ signaling in the innate immune system. In atherosclerosis, the principal effector cells of the innate immunity are dendritic cells (DC), monocytes/macrophages, neutrophils and NK cells, which all express CD11c.

In the present study, we investigated the effect of TGF- $\beta$ signaling in CD11 $c^{+}$cells in atherosclerosis using $\mathrm{ApoE}^{-/}$mice that contained a dysfunctional TGF- $\beta$ Receptor II (ApoE ${ }^{-1-}$ CD11cDNR). We found that blockade of TGF- $\beta$ signaling in $C D 11 c^{+}$cells accelerated atherogenesis, enhanced the influx of both $\mathrm{CD}^{+}$and $\mathrm{CD} 8^{+} \mathrm{T}$-cells into the plaques and decreased fibrosis. Systemically, an increased differentiation of T-cells towards effector memory Tcells (CD44 ${ }^{\text {high }}$ CD62L $^{\text {low }}$ ) was found together with increased levels of Th1, Th2 and Th17 cytokines. Our data illustrate the important role of TGF- $\beta$ as a regulator between innate and adaptive immunity in atherosclerosis.

\section{Methods}

\section{ApoE-1-CD11c-dnTGFBRII transgenic mice}

CD11c-dnTGFBRII (CD11CDNR) mice were generated as described previously and were backcrossed to $\mathrm{ApoE}^{-1-}$ mice (both genotypes were on a C57Bl6 background). ${ }^{30}$ The transgene was composed of the human TGF- $\beta$ type II receptor sequence between nucleotides -7 and +573 that encodes for the extracellular and transmembrane regions, but not the intracellular region of the TGF- $\beta$ type II receptor and cloned into the EcoRI site of rabbit $\beta$-globin gene exon 3 of the plasmid CD11c promoter vector pDOI-5. ${ }^{30}$ At the age of 20 weeks, mice were euthanized. Blood was obtained from the retro-orbital plexus and plasma cholesterol was measured using a colorimetric assay (CHOD-PAP, Roche). Spleen, liver and lymph nodes were harvested after in situ perfusion using PBS. Heart and aorta were isolated after subsequent perfusion using $1 \%$ parafomaldehyde. Hearts were frozen in Tissue-Tek (Shandon, Veldhoven, The Netherlands). Organs for autopsy were collected in $4 \%$ paraformaldehyde. All animal experiments were performed under approved Institutional Animal Care and Use Committee protocols (Yale University).

\section{Histology and morphometry}

Plaque area was analyzed using serial sections of $6 \mu \mathrm{m}$ with $42 \mu \mathrm{m}$ intervals, beginning from the onset of the aortic valves until the valves had disappeared. For histological analysis of atherosclerosis, sections were stained with haematoxylin and eosin (HE). The extent of atherosclerosis was assessed in aortic roots and classified as either initial or advanced lesions, based on histological criteria defined by Virmani et al. ${ }^{31}$ Initial lesions are defined as lesions that are mainly composed of foam cells and that can contain areas of extracellular lipid accumulation. Advanced lesions were defined as lesions with the presence of a necrotic core and a fibrous cap. In addition, the number of atherosclerotic plaques was counted. Plaque area was calculated by using a Leica DM3000 Light microscope (Leica Microsystems) coupled to a computerized morphometry system (Leica Qwin 3.5.1).

\section{Immunohistochemistry}

Corresponding sections were immunolabeled with CD45 rat monoclonal antibody (1:5000; Pharmingen) to detect all inflammatory cells, Moma-2 rat monoclonal antibody (1:50; Serotec) to detect macrophages and $\alpha$ SMA monoclonal mouse antibody (1:500; DAKO) as a marker for vascular smooth muscle cells and fibroblasts. CD3 rabbit monoclonal antibody (1:200;DAKO) to detect T lymfocytes, and CD4 and CD8 rat monoclonal antibodies (undiluted, gift from W. Buurman) to distinguish between respectively T-helper cells and cytotoxic T-cells. Sirius red staining was used to detect collagen content. Morphometric analyses were performed using a Leica Quantimet with Qwin3.5.1 software (Leica Microsystems)

Fluorescent immunohistochemistry was used to determine the presence of $\mathrm{CD} 11 \mathrm{c}^{+}$cells in the aortic lesions. CD11c, CD11b, DX5, CD4 and CD8 antibodies (all BD Biosciences) were conjugated to fluorescein isothiocyanate (FITC), phycoerythrin (PE) or peridinin chlorophyll protein (PerCP). Sections were analyzed with a Leica TCS SP5 multi-photon microscope (Leica, Germany).

\section{Flow Cytometry}

Spleen and lymph nodes were harvested from donor mice and single cell suspensions were prepared and stained with anti-TCR, -CD3, -CD4, -CD8, CD25, FoxP3, -CD44, -CD62L, -CD11C (BD Biosciences) or isotype control IgG (PharMingen). Antibodies were conjugated to fluorescein isothiocyanate (FITC), phycoerythrin (PE), allophycocyanin (APC) or peridinin chlorophyll protein (PerCP). Cells were analyzed using a FACS-Canto II (BD Biosciences) 


\section{Cytokine production}

Spleen and lymph nodes from ApoE-/- and ApoE ${ }^{-/}$CD11cDNR mice treated $(n=5)$ were isolated and gently mashed trough a $70 \mu \mathrm{m}$ nylon cell strainer. Red blood cells were lysed using $0.83 \% \mathrm{NH}_{4} \mathrm{Cl}$ in $0.01 \mathrm{M}$ tris/HCL, $\mathrm{pH}$ 7.2. Splenocytes and lymph node cells were cultured in triplicate at $3 \times 10^{5}$ cells/well in the presence of soluble $\alpha$ CD3/CD28 $(2 \mathrm{ug} / \mathrm{ml})$ in cRPMI. After 48 hours, supernatants were collected and TGF- $\beta$, IFN- $\gamma$, IL-10, IL-12p70, IL-4 and IL-17 were measured. Cytokine levels were determined in undiluted supernatant following the manufacturer's instructions. (All ELISAs were purchased at Ebioscience, Belgium).

\section{Statistical analysis}

Values are expressed as mean \pm SEM. Either a two-tailed Student's $T$ test or a non-parametric Mann-Withey U-test was used to analyze the data. Statistical analysis was performed using Prism software (GraphPad software, San Diago). Probability values of $\mathrm{P}<0.05$ were considered significant.

\section{Results}

\section{General}

At 20 weeks of age, no significant differences were observed between ApoE ${ }^{-/ C D 11 c D N R}$ mice and $A \mathrm{poE}^{-}$- mice with regard to body weight. Decreased levels of total plasma-cholesterol were detected in ApoE ${ }^{-/} \mathrm{CD} 11 \mathrm{cDNR}$ animals compared to ApoE-/- controls (ApoE1-CD11cDNR $5.97 \pm 1.25 \mathrm{mmol} / \mathrm{I}$ vs ApoE ${ }^{-1} 10.10 \pm 0.78 \mathrm{mmol} / \mathrm{I} p<0.05$ ) while serum triglycerides (TG) did not differ between both groups (ApoE ${ }^{-1}$ CD11CDNR $2.33 \pm 0.24 \mathrm{mmol} / \mathrm{l}$ vs

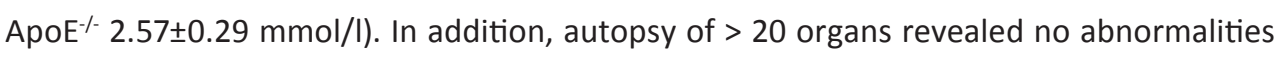
or pathologies.

\section{Localisation and subtype of CD11c cells in atherosclerotic plaques}

To detect whether $\mathrm{CD} 11 \mathrm{c}^{+}$cells are present in atherosclerotic plaques, to determine their localisation and which plaque cell types express CD11c, aortic roots of both ApoE ${ }^{-1}$ CD11CDNR and ApoE-- mice were double labelled CD11c and cell-type specific markers. Using 2-photon microscopy we were able to clearly distinguish between the different CD11c expressing cell types (fig. 5.1).
CD11c positive cells were commonly present in the shoulder region of the plaque and in the adventitia. Interestingly, only a small percentage of CD11 $\mathrm{c}^{+}$cells expressed CD11b or DX5. This indicates that the majority of $\mathrm{CD} 11 \mathrm{c}^{+}$cells in the plaque were either dendritic cells, which was confirmed by double staining with $\mathrm{CD} 11 \mathrm{c}, \mathrm{CD} 4$ and/or CD8, or macrophage foam cells which are also known to be CD11 $c^{+} C D 11 b^{-}{ }^{32}$ but not NK-cells (fig. 5.1).
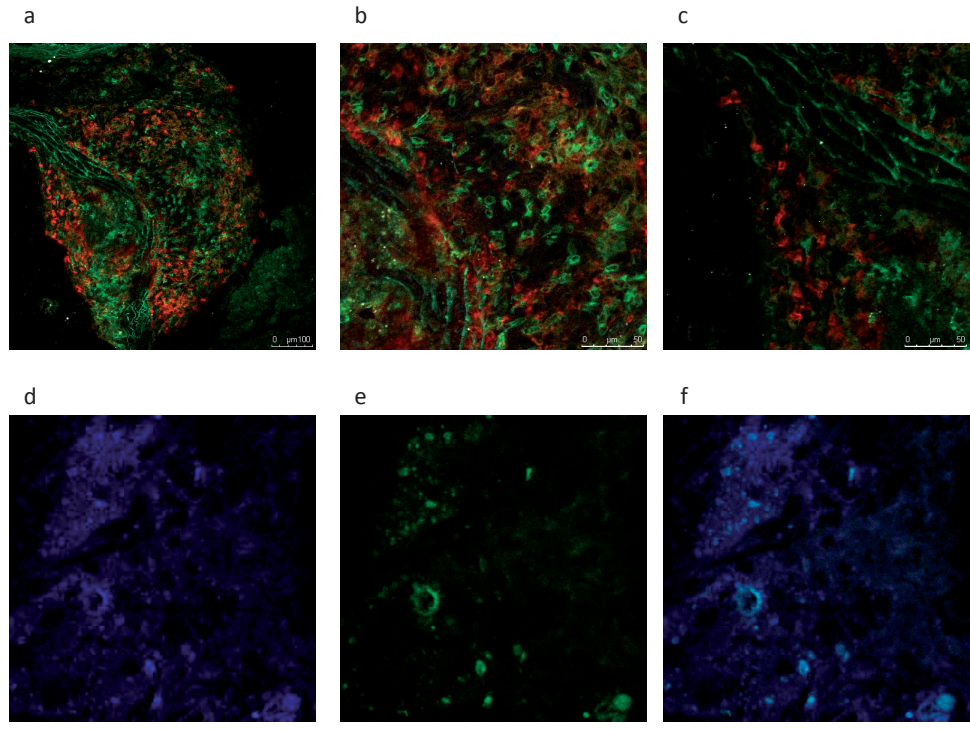

Figure 5.1

Immunohistochemistry was used to determine the presence of $C D 11 c^{+}$cells in the aortic lesions by multi-photon microscopy. (a) CD11c-FITC and CD11b-PE. Both cell types are clearly present in both lesion and adventitia. Only few double positive cells are present. (b) Detail of adventitia where massive infiltration of CD11c positive cells (FITC) is observed. (c) Detail of the atherosclerotic lesion. CD11c positive cells (FITC) together with CD11b positive cells (PE) are present in the shoulder region of the plaque. (d-f) CD11c $C^{+} C D 8^{+} D C$ present in the lesion. (d) CD11cPerCP, (e) CD8-FITC, (f) merge.

\section{Defective TGF-B signaling in CD11c cells accelerates atherosclerosis}

ApoE ${ }^{-/}$mice with disrupted TGF- $\beta$ signaling in $\mathrm{CD} 11 \mathrm{c}^{+}$cells (ApoE ${ }^{--C D 11 c D N R}$ ) exhibited a 2-fold increase in atherosclerotic plaque area in the aortic root (ApoE $/$ CD11cDNR 2.37E10 $\pm 5.33 \mathrm{E} 10^{4} \mu \mathrm{m}^{2}$ vs ApoE-/- $1.11 \mathrm{E} 10^{5} \pm 2.09 \mathrm{E} 10^{4} \mu \mathrm{m}^{2}, \mathrm{n}=8 /$ group, $\mathrm{p}<0.05$ ) (fig. 5.2). Moreover, $88 \%$ of the plaques of ApoE ${ }^{-1}$ CD11cDNR mice had an advanced morphology whereas plaques in the $\mathrm{ApoE}^{-/}$control group had a clear initial morphology (only $40 \%$ advanced lesions) 


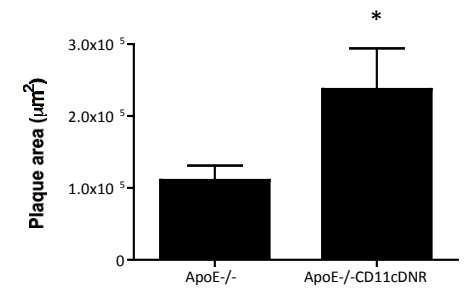

B

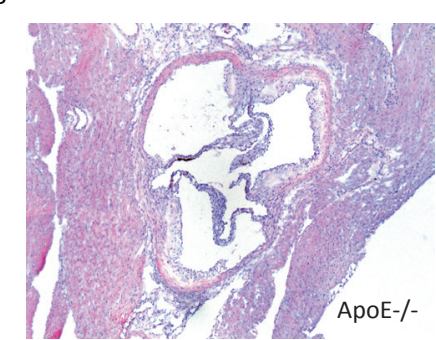

C

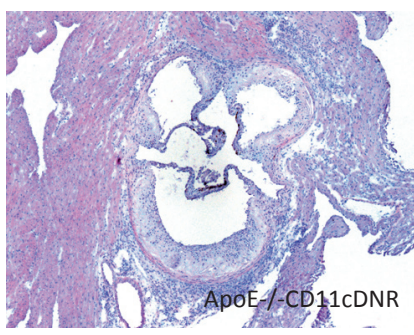

Figure 5.2

Defective TGF- $B$ signaling in CD11c positive cells accelerates atherosclerosis. (a) Plaque area $\left(\mu m^{2}\right)$ in the aortic root of APOE $\%$ and APOE $\% C D 11 C D N R$ animals $\left(n=8,{ }^{*} p<0.05\right)$, (b) and (c) representative HE staining of atherosclerotic lesions in the aortic root (magnification $5 x)$.

\section{Defective TGF-6 signaling in CD11c cells enhances plaque inflammation}

The percentage of $\mathrm{CD}^{2} 5^{+}$leukocytes was drastically increased in plaques of $\mathrm{ApoE} \mathrm{E}^{-1} \mathrm{CD} 11 \mathrm{c}$ DNR animals compared to controls (fig. $5.3 \boldsymbol{a}$-c). In order to have a more precise view on which leukocyte subsets were increased, we analyzed the lesions for the presence of different T-cell (CD3, CD4, CD8, FoxP3), and macrophage markers (Moma-2). Plaques of ApoE ${ }^{--C D 11 c D N R}$ mice contained significantly more $\mathrm{CD}^{+} \mathrm{T}$-cells then the controls (fig. $\mathbf{5 . 3}$ $\boldsymbol{d}$-f). Interestingly, increased levels of $\mathrm{CD} 4^{+} \mathrm{T}$-helper cells and $\mathrm{CD} 8^{+}$cytotoxic T-cells were found in plaques of ApoE ${ }^{-/} \mathrm{CD} 11 \mathrm{cDNR}$ (fig. 5.4 a-f). No differences in the number of FoxP3 ${ }^{+}$ cells could be observed, which was not surprising considering the low numders of FoxP3 ${ }^{+}$ cells present in plaques (ApoE $-\mathrm{CD}_{11} \mathrm{CDNR} 1.0 \times 10^{-2} \pm 0.5 \times 10^{-2} \%$ vs ApoE $\mathrm{E}^{-/} 0.8 \times 10^{-2} \pm 0.4 \times 10^{-2 \%}$ FoxP3 ${ }^{+}$cells). Macrophage (Moma-2) content did not differ between both groups (ApoE-

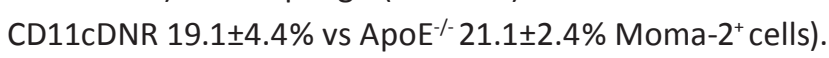
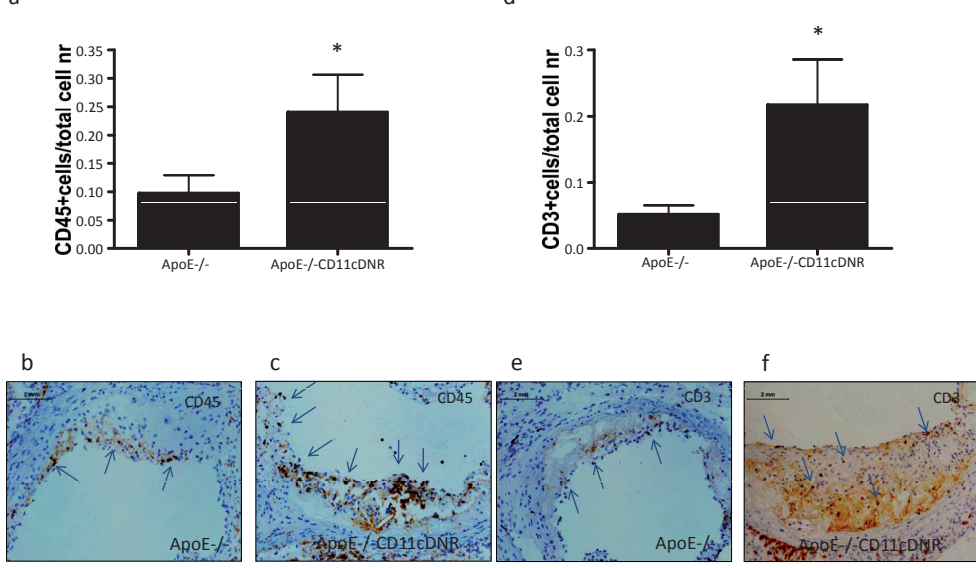

Figure 5.3

Disruption of TGF- 6 signaling in CD11c positive cells enhances plaque inflammation. (a) Number of CD45 positive cells per total cell number in the atherosclerotic plaque $\left(n=8,{ }^{*} p<0.05\right)$. (b) and (c) representative CD45 immunostaining of ADOE $\%$ and ApOE $\% C D 11 C D N R$ aortic root lesions (magnification 20x). (d) Number of CD3 positive cells per total cell number in the atherosclerotic plaque $\left(n=8,{ }^{*} p<0.05\right)$. (e) and (f) representative CD3 immunostaining of $A P O E-$ and $A P O E-C D 11 C D N R$ aortic root lesions (magnification 20x).
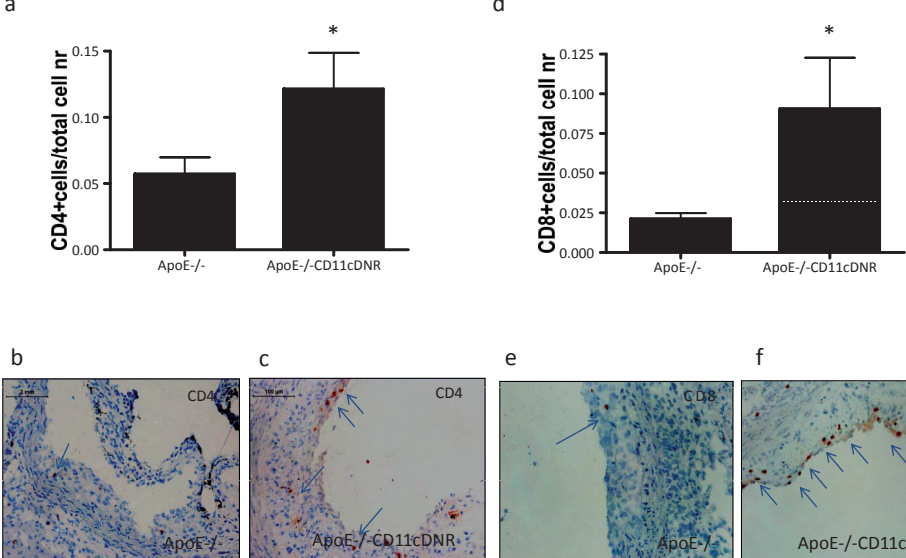

e $\quad f$

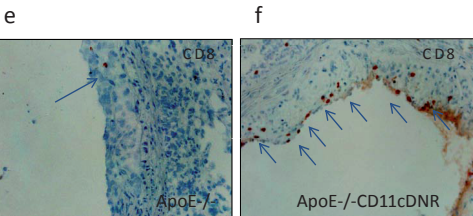

Figure 5.4

Defective TGF- 6 signaling in CD11c positive cells attracts both $C D 4^{+}$and $C D 8^{+} T$-cells into the lesions. (a) Number of $C D 4$ positive cells per total cell number in the atherosclerotic plaque of $\left(n=8,{ }^{*} p<0.05\right)$. (b) and (c) representative CD4 immunostaining of ApoE\% and ApoE $\% C D 11 c D N R$ aortic root lesions (magnification 20x). (d) Number of CD8 positive cells per total cell number in the atherosclerotic plaque $\left(n=8,{ }^{*} p<0.05\right)$. (e) and (f) representative CD8 immunostaining of APOE $\%$ and ApOE $\% C D 11 C D N R$ aortic root lesions (magnification 20x). 


\section{Defective TGF-6 signaling in CD11c cells inhibits plaque fibrosis}

Sirius red-stained sections revealed significantly lower amounts collagen in plaques of ApoE ${ }^{-C D} 11 \mathrm{cDNR}$ mice than in ApoE ${ }^{-/}$mice (fig. 5.5 a-c). The low plaque collagen content was accompanied by a decrease in $\alpha$-smooth muscle cell actin ${ }^{+}$(ASMA) content (ApoE-1CD11cDNR $4.02 \pm 0.71 \%$ vs ApoE ${ }^{-1}$ 9.46 $\pm 1.83 \%$ ASMA $^{+}$area, $p<0.05$ ) (fig. $\mathbf{5 . 5} d-f$ ). These results demonstrate that TGF- $\beta$ receptor deficiency in $\mathrm{CD} 11 \mathrm{c}^{+}$cells reduces plaque fibrosis, indicative of plaque destabilization.
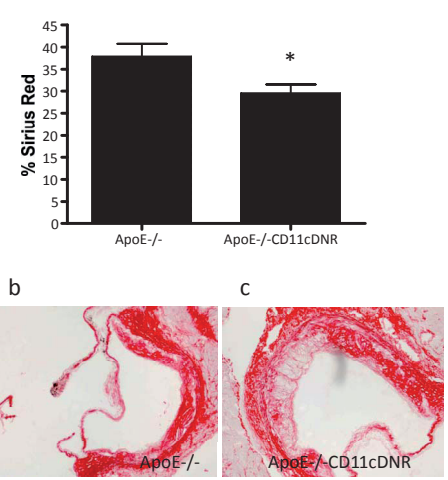
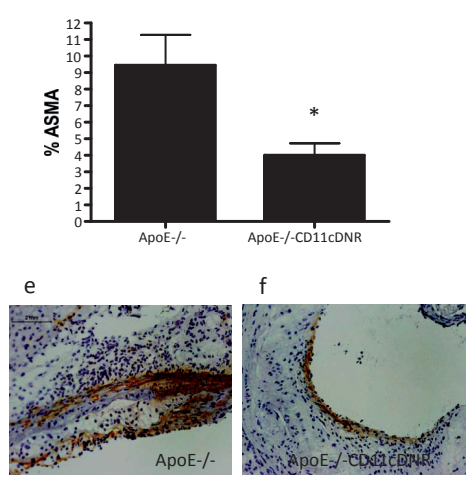

Figure 5.5

Defective TGF- 6 signaling in CD11c positive cells leads to an unstable plaque phenotype. (a) Percentage of Sirius red positive staining of $A p O E=$ and $A p O E=C D 11 c D N R$ aortic root lesions $\left(n=8,{ }^{*} p<0.05\right)$. (b) and (c) representative ApoE ${ }^{-C D}$ CD11cDNR aortic roots $\left(n=8,{ }^{*} p<0.05\right)$. (e) and (f) representative ASMA stainings (magnification 20x).

\section{Defective TGF-6 signaling in CD11c cells alters T-cell homeostasis}

To check whether the increased T-cell content in the ApoE ${ }^{-1}$ CD11cDNR lesions was due to an altered T-cell homeostasis, we used flow cytometry to determine the expression of homing receptors $\mathrm{CD} 44$ and $\mathrm{CD} 62 \mathrm{~L}$ on $\mathrm{CD} 4^{+}$and $\mathrm{CD} 8^{+} \mathrm{T}$-cells in the spleen to distinguish naive $\left(\mathrm{CD} 44^{\text {low }}{ }^{\mathrm{CD}} 62 \mathrm{~L}^{\mathrm{high}}\right)$ from effector-memory $\left(\mathrm{CD} 44^{\text {high }} \mathrm{CD} 62 \mathrm{~L}^{\text {low }}\right)$ T-cells (fig. 5.6). The $\mathrm{CD} 4^{+}$ T-cell population of the ApoE - CD11CDNR group had a significant decrease in the amount of naive T-cells and an increase in the amount of effector T-cells. Similar effects were seen in the CD8 population. CD62L surface expression is lost when cells become activated. This means that both $\mathrm{CD} 4^{+} \mathrm{T}$-helper cells and $\mathrm{CD} 8^{+}$cytotoxic $\mathrm{T}$-cells from $\mathrm{ApoE}-\mathrm{CD}^{-} \mathrm{CD} 1 \mathrm{cDNR}$ have characteristics of differentiated T-cells. These effector T-cells, in contrast to naive T-cells, are potent to enter inflamed tissues. In addition to T-cell differentiation, an enhanced CD4/ CD8 ratio was observed in CD11cDNR animals (fig. 5.7 a-c). Finally, a significant increase was observed in the amount of $\mathrm{CD} 4^{+} \mathrm{CD} 25^{+} \mathrm{FoxP}^{+}$regulatory T-cells (Tregs) in the spleen of ApoE ${ }^{-}$CD11cDNR animals (fig. $\mathbf{5 . 7}$ d). This increase can be considered as a compensatory effect of the increased effector T-cell phenotype.
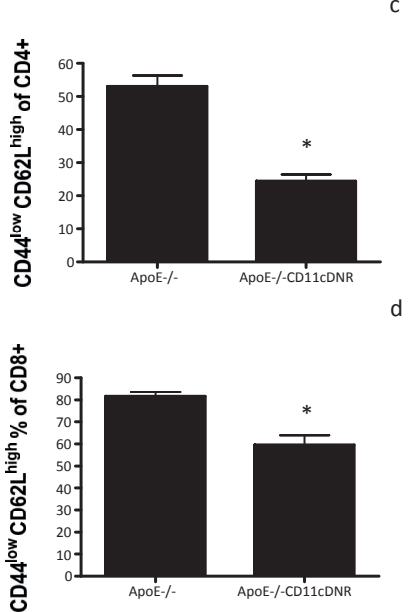
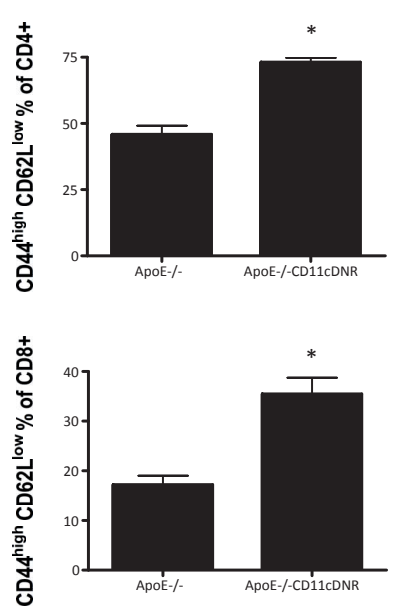

Figure 5.6

Loss of TGF- 6 signaling in CD11c positive cells leads to the generation of $C D 4^{+}$and $C D 8^{+} C D 44^{\text {high }} \mathrm{CD62L^{ \text {Low } }}$ effector memory $T$-cells, and decreases the fraction of naive T-cells. Depicted are the results of FACS experiments of splenic cells from ApoE $\%$ and ApoE $\% C D 11 C D N R$ mice $\left(n=5,{ }^{*} p<0.05\right)$. (a) Percentage of naive (CD44 ${ }^{\text {low }} C D 62 L^{\text {high }}$ ) CD4 positive T-cells. (b) Percentage of naive (CD44lowCD62Lhigh) CD8 positive T-cells. (c) Percentage of effector (CD44high CD62L Low) CD4 positive T-cells. (d) Percentage of effector (CD44high CD62Llow) CD8 positive T-cells. 

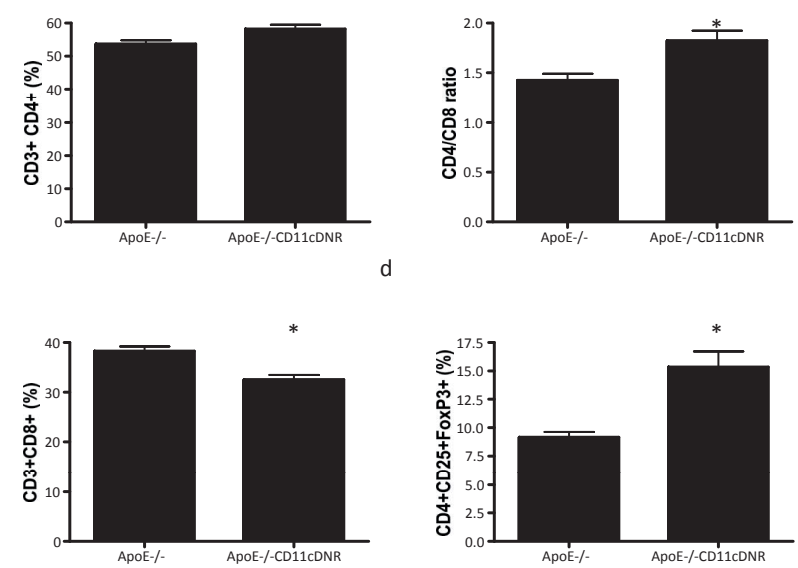

Figure 5.7

Inhibition of TGF- $B$ signaling in CD11c positive cells disturbs $T$-cell homeostasis in spleen. Depicted are the results of FACS experiments of splenic cells from ApoE $\%$ and ApoE $\% C D 11 C D N R$ mice $\left(n=5,{ }^{*} p<0.05\right)$. (a) Percentage of $C D 3^{+} C D 4^{+} T$-cells $\left(n=5,{ }^{*} p<0.05\right)$. (b) Percentage of $C D 3^{+} C D 8^{+} T$-cells $\left(n=5,{ }^{*} p<0.05\right)$. (c) CD4/CD8 ratio T-cells ( $n=5$, $\left.{ }^{*} p<0.05\right)$. (d) Percentage CD25 $5^{*}$ FoxP $3^{+}$of CD4 positive T-cells $\left(n=5,{ }^{*} p<0.05\right)$.

\section{TGF- 6 deficiency in CD11c cells is associated with increased levels of Th1, Th2 and Th17} cytokines

To determine whether the observed T-cell phenotype correlated with enhanced cytokine levels, T-cell cytokines were determined in the spleen after re-stimulation in vitro with anti-CD3/CD28. An 8-fold increase of the Th1 cytokine IFN- $p$ was detected in the ApoECD11cDNR group (fig. 5.8 a). Furthermore, significant increases were found in Th2 cytokines IL-4 and IL-10 (fig. 5.8 b-c). Finally, a 5-fold increase in IL-17 levels was detected (fig. $5.8 \mathrm{~d}$ ). In addition to cytokine levels, T-cell proliferation was measured but no significant differences could be observed in T-cell proliferation (data not shown).
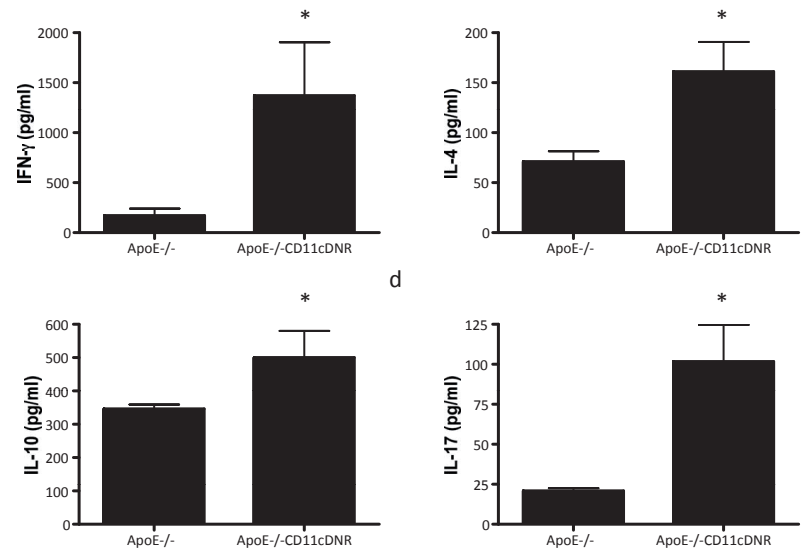

Figure 5.8

Disruption of TGF- $B$ signaling in CD11c positive cells increases cytokine expression. Concentrations $(\mathrm{pg} / \mathrm{ml})$ of $(a)$

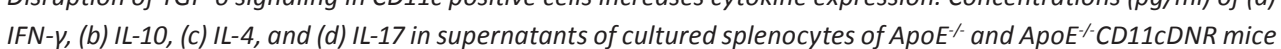
$\left(n=5,{ }^{*} p<0.05\right)$, stimulated with anti-CD3/CD28.

\section{TGF-B def inhibition of TGF-6 signaling does not affect DC maturation}

Since the net outcome of T-cell immune responses is influenced by the activation stage of antigen-presenting cells, ${ }^{33}$ we analyzed the maturation status of the CD11 $c^{+}$DCs. TGF- $\beta$ is known to inhibit critical co-stimulatory molecules on the surface of DCs ${ }^{34}$ and therefore regulates DC maturation. However, analysis of cell surface markers of dendritic cells showed that DCs from ApoE ${ }^{-/ C D} 11 \mathrm{cDNR}$ animals had a differentiation process similar to ApoE $\%$ DCs. No differences could be observed in MHCII, CD86 or CD40 expression (suppl. fig. 5.1). 


\section{Discussion}

In the present study, we highlight the importance of TGF- $\beta$ signaling in cells of the innate immune system in the progression of atherosclerosis. When TGF- $\beta$ signaling in CD11 $\mathrm{c}^{+}$cells (i.e. monocytes, dendritic cells, macrophages and NK-cells) s0,35 $^{30}$ was abrogated, atherosclerotic plaque size increased significantly. Moreover, plaques contained increased amounts of $\mathrm{CD}^{+}$and $\mathrm{CD} 8^{+} \mathrm{T}$-cells and a low percentage of collagen, reminiscent of a vulnerable, rupture prone plaque in humans.

Several studies have provided evidence for an important role for TGF- $\beta$ as an immune modulating cytokine in atherosclerosis (table 5.1). Systemic inhibition of TGF- $\beta$ signaling in ApoE $\%$ mice by using a recombinant soluble TGF- $\beta$ type II receptor ${ }^{24}$ or a blocking TGF- $\beta 1$ antibody resulted in an unstable atherosclerotic plaque phenotype, whereas cardiac overexpression of TGF- $\beta 1$ (resulting in increased plasma levels of TGF- $\beta$ ) limited plaque growth and induced plaque stabilization. ${ }^{25}$ These effects can partly be attributed to the effects of TGF- $\beta$ signaling on T-cells. Two studies specifically addressed the effect of TGF- $\beta$ signaling in T-cells. ${ }^{27,29}$ When TGF- $\beta$ signaling was abrogated in either in $\mathrm{CD}^{+}$or in $\mathrm{CD} 2^{+}$cells, plaques contained inflammatory cells in abundance together with a decreased plaque fibrosis. Systemically, deficiency of TGF- $\beta$ increased the amount of Th1 and Th2 cytokines, while over-expression of TGF- $\beta$ reduced their levels.

\begin{tabular}{|c|c|c|c|c|c|c|}
\hline $\begin{array}{l}\text { Group } \\
\text { (year) }\end{array}$ & Ref & Experiment & $\begin{array}{c}\text { Plaque } \\
\text { Area }\end{array}$ & $\begin{array}{c}\text { Plaque } \\
\text { Inflammation }\end{array}$ & $\begin{array}{l}\text { Plaque } \\
\text { Fibrosis }\end{array}$ & $\begin{array}{c}\text { Induced } \\
\text { Cytokines }\end{array}$ \\
\hline $\begin{array}{l}\text { Mallat } \\
2001\end{array}$ & 25 & $\begin{array}{l}\text { Abs against TGF- } \beta 1 \text {, } \\
\text { TGF- } \beta 2 \text { and TGF- } \beta 3 \\
\text { ApoE- }{ }^{-1} \text { acceptor mice }\end{array}$ & + & + & - & \\
\hline $\begin{array}{l}\text { Lutgens } \\
(2002)\end{array}$ & 24 & $\begin{array}{c}\text { rs TGF } \beta R I I \\
\text { ApoE-- acceptor mice }\end{array}$ & - & + & - & \\
\hline $\begin{array}{l}\text { Robertson } \\
\text { (2003) }\end{array}$ & 27 & $\begin{array}{l}\text { CD4-dnTGF } \beta R I I \text { tg+ } \\
\text { ApoE }- \text { - background }\end{array}$ & + & + & - & $\begin{array}{l}\text { 个 IFN- }- \text {, } \\
\text { 个 TNF- } \alpha, \\
\text { 个 IL4,5,10 }\end{array}$ \\
\hline $\begin{array}{l}\text { Gojova } \\
\text { (2003) }\end{array}$ & 29 & $\begin{array}{l}\text { CD2-dnTGF } \beta R I I \text { tg+ } \\
\text { BMT in LDLr'- mice }\end{array}$ & - & + & - & $\begin{array}{l}\text { 个 IFN-V, } \\
\text { 个 IL4, IL5 }\end{array}$ \\
\hline $\begin{array}{l}\text { Frutkin } \\
\text { (2009) }\end{array}$ & 26 & $\begin{array}{l}\text { Cardiac specific TGF- } \beta \\
\text { overexpression } \\
\text { ApoE-// background }\end{array}$ & - & - & + & $\begin{array}{l}\downarrow \text { IFN- } \gamma, \\
\downarrow \text { TNF- } \alpha, \\
\downarrow \text { MIP1- } \alpha\end{array}$ \\
\hline
\end{tabular}

Table 5.1

Overview of studies on the effects of TGF-B signaling in atherosclerosis, with focus on plaque area, plaque phenotype and the induced cytokines.

(Ref: Reference; BMT: Bone Marrow Transplantation; +: increase; - : decrease)
However, the immune modulating effects of TGF- $\beta$ are not restricted to T-cells. Although TGF- $\beta$ producing regulatory T-cells are well known to control T-cell activation and differentiation, and to play a crucial role in atherosclerosis ${ }^{36}$, the immune-regulatory capacity of other cell-types is also controlled via TGF- $\beta$. Interestingly, it has been reported that phagocytosis of apoptotic cells leads to TGF- $\beta$ secretion, which inhibits the production of inflammatory cytokines and chemokines (including IL-1 $\beta$ and TNF- $\alpha$ ) in macrophages. ${ }^{19}$ In addition, several studies have shown that TGF- $\beta$ inhibits in vitro activation and maturation of DCs. ${ }^{37,38}$ TGF- $\beta$ inhibits expression of critical co-stimulatory molecules on the DC surface (CD80 and CD86), thereby reducing its antigen-presenting capacity and DC mediated Tcell responses. ${ }^{33,37,38}$ However these studies focused on Langerhans cell development, and might not be attributable to the present study, where we did not observe an effect on DC maturation.

Here we proved the importance of TGF- $\beta$ signaling in CD11c positive cells in atherosclerosis using the CD11C-DNR mouse..$^{30}$ In this mouse model, specific expression of dnTGF $\beta R I I$ was found in CD11c expressing cells, including DC subsets and NK cells, whereas no expression was found in NKT cells, T-cells or B-cells. ${ }^{30}$ DCs and NK cells were found to be the most common cells expressing CD11c. ${ }^{30}$

In atherosclerotic plaques, an important local and systemic role for CD11c expressing cells has been reported recently. $32,39,40$ In conditions of hypercholesterolemia, monocytes expressed high levels of $C D 11 \mathrm{C}$, and show increased adherance to the arterial wall. ${ }^{32}$ In $\mathrm{CD} 11 \mathrm{C}^{-1-} \mathrm{ApoE}^{-/}$mice, monocyte recruitment was impaired and only small atherosclerotic plaques developed..$^{32}$ This was also observed in the atherosclerotic plaque, where CD11 $\mathrm{c}^{+}$ cells with foam cell morphology also were positive for Moma-2, a macrophage marker. Cho et al. studied gene expression profiles during foam cell formation and confirmed that foam cells develop a dendritic cell-like phenotype accompanied by CD11c expression. ${ }^{35}$ Moreover, CD11c plays a crucial, but yet unidentified role in cholesterol homeostasis. ${ }^{39}$ When there is an expansion of $\mathrm{CD} 11 \mathrm{c}^{+}$cells, cholesterol levels, and the amount of atherosclerosis decreases, while a depletion of $\mathrm{CD} 11 \mathrm{c}^{+}$cells results in hypercholesterolemia and an increase in atherosclerosis. ${ }^{39}$ Frutkin et al. described that hypercholesterolemia induces TGF- $\beta$ expression. ${ }^{41}$ Surprisingly, decreased levels of cholesterol were found in the plasma of $A p o E^{-1} \mathrm{CD} 11 \mathrm{cDNR}$ mice. This decrease was also found by Robertson et al. in the plasma of ApoE ${ }^{-1}$ CD4DNR mice. ${ }^{27}$ Since in our study we blocked TGF- $\beta$ signalling in DCs, our data may suggest an interaction between TGF- $\beta, D C s$ and the cholesterol metabolism. However, why the reduced cholesterol levels did not result in reduced lesion size remains unclear.

In the present study, we found that TGF- $\beta$ signaling in CD11 $c^{+}$cells is involved in the recruitment of inflammatory cells into the plaque, as well as in maintaining T-cell homeostasis. Lack of TGF- $\beta$ signaling in $\mathrm{CD} 11 \mathrm{c}^{+}$cells results in massive infiltration of $\mathrm{CD} 4^{+}$and $\mathrm{CD} 8^{+}$cells in atherosclerotic plaques and systemic expansion of $C D 44^{\text {high }} C D 62 L^{\text {low }} \mathrm{T}$-cells, which dem- 
onstrates that blockage of TGF- $\beta$ signaling in CD11c cells leads to a shift from naïve T-cells towards effector (CD44 ${ }^{\text {High }} \mathrm{CD} 62 \mathrm{~L}^{\text {Low }}$ ) T-cells. This effector-T-cell phenotype explains the influx of large amounts of $\mathrm{CD}^{+}$and $\mathrm{CD} 8^{+} \mathrm{T}$-cells into the lesions, since naive T-cells are not capable of infiltrating inflamed tissues. In addition, elevated levels of IFN- $\gamma$, TNF- $\alpha$, IL-4, IL-10, IL-17 were detected. This broad array of expressed cytokines refers to both Th-1 and Th- 2 subsets. The effect on atherosclerosis can therefore not be explained by a shift in the Th-1/Th-2 balance. In addition, high levels of II-17 were detected in the CD11CDNR animals, referring to an enhanced Th17 phenotype as well. These results are in concordance with Laouar et al. who studied the CD11CDNR mouse in experimental autoimmune encephalomyelitis (EAE) where an increase in inflammation in the CNS is accompanied with increased levels of Th1 and Th17 cytokines. ${ }^{42}$ Even more, abrogation of IL-17 receptor signaling in LDLr-/- mice attenuated atherosclerosis. ${ }^{43}$ Moreover, Th17 cells have been identified in patients with acute coronary syndrome. ${ }^{44}$ Taken together these data suggest a potential proatherogenic role. We therefore hypothesize that interruption of TGF- $\beta$ signaling in CD11c+ cells results in altered T-cell priming by DCs.

In conclusion, we state that TGF- $\beta$ signaling in CD11c expressing cells plays a key role in the regulation of the immune system during atherogenesis. TGF- $\beta$ signaling in CD11c expressing cell types (i.e. cells of the innate immune system) provides a first inhibitory link between the innate and adaptive immune response. It indirectly modulates adaptive immune responses by inhibiting DCs from the innate immune system to prime T-cells towards an effector T-cell phenotype. Therefore inhibition of TGF $\beta$ signalling leads to an increased atherosclerosis progression, an increase in T-cell inflammation in the atherosclerotic lesion with, in spite of low cholesterol levels the consequential development of plaques, which are high in inflammation and low in fibrosis.
Supplementary figure legends
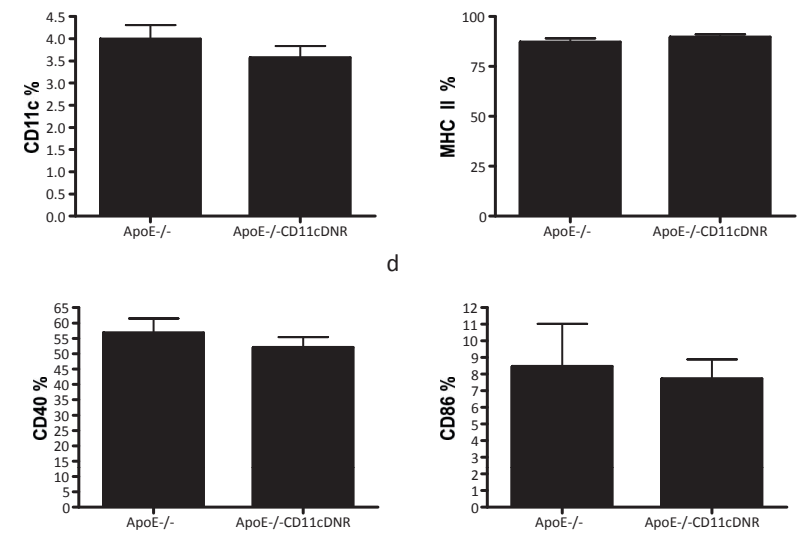

Suppementary figure 5.1

Disruption of TGF-B signaling in CD11c positive cells does not alter DC maturation in vivo. (a) Percentage of CD11c positive cells in spleen. FACS analysis of maturation markers (b) CD40, (c) MHCII, (d) CD86 of ApoE- and ApoE $\%$ CD11CDNR splenocytes. 


\section{References}

1. Galkina E, Ley K. Immune and inflammatory mechanisms of atherosclerosis $(*)$. Annu Rev Immunol. 2009;27:165-197.

2. Lusis AJ. Atherosclerosis. Nature. 2000;407(6801):233.

3. Weber C, Zernecke A, Libby P. The multifaceted contributions of leukocyte subsets to atherosclerosis: lessons from mouse models. Nat Rev Immunol. 2008;8(10):802-815.

4. Tedgui A, Mallat Z. Cytokines in atherosclerosis: pathogenic and regulatory pathways. Physiol Rev. 2006;86(2):515-581.

5. Kleemann R, Zadelaar S, Kooistra T. Cytokines and atherosclerosis: a comprehensive review of studies in mice. Cardiovasc Res. 2008;79(3):360-376.

6. Zernecke A, Shagdarsuren E, Weber C. Chemokines in Atherosclerosis. An Update. Arterioscler Thromb Vasc Biol. 2008.

7. Charo IF, Ransohoff RM. The many roles of chemokines and chemokine receptors in inflammation. N Engl J Med. 2006;354(6):610-621.

8. Mallat Z, Tedgui A. The role of transforming growth factor beta in atherosclerosis: novel insights and future perspectives. Curr Opin Lipidol. 2002;13(5):523-529.

9. Grainger DJ. TGF-beta and atherosclerosis in man. Cardiovasc Res. 2007;74(2):213-222.

10. Cipollone F, Fazia M, Mincione $\mathrm{G}$, lezzi A, Pini B. Increased expression of transforming growth factor- 1 as a stabilizing factor in human atherosclerotic plaques. Stroke. 2004;35:2253.

11. Grainger DJ. Transforming Growth Factor \{beta\} and Atherosclerosis: So Far, So Good for the Protective Cytokine Hypothesis. Arterioscler Thromb Vasc Biol. 2004;24(3):399-404.

12. Brown $C B$, Boyer AS, Runyan RB, Barnett JV. Requirement of type III TGF- receptor for endocardial cell transformation in the heart. Science. 1999;283:2080.

13. Massague J. TGF- signal transduction. Annu. Rev. Biochem. 1998;67:753.

14. Shi Y, Massague J. Mechanisms of TGF- signaling from cell membrane to the nucleus. Cell. 2003;113:685

15. Attisano L, Wrana JL. Smads as transcriptional co-modulators. Curr. Opin. Cell Biol. 2000;12:235.

16. WahI SM, Wen J, Moutsopoulos N. TGF-beta: a mobile purveyor of immune privilege. Immunological Reviews. 2006;213(1):213-227.

17. Massague J, Gomis RR. The logic of TGFbeta signaling. FEBS Lett. 2006;580(12):2811-2820.

18. Grainger DJ. TGF-[beta] and atherosclerosis in man. Cardiovascular Research. 2007;74(2):213-222.

19. Li MO, Wan YY, Sanjabi S, Robertson AK, Flavell RA. Transforming growth factor-beta regulation of immune responses. Annu Rev Immunol. 2006;24:99-146.

20. Park SK, Yang WS, Lee SK, Ahn H, Park JS. TGF-1 down-regulates inflammatory cytokine-induced VCAM-1 expression in cultured human glomerular endothelial cells. Nephrol. Dial. Transplant. 2000;15:596.

21. Smith WB, Noack L, Khew-Goodall $Y$, Isenmann S, Vadas MA, Gamble JR. Transforming growth factor-1 inhibits the production of IL-8 and the transmigration of neutrophils through activated endothelium. J. Immunol. 1996;157:360.

22. Ignotz RA, Endo T, Massague J. Regulation of fibronectin and type I collagen mRNA levels by transforming growth factor-beta. J Biol Chem. 1987;262(14):6443-6446.

23. Amento EP, Ehsani N, Palmer H, Libby P. Cytokines and growth factors positively and negatively regulate interstitial collagen gene expression in human vascular smooth muscle cells. Arterioscler. Thromb. 1991;11:1223
24. Lutgens E, Gijbels M, Smook M, Heeringa P, Gotwals P. Transforming growth factor- mediates balance between inflammation and fibrosis during plaque progression. Arterioscler. Thromb. Vasc. Biol. 2002;22:975.

25. Mallat Z, Gojova A, Marchiol-Fournigault C, Esposito B, Kamate C. Inhibition of transforming growth factor- signaling accelerates atherosclerosis and induces an unstable plaque phenotype in mice. Circ. Res. 2001;89:930.

26. Frutkin $A D$, Otsuka $G$, Stempien-Otero $A$, Sesti C, Du L, Jaffe $M$, Dichek HL, Pennington CJ, Edwards DR, Nieves-Cintron M, Minter D, Preusch M, Hu JH, Marie JC, Dichek DA. TGF-\{beta\}1 Limits Plaque Growth, Stabilizes Plaque Structure, and Prevents Aortic Dilation in Apolipoprotein E-Null Mice. Arterioscler Thromb Vasc Biol. 2009.

27. Robertson AK, Rudling M, Zhou X, Gorelik L, Flavell RA, Hansson GK. Disruption of TGF- signaling in T cells accelerates atherosclerosis. J. Clin. Invest. 2003;112:1342.

28. Ovchinnikova O, Robertson AK, Wagsater D, Folco EJ, Hyry M, Myllyharju J, Eriksson P, Libby P, Hansson GK. T-cell activation leads to reduced collagen maturation in atherosclerotic plaques of Apoe(-/-) mice. Am J Pathol. 2009;174(2):693-700.

29. Gojova A, Brun V, Esposito B, Cottrez F, Gourdy P. Specific abrogation of transforming growth factor- signaling in T cells alters atherosclerotic lesion size and composition in mice. Blood. 2003;102:4052.

30. Laouar Y, Sutterwala FS, Gorelik L, Flavell RA. Transforming growth factor- controls T helper type 1 cell development through regulation of natural killer cell interferon. Nat. Immunol. 2005;6:600.

31. Virmani R, Kolodgie FD, Burke AP, Farb A, Schwartz SM. Lessons from sudden coronary death: a comprehensive morphological classification scheme for atherosclerotic lesions. Arterioscler Thromb Vasc Biol. 2000;20(5):1262-1275

32. Wu H, Gower RM, Wang H, Perrard XY, Ma R, Bullard DC, Burns AR, Paul A, Smith CW, Simon SI, Ballantyne $\mathrm{CM}$. Functional role of $\mathrm{CD} 11 \mathrm{c}+$ monocytes in atherogenesis associated with hypercholesterolemia. Circulation. 2009;119(20):2708-2717.

33. Strobl H, Knapp W. TGF-1 regulation of dendritic cells. Microbes Infect. 1999;1:1283.

34. Strobl H, Bello-Fernandez C, Riedl E, Pickl WF, Majdic O. flt3 ligand in cooperation with transforming growth factor-1 potentiates in vitro development of Langerhans-type dendritic cells and allows single-cell dendritic cell cluster formation under serum-free conditions. Blood. 1997;90:1425.

35. Cho HJ, Shashkin P, Gleissner CA, Dunson D, Jain N, Lee JK, Miller Y, Ley K. Induction of dendritic cell-like phenotype in macrophages during foam cell formation. Physiol Genomics. 2007;29(2):149-160.

36. Ait-Oufella H, Salomon BL, Potteaux S, Robertson AK, Gourdy P, Zoll J, Merval R, Esposito B, Cohen JL, Fisson S, Flavell RA, Hansson GK, Klatzmann D, Tedgui A, Mallat Z. Natural regulatory T cells control the development of atherosclerosis in mice. Nat Med. 2006;12(2):178-180.

37. Geissmann F, Revy P, Regnault A, Lepelletier Y, Dy M, Brousse N, Amigorena S, Hermine O, Durandy A. TGF-beta 1 prevents the noncognate maturation of human dendritic Langerhans cells. J Immunol. 1999;162(8):4567-4575.

38. Yamaguchi Y, Tsumura H, Miwa M, Inaba K. Contrasting effects of TGF-beta 1 and TNF-alpha on the development of dendritic cells from progenitors in mouse bone marrow. Stem Cells. 1997;15(2):144-153.

39. Gautier EL, Huby T, Saint-Charles F, Ouzilleau B, Pirault J, Deswaerte V, Ginhoux F, Miller ER, Witztum JL, Chapman MJ, Lesnik P. Conventional dendritic cells at the crossroads between immunity and cholesterol homeostasis in atherosclerosis. Circulation. 2009;119(17):2367-2375.

40. Choi JH, Do Y, Cheong C, Koh H, Boscardin SB, Oh YS, Bozzacco L, Trumpfheller C, Park CG, Steinman RM. Identification of antigen-presenting dendritic cells in mouse aorta and cardiac valves. J Exp Med. 2009;206(3):497-505. 
41. Frutkin AD, Otsuka G, Stempien-Otero A, Sesti C, Du L, Jaffe M, Dichek HL, Pennington CJ, Edwards DR, Nieves-Cintron M, Minter D, Preusch M, Hu JH, Marie JC, Dichek DA. TGF-[beta]1 limits plaque growth, stabilizes plaque structure, and prevents aortic dilation in apolipoprotein E-null mice. Arterioscler Thromb Vasc Biol. 2009;29(9):1251-1257.

42. Laouar Y, Town T, Jeng D, Tran E, Wan Y, Kuchroo VK, Flavell RA. TGF-beta signaling in dendritic cells is a prerequisite for the control of autoimmune encephalomyelitis. Proc Natl Acad Sci U S A. 2008;105(31):1086510870.

43. van Es T, van Puijvelde GH, Ramos OH, Segers FM, Joosten LA, van den Berg WB, Michon IM, de Vos P, van Berkel TJ, Kuiper J. Attenuated atherosclerosis upon IL-17R signaling disruption in LDLr deficient mice. Biochem Biophys Res Commun. 2009;388(2):261-265.

44. Cheng X, Yu X, Ding YJ, Fu QQ, Xie JJ, Tang TT, Yao R, Chen Y, Liao YH. The Th17/Treg imbalance in patients with acute coronary syndrome. Clin Immunol. 2008;127(1):89-97. 


\section{PLATELET CD40L MEDIATES THROMBOTIC}

AND INFLAMMATORY PROCESSES IN ATHEROSCLEROSIS

Dirk Lievens,* Alma Zernecke,* Tom Seijkens, Linda Beckers, Imke C Munnix, Erwin Wijnands, Richard A Flavell, Randolph J Noelle, Erik A Biessen, Johan W Heemskerk, Mat JAP Daemen, Christian Weber and Esther Lutgens.

* these authors contributed equally

submitted 


\section{Abstract}

CD40L, a tumor necrosis receptor family member, acts as a co-stimulatory molecule, but is also highly expressed on platelets, a 'hemostatic' cell type that plays a significant role in immunological processes. Here, we investigated the thrombotic and inflammatory potential of platelet $\mathrm{CD} 40 \mathrm{~L}$ in atherosclerosis. Deficiency in platelet $\mathrm{CD} 40 \mathrm{~L}$ reduced in vitro platelet aggregation on collagen, without affecting bleeding times, clot retraction, or Pselectin, GPIba and $\alpha$ llbB3 expression. In vivo, repeated injections of activated $\mathrm{CD}^{-} \mathrm{OL}^{-/}$ ApoE ${ }^{-/}$platelets into ApoE- mice prevented leukocyte adhesion to the endothelium of the carotid artery, and decreased plasma CCL2 levels when compared to mice that received activated $\mathrm{CD} \mathrm{OL}^{+/+} \mathrm{ApoE}-/$ platelets. Moreover, $\mathrm{CD}^{-1} 0 \mathrm{~L}^{-/} \mathrm{ApoE}-\mathrm{F}^{-/}$platelets had an impaired capacity to form pro-inflammatory platelet-leukocyte aggregates. Repeated injection of activated $\mathrm{CD} 4 \mathrm{~L}^{-/} \mathrm{ApoE} \mathrm{E}^{-/-}$platelets prevented the increase in atherosclerosis in $\mathrm{ApoE}^{-/-}$mice, which was induced by injection of $\mathrm{CD}_{40 \mathrm{~L}^{++}} \mathrm{ApoE}^{-/-}$platelets, and the former resulted in plaques with less macrophages, less apoptosis and no intra-plaque hemorrhages. Even in ApoE $\mathrm{E}^{-/-}$mice with developed plaques, treatment with activated $\mathrm{CD} 40 \mathrm{~L}^{-/-} \mathrm{ApoE}^{-/-}$platelets prevented platelet-induced atherosclerosis progression. We conclude that platelet CD40L has marked pro-thrombotic and pro-inflammatory capacities and thereby accelerates development and progression of atherosclerosis. Blockade of platelet CD40L harbors the potential to achieve therapeutic effects in atherosclerosis.

\section{Introduction}

The glycoprotein CD40L and its counter-receptor CD40, which are co-stimulatory molecules of the TNF- and TNF-receptor family, have important roles in modulating immune responses and inflammation. ${ }^{1,2}$ In atherosclerosis, as a chronic inflammatory disease of the large arteries involving immune-cell subsets, ${ }^{3,4}$ the cross-cellular interaction of CD40L with $\mathrm{CD} 40$ plays a major role. Thus, deficiency or inhibition of $\mathrm{CD} 40 \mathrm{~L}$ in $\mathrm{ApoE}^{-/}$or $\mathrm{LDLr}^{/-}$ mice not only reduced the atherosclerotic proces, but also conferred a clinically favorable plaque phenotype, consisting of extensive fibrosis and reduced accumulation of inflammatory cells..$^{5-8}$

CD40L is expressed on a plethora of cell types present in or around atherosclerotic plaques, such as T-cells, macrophages, smooth muscle cells and endothelial cells, ${ }^{9}$ but it is also expressed on circulating monocytes and platelets. It has been documented that platelets are even the most important source of circulating CD40L. ${ }^{9}$ However, until now the contribution of platelet CD40L on atherosclerosis is unclear.

Already in 1998, Henn et al. reported that activated platelets express CD40L, which induces endothelial cells to secrete chemokines and express adhesion molecules, thereby initiating an inflammatory response of the vessel wall. ${ }^{10}$ However, later it also appeared that platelet $\mathrm{CD} 40 \mathrm{~L}$ acts in an autocrine way by binding to integrin $\alpha \mathrm{llb} \beta 3$, contributing to the stabilization of thrombi. ${ }^{11,12}$ This suggests a role for platelet CD40L in both inflammation and thrombosis, both of which processes that are imperative in atherosclerosis.

While the hemostatic and thrombotic roles of platelets are well-established, their function as potent immune cells is also emerging, capable of initiating and mediating inflammation in the vasculature. ${ }^{13-16}$ For instance, adhesion of activated platelets via P-selectin, glycoprotein (GP) Ib $\alpha$ and $\alpha$ llb $\beta 3$ to the endothelium induces expression of endothelial leukocyte adhesion molecules such as vascular cellular adhesion molecule-1 (VCAM-1), intracellular adhesion molecule-1 (ICAM-1), E-selectin, chemokines (e.g., CCL2, CXCL4 and CCL5) and matrix metallo-proteinases (MMP-1, MMP-2 and MMP-9). These factors facilitate leukocyte recruitment into the lesion and thereby accelerate atherosclerotic plaque formation. ${ }^{17-23}$

In addition to this, activated platelets also in an indirect way to atherosclerosis, promote leukocyte recruitment via the formation of platelet-leukocyte aggregates (PLAs). ${ }^{24}$ Through P-selectin, platelets bind to the P-selectin ligand (PSGL) on leukocytes, and the multi-cellular conjugates produce chemokines like CCL2 and CCL5 and cytokines like IL$1 \beta$ to further activate the leukocytes. ${ }^{22-27}$ In vitro observations have indicated that these conjugates tether and roll on endothelial cells with a higher avidity than non-conjugated 
leukocytes, thereby enhancing endothelial activation. ${ }^{25-27}$ In addition, PLAs have been observed in pre- or prothrombotic clinical conditions, and may provide an efficient marker of acute myocardial infarction. ${ }^{28,29}$

The same two mechanisms were shown to contribute to atherogenesis. This was for instance demonstrated by the finding that repeated injection of thrombin-activated platelets into $\mathrm{ApoE}^{-/}$mice resulted in acceleration of the atherosclerotic process. This was shown to be caused by platelet mediated activation of the endothelium, as well as by the formation of PLAs, which was in part P-selectin dependent. ${ }^{22}$

Because of the reported role of platelet CD40L in both thrombosis and inflammation we investigated the atherogenic propensity of platelet CD40L. Platelet CD40L promoted leukocyte adhesion to the endothelium via CCL2, and mediated the formation of plateletleukocyte aggregates. Repeated intravenous injection of activated $\mathrm{CD}^{2} \mathrm{LL}^{-/} \mathrm{Apo}-\mathrm{E}^{-}$platelets into $\mathrm{ApoE}^{-/}$mice prevented the profound increase of atherosclerosis that occurred after injection of activated $\mathrm{CD} 4 \mathrm{~L}^{+/+} \mathrm{ApoE} \mathrm{E}^{-/-}$platelets.

\section{Material and methods}

\section{Mice}

$\mathrm{CD} 40 \mathrm{~L}^{-}-\mathrm{ApoE}-\%$ and $\mathrm{CD} 40 \% \mathrm{ApoE}^{-} /$mice were generated by interbreeding $\mathrm{CD}^{-1} \mathrm{~L}^{-/}$and $\mathrm{CD} 40 \%$ mice with ApoE ${ }^{-1}$ mice (Jackson laboratories, Bar Harbor, ME), all on a C57BI6 background. All mice were housed and bred in accordance with institutional guidelines. Experiments were approved by the local animal experimental and care committees.

\section{Platelet function assays}

Blood was obtained from the retro-orbital plexus and collected into citrate containing tubes. For clot retraction, platelet-rich plasma (PRP) was prepared by centrifugation, and the platelet concentration was adjusted to $2 \times 10^{8}$ platelets $/ \mathrm{ml}$ with Tyrodes-HEPES containing $\mathrm{CaCl}_{2}(2 \mathrm{mM})$. PRP was placed in a glass tube and incubated at $37^{\circ} \mathrm{C}$ for 5 minutes. Thrombin $(11 \mathrm{nM})$ was added and clot retraction was recorded at different time points by photographic images. Expression levels of P-selectin, GPIb $\alpha$, and $\alpha$ llb $\beta 3$ were measured by flow cytometry (FACS CANTO II, BD Biosciences). Bleeding time was assessed in 6 to 8 -week-old mice. Tails were cut $2 \mathrm{~mm}$ from the distal end and placed in $37^{\circ} \mathrm{C}$ normal saline. The times to cessation of bleeding and any re-bleeding were recorded. ${ }^{30}$

\section{Measurement of thrombus formation under flow}

Adhesion experiments under flow conditions were performed with mouse blood collected into PPACK and heparin. ${ }^{31}$ Blood was perfused over collagen-coated coverslips mounted on a transparent, parallel-plate perfusion chamber at a shear rate of $1000 \mathrm{~s}^{-1}$ for 4 minutes. ${ }^{32}$ To assess platelet adhesion, microscopic phase-contrast images were recorded using a Visitech digital imaging system (Sunderland) equipped with two intensified, charge-coupled device (CCD) cameras. $^{33}$ Images were captured with a 40x UV-transparent objective and $1.5 x$ optical magnification.

\section{Platelet-leukocyte interactions}

Laminar flow assays were performed as described. ${ }^{34}$ Washed $\mathrm{CD}_{40 \mathrm{~L}^{-1} \mathrm{ApoE}}{ }^{-1}$ or $\mathrm{CD} \mathrm{OL}^{+/+} \mathrm{ApoE}^{-/-}$platelets were immobilized at the lower wall of a flow chamber on the stage of an Olympus IX 50 inverted phase-contrast microscope (Olympus Optical). Adherent platelets were activated with thrombin $(1.1 \mathrm{nM})$ at $37^{\circ} \mathrm{C}$. Leukocytes were then perfused through the chamber for 10 minutes at $1000 \mathrm{~s}^{-1}$. The number of firmly adherent cells was quantified in multiple microscopic fields by analysis of images recorded with a JVC $3 C C D$ video camera and recorder.

Platelet-leukocyte aggregate formation was also studied by flow cytometry. Washed platelets were prepared from PRP, re-suspended in Hepes buffer, and activated with thrombin $(1.1 \mathrm{nM})$ at $37^{\circ} \mathrm{C}$. Leukocytes were isolated from the sediments obtained after centrifugation and removal of PRP. After lysis of erythrocytes (Pharmlyse, kit BD Biosciences), leukocytes were washed twice with ice-cold Hanks' HEPES buffer. Leukocytes were added to the activated platelets and incubated during 20 minutes (at $37^{\circ} \mathrm{C}$ ) to create platelet-leukocyte aggregates. Samples were stained with fluorescent-labeled antibodies against CD11b (PerCP), CD41 (PE) or isotype control antibodies and analyzed by flow cytometry (FACS CANTO II, BD Biosciences)

\section{Intravital microscopy}

Intravital microscopy was performed to monitor leukocyte recruitment to the endothelium of an atherosclerotic carotid artery. Rhodamine-6G (Molecular Probes) was administered intravenously (i.v.) in mice, which had been injected with activated $\mathrm{CD} 40 \mathrm{~L}^{+/+} \mathrm{ApoE}^{-/-}$or $\mathrm{CD} 4 \mathrm{LL}^{--} \mathrm{Apo} \mathrm{E}^{-/-}$platelets once every 5 days during 12 weeks. The carotid arteries were dissected free and arrest of labeled leukocytes was analyzed by epifluorescence microscopy (Zeiss Axiotech, 20x water immersion). Leukocytes were considered to be adherent when they remained stationary for more than 30 seconds..$^{35}$ 


\section{Atherosclerosis experiments}

Preparation of donor platelets

Blood from $\mathrm{CD} 4 \mathrm{~L}^{+/+} \mathrm{ApoE} \mathrm{E}^{-/}$and $\mathrm{CD} \mathrm{CL}^{-/}-\mathrm{ApoE}^{-/}$donor mice was obtained from the retroorbital plexus and collected in acid-citrate-dextrose (ACD) containing tubes. PRP was prepared and platelets were washed extensively. Washed platelets were activated with 0.05 $\mathrm{U} / \mathrm{ml}$ thrombin for 15 minutes, followed by neutralization with an equimolar dose of hirudin. Activated $\mathrm{CD} 4 \mathrm{~L}^{-/-} \mathrm{ApoE} \mathrm{E}^{-/-}$or $\mathrm{CD} 4 \mathrm{~L}^{+/+} \mathrm{ApoE}^{-/}$platelets ( $3 \times 10^{7}$ per $20 \mathrm{~g}$ mouse weight) were administered every 5 days to Apoe-/- acceptor mice via tail vein injections. ${ }^{22}$

\section{Plaque initiation}

To study the effects of platelet CD4OL on plaque development, injections of activated

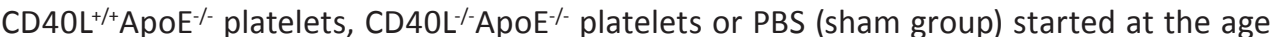
of 5 weeks ( $n=11 /$ group), when no signs of atherosclerosis were present in the aortic arch, and continued until 17 weeks of age, when the first fatty streak lesions appeared. The animals were fed a normal chow diet.

Advanced plaque development

Advanced atherosclerotic plaques were induced by placing a slightly constrictive silastic collar in 14 week old ApoE- mice, $^{36}$ which were fed a $0.21 \%$ cholesterol diet for 3 weeks. Injections of activated $\mathrm{CD} 40 \mathrm{~L}^{+/+} \mathrm{ApoE} /$ platelets, activated $\mathrm{CD}^{-10 \mathrm{~L}^{-/} \mathrm{ApoE}} \mathrm{E}^{-/}$platelets or PBS (sham group) started at five days after collar placement ( $n=10 /$ group), and, together with the diet, were continued for 6 weeks.

\section{Established plaques}

The effect of platelet injections on established plaques was determined using 17-weekold $\mathrm{ApoE}^{-/}$mice, which already contained atherosclerotic plaques. The mice were injected

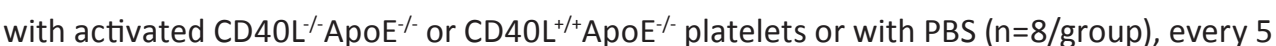
days during 12 additional wks. Atherosclerosis was quantified at week 29, and compared to lesion size of 17 -week-old ApoE $\%$ mice, which did not receive platelet injections. For all studies, plasma cholesterol levels were determined in duplicate using a colorimetric assay (CHOD-PAP, Roche).

\section{Tissue processing, histology and morphometry}

At the end of experiments, mice were sacrificed at 4 hours after fasting. Blood was obtained from the retro-orbital plexus. The arterial tree was perfused for 5 minutes with PBS containing sodium nitroprusside (Sigma) and 1\% paraformaldehyde. The aortic arch including main branch points was removed, fixed overnight in $1 \%$ paraformaldehyde, longitudinally embedded in paraffin, and sectioned. Twenty consecutive sections $(4 \mu \mathrm{m})$ representing the central area of the aortic arch with an intact morphology of the arch and branch points were selected. ${ }^{6}$ For histological analysis of atherosclerosis, 4 sections ( $20 \mu \mathrm{m}$ apart) were stained with hematoxylin and eosin (HE). Aortic root lesions were analyzed using serial sections of $4 \mu \mathrm{m}$ with $42 \mu \mathrm{m}$ intervals, beginning from the onset of the aortic valves until the valves had disappeared. For mice with a collar placed, the right carotid artery was analyzed. To determine plaque volume, plaque area was measured on cross-sections, 100 $\mu \mathrm{m}$ apart, thereby covering the entire plaque. Atherosclerotic lesions were analyzed and classified as either initial or advanced lesions, based on histological criteria defined by Virmani et al. ${ }^{37}$ Number of atherosclerotic plaques and the presence or absence of lipid cores was determined. Plaque area was calculated using a Leica DM3000 light microscope (Leica Microsystems) coupled to a computerized morphometry system (Leica Qwin 3.5.1)

\section{(Immuno)histochemistry}

Aortic sections were immunolabeled with anti-Mac3 mAb (1:30; Pharmingen) to detect macrophages; anti-CD3 (1:200; DAKO) to detect T lymphocytes; anti-CD45 mAb (1:5000; Pharmingen) to detect leukocytes, anti-cleaved caspase-3 mAb (1:100; Cell signaling) to detect apoptosis, and anti- $\alpha$ SMA mAb (1:500; DAKO) as a marker for vascular smooth muscle cells and fibroblasts. Antibody staining was visualized by diaminobenzidine or Vector red. Perl's staining was used to detect iron deposition and Sirius red staining for analysis of collagen content.

\section{Immune-phenotyping of ApoE $/$ mice}

To determine potential effects of platelet injections on the immune system, cells from blood, spleen and lymph nodes were harvested upon sacrifice of mice, and analyzed for the relative distribution of monocyte, T-cell and B-cell subsets. Cells were stained with antibodies against CD3, CD4, CD8, CD25, FoxP3, CD11b, Ly6C, Ly6G, CD11c and B220 (all from $\mathrm{BD}$ Biosciences or eBioscience). Isotype IgG1 was used as a control.

\section{Analysis of chemokine and cytokine profiles}

Concentrations of cytokines IL-6, IL-10, CCL2, IFN- $\gamma$, TNF $\alpha$ and IL-12p70 were measured in plasma with a Cytometric Bead Array ready-to-use mouse inflammation kit (BD Biosciences). ELISA assays were used to quantify CCL5, IL-1 $\beta$ and sVCAM levels in plasma (BD Biosciences). 


\section{Statistical analysis}

Results are expressed as mean \pm s.e.m. $\mathrm{CD} 4 \mathrm{~L}^{-1} \mathrm{ApoE}-\mathrm{E}^{--}$mice were compared with $\mathrm{CD}_{40 \mathrm{~L}}+/ \mathrm{ApoE} \mathrm{E}^{-/}$mice, $\mathrm{CD} 40^{-/} \mathrm{ApoE}^{-}-$mice and sham treated mice by a non-parametric Mann-Whitney U-test or a Fisher's exact test. A value of $\mathrm{P}<0.05$ was considered to be statistically significant.

\section{Results}

\section{Platelet CD40L promotes thrombus formation}

$\mathrm{CD} 4 \mathrm{~L}^{+/+} \mathrm{ApoE}-\mathrm{F}^{-/}$and $\mathrm{CD} \mathrm{OL}^{-/}-\mathrm{ApoE}^{-/}$mice exhibited normal platelet counts and had similar tail bleeding times. The PRP from these mice showed normal clot retraction (table 6.1). Furthermore, activated $\mathrm{CD} 40 \mathrm{~L}^{-1-} \mathrm{ApoE}^{-}-$platelets expressed unchanged levels of P-selectin and GPIba.

\begin{tabular}{lcc}
\hline & CD40L+/+ApoE-/- & CD40L-/-ApoE-/- \\
\hline RBC $\left(\times 10^{12} / \mathrm{L}\right)$ & $6.8 \pm 0.1$ & $6.5 \pm 0.3$ \\
\hline WBC $\left(\times 10^{9} / \mathrm{L}\right)$ & $1.8 \pm 0.2$ & $2.1 \pm 0.3$ \\
\hline Hemoglobin (g/l) & $6.6 \pm 0.1$ & $6.2 \pm 0.2$ \\
\hline Hematocrit & $0.31 \pm 0.01$ & $0.31 \pm 0.01$ \\
Platelets (10/L) & $1074 \pm 74$ & $1091 \pm 92$ \\
\hline Bleeding time (min) & $2^{\prime} 51^{\prime \prime} \pm 14^{\prime \prime}$ & $3^{\prime} 11^{\prime \prime} \pm 17^{\prime}$ \\
P-selectin (G mean) & $87 \pm 2$ & $89 \pm 1$ \\
\hline GPlba (G mean) & $94 \pm 1$ & $92 \pm 1$ \\
Clot retraction & +++ & +++ \\
\hline
\end{tabular}

\section{Table 6.1}

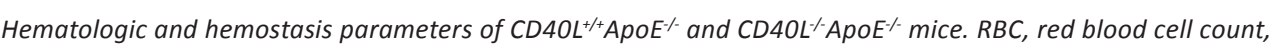
WBC, white blood cell count, Levels of P-selectin and GPIba expression of thrombin-activated platelets (mean fluorescent level) Clot retraction was complete in both groups after 60 minutes.

Blood from these mice was used to determine the role of CD4OL in collagen-dependent thrombus formation. Perfusion of $\mathrm{CD} \mathrm{OL}^{++} \mathrm{ApoE}^{-/-}$blood over a collagen surface at intermediate, high shear rate resulted in rapid formation of platelet aggregates. Markedly, thrombus formation was greatly impaired when $\mathrm{CD}^{2} \mathrm{LL}^{-/}-\mathrm{ApoE}^{-/}$blood was used. Analysis of platelet deposition showed that $32.8 \pm 0.9 \%$ of the surface was covered with $\mathrm{CD} 40 \mathrm{~L}^{+++} \mathrm{ApoE}^{-1-}$ platelets. In contrast, only $11.7 \pm 4.3 \%$ of the surface was covered with $\mathrm{CD} 4 \mathrm{~L}^{-/} \mathrm{Apoe} \mathrm{e}^{-/}$plate- lets (fig. 6.1 $\boldsymbol{a}$-b). Platelet aggregates were still formed, but the aggregate size was relativeIy small due to instability of the aggregates at these high-shear conditions. These results prove a key role for $\mathrm{CD} 40 \mathrm{~L}$ in platelet-platelet interactions under flow conditi ons.
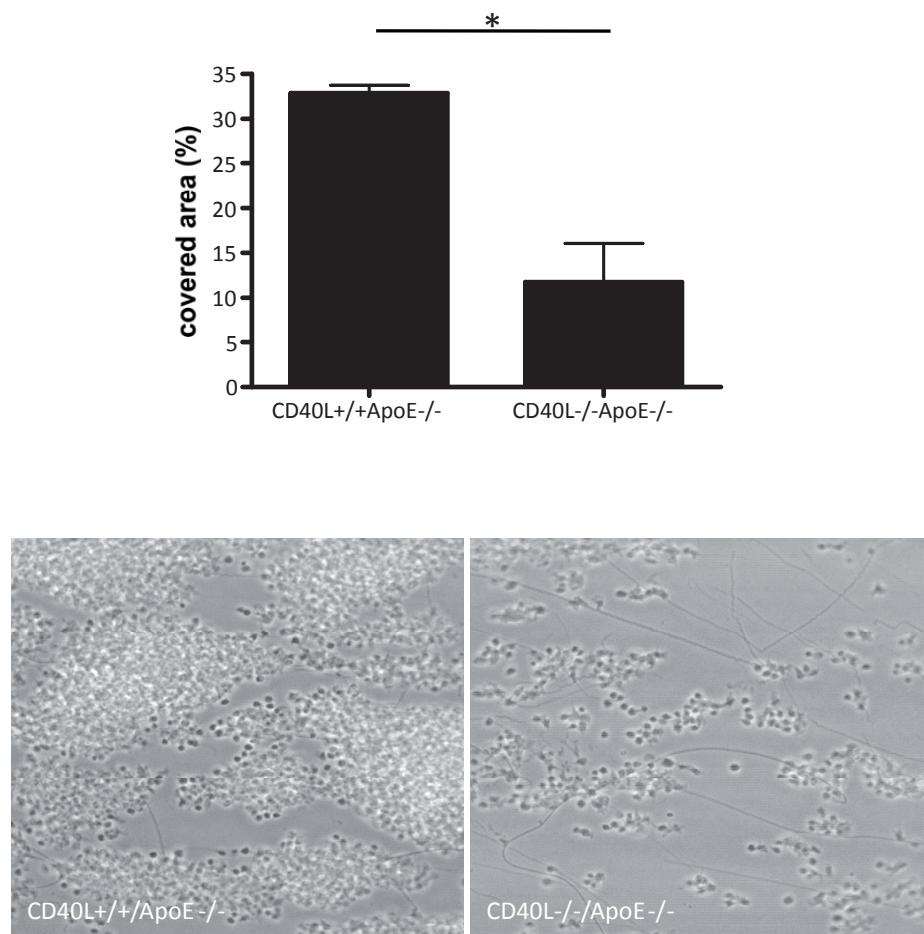

Figure 6.1

CD4OL enforces thrombus formation in Apoe-deficient mice under flow. Heparin/PPACK-anti-coagulated blood

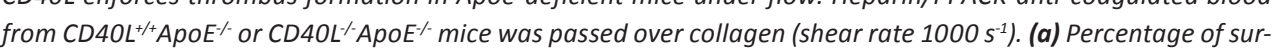
face area coverage with thrombi. (b) Representative phase-contrast images after 4 minutes. $\left(n=6,{ }^{*} p<0.05\right)$

\section{CD40L facilitates platelet-leukocyte interactions}

Activated platelets in the circulation are known to bind leukocytes and form pro-inflammatory platelet-leukocyte aggregates (PLAs).22,38 Here we studied the role of CD4OL in the formation of PLAs by analyzing the adhesion of $\mathrm{ApoE}^{-/}$leukocytes to immobilized thrombin-activated $\mathrm{CD} 4 \mathrm{~L}^{-/} \mathrm{ApoE} \mathrm{E}^{-/}$or $\mathrm{CD} 4 \mathrm{~L}^{+/+} \mathrm{ApoE} \mathrm{E}^{-/}$platelets. In contrast to the abundant leukocyte adhesion elicited by $\mathrm{CD} 4 \mathrm{~L}^{+/+} \mathrm{ApoE} / /$ platelets, deficiency of platelet $\mathrm{CD} 40 \mathrm{~L}$ resulted in a $30 \%$ decrease in the number of adhered leukocytes (fig. $\mathbf{6 . 2}$ a). 
To investigate the contribution of $\mathrm{CD} 40$ and $\mathrm{CD} 40 \mathrm{~L}$ to PLA formation, we investigated this

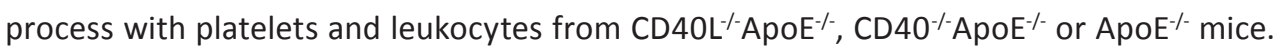
Flow cytometric analysis demonstrated that the formation of $\mathrm{CD} 11 \mathrm{~b}^{+} \mathrm{CD} 41^{+} \mathrm{PLAs}$ was reduced, when CD40L was absent from platelets, or when CD40 was absent from leukocytes. Lowest numbers of PLAs were detected with platelets lacking CD40L plus leucocytes lacking CD40, indicating that the interaction between platelet CD40L and leukocyte CD40 is facilitating in PLA formation (fig. 6.2 b)

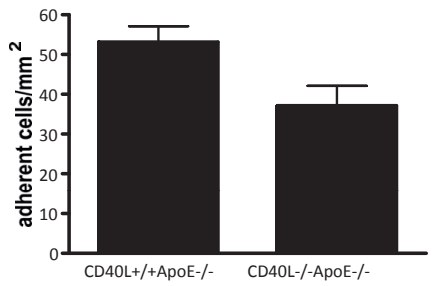

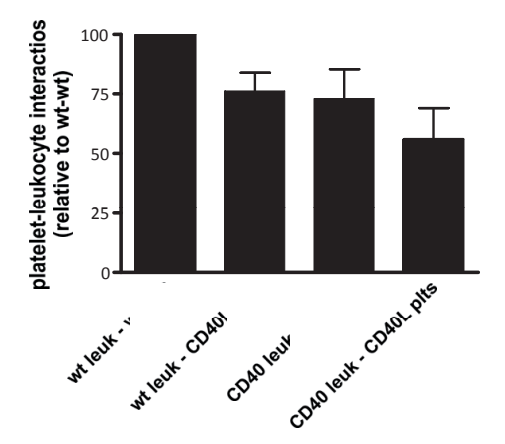

Figure 6.2

Roles of both CD4OL and CD4O in formation of platelet leukocyte-aggregates in ApoE-deficient mice. (a) Num-

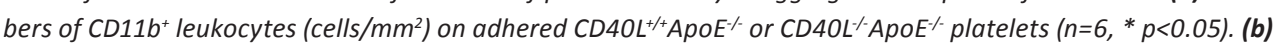
Flow cytometric analysis of formation of $C D 41^{+}-C D 11 b^{+}$cell aggregates showing contribution of platelet $C D 40 L$ and leukocyte $C D 40\left(n=6,{ }^{*} p<0.05\right)$

\section{Platelet CD40L mediates leukocyte recruitment via CCL2}

An ongoing process in atherosclerosis is adhesion of leukocytes to the endothelium, followed by their migration into the diseased arterial wall. We studied whether repeated injection of thrombin-activated platelets from $\mathrm{CD} 4 \mathrm{~L}^{-/} \mathrm{ApoE}^{-/-}$or $\mathrm{CD}_{40 \mathrm{~L}} \mathrm{~L}^{+/} \mathrm{ApoE} \mathrm{E}^{-/}$mice (injection every 5 days during 10 weeks) affected leukocyte-recruitment in donor ApoE-/ mice. Intra-vital microscopy of the left common carotid artery showed that leukocyte adhesion was prevented in mice that had been injected with $\mathrm{CD} 40 \mathrm{~L}^{--} \mathrm{ApoE}-\mathrm{F}^{-}$platelets compared to mice injected with $\mathrm{CD} 4 \mathrm{~L}^{+/+} \mathrm{ApoE} \mathrm{E}^{-/}$platelets (fig. 6.3 a-d). This experiment demonstrated that long-term injection with activated platelets led to increased leukocyte sequestration to the endothelium, an effect that was fully prevented in the absence of platelet CD40L.
Using cytometric bead assays, we analyzed the cytokine levels in plasma from the animals injected with activated platelets. Injection of activated $\mathrm{CD} 4 \mathrm{~L}^{+++} \mathrm{ApoE}^{-/-}$platelets caused a significant increase in chemokine CCL2 (a monocyte chemoattractant), which was absent when $\mathrm{CD} 40 \mathrm{~L}^{-/}$platelets were injected (fig. 6.3 e). Levels of TNF $\alpha$, IL-6, IL-10, IFNY or IL-12 were not affected (data not shown). In addition, levels of platelet chemokines CCL5 (RANTES) or IL1 $\beta$ were also not affected (CCL5: $\mathrm{CD} 4 \mathrm{~L}^{+/+} \mathrm{ApoE}^{-/-}$platelets $215 \pm 18 \mathrm{pg} / \mathrm{ml}$ vs $\mathrm{CD}_{40 \mathrm{~L}^{-}-\mathrm{ApoE}}-$ platelets $210 \pm 22 \mathrm{pg} / \mathrm{ml}$ vs sham injection $\left.242 \pm 26 \mathrm{pg} / \mathrm{ml}\right)$. Interestingly, CCL5 was deposited at lesion sites immediately after injection of the activated platelets. However, no differences were observed between the $\mathrm{CD} 4 \mathrm{LL}^{+/+} \mathrm{ApoE}-\mathrm{F}^{--}$and $\mathrm{CD} 40 \mathrm{~L}^{-/} \mathrm{ApoE}-\mathrm{E}^{-/}$ groups compared to sham controls (CCL5 deposition: $\mathrm{CD} 4 \mathrm{OL}^{+/+} \mathrm{ApoE}^{-/}$platelets $34.8 \pm 5.3 \%$

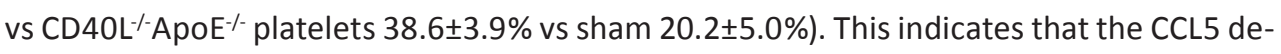
position was not mediated by platelet CD40L. Plasma levels of IL-1 $\beta$, a cytokine excreted by platelets, and of soluble VCAM, a measure of endothelial cell activation, were not affected by platelet CD40L deficiency (data not shown).

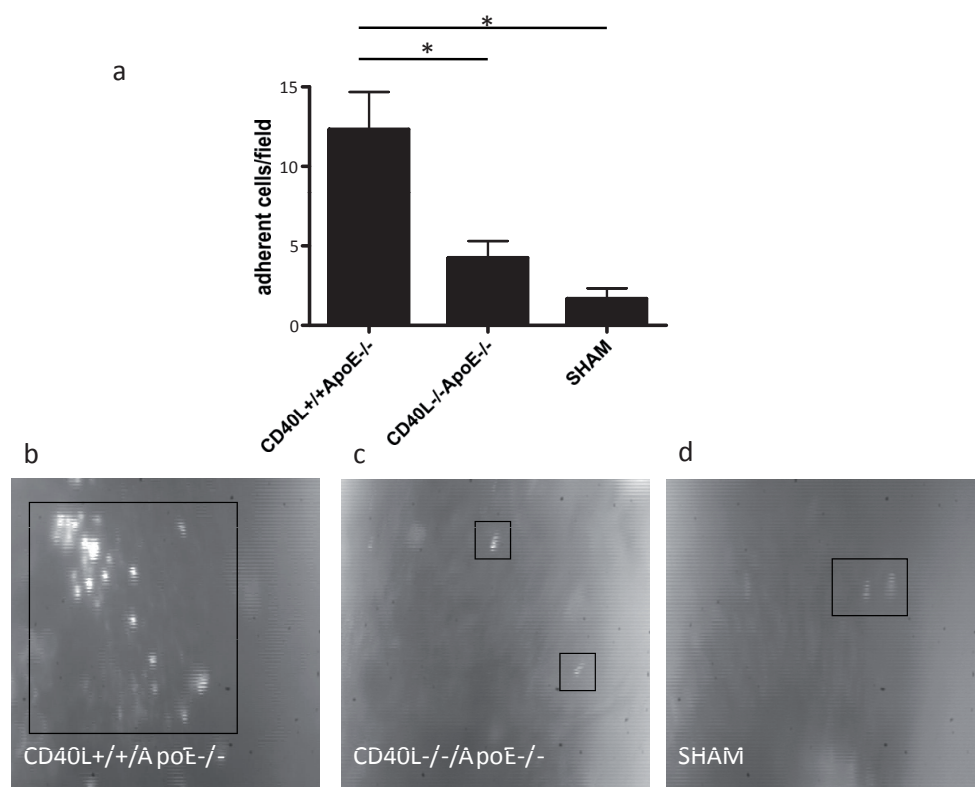

Figure 6.3

Major role of platelet CD4OL in leukocyte adhesion to atherosclerotic arterial wall. (a-d) Intravital microscopy of

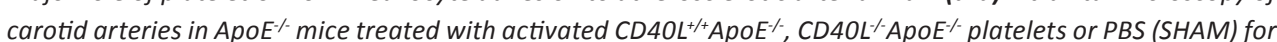
10 weeks. $(n=4-6, * p<0.05)$ (e) Reduction of serum CCL2 levels after repeated injection of CD4OL-A ApOE- platelets into ApoE $\%$ mice; comparison to injection of $\mathrm{CD} 4 \mathrm{LL}^{++} \mathrm{ApOE} \%$ platelets $(n=9, * p<0.05)$. 


\section{Platelet CD40L accelerates early stages of atherosclerosis}

The results so far indicate that platelet CD40L has a key role in platelet-platelet interactions during thrombus formation, PLA formation, and leukocyte recruitment to the arterial wall. We therefore investigated the contribution of platelet $\mathrm{CD} 40 \mathrm{~L}$ in the atherosclerotic process in vivo. This was done by using an established model of platelet-mediated atherosclerotic plaque formation in Apoe ${ }^{-/}$mice, driven by repeated injection of thrombinactivated platelets. ${ }^{22}$

After these injections, no differences could be observed in body weight (SHAM 28.3 \pm 0.4

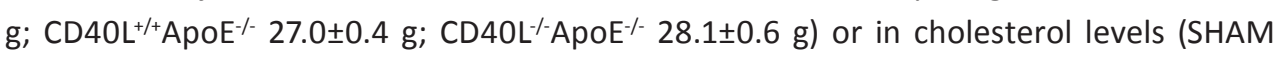

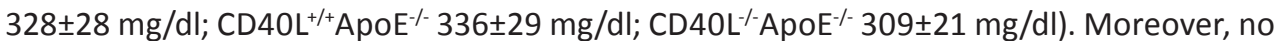
macroscopic or microscopic complications of the injections of activated platelets could be observed in $>20$ organs analyzed, especially no signs of hemorrhage or thrombosis.

Blood leukocyte populations were analyzed by flow cytometry at 12 hours after the last injection of activated platelets. Lower numbers of $\mathrm{CD}^{+} \mathrm{T}$-cells were present in the circulation of animals injected with $\mathrm{CD} 4 \mathrm{LL}^{++} \mathrm{ApoE}^{-/}$platelets. Moreover, this decrease was accompanied by an increased ratio of CD4/CD8 positive cells (suppl. fig. 6.1 a-c), and a decrease in regulatory T-cells (CD4 ${ }^{+} \mathrm{CD} 25^{+} \mathrm{FoxP} 3^{+}$cells), indicating that platelet injection induced activation of T-effector cells. The shift towards effector-T-cells was absent when animals were injected with activated $\mathrm{CD} 4 \mathrm{LL}^{-1-} \mathrm{ApoE}^{-/}$platelets or vehicle (suppl. fig. $6.1 \mathrm{~d}$ ). Similarly, numbers of $\mathrm{CD} 11 \mathrm{~b}^{+}$cells were significantly decreased in the circulation of animals injected with activated $\mathrm{CD} 4 \mathrm{~L}^{+/+} \mathrm{ApoE}-/$ platelets, but not in animals injected with activated $\mathrm{CD} 4 \mathrm{~L}^{-1-} \mathrm{ApoE} \mathrm{E}^{-/}$platelets or vehicle (suppl. fig. 6.2). No differences could be observed in levels of $\mathrm{B} 22 \mathrm{O}^{+} \mathrm{B}$-cells or $\mathrm{Ly}_{6 \mathrm{G}}{ }^{+}$granulocytes (data not shown).

\section{Platelet CD40L accelerates plaque development}

To analyze a role of platelet $\mathrm{CD} 40 \mathrm{~L}$ on the initiation of atherosclerosis, $\mathrm{ApoE}^{--}$mice received thrombin-activated platelets every 5 days from the age of 5 to the age of 17 weeks. At the latter age, predominantly early atherosclerotic lesions (intimal thickening and intimal xanthoma) were present in the aortic arch and the main branch points. As expected, injection of activated $\mathrm{CD} 4 \mathrm{LL}^{+/+} \mathrm{ApoE}^{-/}$platelets significantly increased atherosclerotic plaque area as compared to the vehicle-treated group. Interestingly, injection of activated $\mathrm{CD} 40 \mathrm{~L}^{-1} \mathrm{ApoE}-$ platelets suppressed this increase in atherosclerosis, and plaque areas were comparable to vehicle-treated animals (fig. $6.4 \boldsymbol{a}$-d). This decrease was due to a reduced

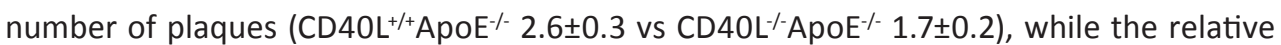
amount of initial and advanced plaques was not affected $\left(\mathrm{CD} 40 \mathrm{~L}^{+/+} \mathrm{ApoE^{-/ }}: 71.2 \pm 13.0 \%\right.$ ini;

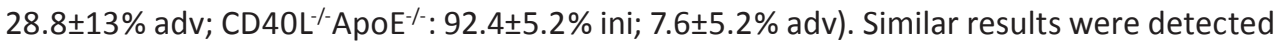
in the aortic root (fig $6.4 \mathrm{e}$ ).
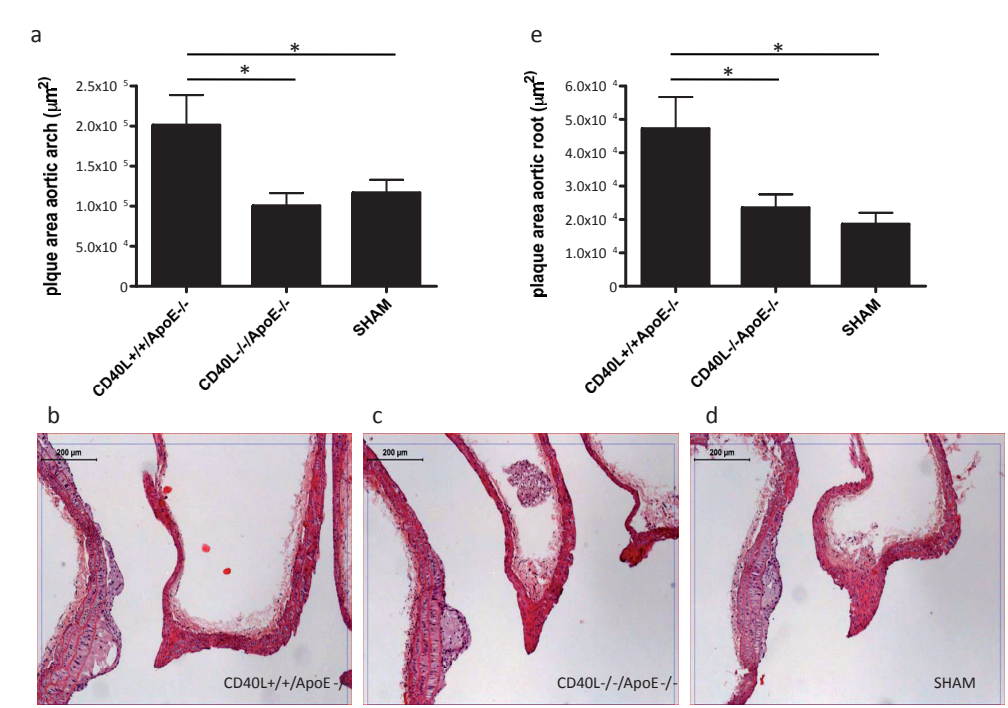

Figure 6.4

Role of platelet CD4OL in atherosclerosis initiation. (a) Plaque area $\left(\mu m^{2}\right)$ of the aortic arch including the main branch points [brachiocephalic trunk (BCT), left common carotid artery (LCC), left subclavian artery (LSA)] of ApoE - mice, which were injected during 12 consecutive wks with activated $C D 4 O L^{++} A p O E^{-}-$platelets, $C D 4 O L^{-}$ ApoE- platelets or PBS ( $n=11$ / group). (b-d) Representative longitudinal sections (HE-staining) of the aortic arch and main branch points. Note the early, foam cell rich atherosclerotic lesions formed in the brachiocephalic trunk (scale bar, $200 \mu \mathrm{m})$. (e) Plaque area $\left(\mu \mathrm{m}^{2}\right)$ of the aortic root ( $n=9 /$ group).

In this early phase of the disease, where lesions were small and foam cell rich, no differences in plaque composition were observed between the treatment groups. However, plaques of animals injected with $\mathrm{CD} 40 \mathrm{~L}^{-/} \mathrm{ApoE}-\mathrm{E}^{-/}$platelets contained a reduced number of macrophages, reflecting the prevention of leukocyte recruitment in absence of platelet $\mathrm{CD} 40 \mathrm{~L}$. These data demonstrate that CD40L from activated platelets accelerates the initial stages of atherosclerosis.

\section{Platelet CD4OL affects the progression towards advanced atherosclerosis}

To investigate whether platelet $\mathrm{CD} 40 \mathrm{~L}$ also has a role in more advanced stages of atherosclerosis, we used a collar-induced atherosclerosis model. ${ }^{36}$ After 6 weeks, advanced plaques were present in the right carotid artery of all treatment groups. Again, injection of activated $\mathrm{CD} 4 \mathrm{LL}^{+/+} \mathrm{ApoE}^{-/-}$platelets significantly increased plaque volume, while injection of activated $\mathrm{CD} 4 \mathrm{~L}^{-/} \mathrm{ApoE} \mathrm{E}^{-/-}$platelets prevented this increase. Plaque volumes were comparable to those of the vehicle-treated group (fig. 6.5 a). From these data we can conclude that platelet CD40L, besides the role in atherosclerosis initiation, is also accountable for plaque progression and advanced atherosclerosis. 


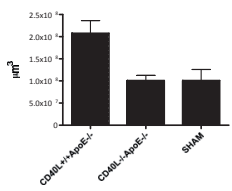
等

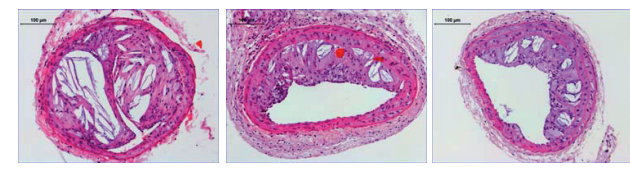

(2)
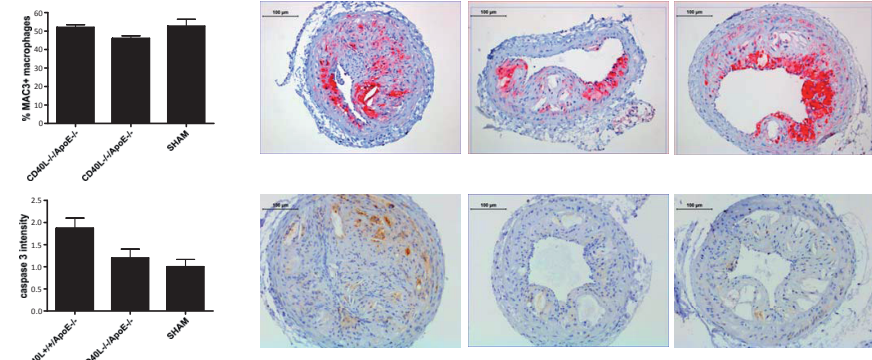

.
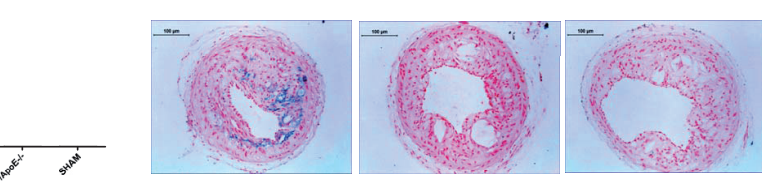

Figure 6.5

Additional role of platelet CD4OL in advanced plaque development. Silastic collars were placed in 14-week old

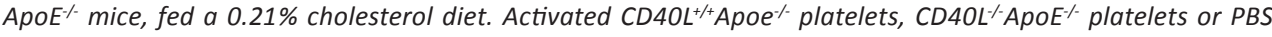
$(n=9)$ were injected once every 5 days during 6 weeks. Plaque volume $\left(\mu m^{3}\right)$ was calculated from the plaque areas measured in 6 slices. (a). Macrophage infiltration: representative staining and are percentage of Mac 3 positive cells of all plaque cells (b). Cleaved caspase-3 was determined by immunodetection and grading from $O$ (not present) to 3 (highly present) (c). Formation of of iron depositions (numbers of positive vessels) was measured by Perl's iron staining. (d). $(n=9, * p<0.05$, scale bars, $100 \mu \mathrm{m})$.

\section{Platelet CD4OL induces plaque macrophage infiltration and intra-plaque hemorrhage}

Extensive analysis of the lesions in the collar-induced atherosclerosis model revealed that the plaques from $\mathrm{ApoE}^{-/}$mice treated with activated $\mathrm{CD} 4 \mathrm{LL}^{-1} \mathrm{ApoE}^{-/}$platelets contained less

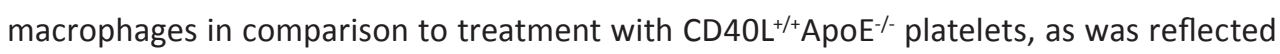
by a decrease in percentages and numbers of $\mathrm{Mac}^{+}$cells (fig. $6.4 \mathrm{~b}$ ). Also the number of macrophages with apoptotic, cleaved caspase-3 was significantly less in mice injected with $\mathrm{CD} 4 \mathrm{LL}^{-1-} \mathrm{ApoE}^{-1-}$ platelets (fig. 6.4 c). The number of $\mathrm{CD}^{+} \mathrm{T}$-cells and $\mathrm{CD}^{2} 5^{+}$leukocytes did not differ between the experimental groups ( $\mathrm{CD3}^{+}$: SHAM $4.0 \pm 0.4 \% ; \mathrm{CD}^{\circ} \mathrm{L}^{+/+} \mathrm{ApoE}^{-/-}$

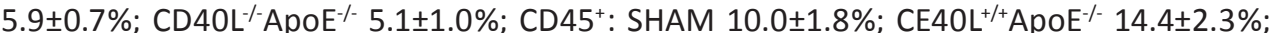
$\left.\mathrm{CD} 40 \mathrm{~L}^{-}-\mathrm{ApoE}^{-}-15.6 \pm 2.3 \%\right)$. Interestingly, no iron depositions and only limited amounts of erythrocyte deposits were found in plaques from $\mathrm{ApoE}^{-/}$mice treated with activated $\mathrm{CD} 4 \mathrm{~L}^{-1-} \mathrm{ApoE}^{-1}$ platelets or vehicle (fig. $6.2 \mathrm{~d}$ ), while these were abundantly present in plaques from mice treated with activated $\mathrm{CD} 4 \mathrm{~L}^{+/+} \mathrm{ApoE}^{-/}$platelets. Collagen content in plaques did not differ between mice injected with platelets, but it was significantly lower than in vehicle-treated mice (SHAM 52.4 $\pm 2.1 \%$; $\mathrm{CD}^{2} \mathrm{~L}^{+/+} \mathrm{ApoE}^{-/-} 43.9 \pm 1.3 \%$; $\mathrm{CD} 40 \mathrm{~L}^{-/} \mathrm{ApoE}^{-/-}$ $44.0 \pm 2.9 \%)$. As reported by others ${ }^{39}$ injection of activated platelets caused an increase in the amount of intimal smooth muscle cells, which was not observed in the $\mathrm{CD} 4 \mathrm{LL}^{-1} \mathrm{ApoE} \mathrm{E}^{-1-}$

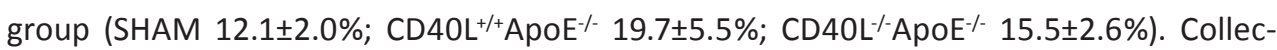
tively, these data indicate that platelet $\mathrm{CD} 40 \mathrm{~L}$ deficiency prevents plaque macrophage infiltration, subsequent macrophage death and intra-plaque hemorrhage induced by activated platelets.

Platelets deficient in CD4OL impede the progression of established atherosclerotic plaques

In a third study, we examined the potential effect of platelet CD40L on established atherosclerotic plaques. Therefore, the intervention by platelet injection was started when ApoE ${ }^{-/}$mice already had plaques (17 weeks old) and treatment was continued for 12 more weeks. To measure plaque growth, we compared lesion size of 29 weeks old $\mathrm{ApoE}^{-/}$ani-

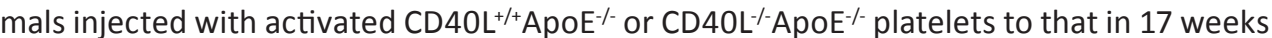
old baseline animals, which had not received platelets (fig 6.6 a). Lesion size in mice injected with activated $\mathrm{CD}_{40 \mathrm{~L}^{++}} \mathrm{ApoE}^{-/-}$platelets was 5 -fold higher than in baseline animals, whereas injection of activated $\mathrm{CD} 4 \mathrm{LL}^{-/-} \mathrm{ApoE}^{-/-}$platelets significantly reduced lesion progression. In the latter case, lesion size was similar to that in animals of the vehicle-treated group. Despite the fact that animals injected with $\mathrm{CD} 4 \mathrm{~L}^{+/+} \mathrm{ApoE}^{-/}$platelets displayed a twofold increase in lesion area compared to animals injected with $\mathrm{CD}^{2} 0 \mathrm{~L}^{-1} \mathrm{ApoE}-$ platelets, no differences in plaque phenotype could be observed. Plama cholesterol levels in all 29week $\mathrm{ApoE}^{-/}$animals were equally high (fig. 6.6 b). The difference in plaque area indicated that platelet $\mathrm{CD} 40 \mathrm{~L}$, besides its importance in plaque initiation, is fundamental in plaque progression. 

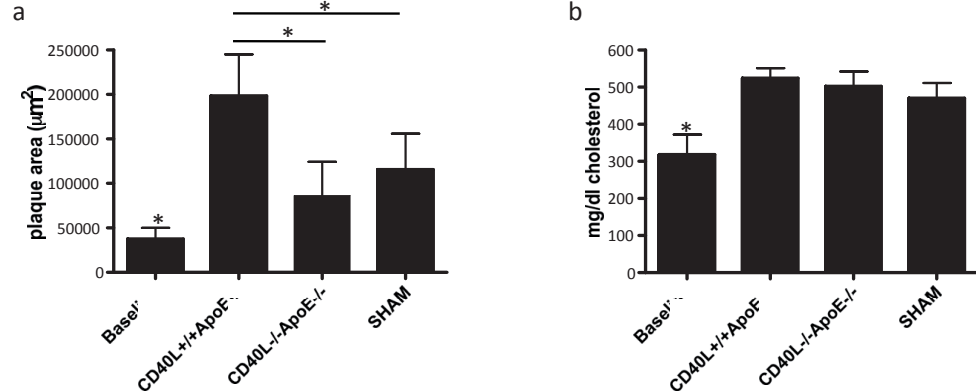

Figure 6.6

Contribution of platelet $C D 40 \mathrm{~L}$ in to development of established plaques. 17-week-old ApoE- mice were inject-

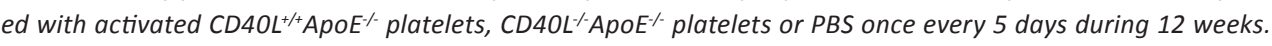
Plaque area $\left(\mu \mathrm{m}^{2}\right)$ was quantified in the aortic arch and main branch points at 29 weeks and compared to the baseline lesion size of 17-week old ApoE- mice (a). Cholesterol levels ( $\mathrm{mg} / \mathrm{dl})$ were determined in mouse plasmas (b). $(n=8, * 0<0.05)$

\section{Discussion}

Our data disclose an important role for platelet $\mathrm{CD} 40 \mathrm{~L}$ in both the initiation and progression of atherosclerosis in mice. Although we noted a key role of platelet $\mathrm{CD} 40 \mathrm{~L}$ in plateletplatelet interactions in thrombus formation and stability, our results particularly point towards a crucial function of this platelet glycoprotein in mediating inflammatory processes in atherogenesis.

Our results add to previous reports that platelets are potent modulators of vascular inflammation. Injection of activated platelets resulted in increased formation of platelet-leukocyte aggregates, leukocyte recruitment into the intima, and aggravated atherosclerosis. Here, we also showed that injection of activated platelets was able to activate the systemic immune system by generating more CD4+ effector T-cells and decreasing the amount of regulatory T-cells. Surprisingly, deficiency of platelet CD40L was able to completely prevent the pro-inflammatory deleterious effects of activated platelets, both systemically and locally in the arterial wall.

Deficiency of platelet CD40L especially seems to effect leukocyte recruitment into the intima, thereby preventing the initiation of atherosclerosis. Platelet induced leukocyte recruitment has been reported to depend on several adhesive protein $\mathrm{s}^{13}$ including Pselectin, ${ }^{22,40}$ von Willebrand factor, ${ }^{41}$ platelet GPIb complex and integrin $\alpha$ llb $\beta 3 .{ }^{21}$ However, in the present study, expression of these adhesive proteins was not altered in CD4OL deficient platelets, suggesting that platelet $\mathrm{CD} 40 \mathrm{~L}$ mediates leukocyte recruitment via alternative pathways.

Platelets are an essential source of chemokines and express numerous chemokine receptors. ${ }^{42}$ Several of these (primarily) platelet chemokines like CXCL4, CCL5 and CXCL7 are well known to affect leukocyte recruitment and atherosclerosis. ${ }^{42-44}$ Both CXCL4 and CCL5 are delivered by activated platelets and induce monocyte arrest in the carotid artery, thereby inducing atherosclerosis. ${ }^{44,45}$ In addition, CXCL4 and CCL5 have been shown to heterodimerize, which enhances monocyte recruitment. ${ }^{43}$ Disruption of this interaction inhibits atherosclerosis in mice. ${ }^{44}$ In the present study, we were able to confirm the increased presence of CCL5 on plaques of Apoe-/- mice that were repeatedly injected with activated platelets. However, repeated injection of $\mathrm{CD} 40 \mathrm{~L}^{+/} \mathrm{ApoE} \mathrm{E}^{-/}$and $\mathrm{CD} 4 \mathrm{~L}^{-/} \mathrm{ApoE} \mathrm{E}^{-/}$platelets both resulted in accumulation of $\mathrm{CCL} 5$ on the plaque, suggesting that this phenomenon is independent of CD40L. Moreover, we could not detect any changes in serum levels of CCL5 nor IL1 $\beta$ in animals injected with CD40L deficient platelets.

The only chemokine found to be regulated by platelet CD40L was CCL2, a chemokine involved in attracting monocytes. ${ }^{46} \mathrm{CCL} 2$ is known to play an important role in atherosclerosis. It is not only a key factor in the initiation of atherosclerosis, by guiding monocytes 
into the intima, but it also continues these actions when plaques are established, and even contributes to atherosclerotic plaque rupture. In a previous study, we found inhibition of CCL2 resulted in plaques that were smaller, contained less macrophages, T-lymphocytes, iron depositions, and had a stable, fibrotic appearance ${ }^{47}$ Here, we observed a similar plaque phenotype. Upon repeated injection of activated $\mathrm{CD} 4 \mathrm{LL}^{-1} \mathrm{Apo}-1-$ platelets, we note a delayed plaque initiation by hampered monocyte recruitment, and once plaques had developed, a reduced content of macrophages, apoptotic cells and absence of intra-plaque hemorrhages.

Besides leukocyte recruitment, we found that CD40-CD40L interactions were involved in the formation of pro-inflammatory platelet-leukocyte aggregates. PLAs are known to form when platelet P-selectin interacts with leukocyte PSGL. ${ }^{22,26}$ Until now, only few molecules are known that affect PLA-formation, and consequently prevent their pro-inflammatory actions. One of these molecules is growth arrest specific gene 6 (Gas6), which prevents PLA formation by down-regulating P-selectin expression on platelets. ${ }^{48}$ Interestingly it has also been reported that administration of $\mathrm{SCD} 40 \mathrm{~L}$ increased platelet P-selectin expression, and consequently PLA formation in human and murine platelets. ${ }^{49,50}$ However, here, deficiency in platelet CD40L did not affect platelet P-selectin levels, but did affect PLA formation, which was dependent on CD40 expression on leukocytes, suggesting that CD40LCD40 interactions play a P-selectin independent role in the formation of PLAs.

Compared to complete deficiency in $\mathrm{CD} 40 \mathrm{~L}$ ( $\mathrm{CD} 4 \mathrm{OL}^{-/} \mathrm{ApoE}^{--}$mice), ${ }^{6}$ the effects of deficiency of platelet CD40L alone on atherosclerosis are slightly less spectacular. Deficiency of platelet $\mathrm{CD} 40 \mathrm{~L}$ alone is able to attenuate atherosclerosis progression, and to induce a plaque phenotype that is low in inflammation and protects against intra-plaque hemorrhages, but fails to induce true fibrotic plaques. This may be due to the fact that activated platelets might impede the synthesis of collagen in the plaque and induce the proliferation and migration of SMCs..$^{39}$ Effects that are apparently not regulated by CD40L. However, the inhibition of platelet CD4OL does not result in immune-suppression and does not cause hemorrhage or bleeding in our study, thereby favoring the use of platelet CD4OL inhibition as target in the treatment of atherosclerosis.

We conclude that platelet $\mathrm{CD} 40 \mathrm{~L}$ is a potent inducer of inflammation via cell-cell contact between platelets, leukocytes and endothelial cells, thereby mediating atherosclerosis initiation and progression. Inhibition of platelet CD40L provides an interesting therapeutic target for the treatment of atherosclerosis. However, caution is warranted as inhibition of platelet CD40L may affect thrombus stability.
Supplementary figure legends

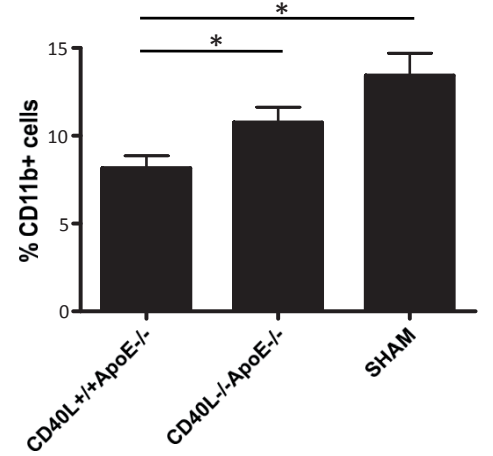

Supplementary figure 6.1

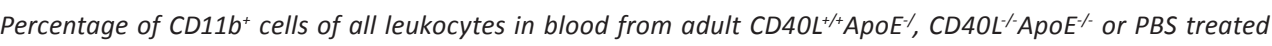
(SHAM) mice. $(n=8, * 0<0.05)$.
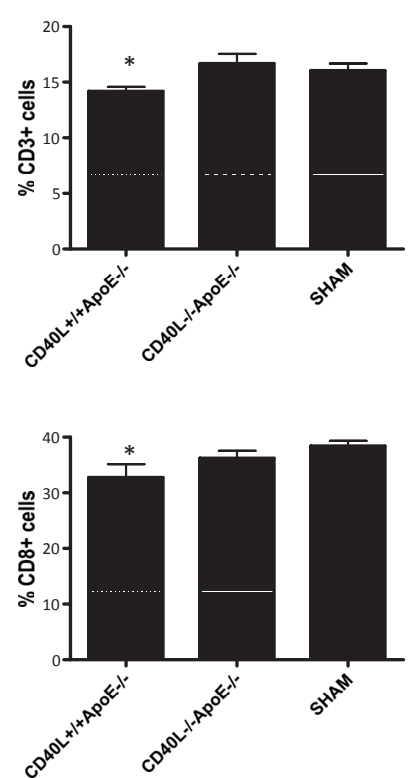
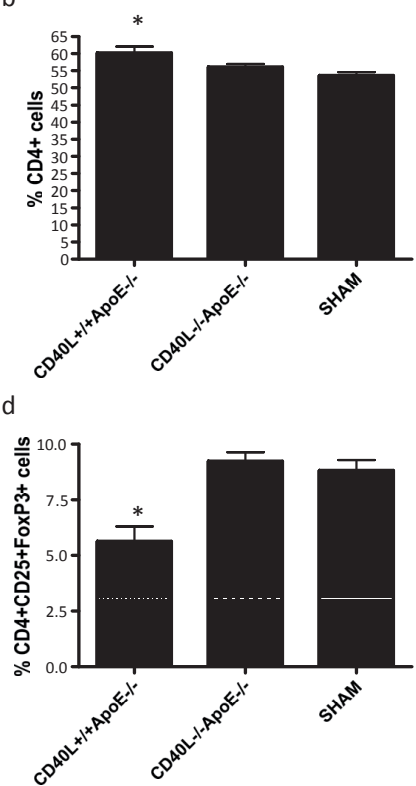

Supplementary Figure 6.2

Flow cytometric analysis of $\mathrm{T}$-cell distribution in blood from adult ApOE $\%$ mice treated with $\mathrm{CD}^{2} \mathrm{OL} \mathrm{L}^{+/} \mathrm{APOE} \%, \mathrm{CD} 4 \mathrm{OL}$ ${ }^{\prime}$ ApoE $\%$ or platelets or SHAM buffer. Percentage of $\mathrm{CD}^{+}{ }^{+} \mathrm{T}$-cells (relative to all leukocytes) decreased after platelet treatment (a). Further, changes in percentages of $C D 3^{+} C D 4^{+} T$-cells $(b), C D 3^{+} C D 8^{+} T$-cells $(c)$, and $C D 4^{+} C D 25^{+}$Fox $P 3^{+}$ regulatory $T$-cells $(d)$. 


\section{References}

1. Schonbeck U, Libby P. CD40 signaling and plaque instability. Circ Res. 2001;89:1092-1103.

2. Schonbeck U, Libby P. The CD40/CD154 receptor/ligand dyad. Cell Mol Life Sci. 2001;58:4-43.

3. Weber C, Zernecke A, Libby P. The multifaceted contributions of leukocyte subsets to atherosclerosis: lessons from mouse models. Nat Rev Immunol. 2008;8:802-815.

4. Galkina E, Ley K. Immune and inflammatory mechanisms of atherosclerosis. Annu Rev Immunol. 2009;27:165-197.

5. Mach F, Schonbeck U, Sukhova GK, Atkinson E, Libby P. Reduction of atherosclerosis in mice by inhibition of CD40 signalling. Nature. 1998;394:200-203.

6. Lutgens E, Gorelik L, Daemen MJ, et al. Requirement for CD154 in the progression of atherosclerosis. Nat Med. 1999;5:1313-1316.

7. Lutgens E, Cleutjens KB, Heeneman S, Koteliansky VE, Burkly LC, Daemen MJ. Both early and delayed antiCD40L antibody treatment induces a stable plaque phenotype. Proc Natl Acad Sci U S A. 2000;97:74647469

8. Schonbeck U, Sukhova GK, Shimizu K, Mach F, Libby P. Inhibition of CD40 signaling limits evolution of established atherosclerosis in mice. PNAS. 2000;97:7458-7463.

9. Lutgens E, Daemen MJ. CD40-CD40L interactions in atherosclerosis. Trends Cardiovasc Med. 2002;12:27-

10. Henn V, Slupsky JR, Grafe M, et al. CD40 ligand on activated platelets triggers an inflammatory reaction of endothelial cells. Nature. 1998;391:591.

11. Andre P, Prasad KS, Denis CV, et al. CD40L stabilizes arterial thrombi by a beta3 integrin-dependent mechanism. Nat Med. 2002;8:247-252.

12. Andre P, Nannizzi-Alaimo L, Prasad SK, Phillips DR. Platelet-Derived CD40L: The Switch-Hitting Player of Cardiovascular Disease. Circulation. 2002;106:896-899.

13. von Hundelshausen $P$, Weber $C$. Platelets as immune cells: bridging inflammation and cardiovascular disease. Circ Res. 2007;100:27-40.

14. Gawaz M, Langer H, May AE. Platelets in inflammation and atherogenesis. J Clin Invest. 2005;115:33783384.

15. May AE, Seizer P, Gawaz M. Platelets: inflammatory firebugs of vascular walls. Arterioscler Thromb Vasc Biol. 2008;28:55-10.

16. Langer $\mathrm{HF}$, Gawaz M. Platelet-vessel wall interactions in atherosclerotic disease. Thromb Haemost. 2008;99:480-486.

17. Hawrylowicz $\mathrm{CM}$, Howells $\mathrm{GL}$, Feldmann M. Platelet-derived interleukin 1 induces human endothelial adhesion molecule expression and cytokine production. J Exp Med. 1991;174:785-790.

18. Miller DL, Yaron R, Yellin MJ. CD40L-CD40 interactions regulate endothelial cell surface tissue factor and thrombomodulin expression. J Leukoc Biol. 1998;63:373-379.

19. Kotowicz K, Dixon GL, Klein NJ, Peters MJ, Callard RE. Biological function of CD40 on human endothelial cells: costimulation with CD40 ligand and interleukin-4 selectively induces expression of vascular cell adhesion molecule-1 and P-selectin resulting in preferential adhesion of lymphocytes. Immunology. 2000;100:441-448.

20. von Hundelshausen $\mathrm{P}$, Weber KS, Huo $\mathrm{Y}$, et al. RANTES deposition by platelets triggers monocyte arrest on inflamed and atherosclerotic endothelium. Circulation. 2001;103:1772-1777.
21. Massberg S, Brand K, Gruner S, et al. A critical role of platelet adhesion in the initiation of atherosclerotic lesion formation. J Exp Med. 2002;196:887-896.

22. Huo $\mathrm{Y}$, Schober A, Forlow $\mathrm{SB}$, et al. Circulating activated platelets exacerbate atherosclerosis in mice deficient in apolipoprotein E. Nat Med. 2003;9:61.

23. Weber C. Platelets and chemokines in atherosclerosis: partners in crime. Circ Res. 2005;96:612-616.

24. da Costa Martins P, van den Berk N, Ulfman LH, Koenderman L, Hordijk PL, Zwaginga J. Platelet-monocyte complexes support monocyte adhesion to endothelium by enhancing secondary tethering and cluster formation. Arterioscler Thromb Vasc Biol. 2004;24:193-199.

25. Rinder HM, Bonan JL, Rinder CS, Ault KA, Smith BR. Dynamics of leukocyte-platelet adhesion in whole blood. Blood. 1991;78:1730-1737.

26. van Gils JM, da Costa Martins PA, Mol A, Hordijk PL, Zwaginga JJ. Transendothelial migration drives dissociation of platelet monocyte complexes. Thromb Haemost. 2008;100:271-279.

27. van Gils JM, Zwaginga JJ, Hordijk PL. Molecular and functional interactions among monocytes, platelets, and endothelial cells and their relevance for cardiovascular diseases. J Leukoc Biol. 2009;85:195-204.

28. Lippi G, Montagnana M, Salvagno GL, et al. Risk stratification of patients with acute myocardial infarction by quantification of circulating monocyte-platelet aggregates. Int J Cardiol. 2007;115:101-102.

29. Furman $\mathrm{MI}$, Barnard $\mathrm{MR}$, Krueger $\mathrm{LA}$, et al. Circulating monocyte-platelet aggregates are an early marker of acute myocardial infarction. J Am Coll Cardiol. 2001;38:1002-1006.

30. Crittenden JR, Bergmeier $W$, Zhang $\mathrm{Y}$, et al. CalDAG-GEFI integrates signaling for platelet aggregation and thrombus formation. Nat Med. 2004;10:982-986.

31. Kuijpers MJ, Schulte V, Bergmeier W, et al. Complementary roles of glycoprotein VI and alpha2beta 1 integrin in collagen-induced thrombus formation in flowing whole blood ex vivo. FASEB J. 2003;17:685-687.

32. Munnix IC, Strehl A, Kuijpers MJ, et al. The glycoprotein VI-phospholipase Cgamma2 signaling pathway controls thrombus formation induced by collagen and tissue factor in vitro and in vivo. Arterioscler Thromb Vasc Biol. 2005;25:2673-2678.

33. Heemskerk JW, Vuist WM, Feijge MA, Reutelingsperger CP, Lindhout T. Collagen but not fibrinogen surfaces induce bleb formation, exposure of phosphatidylserine, and procoagulant activity of adherent platelets: evidence for regulation by protein tyrosine kinase-dependent Ca2+ responses. Blood. 1997;90:26152625.

34. Zernecke A, Liehn EA, Fraemohs L, et al. Importance of junctional adhesion molecule-A for neointimal lesion formation and infiltration in atherosclerosis-prone mice. Arterioscler Thromb Vasc Biol. 2006;26:e10-

35. Bernhagen J, Krohn R, Lue H, et al. MIF is a noncognate ligand of CXC chemokine receptors in inflammatory and atherogenic cell recruitment. Nat Med. 2007;13:587-596.

36. von der Thusen JH, van Berkel TJC, Biessen EAL. Induction of rapid atherogenesis by perivascular carotid collar placement in apolipoprotein E-deficient and low-density lipoprotein receptor-deficient mice. Circulation. 2001;103:1164-1170

37. Virmani R, Kolodgie FD, Burke AP, Farb A, Schwartz SM. Lessons from sudden coronary death: a comprehensive morphological classification scheme for atherosclerotic lesions. Arterioscler Thromb Vasc Biol. 2000;20:1262-1275.

38. Furman MI, Benoit SE, Barnard MR, et al. Increased platelet reactivity and circulating monocyte-platelet aggregates in patients with stable coronary artery disease. J Am Coll Cardiol. 1998;31:352-358.

39. Massberg S, Vogt F, Dickfeld T, Brand K, Page S, Gawaz M. Activated platelets trigger an inflammatory response and enhance migration of aortic smooth muscle cells. Thromb Res. 2003;110:187-194. 
40. Huo Y, Ley KF. Role of Platelets in the Development of Atherosclerosis. Trends in Cardiovascular Medicine. 2004;14:18.

41. Theilmeier G, Michiels C, Spaepen E, et al. Endothelial von Willebrand factor recruits platelets to atherosclerosis-prone sites in response to hypercholesterolemia. Blood. 2002;99:4486-4493.

42. Gleissner CA, von Hundelshausen P, Ley K. Platelet chemokines in vascular disease. Arterioscler Thromb Vasc Biol. 2008;28:1920-1927.

43. von Hundelshausen $P$, Koenen RR, Sack $M$, et al. Heterophilic interactions of platelet factor 4 and RANTES promote monocyte arrest on endothelium. Blood. 2005;105:924-930.

44. Koenen RR, von Hundelshausen P, Nesmelova IV, et al. Disrupting functional interactions between platelet chemokines inhibits atherosclerosis in hyperlipidemic mice. Nat Med. 2009;15:97-103.

45. von Hundelshausen $\mathrm{P}$, Weber KSC, Huo $\mathrm{Y}$, et al. RANTES peposition by platelets triggers monocyte arrest on inflamed and atherosclerotic endothelium. Circulation. 2001;103:1772-1777.

46. Zernecke A, Shagdarsuren E, Weber C. Chemokines in Atherosclerosis. An Update. Arterioscler Thromb Vasc Biol. 2008.

47. Lutgens $E$, Faber $B$, Schapira $K$, et al. Gene profiling in atherosclerosis reveals a key role for small inducible cytokines: validation using a novel monocyte chemoattractant protein monoclonal antibody. Circulation. 2005;111:3443-3452.

48. Tjwa $M$, Bellido-Martin L, Lin $Y$, et al. Gas6 promotes inflammation by enhancing interactions between endothelial cells, platelets, and leukocytes. Blood. 2008;111:4096-4105.

49. Chakrabarti S, Varghese S, Vitseva O, Tanriverdi K, Freedman JE. CD40 ligand influences platelet release of reactive oxygen intermediates. Arterioscler Thromb Vasc Biol. 2005;25:2428-2434.

50. Li G, Sanders JM, Bevard MH, et al. CD40 ligand promotes Mac-1 expression, leukocyte recruitment, and neointima formation after vascular injury. Am J Pathol. 2008;172:1141-1152. 
THE CD40-TRAF6 AXIS IS THE KEY

REGULATOR OF THE CD40-CD40L SYSTEM IN NEOINTIMA FORMATION AND ARTERIAL REMODELING 


\section{Abstract}

We investigated the role of $\mathrm{CD} 40$ and $\mathrm{CD} 40 \mathrm{~L}$ in neointima formation and vascular remodeling and identified the downstream CD40-signaling intermediates (TNF-receptor associated factors (TRAF)) involved.

Neointima formation was induced in wild type, $\mathrm{CD}_{40} \%, \mathrm{CD}_{40 \mathrm{~L}} \%$ and in $\mathrm{CD} 40^{-}$mice that contained a CD40 transgene with or without mutations at the CD40-TRAF2,3\&5, TRAF6 or TRAF2,3,5\&6 binding sites. Compared to wild type mice, CD40\% mice showed a significant decrease in neointima formation $(87 \%, p=0.001)$ with increased collagen deposition $(50 \%, p=0.016)$ and decreased inflammatory cell infiltration $(95 \%, p<0.001)$. Ligated carotid arteries of $\mathrm{CD} 40 \%$ mice showed a smaller total vessel volume $(49 \%, \mathrm{p}=0.001)$ and decreased gelatinolytic/collagenolytic activity (16\%), due to reduced levels of MMP-2 and -9 , indicating an impaired remodeling capacity. Comparable results were found in mice with defects in CD40-TRAF6 and CD40-TRAF 2/3/5\&6 binding, but not in mice with defects in CD40-TRAF2/3\&5 binding. Neointima formation was also impaired in wild type mice reconstituted with $\mathrm{CD} 40 \%$ bone marrow.

Neointima formation and vascular remodeling in CD40-receptor deficient mice is impaired, due to a decreased inflammatory cell infiltration and matrix-degrading protease activity, with CD40-TRAF6 signaling as the key regulator. This identifies the CD40-TRAF6 axis as a potential therapeutic target in vascular disease.

\section{Introduction}

The CD40-CD40L system is an important pathway in immune responses that has been implicated in several inflammatory diseases, such as rheumatoid arthritis, transplant rejection, multiple sclerosis ${ }^{1-2}$ and atherosclerosis. ${ }^{3-5}$

CD40 is a receptor of the TNF-receptor superfamily that by itself has no intrinsic signaling ability. Binding of its ligand (CD4OL) induces receptor trimerization and recruitment of adaptor proteins called TNF-Receptor Associated Factors (TRAFs), upon which CD40 signaling is elicited. This results in the production of pro-inflammatory and pro-atherogenic cytokines/chemokines, growth factors (e.g. VEGF), matrix metalloproteinases (MMPs), and adhesion molecules. ${ }^{6}$

The cytoplasmic tail of CD40 contains two independent TRAF-binding domains: a membrane proximal region binding TRAF6 and a distinct membrane distal domain that binds TRAF2\& 3 and indirectly TRAF5. Interestingly, as in other TNF-R members, both TRAF binding sites can initiate different CD40 downstream mediators and effectors. For example, in monocytes and macrophages, CD40-TRAF6 interactions result in activation of SrC/ERK1/2 and IKK/NFKB pro-inflammatory pathways, ${ }^{8}$ while in endothelial cells and smooth muscle cells, inflammation is predominantly mediated via CD40-TRAF2 interactions. ${ }^{9}$ This was also confirmed in a recent study, in which the different CD40-TRAF interactions differentially modulate chemokine and cytokine expression. ${ }^{10}$

Although a pivotal role of $\mathrm{CD} 40 \mathrm{~L}$ in atherosclerotic plaque development, progression and stability has been proven extensively, ${ }^{3-5}$ the role of CD40-CD40L interactions in neointima formation, the process associated with luminal narrowing causing major complications after arterial intervention (e.g. balloon angioplasty and stenting) in humans, have shown contradictory results. ${ }^{11-13}$ Moreover, the involvement of downstream CD40 adaptor molecules (TRAFs) in vascular pathology has not been fully elucidated so far.

The aim of this study was to investigate the role of CD40 and CD40L in neointima formation and vascular remodeling using a mouse model of carotid artery ligation ${ }^{14}$ and to identify which TRAF members are involved in these processes. Since TRAFs are also involved in signaling of other TNF-receptor family members (e.g. Toll-like receptors), we used transgenic mice with mutations in the specific TRAF-binding domains of CD40. These mice contain intact, functional TRAFs, but lack the binding of specific TRAFs to CD40, thereby disrupting CD40 signaling, without affecting signaling of other TRAF-dependent receptors. This study demonstrates that the $\mathrm{CD} 40 / \mathrm{CD} 40 \mathrm{~L}$ system is a major pathway required for neointima formation and arterial remodeling that is mainly mediated by signaling through TRAF6. 


\section{Materials and methods}

\section{Animals and surgery}

In total, 314 male wild type C57BL6/J mice $(\mathrm{wt}), \mathrm{CD} 40 \%$ mice, $\mathrm{CD}^{\circ} \mathrm{L}^{-}$- mice were fed a normal chow throughout the experiment (12-14 weeks of age, $n=7-14$ per group for histology and blood pressure measurements; $n=24-35$ per group for real time PCR, zymography and gelatinase/collagenase assays, FACS analysis and platelet assays). To identify the TRAFs required for $\mathrm{CD} 40$ signaling in neointima formation, we used $\mathrm{CD} 40 \%$ mice that express a human/mouse chimeric CD40 transgene (mouse CD40 extracellular domain; human CD40 transmembrane and cytoplasmic domain) under a major histocompatability complex (MHC)II promoter, containing mutations at the TRAF2,3\&5 (CD40-T2/3/5), TRAF6 (CD40T6) or both the TRAF2/3/5 and TRAF6 (CD40-T2/3/5\&6) binding site on CD40 or CD40 $\%$ mice containing the human CD40 construct without any mutations at the TRAF binding sites of CD40 (CD40-T-wt) ${ }^{15}$ (suppl. fig. 7.1). Mice were anesthetized with $2.5 \%$ isoflurane and the right common carotid artery was ligated with a silk suture (5-0) near the carotid bifurcation to induce neointima formation as described by Kumar et al. ${ }^{14}$ Experiments were approved by the animal ethics committee of the Maastricht University and performed according to the institutional guidelines.

\section{Bone marrow transplantation}

Female C57BI6/J mice ( $n=30$ ) (age 9 wks old) were maintained in filtertop cages and given water containing polymyxin B sulphate $(60.000 \mathrm{U} / \mathrm{l})$ and neomycin $(100 \mathrm{mg} / \mathrm{l})$ starting 1 week before bone marrow transplantation until 4 wks thereafter. Mice were lethally irradiated (10Gy, 0.5 Gy/min, Philips MU15F/225 kV, Hamburg, Germany) and intravenously injected with $10^{7}$ bone marrow cells from male $\mathrm{CD} 40^{-1}$ mice or $\mathrm{C} 57 \mathrm{BI} / \mathrm{J}$ mice.

Four weeks after the transplantation, the right carotid artery was ligated as described above.

\section{Tissue harvesting and histological analysis}

Four weeks after carotid artery ligation, mice were sacrificed and the arterial tree was perfused through a catheter inserted in the left cardiac ventricle with PBS containing $0.1 \mathrm{mg} /$ $\mathrm{ml}$ sodium nitroprusside (Sigma) and subsequently with $1 \%$ paraformaldehyde. The carotid arteries were removed, fixed overnight in $1 \%$ paraformaldehyde and embedded in paraffin. Cross-sections ( $4 \mu \mathrm{m}$ thick) were cut at $200 \mu \mathrm{m}$ or $100 \mu \mathrm{m}$ (bone marrow transplantation) intervals throughout the common carotid artery. For each level, a cross-section was stained with Elastica-von-Giesson staining (EvG) and hematoxylin and eosin (HE). EvG- stained cross-sections were used for morphometric analysis of the lumen area, intimal area (the area within the internal elastic lamina (IEL) minus the lumen area), medial area (defined as the area within the external elastic lamina (EEL) minus the area within the IEL) and total vessel area (area encompassed by the EEL). Intima volumes were determined by multiplying intimal areas with the distance over the levels neointimas were present. Luminal and total vessel volumes were determined by multiplying lumen and total vessel areas with the distance over 8 levels.

Sections were stained with anti-CD45 (1: 50, Pharmingen) for analysis of inflammatory cell infiltration, anti-CD3 (1: 50, Lab Vision Corporation) specifically for T cells, anti-mac3 (1: 50, Pharmingen) for macrophages, anti-CD31 (1: 100, cell signaling) for endothelial cells, picrosirius red for collagen or with anti- $\alpha$-smooth muscle actin (ASMA)-fluorescein-isothiocyanate (FITC) conjugated antibody (1: 3000, Sigma Diagnostics) and anti-FITC-horse radish peroxidase as secondary antibody for staining of SMCs/myofibroblasts. For apoptosis and cell proliferation, sections were stained with anti-cleaved caspase-3 (1: 200, Cell Signaling) and ki-67 (1: 50, Dako), respectively. TGF $\beta$ was stained using LAP TGF $\beta 1$ antibody (1: 30, R\&D Systems). Double staining with MMP-2 (Santa Cruz, 1: 50) or -9 (Santa Cruz, 1: 50) and Mac3 was performed according to standard procedures. The expression of the different TRAFs in vessel wall was determined by immunohistochemistry with TRAF2 (1: 50, Santa Cruz), TRAF3 (1: 50, Santa Cruz) and TRAF6 (1: 50 Santa Cruz) antibodies. For MHC-II immunostaining, cryosections were stained with rat anti-mouse MHC-II (1: 400, Abcam). Morphometric and morphological analysis were performed by one blinded investigator (intra-observer variability was $<10 \%$ ).

\section{Blood pressure measurement}

A polyethylene catheter (PE 20 heat-stretched) was implanted in the femoral artery under isofluorane anesthesia (1.5-2.5\%) at constant temperature and its tip was advanced into the abdominal aorta. Blood pressure measurements were performed as described in Janssen et al. ${ }^{16}$ Beat-to-beat values of mean arterial pressure were calculated as the area under the curve of each pressure wave using the end diastolic value to determine the heart rate. Data were recorded and averaged over a 10 minute period 15-30 minutes after completion of the surgery when hemodynamics were stabilized.

\section{Fluorescence-activated cell sorting (FACS)-analysis}

Blood, spleen and lymph nodes of wt, CD40\%, CD40-Twt and CD40-T6 mice ( $\mathrm{n}=6 /$ group) were collected, processed and stained with fluorescent antibodies against CD3 (for T-cells), CD4 (T-helper cells), CD25 (activated T-cells), CD69 (activated T-cells), B220 (B-cells), Gr1 (granulocytes) and Mac1 (macrophages), and analyzed as described previously. ${ }^{17}$ 


\section{Thrombus formation on collagen under flow}

Thrombus formation was measured ex vivo with blood from wt, CD40\%, CD40-Twt or CD40-T6 mice. Blood was collected in PPACK/heparin and perfused over a type-I collagen coated coverslip at a shear rate of $1000 \mathrm{~s}^{-1}$ for $4 \mathrm{~min}$ as described previously. ${ }^{18}$

\section{Gelatinase/collagenase assay}

Two pools of 6 carotid arteries of CD40 $\%$ and wt mice, respectively, were harvested one week after ligation and snap frozen in liquid nitrogen. Proteins were extracted using a lysis buffer containing $1 \%$ Triton X-100, $0.1 \%$ Sodium Dodecyl Sulphate, $0.5 \%$ Sodium Deoxycholate and $0.2 \%$ Sodium Azide in a phosphate-buffered saline solution (PBS). Gelatinolytic/collagenolytic activity in ligated carotid arteries was determined using the EnzChek gelatinase/collagenase assay kit (Molecular Probes). Equal concentrations of the protein extracts were used to digest a gelatin substrate, yielding highly fluorescent digestion products proportionally to gelatinase and collagenase activity in the ligated carotid arteries. Fluorescence was measured at 24, 48 and 72 hrs using a fluorescence microplate reader at $515 \mathrm{~nm}$ emission wavelength and protease activity was calculated using a standard curve of Clostridium histolyticum type IV collagenase (according to the manufacturer's protocol).

\section{Gelatin zymography}

MMP-2 and MMP-9 activity was determined in carotid arteries of wt, CD40 $\%$, CD40-Twt, CD40-T2/3/5 and CD40-T6 1 week after ligation. Tissue samples were extracted in 150 $\mu$ I SDS-lysis (10\% glycerol, $20 \%$ SDS, $10 \% 1.5 \mathrm{M}$ Tris $\mathrm{pH}$ 6.8) buffer by cutting the tissue into small pieces. MMP-2 and MMP-9 activity in extracts were detected as previously described. ${ }^{19}$ Briefly, $4 \mu$ l of tissue extracts was diluted (1:5) with distilled water. Samples were electrophoresed in the presence of non-reducing buffer at $4^{\circ} \mathrm{C}$ in $7.5 \%$ SDS-polyacrylamide gels containing $2 \mathrm{mg} / \mathrm{mL}$ gelatin. After the removal of SDS, gelatinase activity was revealed by overnight incubation at $37^{\circ} \mathrm{C}$ and staining with $0.1 \%$ Coomassie brilliant blue. Zymograms were quantified in the linear range by densitometry with Quantity One 1-D Image Analysis software system (Bio-Rad).

\section{Real-time PCR}

RNA was isolated from mouse carotid arteries 1 week after ligation (pools of 3-4 carotids) using the bead-beater and RNeasy kit (Qiagen). One $\mu \mathrm{g}$ of total RNA was used as a template to generate cDNA using random primers. Real-time PCR reactions (MyiQ Icycler, Biorad) were carried out with CDNA (10 ng RNA template), IQ tm SYBR ${ }^{\circledR}$ Green super mix (Biorad) and $3 \mathrm{mM}$ of forward and reverse primers for MMP-2, MMP-9, MMP-13, MMP-14, TIMP-2 and TIMP-3. PCR conditions were: $3 \mathrm{~min}$ at $95^{\circ} \mathrm{C}$ and 40 cycles of $10 \mathrm{sec}$ at $95^{\circ} \mathrm{C}$ and $45 \mathrm{sec}$ at $60^{\circ} \mathrm{C}, 1 \mathrm{~min} 95^{\circ} \mathrm{C}$. Samples were run in duplicate. RNA copy numbers were calculated using a standard curve and normalized to housekeeping gene (cyclophilin A) mRNA expression.

\section{Statistical analysis}

Values are expressed as mean \pm SEM and a Mann-Whitney non-parametrical test was used to compare individual groups of animals. Probability values of $<0.05$ were considered significant.

\section{Results}

\section{CD40-CD40L signaling is required for neointima formation and vascular remodeling}

In response to ligation, neointimal lesions developed in the common carotid artery up to $2 \mathrm{~mm}$ from the point of ligation. In these neointimal lesions, we found expression of TRAF2, TRAF3 and TRAF6 (suppl. fig. 7.2). For all TRAFs, staining was most prominent in the neointima, while TRAF staining was only modest in the media (M). The first 9 cross-sections (with intervals of $200 \mu \mathrm{m}$ ) were used for analysis. Figures 7.1 a-c show representative cross-sections of the ligated common carotid artery with a neointimal lesion of $\mathrm{wt}, \mathrm{CD} 40^{\%}$, $\mathrm{CD} 4 \mathrm{~L}^{-}$mice. We calculated the mean neointimal area and intima/media ratios for each individual level, as well as the mean neointimal volumes. Compared to wt mice, neointima formation and intima/media ratios throughout the ligated carotid artery (fig. $7.1 \mathrm{~d}$ and fig. $7.1 \mathrm{~h}$ ) were considerably reduced in $\mathrm{CD} 40^{-/}$mice, resulting in a significantly reduced neointimal volume (fig. 7.1 e). In $\mathrm{CD} \mathrm{OL}^{-/-}$mice, neointimal volume was reduced, although not significantly (fig. 7.1 e and fig. $7.1 \mathrm{~h}$ ). Lumen area and total vessel area of $\mathrm{CD} 40^{-\%}$ mice and total vessel area of $\mathrm{CD}_{40 \mathrm{~L}^{-}-}$mice were significantly smaller than observed in wt mice (fig. $7.1 \mathrm{f}$-g), suggesting an impaired remodeling capacity of ligated arteries of CD40 and CD40L-deficient mice. The percentage of maximal stenosis was reduced in both CD40 and CD40L deficient mice (fig. 7.1 i). 
A

Wt
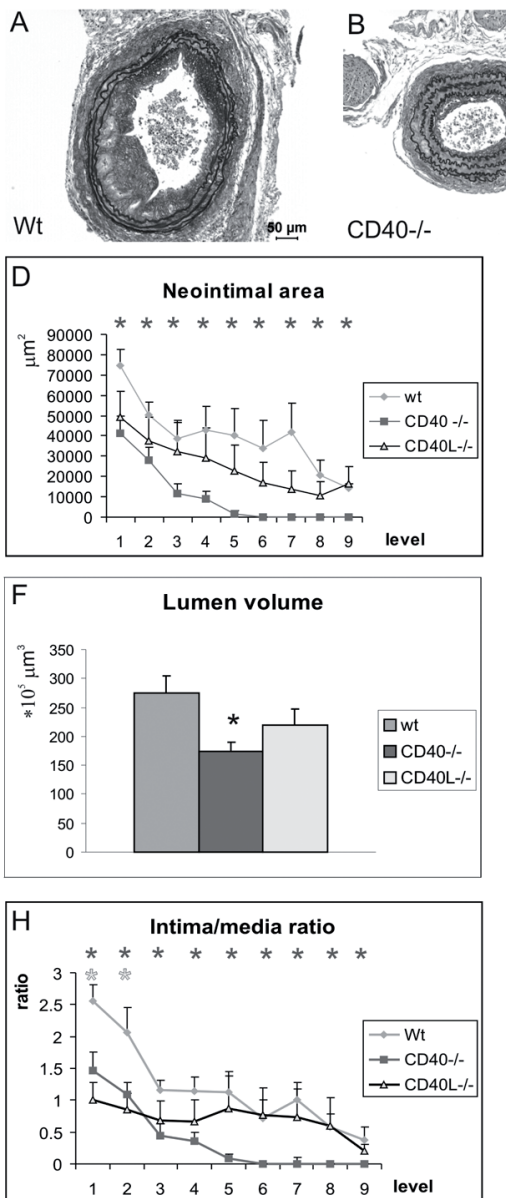

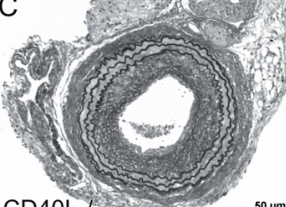

som
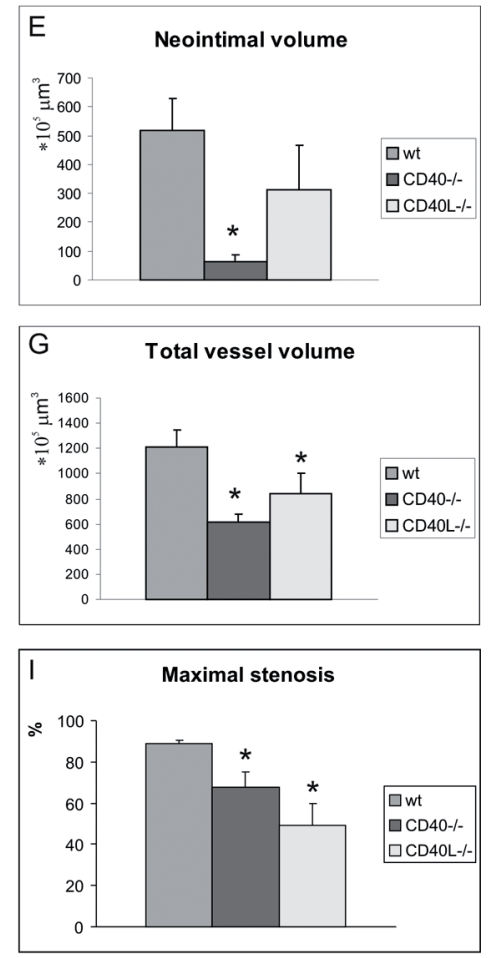

Figure 7.1

Neointima formation and vascular remodeling in wt, $\mathrm{CD} 40 \%$ and $\mathrm{CD} 40 \mathrm{OL} \%$ mice. Representative cross-sections are shown in panels $\boldsymbol{a}-c ; n=10,11$ and 10 mice, respectively. Neointima was measured at individual levels (200 $\mathrm{\mu m}$ intervals) throughout the ligated carotid artery segment (d) and neointimal volume was calculated (e). Furthermore, volumes of lumen (f) and total vessel wall (g) were calculated, as well as intima/media ratios (h) and the maximal stenosis rate (I).* $p<0.05$ compared to wt mice. Neointima formation in $\mathrm{CD} 40 \%$ mice was significantly reduced compared to wt mice at all individual levels analyzed throughout the ligated carotid artery.

This could not be explained by differences in hemodynamics, since no differences in blood pressure, heart rate, heart weight, body weight, and heart weight/body weight ratio were found between $\mathrm{CD} 40^{\%}$ mice and controls (table 7.1). In the contralateral left, non-ligated carotid artery no differences in vessel geometry were found between wt, $\mathrm{CD} 40^{-\%}$ or

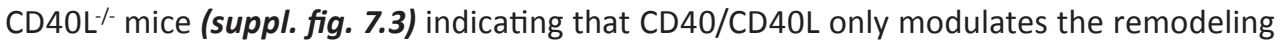
response induced by a considerable change in blood flow and the development of neointi-

ma after arterial ligation. No differences in baseline geometry or medial SMC content (as an indication of contractile capacity) of the right carotid artery were found between wt and $\mathrm{CD} 40^{-/}$mice (suppl. fig. 7.4).

Table 7.1

\begin{tabular}{lll}
\hline & Wt & CD40 $\%$ \\
\hline MAP (mmHg) & $87.3 \pm 2.0$ & $84.5 \pm 3.4$ \\
\hline HR/min & $539.2 \pm 35.3$ & $516.5 \pm 20.1$ \\
\hline Body weight (g) & $26.5 \pm 0.76$ & $26.2 \pm 0.87$ \\
\hline Heart weight (g) & $0.15 \pm 0.01$ & $0.15 \pm 0.01$ \\
\hline Heart weight/body weight *10-3 & $5.8 \pm 0.3$ & $5.6 \pm 0.2$ \\
\hline
\end{tabular}

Hemodynamic parameters of $\mathrm{CD} 40 \%$ mice compared to wildtype controls. MAP: Mean Arterial Pressure, HR: Heart Rate.

Neointima formation and vascular remodeling is mediated by CD40-signaling through TRAF6

CD40 cannot initiate signal transduction by itself and CD40-signaling depends on the recruitment of TRAF-adaptor proteins. To determine which CD40-TRAF interactions are required for the development of neointima and remodeling of the arterial wall, we used $\mathrm{CD} 40 \%$ mice that express a chimeric human/mouse CD40 transgene, under a MHC-II promoter, which contains mutations in the cytoplasmic tail of CD40, that selectively disrupt the binding of specific TRAFs to CD40 (suppl. fig. 7.1 a). MHC-II (and therefore also the CD40 transgene) was found to be expressed in the neointimal lesions (suppl. fig. 7.1 b).

Figures $7.2 \boldsymbol{a}$ - $\boldsymbol{d}$ show representative cross-sections of the ligated common carotid artery with a neointimal lesion of CD40-Twt (with no defects in CD40-TRAF binding), CD40-T2/3/5, CD40-T6 and CD40-T2/3/5\&6 (with a defect in binding TRAF2,3,5 and TRAF6) mice. Neointima formation and intima/media ratios were significantly reduced, both at individual levels throughout the ligated artery and neointimal volumes (fig. 7.2 e-f), in mice with defective CD40-T6 binding (levels 1-5) and in CD40-T2/3/5\&6 mice (levels 2-7). Neointima in CD40-T2/3/5\&6 mice was not further reduced compared to CD40-T6, indicating that mainly CD40 signaling through TRAF6 is involved in neointima formation. Furthermore, intima/ media ratio and maximal stenosis rates were reduced in both CD40-T6 and CD40T2/3/5\&6 mice (fig. 7.2 i-j). Besides CD40-TRAF signaling in neointima formation, we also investigated the involvement of distinct TRAF proteins required for CD40 signaling in vascular remodeling. Although effects on lumen volume are less pronounced in CD40-TRAF defective mice compared to complete CD40 deficiency (fig. 7.2 g), TRAF6 also appears to be mediating the effects of $C D 40$ on vascular remodeling, since total vessel area of CD40-T6 and of CD40-T2/3/5\&6 mice was significantly reduced compared to CD40-Twt mice (fig. 
7.3 h). Like in CD40 or CD40L-deficient mice, no differences in vessel geometry of the contralateral, non-ligated artery were found between CD40-Twt, CD40-T2/3/5, CD40-T6 or CD40-T2/3/5\&6 mice (suppl. fig. $7.3 c$-d). These results indicate that signaling through the CD40-TRAF6 axis is crucial for neointima formation and vascular remodeling in mice.
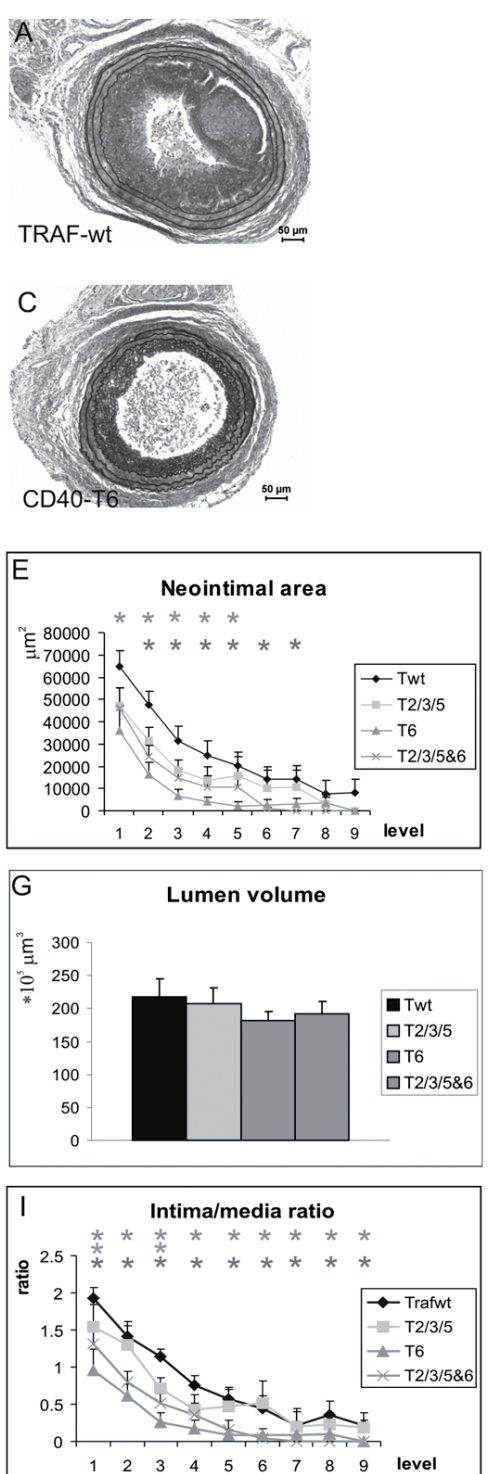
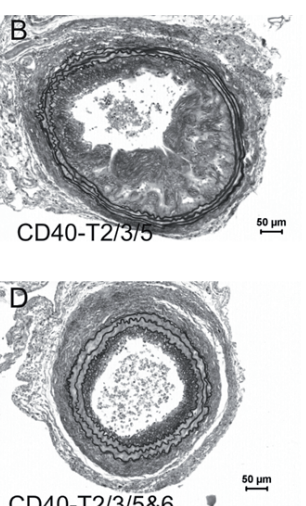

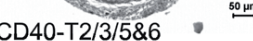

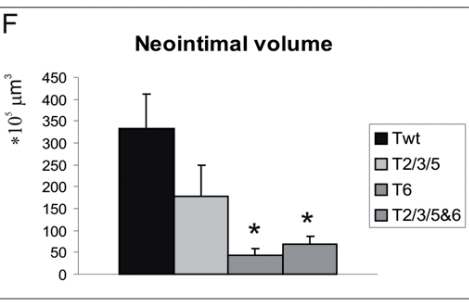

Total vessel volume
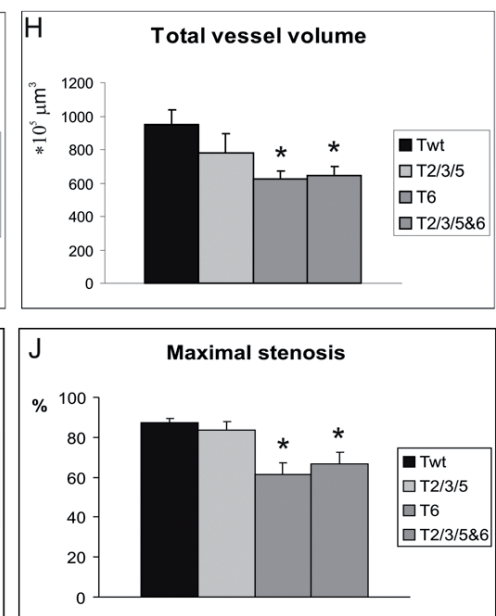

Figure 7.2

Neointima formation and carotid artery remodeling in CD4O-Twt, CD40-T2/3/5, CD4O-T6 and CD4O-TRAF2/3/5\&6 mice. Representative cross-sections are shown in panels $A-D ; n=14, n=10, n=7$ and $n=14$, respectively. Neointima was measured at individual levels (200 $\mu \mathrm{m}$ intervals) throughout the ligated artery segments $(E)$ and neointimal volume was calculated ( $f$ ). Furthermore, volumes of lumen (g) and total vessel wall (h) were calculated, as well as intima/media ratios (i) and maximal stenosis rates (j) * $p<0.05$ compared to CD40-Twt mice. Neointima formation in CD40-T6 mice was significantly reduced compared to CD40-Twt mice at levels 1-5, whereas reduction in neointima formation in CD40-T2/3/5\&6 mice was significant at levels 2-7.
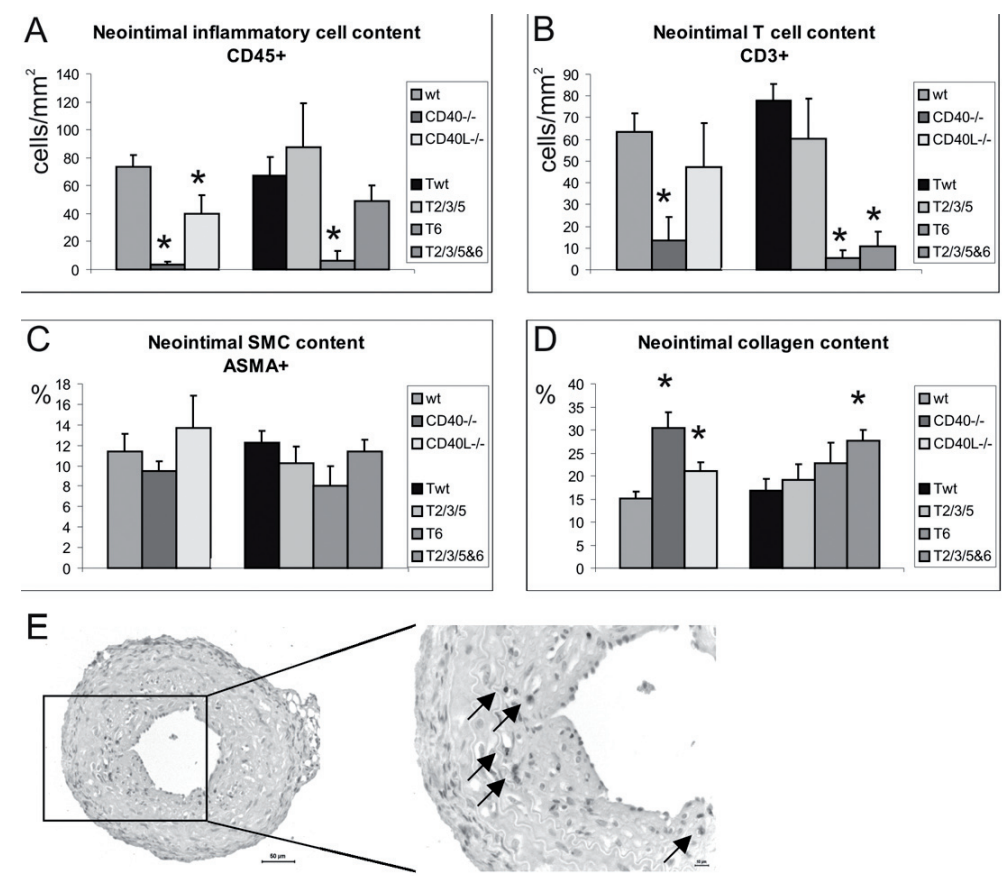

Figure 7.3

Neointimal lesion composition in $\mathrm{CD} 40 / \mathrm{CD} 40 \mathrm{O}$ deficiency or in mice with defective CD4O-TRAF binding compared to controls. (a) Inflammatory cells stained with CD45-antibody, (b) CD3+T cell content of neointima, (c) Amount of ASMA-positive SMCs and (d) collagen content of neointimal lesions. * $p<0.05$ compared to wt (for CD40\% and CD4OL־ mice) or compared to CD40-Twt (for CD40-T2/3/5, CD4O-T6 and CD4O-T2/3/5\&6 mice).

\section{CD40-TRAF6 signaling is required for inflammatory cell infiltration and collagen turnover} in the neointima

Immunohistochemical staining showed the presence of inflammatory cells in the neointimal layer of the ligated carotid artery, although the absolute amount of inflammatory cells was low ( $<10$ cells per cross-section, fig. $\mathbf{7 . 3} \boldsymbol{e}$ ). Nevertheless we found a significant reduction in CD45+ cells relative to neointimal area in CD40 and CD40L-deficient mice compared to wt as well as a significant reduction in relative amount of CD3+ T cells and Mac3+ cells in CD40\% mice (fig. $7.3 \boldsymbol{a}-\boldsymbol{b}$ ). CD40 signaling through TRAF6 appeared to be required for 
the infiltration of inflammatory cells, since the amount of T cells was reduced in neointimal lesions of mice in which binding of TRAF6 (CD40-T6) and binding of TRAF2/3/5\&6 (CD40T2/3/5\&6) to CD40 was disrupted (fig. $7.3 a-b)$.

FACS-analysis on blood, spleen and lymph nodes showed that $\mathrm{CD} 40^{-\%}$ mice have a higher amount of Gr1+ cells in their blood compared to wt mice (fig. 7.4). Furthermore, CD40\% mice had slightly more $\mathrm{CD} 3+\mathrm{T}$ cells and an increased ratio of $\mathrm{CD} 4+/ \mathrm{CD} 8+\mathrm{T}$ cells in lymph nodes, but not in blood or spleen. However, no differences were found in the relative amount of activated (CD25+ or CD69+) T cells in blood, spleen or lymph nodes. Also no differences in the amount of (activated) T cells, CD4/CD8 ratio, the amount of B-cells, macrophages or granulocytes were found in blood, spleen and lymph nodes of CD40-T6 mice compared to the CD40-Twt mice (fig. 7.4 a-e).

The amount of ASMA-positive SMCs tended to be reduced in neointima of CD40-T6 mice, but this was not significant (fig. 7.3 c). No significant differences were found in neointimal cell proliferation and apoptosis or angiogenesis(data not shown). An increase in neointimal collagen accumulation was found in $\mathrm{CD}^{2} \%$ and $\mathrm{CD} \mathrm{LL}^{-} \%$ mice compared to wt, which was also observed in CD40-T2/3/5\&6 mice compared to the Twt controls (fig. $7.4 \mathrm{~d}$ ). This increase in collagen content was accompanied by an increase in TGF $\beta$ levels in mice with a deficient CD40-signaling or a deficient CD40-T6 signaling (staining intensity: CD40 $\% 3.3 \pm 0.4$ vs wt $1.3 \pm 0.1 ; p<0.05)$; CD40-T6 2.9 \pm 0.3 vs CD40-Twt: $1.8 \pm 0.3 ; p=0.055)$
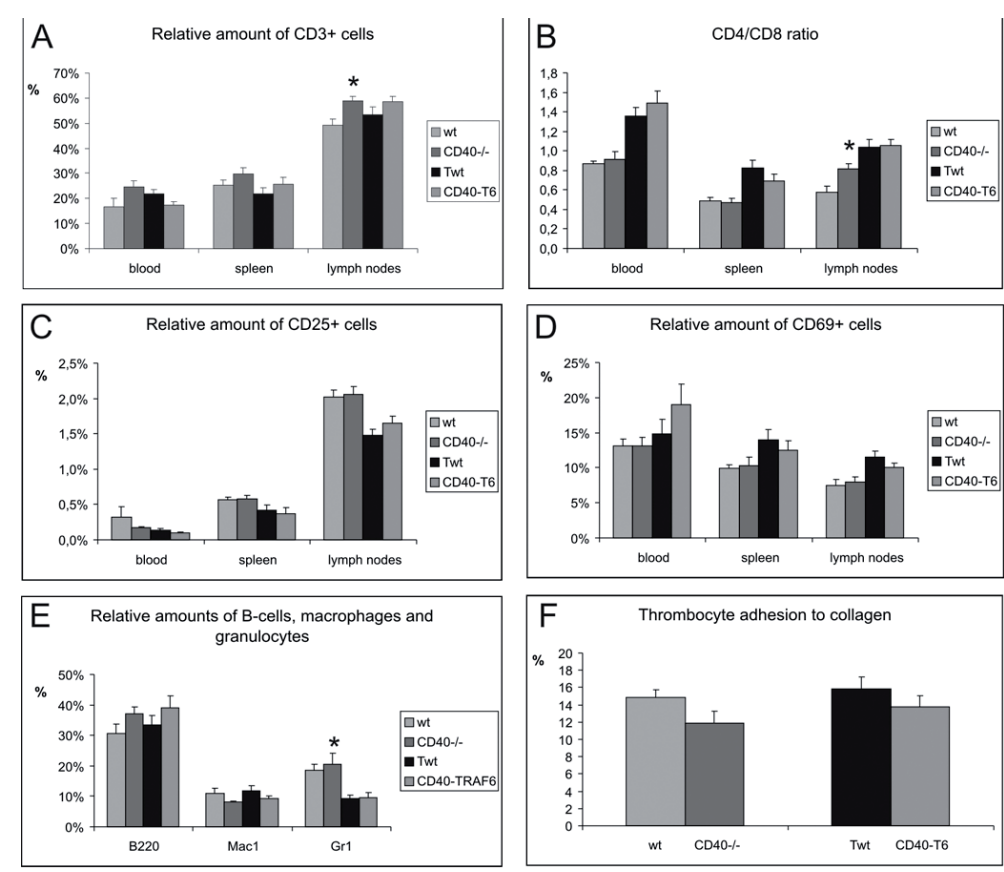

Figure 7.4

FACS analysis and thrombus formation in wt vs $\mathrm{CD} 40 \%$ and $C D 40-T w t$ vs CD40-T6 mice. Relative amount of CD3 ${ }^{+}$ $T$ cells (a), CD4/CD8 ratio (b) and relative amounts of activated $T$ cells (c-d showing CD25+ and $C D 69^{+} T$ cells, respectively) were assessed in blood spleen and lymph nodes. Furthermore, relative amounts of circulating B cells, macrophages and granulocytes were determined (e). Thrombocyte adhesion to collagen was measured under flow conditions. Data are percentage of surface covered with platelets after 4 min of perfusion (f). ${ }^{*} p<0.05$ compared to wt

CD40-expressing leukocytes partly contribute to neointima formation and vascular remodeling

Since the decrease of neointima formation in absence of CD40 signaling is associated with a decreased number of inflammatory cells, we investigated the effect of deficiency of leukocyte $\mathrm{CD} 40$ on neointima formation by creating bone marrow chimeras. Wild type mice reconstituted with $\mathrm{CD} 40 \%$ bone marrow indeed showed a decrease in neointima formation, reflected by a decrease in neointimal volume and a decrease in maximal stenosis rate (fig. $7.5 a-d$ ). Moreover, deficiency of leukocyte CD40 induced an impaired remodeling capacity, reflected by a decrease in total vessel volume (fig. $7.5 \mathrm{c}$ ).

This shows that the effects of CD40 on neointima formation are for a large part mediated by immune cells. However, the decrease in neointima formation in these mice was somewhat less pronounced compared to the decrease in neointima formation in CD40-deficient mice. This is shown in figures $\mathbf{7 . 5} \boldsymbol{a}-\boldsymbol{b}$ where neointimal areas and intima/media ratios are 
only decreased in the first 2 levels, where the largest lesions are found. Moreover, no phenotypical differences in CD3, CD45, Mac3, collagen and ASMA content could be observed in neointimas between mice reconstituted with $\mathrm{CD} 40 \%$ or wt bone marrow.
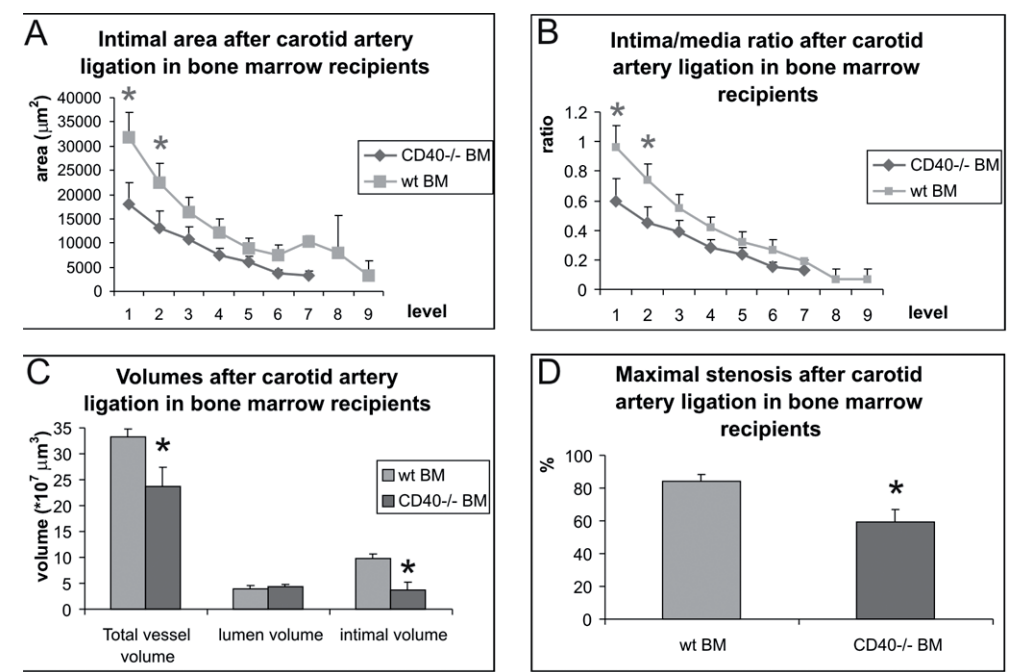

Figure 7.5

Neointima formation and carotid artery remodeling in wild type mice reconstituted with wild type bone marrow (wt BM) or CD40\% BM. Neointima area and intima-media/ratio was measured at individual levels (100 $\mu \mathrm{m}$ intervals) throughout the ligated artery segments (a-b) and neointimal volume, lumen volume and total vessel volume was calculated (c), as well as maximal stenosis rate (d). * $p<0.05$ compared to wild type mice reconstituted with wt BM. Neointima formation and stenosis rate was significantly reduced in mice reconstituted with $C D 40 \% B M$.

\section{Thrombosis}

Since the model of carotid artery ligation is partly based on thrombosis formation and remodeling of the thrombus, we investigated platelet deposition and thrombus formation on collagen under high-shear flow conditions. No differences were found in the rate and extent of thrombus formation between blood from $\mathrm{CD} 40^{-\%}$ or $\mathrm{CD} 40-\mathrm{T} 6$ mice compared to wt or CD40-Twt, respectively (fig. $\mathbf{7 . 4}$ f).

\section{Gelatinase/collagenase activity is reduced in $\mathrm{CD} 40 \%$ mice}

Since matrix-degrading enzymes such as MMPs are required for extracellular matrix turnover and vascular remodeling, we measured gelatinolytic/collagenolytic activity in carotid arteries from $\mathrm{CD} 40^{-}$mice compared to wt controls at 1 week after ligation, when MMPactivity is reported to be maximal. ${ }^{20}$ Per group, 2 pools of 6 ligated carotid arteries were used and protease activity was measured in duplo (total of 4 measurements per group) after 24, 48 and 72 hrs of digestion. Gelatinase/collagenase activity in the ligated carotid arteries of $\mathrm{CD}_{40} \%$ mice was $16 \%$ decreased compared to wt mice (average of the 3 time points, fig. $7.6 \boldsymbol{a}$ ), which could explain the impaired remodeling response and increased collagen content of neointimal lesions in $\mathrm{CD} \mathrm{O}^{\%}$ mice.

To determine the metalloproteinases responsible for this decrease in gelatinolytic/collagenolytic activity, we investigated the mRNA expression levels of distinct MMPs and their inhibitors, the tissue inhibitors of metalloproteinases (TIMPs) in carotid arteries of wt, CD40\%, CD40-Twt and CD40-T6 mice one week after ligation. MMP-9 mRNA expression levels were markedly reduced in $\mathrm{CD}_{40} \%$ mice compared to $\mathrm{wt}$, although this was not significant due to low sample numbers used (fig. 7.6 b). Expression levels of TIMP-2 and -3 tended to be increased. No differences could be observed between CD40-Twt and CD40-T6 mice. Since mRNA expression does not always reflect the activity of the MMPs, we investigated MMP-2 and MMP-9 activity in carotid arteries of wt, CD40 $\%, C D 40-T w t$, CD40-T2/3/5 and CD40-T6 mice one week after ligation using zymography. MMP-2 activity was significantly reduced in $\mathrm{CD} 40 \%$ compared to wt mice, whereas MMP-9 was reduced but not significant (fig. 7.6 c). The CD40-T6 mice showed a similar decrease, although not significant, in MMP-2 and -9 activity as in the CD40-Twt mice.
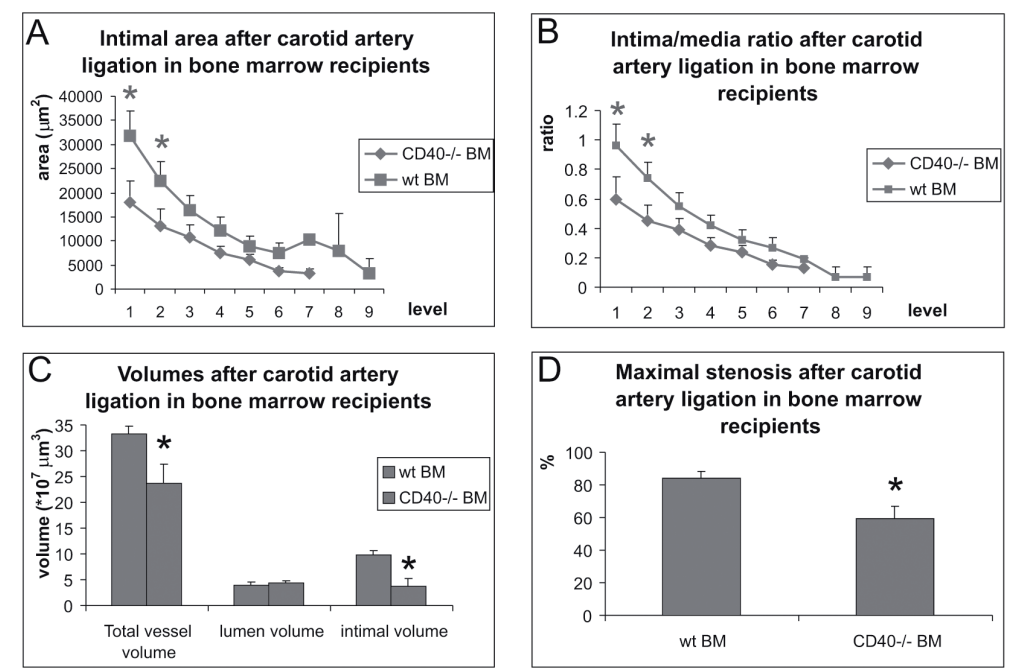

Figure 7.6

(a) Gelatinase/collagenase activity in ligated carotid arteries of $C D 40 \%$ mice vs controls. Per group, 2 pools of 6 carotid arteries were used and assayed in duplo (total of 4 measurements per group). Fluorescence was measured at $515 \mathrm{~nm}$ after 24,48 and $72 \mathrm{hrs}$ of digestion and average protease activity was calculated for both groups. (b) Real time PCR of MMP-2,9,13,14 and TIMP-2 and -3 on ligated carotid arteries of CD40\% and wt mice reveals a decrease in MMP-2 and -9 levels and an increase in TIMP-2 and -3 levels. (c) Zymography for MMP-2 and -9 reveals a decrease in MMP-2 and -9 activity in CD40\% mice compared to wt mice, and in CD4O-T6 mice compared to CD40-Twt mice. 
A reason for the decrease in MMP-expression as observed in ligated carotid arteries of CD40 $\%$ and CD40-Traf6 mice is probably due to the decrease in immune cells into the neo-intima and/or adventitia. Indeed, double immuno-histochemistry for MMP2 or MMP9 with the macrophage marker Mac3 revealed that MMP-2 and MMP-9 expression is predominantly found in intimal macrophages, suggesting that the reduced MMP expression is caused by a reduced recruitment of macrophages (suppl. fig. 7.5).

\section{Discussion}

The CD40-CD40L system is widely known to be involved in chronic inflammatory diseases such as atherosclerosis. However, its role in neointima formation remains unclear. In the present study, we show that deficiency of $\mathrm{CD} 40$ considerably reduces neointima formation after carotid artery ligation, whereas the effects of CD40 Ligand (CD40L) deficiency were less predominant.

The pathogenesis of neointima formation and arterial remodeling involves SMC proliferation and extracellular matrix remodeling, but also inflammation and immunity. ${ }^{21}$ This was reflected in the present study.

Deficiency of CD40-CD40L signaling is known to reduce the production of chemokines, cytokines and adhesion molecules, but also decreases proteolytic activity and inhibits angiogenesis. ${ }^{22,23}$. In mice deficient in CD40, neointimas were smaller, which was indeed associated with a decrease in inflammatory cell influx, an increase in collagen and TGF $\beta$ expression, and a decreased protease activity, but not with impaired angiogenesis. Interestingly, irradiated mice reconstituted with $\mathrm{CD} 40^{-/}$bone marrow cells, showed a similar phenotype, although the phenotype was less pronounced than in mice that completely lack CD40. This shows that leukocyte CD40 plays an important role in the pathogenesis of neointima formation, but that CD40 expressing SMCs and endothelial cells contribute to the process as well.

Besides its role in neointima formation, CD40 was shown to mediate arterial remodeling of the ligated artery. In CD40 $\%$ and CD40-T6 and CD40-T2/3/5\&6 mice, total vessel volume was smaller compared to controls. This could not be explained by differences in hemodynamics or baseline vessel geometry/morphology between both genotypes. In response to flow-cessation in the ligated artery, blood flow in the contra-lateral carotid artery has been shown to be increased and to induce outward remodeling. ${ }^{24}$ In our study, we did not find any differences in vascular geometry in the contra-lateral non-ligated artery between $\mathrm{CD} 40^{\%}$ and wt mice, indicating that only outward remodeling in response to the neointima formation was impaired in $\mathrm{CD} 40^{-\%}$ mice. The impaired remodeling response in $\mathrm{CD} 40^{-\%}$ and CD40-T6 and CD40-T2/3/5\&6 mice could be due to either a reduction in activity of matrixdegrading enzymes due to an impaired recruitment of MMP-expressing inflammatory cells into the neointima, or simply because there is no need for a substantial outward remodeling since the neointimal lesions are small. This was especially true for the $\mathrm{CD} 40^{-\%}$ mouse, in which even the lumen volume is significantly smaller, which can be explained by total lack of outward remodelling when small neointimas develop. This indicates that $\mathrm{CD} 40^{-\%}$ mice strongly resist remodeling of the ligated artery. Activation of CD40 is known to induce the 
expression of matrix-degrading enzymes such as MMPs, which are required for arterial remodeling. ${ }^{25}$ Indeed, in this study we showed that in ligated carotid arteries total gelatinolytic/collagenolytic activity in $\mathrm{CD} 40^{-\%}$ mice was reduced compared to controls.

In contrast to the prominent effects of CD40-deficiency, effects of CD40L deficiency were limited. In previous studies using inhibition of CD4OL in transplantation models, several laboratories have shown a significant reduction in transplant arteriosclerosis. ${ }^{12-13}$ In contrast, Remskar et al. found an increase in intimal thickening after acute collar-induced arterial injury, ${ }^{11}$ which was attributed to the decrease in T-lymphocyte activation in absence of CD40L. In our study, the effects of CD40L inhibition were limited. Only the maximal stenosis rate was significantly reduced in $\mathrm{CD} 4 \mathrm{~L}^{-/}$mice compared to wild type mice, while neointimal volumes and intima/media ratios did not differ. In a separate experiment, we ligated the carotid artery of $\mathrm{CD} 4 \mathrm{~L}^{-/} / \mathrm{ApoE}^{-/}$mice and $\mathrm{ApoE}^{-/}$mice to induce a foam cell containing SMC rich neointima and obtained similar results (data not shown). Possible explanations for these discrepancies on the role of CD40L on neointima formation comprise the pathogenesis of the models that are used. Transplant arteriosclerosis is a slow process, in which CD40L-mediated T-lymphocyte activation seems to play a major role, ${ }^{13}$ while in acute vascular injury, CD40L-mediated T-lymphocyte activation apparently is protective, ${ }^{11}$ whereas in our flow cessation model, the role of CD40L is limited. It is not clear what causes the difference between $\mathrm{CD}_{40} \%$ and $\mathrm{CD}^{-1} \mathrm{~L}^{-/}$mice. A possible explanation could be the existence of another ligand for CD40, however, to date no other ligand for CD40 has been identified.

Previous studies have shown that inhibition of CD40L in mice attenuated the development of atherosclerosis and increased atherosclerotic plaque stability. ${ }^{3-5}$ The associated immune suppression makes complete inhibition of CD40/CD40L signaling not an attractive therapy for vascular diseases. Identification of specific mediators of CD40 signaling in vascular disease may provide valuable information for the development of more specific interventions. So far, little is known about the downstream signaling pathways of CD40 in vascular pathologies. However, in a recent paper by Zirlik et al, the different TRAF proteins were found to be expressed in both human and mouse atherosclerotic plaques and in human aneurysms. ${ }^{10}$ Moreover, inhibition of the different CD40-TRAF interactions in cultured endothelial cells revealed a tight modulation of the outcome of inflammation, depending on the TRAF that was bound to $\mathrm{CD} 40 .{ }^{10}$ However, animal studies of the role of distinct TRAF proteins in CD40 effector functions have been hampered by the poor viability of most TRAF ${ }^{-/}$mice and the fact that TRAFs are also involved in signaling of other TNF-superfamily members. In this study we used transgenic mice with targeted mutations in the CD40-TRAF binding domains, allowing us to study the role of specific TRAFs in CD40 signaling in neointima formation and carotid arterial remodeling. We showed CD40 signaling through TRAF6 to be the main pathway mediating both neointima formation and arterial remodeling, which was accompanied by an increase in collagen and a decrease in inflammatory cell content of the neointimal lesions. A role for CD40-TRAF6 in production of pro-inflammatory cytokines (i.e. TNF $\alpha$ ) by macrophages in vitro has been described in literature. ${ }^{8} \mathrm{~A}$ reduction in neointimal inflammatory cell infiltration in CD40-TRAF6 defective mice, together with the reduction in matrix-degrading activity, indicates a possible mechanism for this reduction in neointimal response to arterial ligation.

Although we identified TRAF6 as the key player in CD40-signaling in neointima formation, a role for other TRAF proteins can not be fully excluded since TRAF 2, 3 and 5 have overlapping binding sites, which makes it difficult to differentiate individual functions of these distinct TRAF proteins. TRAF3 has been reported to counter-regulate the effects of TRAF2 on NFkB activation. ${ }^{26}$ Since we disrupted binding of both TRAFs simultaneously, we cannot differentiate between functions of TRAF2 and 3. Recently, a new binding site of TRAF2 has been discovered in the cytoplasmic tail of $C D 40,{ }^{27-28}$ which was not disrupted in the CD40$\mathrm{T} 2 / 3 / 5$ or $\mathrm{CD} 40-\mathrm{T} 2 / 3 / 5 \& 6$ mice. Although this CD40-TRAF2 binding site could contribute to neointima formation and carotid artery remodeling, we showed a dramatic reduction in neointimal volume after disruption of the TRAF6 binding site of CD40, indicating that binding of TRAF6 to CD40 is essential for the development of neointimal lesions.

In conclusion, this study shows that deficiency in CD40 reduces neointima formation and remodeling after carotid artery ligation, probably by inhibiting inflammatory cell infiltration and matrix-degrading protease activity. We identified TRAF6 as the key regulator of CD40-signaling in these processes, as specific disruption of CD40-TRAF6 binding markedly reduced neointima formation. Moreover, we showed that leukocyte CD40 largely contributes to neointima formation, but that CD40-signaling in SMCs and endothelial cells seems to be important as well. Since complete disruption of CD40 suppresses the immune system and is therefore not suitable as a therapy, the present identification of specific targets downstream of CD40-signaling may provide valuable information for the development of new therapeutic interventions in vascular disease. 


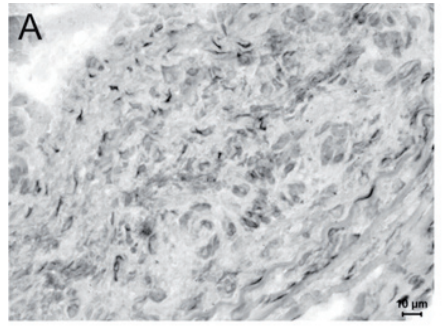

$$
\begin{aligned}
& \text { Wt Wildtype } \\
& \text { CD40L-/- CD40L-I- } \\
& \text { CD40-/- CD40-/- } \\
& \begin{array}{llll|l|}
\hline \text { TRAF-wt } & \text { CD40-I- } & \text { MHC II } & \text { Human CD40 } \\
\hline
\end{array} \\
& \begin{array}{lll|l|}
\hline \text { CD40-T2/3/5 CD40-/- MHC II } & \text { Human CD40 } \\
\hline
\end{array} \\
& \begin{array}{l}
\text { Mutation BD } \\
\text { TRAF2/3/5 }
\end{array} \\
& \begin{array}{ll|l|l|}
\hline \text { CD40-T6 CD40-/- } & \text { MHC II } & \text { Human CD40 } \\
\hline
\end{array} \\
& \begin{array}{l}
\text { Mutation BD } \\
\text { TRAF6 }
\end{array}
\end{aligned}
$$

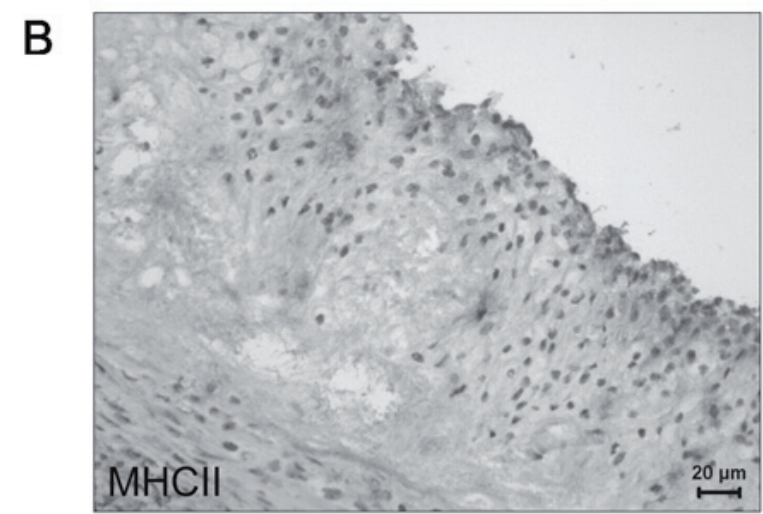

Supplementary figure 7.

Knockout and transgenic mice with defects in $\mathrm{CD} 40$ signaling. (a) Besides wt, $\mathrm{CD} 40 \%, \mathrm{CD} 40 \mathrm{~L}^{\circ}$ we used $\mathrm{CD} 40^{\circ}$ mice that express a human CD40 construct under a MHC-Il promoter. Mutations in TRAF-binding domains of CD40 disrupt binding of specific TRAFs to CD40. wt: wild-type C57BL6/J mice, TRAF-wt: CD40\% mice expressing normal human CD4O under the MHC-II promoter, CD4O-T2/3/5: mice with a defect in binding of TRAF2,3 and 5 to CD40, CD40-T6: mice with a defect in binding of TRAF6 to CD40, CD40-T2/3/5\&6: mice with a defect in both binding domains for TRAF2/3/5 and TRAF6. (b) Immunohistochemical staining showed MHC-II expression in neointimal lesions.

Supplementary figure 7.3

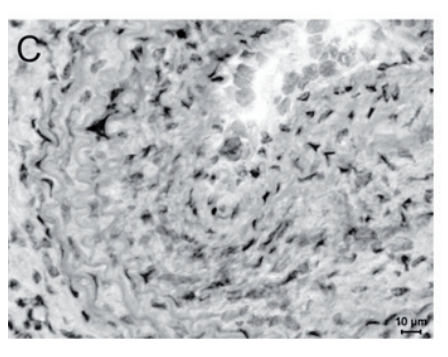

Supplementary figure 7.2

Expression of TRAF2 (a), TRAF3 (b) and TRAF6 (c) in neointimal lesions. All TRAFs are predominantly expressed in the neointima, but also in the media (M).
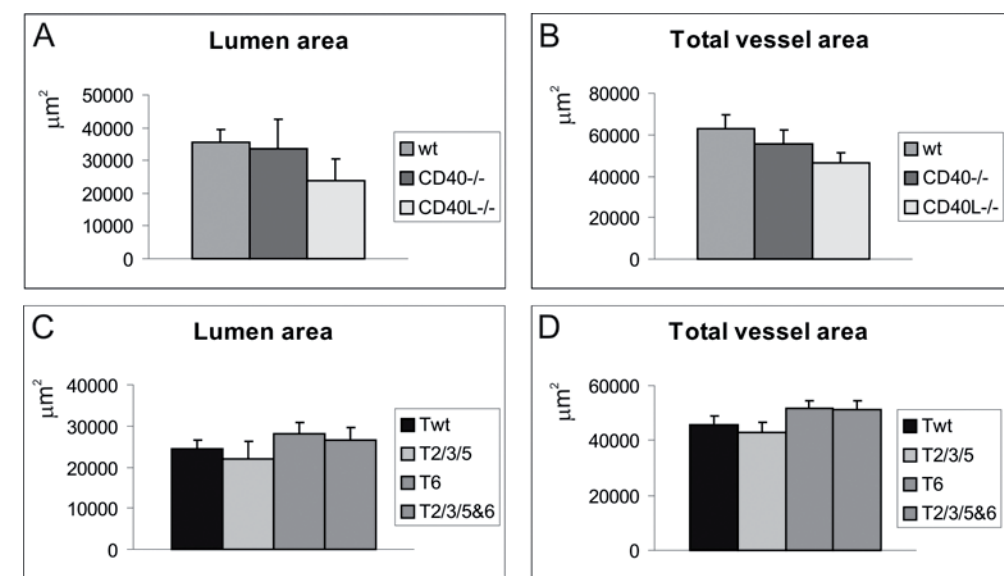

Baseline geometry of the contralateral, non-ligated artery does not differ between the genotypes. 


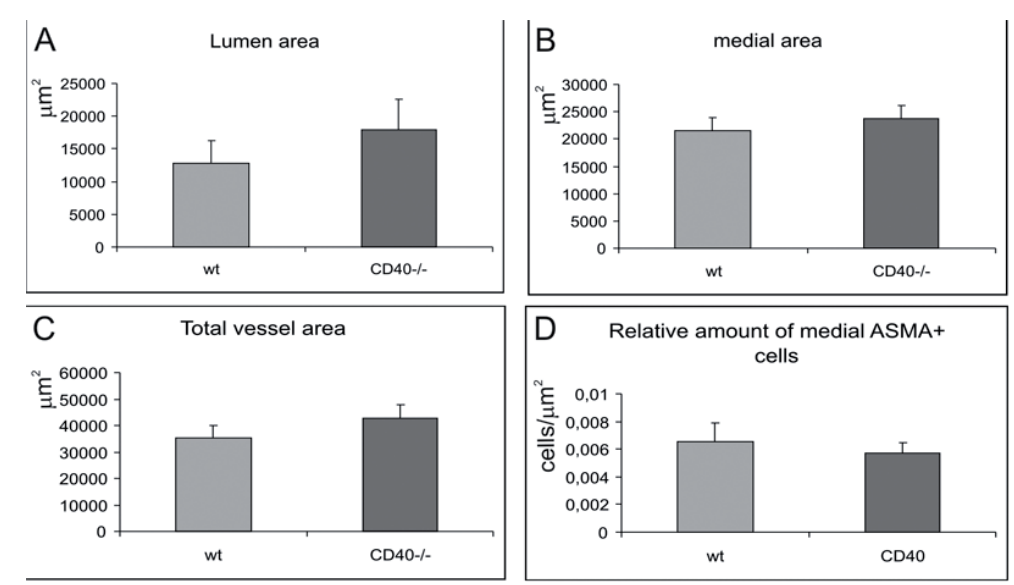

Supplementary figure 7.4

Baseline geometry and SMC content of a normal right carotid artery does not differ between the genotypes.
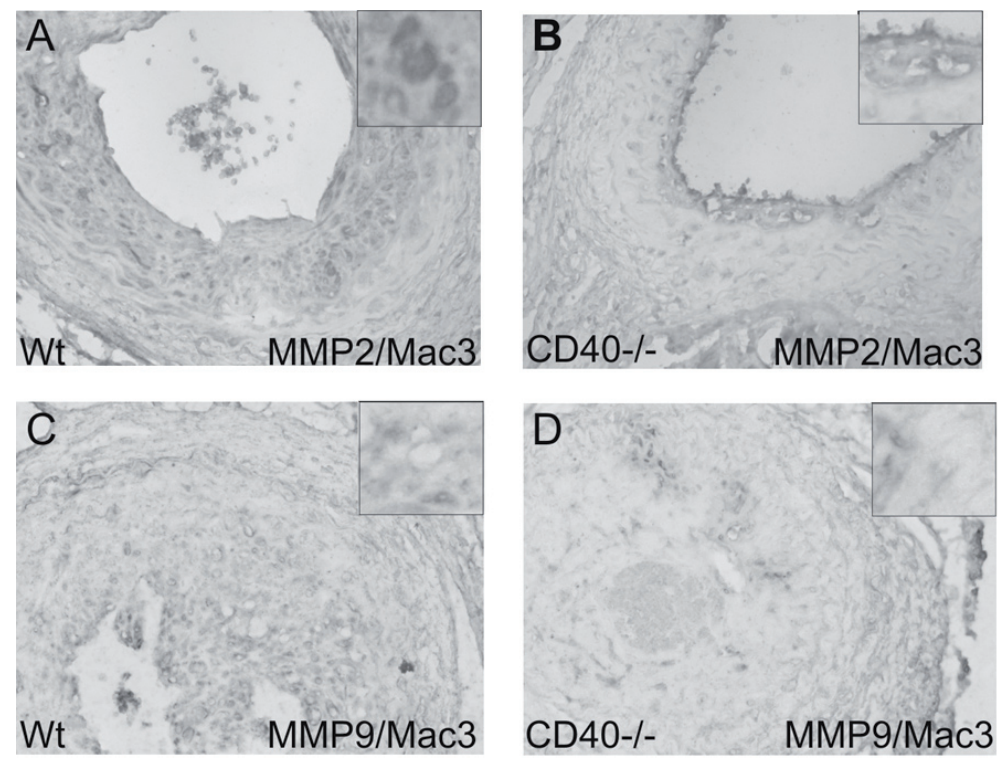

Supplementary figure 7.5

Panel showing double IHC with MMP-2 (blue) or MMP-9 with Mac3 (red) in neo-intimas of wild type (WT) and

CD40\% mice. Macrophages in neo-intimas of both genotypes express MMP-2 and -9. In the CD40\% group, less macrophages are present, resulting in decreased MMP-2 and -9 expression. 


\section{References}

1. Grewal IS, Flavell RA. CD40 and CD154 in cell-mediated immunity. Annu Rev Immunol. 1998;16: 111-135.

2. Gerritse K, Laman JD, Noelle RJ, et al. CD40-CD40 ligand interactions in experimental allergic encephalomyelitis and multiple sclerosis. Proc Natl Acad Sci U S A. 1996;93: 2499-2504.

3. Lutgens E, Gorelik L, Daemen MJ, et al. Requirement for CD154 in the progression of atherosclerosis. NatMed. 1999;5: 1313-1316.

4. Lutgens E, Cleutjens KB, Heeneman S, Koteliansky VE, Burkly LC, Daemen MJ. Both early and delayed anti-CD40L antibody treatment induces a stable plaque phenotype. ProcNatIAcadSciUSA. 2000;97: 74647469.

5. Mach F, Schonbeck U, Sukhova GK, Atkinson E, Libby P. Reduction of atherosclerosis in mice by inhibition of CD40 signalling. Nature. 1998;394: 200-203.

6. Schonbeck U, Libby P. CD40 signaling and plaque instability. CircRes. 2001;89: 1092-1103.

7. Pullen SS, Miller HG, Everdeen DS, Dang TT, Crute JJ, Kehry MR. CD40-tumor necrosis factor receptorassociated factor (TRAF) interactions: regulation of CD40 signaling through multiple TRAF binding sites and TRAF hetero-oligomerization. Biochemistry. 1998;37: 11836-11845.

8. Mukundan L, Bishop GA, Head KZ, Zhang L, Wahl LM, Suttles J. TNF receptor-associated factor 6 is an essential mediator of CD40-activated proinflammatory pathways in monocytes and macrophages. J Immunol. 2005;174: 1081-1090.

9. Mukundan L, Milhorn DM, Matta B, Suttles J. CD40-mediated activation of vascular smooth muscle cell chemokine production through a Src-initiated, MAPK-dependent pathway. Cell Signal. 2004;16: 375-384.

10. Zirlik A, Bavendiek $U$, Libby $P$, et al. TRAF-1, $-2,-3,-5$, and -6 Are Induced in Atherosclerotic Plaques and Differentially Mediate Proinflammatory Functions of CD40L in Endothelial Cells. Arterioscler Thromb Vasc Biol. 2007.

11. Remskar M, Li H, Chyu KY, Shah PK, Cercek B. Absence of CD40 signaling is associated with an increase in intimal thickening after arterial injury. Circ Res. 2001;88: 390-394.

12. Wang $\mathrm{X}$, Huang $\mathrm{W}$, Mihara $\mathrm{M}$, Sinha J, Davidson A. Mechanism of action of combined short-term CTLA4lg and anti-CD40 ligand in murine systemic lupus erythematosus. J Immunol. 2002;168: 2046-2053.

13. Hancock WW, Buelow R, Sayegh MH, Turka LA. Antibody-induced transplant arteriosclerosis is prevented by graft expression of anti-oxidant and anti-apoptotic genes. Nat Med. 1998;4: 1392-1396.

14. Kumar A, Lindner $\mathrm{V}$. Remodeling with neointima formation in the mouse carotid artery after cessation of blood flow. Arterioscler Thromb Vasc Biol. 1997;17: 2238-2244.

15. Ahonen C, Manning E, Erickson LD, et al. The CD40-TRAF6 axis controls affinity maturation and the generation of long-lived plasma cells. NatImmunol. 2002;3: 451-456.

16. Janssen BJ, Leenders PJ, Smits JF. Short-term and long-term blood pressure and heart rate variability in the mouse. Am J Physiol Regul Integr Comp Physiol. 2000;278: R215-225.

17. Donners MM, Bot I, De Windt LJ, et al. Low-dose FK506 blocks collar-induced atherosclerotic plaque development and stabilizes plaques in ApoE ${ }^{-/}$mice. Am J Transplant. 2005;5: 1204-1215.

18. Munnix IC, Strehl A, Kuijpers MJ, et al. The glycoprotein VI-phospholipase Cgamma2 signaling pathway controls thrombus formation induced by collagen and tissue factor in vitro and in vivo. Arterioscler Thromb Vasc Biol. 2005:25: 2673-2678.

19. Southgate KM, Davies M, Booth RF, Newby AC. Involvement of extracellular-matrix-degrading metalloproteinases in rabbit aortic smooth-muscle cell proliferation. Biochem J. 1992:288 (Pt 1): 93-99.
20. Godin D, Ivan E, Johnson C, Magid R, Galis ZS. Remodeling of carotid artery is associated with increased expression of matrix metalloproteinases in mouse blood flow cessation model. Circulation. 2000;102: 2861-2866.

21. Donners MM, Daemen MJ, Cleutjens KB, Heeneman S. Inflammation and restenosis: implications for therapy. Ann Med. 2003;35: 523-531.

22. Lutgens E, Lievens D, Beckers L, Donners M, Daemen M. CD40 and its ligand in atherosclerosis. Trends Cardiovasc Med. 2007;17: 118-123.

23. Deregibus MC, Buttiglieri S, Russo S, Bussolati B, Camussi G. CD40-dependent activation of phosphatidylinositol 3-kinase/Akt pathway mediates endothelial cell survival and in vitro angiogenesis. J Biol Chem. 2003:278: 18008-18014.

24. Korshunov VA, Berk BC. Flow-induced vascular remodeling in the mouse: a model for carotid intima-media thickening. Arterioscler Thromb Vasc Biol. 2003;23: 2185-2191.

25. Schonbeck $\mathrm{U}$, Mach F, Sukhova GK, et al. Regulation of matrix metalloproteinase expression in human vascular smooth muscle cells by T lymphocytes: a role for CD40 signaling in plaque rupture? CircRes. 1997;81: 448-454.

26. Hauer J, Puschner $S$, Ramakrishnan $P$, et al. TNF receptor (TNFR)-associated factor (TRAF) 3 serves as an inhibitor of TRAF2/5-mediated activation of the noncanonical NF-kappaB pathway by TRAF-binding TNFRs. Proc Natl Acad Sci U S A. 2005;102: 2874-2879.

27. Lu LF, Cook WJ, Lin LL, Noelle RJ. CD40 signaling through a newly identified tumor necrosis factor receptorassociated factor 2 (TRAF2) binding site. J Biol Chem. 2003;278: 45414-45418.

28. Lu LF, Ahonen $\mathrm{CL}$, Lind $\mathrm{EF}$, et al. The in vivo function of a noncanonical TRAF2-binding domain in the Cterminus of CD40 in driving B-cell growth and differentiation. Blood. 2007:110: 193-200. 
DEFICIENT CD40-TRAF6 SIGNALING IN LEUKOCYTES PREVENTS ATHEROSCLEROSIS BY SKEWING THE IMMUNE RESPONSE TOWARDS AN ANTI-INFLAMMATORY PROFILE

Esther Lutgens, Dirk Lievens, Linda Beckers, Erwin Wijnands, Oliver Soehnlein, Alma Zernecke, Tom Seijkens, David Engel, Jack Cleutjens, Anna M Keller, Shalin G Naik, Louis Boon, Hafid Ait Oufella, Ziad Mallat, Cory L Ahonen, Randolph J Noelle, Menno P de Winther, Mat J Daemen, Erik A Biessen and Christian Weber

accepted in the Journal of Experimental Medicine 


\section{Abstract}

The CD40-CD40 ligand (CD40L) signaling axis plays an important role in immunological pathways. Consequently, this dyad is involved in a plethora of chronic inflammatory diseases, including atherosclerosis. Inhibition of CD40L in apolipoprotein E-deficient ( $\left.A p o E^{-1}\right)$ mice not only reduced atherosclerosis, but also conferred a clinically favorable plaque phenotype that was low in inflammation and high in fibrosis.

Unfortunately, blockade of CD40L may not be therapeutically feasible, as long-term inhibition will compromise systemic immune responses, or cause thromboembolic complications. Conceivably, more targeted intervention strategies in CD40 signaling will have less deleterious side effects.

Here we report that deficiency in haematopoietic CD40 reduces atherosclerosis and induces features of plaque stability. Absence of CD40-tumor necrosis factor-receptor associated factor- 6 (TRAF6) but not CD40-TRAF2/3/5 signaling in $\mathrm{MHCII}^{+}$cells of $\mathrm{ApoE}^{-1-}$ mice abolishes atherosclerosis and confers plaque fibrosis, indicating that CD40-TRAF6 but not CD40-TRAF2/3/5 mediates the pro-atherogenic pathway. Mice with defective CD40-TRAF6 signaling display a reduced blood count of Ly $6 \mathrm{C}^{\text {high }}$ monocytes, an impaired recruitment of Ly $6 \mathrm{C}^{+}$monocytes to the arterial wall, and polarization of macrophages towards an antiinflammatory 'regulatory' M2 signature. These data unveil a role for CD40-TRAF6 but not CD40-TRAF2/3/5 interactions in atherosclerosis and establish that targeting specific components of the CD40-CD40L pathway harbors the potential to achieve therapeutic effects in atherosclerosis.

\section{Introduction}

Atherosclerosis is a chronic inflammatory disease of the large arteries, which involves multiple immunological processes. ${ }^{1,2}$ During the progression of atherosclerosis, ongoing activation of the immune system causes continuous recruitment of inflammatory cells into the plaque and degradation of its extracellular matrix. This creates a so-called 'vulnerable plaque', which is prone to rupture, and therefore likely to cause acute complications such as myocardial infarction or stroke. ${ }^{3}$

The CD40-CD40L dyad, a co-stimulatory receptor-ligand pair, plays a crucial role in enhancing immune responses and inflammation, and contributes to a plethora of chronic inflammatory diseases, e.g. colitis, arthritis, allergic encephalitis and multiple sclerosis. ${ }^{4-7}$ Disruption of the CD4OL gene in ApoE $\%$ mice abrogated atherosclerosis and caused a plaque phenotype with only few inflammatory cells, and a high percentage of extra-cellular matrix, ${ }^{8}$ reminiscent of a clinically favorable, stable atherosclerotic plaque in humans. ${ }^{3}$ This phenotype was copied when $A p E^{-\%}$ mice with initial plaques or established atheromata were treated with a blocking anti-CD4OL antibody. ${ }^{9-11}$

In principle, these findings render targeting of CD40L a promising strategy to reduce atherosclerosis and to stabilize atherosclerotic plaques. Unfortunately, clinical trials using an anti-CD40L antibody have been omitted due to thromboembolic complications, particularly because CD4OL is present on platelets and can interact with the integrin $\alpha_{11 \mathrm{~b}} \beta_{3}$ in platelets. ${ }^{12,13}$

Antagonizing CD40, the receptor for CD40L, or its signaling intermediates would be an alternative approach for treating human atherosclerosis. However, information on the effects of CD40 and CD40-associated signal transduction pathways in atherosclerosis is scarce. It has been shown that low-density lipoprotein-receptor-deficient $\left(L D L r^{\prime}-\right)$ mice lacking the $C D 40$ gene do not develop smaller atherosclerotic lesions than control $L D L r^{-}$ mice, ${ }^{14}$ albeit a pro-atherogenic role for endothelial CD40-TRAF-1,-2,-3,-5 and -6 signaling in atherosclerosis has been claimed. ${ }^{15}$ Using mice carrying a CD40 transgene with targeted mutations at the CD40-TRAF6 recognition site, we found that CD40-TRAF6 signaling is specifically required for arterial neointima formation. ${ }^{16}$

In the present study, we tried to elucidate the role of CD40 and its associated signaling intermediates, the TRAFs in primary atherosclerosis in vivo in detail. We found that $C D 40^{\%}$ ApoE $\%$ mice had a reduction in atherosclerosis and developed a stable atherosclerotic plaque phenotype. Bone marrow transplantation of $C D 40 \%$ bone marrow into $L D L r$ mice revealed that haematopoietic $C D 40$ was responsible for the observed phenotype. Surprisingly, when CD40-TRAF6, but not CD40-TRAF2/3/5 interactions were defective, atherosclerosis was completely abrogated. 


\section{Materials and methods}

\section{Animals}

CD40\%, CD40-Twt, CD40-T2/3/5\%, CD40-T6\% and CD40-T2/3/5/6\% mice (all on a C57Bl6 background $)^{26}$ were backcrossed for 7 generations to $A p o E^{-/}$mice. $L D L r^{1-}$ mice were purchased from The Jackson Laboratory (Bar Harbor, ME). All mice were treated in accordance with the institutional Animal Care and Use Committee protocols of the University of Maastricht.

\section{Primary atherosclerosis}

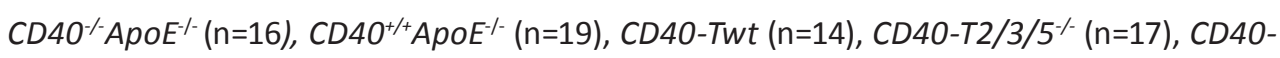
$T_{6} \%(n=26)$ and $C D 40-T 2 / 3 / 5 / 6 \%(n=14)$ mice were fed a normal chow diet throughout the experiment.

\section{Bone marrow transplantation}

$L D L r^{/}$-mice $(n=44)$ were maintained in filtertop cages and given water containing polymyxin B sulfate (60.000U/L; Gibco) and neomycin (100 mg/L; Gibco) starting 1 week before bone marrow transplantation until 4 wks thereafter. Mice were lethally irradiated (10 Gy, $0.5 \mathrm{~Gy} / \mathrm{min}$, Philips MU 15F/225 kV; Hamburg, Germany) and intravenously injected with $10^{7}$ bone marrow cells from $\mathrm{CD} 40^{-/-}$mice or $\mathrm{CD} \mathrm{O}^{+/+}$mice. Four weeks after transplantation, mice were fed a $1.25 \%$ cholesterol diet for 24 weeks.

\section{Atherosclerosis experiments}

Mice were sacrificed and the arterial tree was perfused. The aortic arch and its main branch points were excised, fixed $\mathrm{o} / \mathrm{n}$ and embedded in paraffin. The rest of the arterial tree was fixed, opened, pinned and stained with Oil-red-O for en-face analysis. Longitudinal sections of the aortic arch were analyzed for plaque extent and phenotype as described. ${ }^{3,42}$ For phenotypic parameters, immunohistochemistry was performed for CD3 (Dako), CD45 (BD-Pharmingen), mac-3 (BD-Pharmingen), FVIII (DAKO), -smooth muscle actin (Sigma), caspase 3 (Cell signaling), FoxP3 (e-Bioscience), collagen I (Abcam), collagen III (Abcam), MMP-2 (Cell signaling), MMP-9 (Santa Cruz). In addition, Perl's iron staining and Sirius red staining were as described. ${ }^{42}$ Morphometric analyses were performed using a Leica Quantimet with Qwin3 software. Plasma cholesterol levels were measured enzymatically (Roche), organs were analyzed by HE staining, and no abnormalities were observed. Serum SCD40L levels were measured by ELISA (BenderMed systems).

\section{In-vitro macrophage culture}

Bone-marrow cells were isolated from $n=6$ mice/group and cultured in RPMI supplemented with $L 929$ conditioned medium to generate bone marrow-derived macrophages as described. ${ }^{43}$ Cells were pretreated with $100 \mathrm{U}$ IFN for $24 \mathrm{hrs}$ to induce $\mathrm{MHCll}$ expression, and then treated for $3 \mathrm{hrs}$ with FGK45 (100 ng/ml), a CD40-stimulating antibody. Cytokine levels in the medium were measured by FACS using a cytometric bead assay (BD-pharmingen), and quantitative gene expression of cytokines, M1 and M2 macrophage markers were analyzed as described. ${ }^{44}$

\section{Macrophage migration assay}

Macrophage migration was assessed using 24-well Transwell migration chambers (Costar) with a pore size of $6 \mu \mathrm{m}$. Bone marrow-derived macrophages $\left(0.5^{*} 10^{6}\right)$ of the respective genotypes, suspended in serum free medium were added to each chamber. Complete medium including $100 \mathrm{ng} / \mathrm{mL}$ CCL2 (R\&D systems) was added to the lower chambers and migration was carried out at $37^{\circ} \mathrm{C}$ for 4 hours. Non-migrated cells were removed from the membranes, and migrated cells within the membrane were fixed with methanol and stained with toluidine blue. Membranes were cut out of inserts and mounted onto slides in immersion oil. The number of migrated cells was counted on 5 randomly choosen fields of each membrane.

\section{Gelatinase assay}

Gelatinase activity in the supernatant of FGK45-treated macrophages was determined using the EnzCheck gelatinase/collagenase assay kit (invitrogen). Substrate hydrolysis was analyzed after $24 \mathrm{hrs}$ at room temperature and fluorescence was detected using a fluorescence microplate reader.

\section{Fluorescence-activated cell sorting analysis}

Spleen, lymph nodes and/or blood of all genotypes ( $n=11$ mice/group) were collected, processed and stained with fluorescent antibodies against B220, CD3, CD4, CD8, CD25, FoxP3, CD11b, Ly6C, Ly6G, CD11c and CD19 (all from BD-Pharmingen or eBioscience) to analyze the different lymphocyte, monocyte and dendritic cell subsets using a FACS Canto II (BD).

\section{Intravital microscopy}

Leukocyte endothelial interactions were analyzed by intravital microscopy of the left carotid artery ( $n=8$ mice/group). ${ }^{45} 6$ hours after i.p. injection of murine TNF $\alpha(1.0 \mu \mathrm{g}$, PeproTech), mice were anaesthetized with ketamine/xylazine and the left carotid artery was 
exposed. Circulating leukocytes were labelled by i.v. injection of rhodamine $6 \mathrm{G}$. Ly6C $\mathrm{C}^{+}$ inflammatory monocytes were labelled with fluorescent latex beads as described. ${ }^{46}$ The antibody to IL-10 (clone JES5.2A) was injected twice intraperitoneally ( $500 \mu \mathrm{g} / \mathrm{mouse}), 24$ hrs and 2 hrs before intravital microscopy. Recordings were made using Olympus BX51 microscope equipped with a saline-immersion $20 x$ objective.

\section{Statistics}

Data are presented as mean \pm s.e.m. Data were analyzed by non-parametric Mann-Whitney $\mathrm{U}$ test, or Welch-corrected $t$-test, as appropriate, using GraphPad Prism 4 software. $P$ values $<0.05$ were considered significant.

\section{Results}

\section{CD40 Deficiency Reduces Atherosclerosis}

We generated $\mathrm{CD} 4 \mathrm{O}^{-\mathrm{ApO}} \mathrm{AP}^{-}$mice and analyzed the extent and phenotype of atherosclerosis at 26 wks of age on a normal chow diet. Body weight, as well as cholesterol content or plasma SCD40L levels did not differ between the groups (table 8.1).

\begin{tabular}{|c|c|c|c|c|c|c|}
\hline & Apoe $\%$ & $\begin{array}{l}\text { CD40 } \% \\
\text { Apoe }{ }^{-\%}\end{array}$ & CD40-Twt & $\begin{array}{l}\text { CD40- } \\
\text { T2/3/5 } \%\end{array}$ & CD40-T6 $\%$ & $\begin{array}{c}\text { CD40- } \\
\text { T2/3/5/6\% }\end{array}$ \\
\hline Body weight (g) & $28.7 \pm 0.8$ & $29.2 \pm 0.8$ & $26.1 \pm 0.8$ & $24.9 \pm 0.7$ & $24.8 \pm 0.8$ & $28.9 \pm 0.7$ \\
\hline Cholesterol (mg/dl) & $275 \pm 16$ & $299 \pm 24$ & $328 \pm 26$ & $297 \pm 33$ & $283 \pm 12$ & $330 \pm 36$ \\
\hline sCD40L (ng/ml) & $4.0 \pm 0.8$ & $5.6 \pm 1.6$ & $3.3 \pm 1.0$ & $5.0 \pm 2.6$ & $2.9 \pm 0.5$ & $5.3 \pm 1.9$ \\
\hline
\end{tabular}

\section{Table 81}

Body weights, plasma cholesterol levels and sCD40L serum levels did not differ between the genotypes ( $p>0.05$ )

As in $C D 4 O L^{-}-A p o E$ mice, deficiency of $\mathrm{CD} 40$ reduced the atherosclerotic plaque area in the aortic arch and its branch points, as well as in the thoraco-abdominal aorta (fig. 8.1 a). This was associated with a less inflammatory and more fibrotic plaque quality, as reflected by the low amount of thin fibrous cap atheromata ${ }^{3}$ that developed in absence of CD40 (suppl. fig. 8.1 a). The absence of CD40 reduced the lipid core size ( $A p o E^{\%}: 35.4 \%$ versus $\left.\mathrm{CD}^{2} \mathrm{O}^{-} \mathrm{ApoE}^{-} 23.3 \% ; \mathrm{p}<0.05\right)$, the number of plaque macrophages and the content of $\mathrm{CD} 45^{+}$cells and $\mathrm{CD}^{+}$T-lymphocytes (fig. $8.1 \mathrm{~b}$-c). The number of Foxp3 $3^{+}$regulatory Tcells in plaque or adventitia was unaffected (suppl. fig. $8.1 \mathrm{~b}$-c). The numbers of cleaved caspase- $3^{+}$(apoptotic) cells (suppl. fig. 8.1 d), as well as the degree of iron or fibrin deposition in the plaque (data not shown) were unaffected.
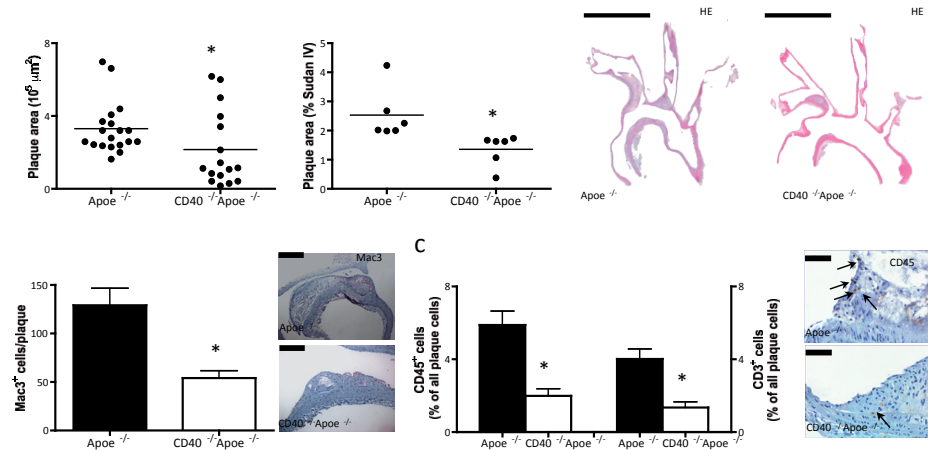

Figure 8.1

Role of CD4O in atherosclerosis. (a-c) ApoE\% mice ( $n=19)$ were fed a normal chow diet for 26 wks and were compared to $\mathrm{CD} 40 \%$ ApoE $\%(n=16)$. Sections of the aortic arch and its main branch points (brachiocephalic artery, right subclavian artery, right carotid artery, left carotid artery and left subclavian artery) were stained with haematoxylin and eosin (HE, representative sections on the right) to analyze the extent of atherosclerosis (plaque area; scale bars, $2 \mathrm{~mm}$ ) (a, left panel: plaque area aortic arch and branch points; middle panel: en face staining thoraco-abdominal aorta) and plaque phenotype (b-c). Macrophage infiltration was expressed as the absolute number of Mac $3^{+}$cells per plaque (scale bars, $\left.100 \mu \mathrm{m}\right)(\boldsymbol{b}) . C D 45$ and $C D 3$ content were expressed as the percentage of $\mathrm{CD}^{+}$or $\mathrm{CD}^{2} 5^{+}$cells of all plaque cells (arrows indicate $\mathrm{CD}^{4} 5^{+}$cells; scale bar, $50 \mu \mathrm{m}$ ) (c).

Besides the decrease in inflammatory cell content, plaques of $\mathrm{CD}^{2} 0^{-1-\mathrm{Apo}} \mathrm{E}^{-/}$mice had a more fibrotic appearance. The content of $\alpha$-smooth muscle actin ( $\alpha \mathrm{SMA}^{+}$cells) (fig. 8.2 a) and collagen (fig. $\mathbf{8 . 2}$ b) was significantly increased. Bright-field polarization microscopy revealed that in the absence of $\mathrm{CD} 40$, the color distribution of the collagen deviated towards the red spectrum, indicating larger collagen fibrils. ${ }^{17}$ Concordant with these findings, we found an increase in the amount of collagen I and III in the plaque (fig. $8.2 d-e$ ). 


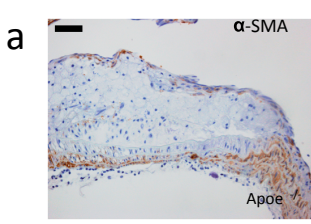

b

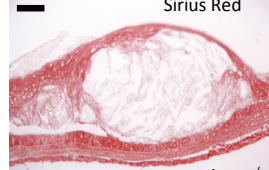

Red

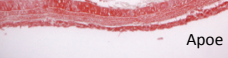

C
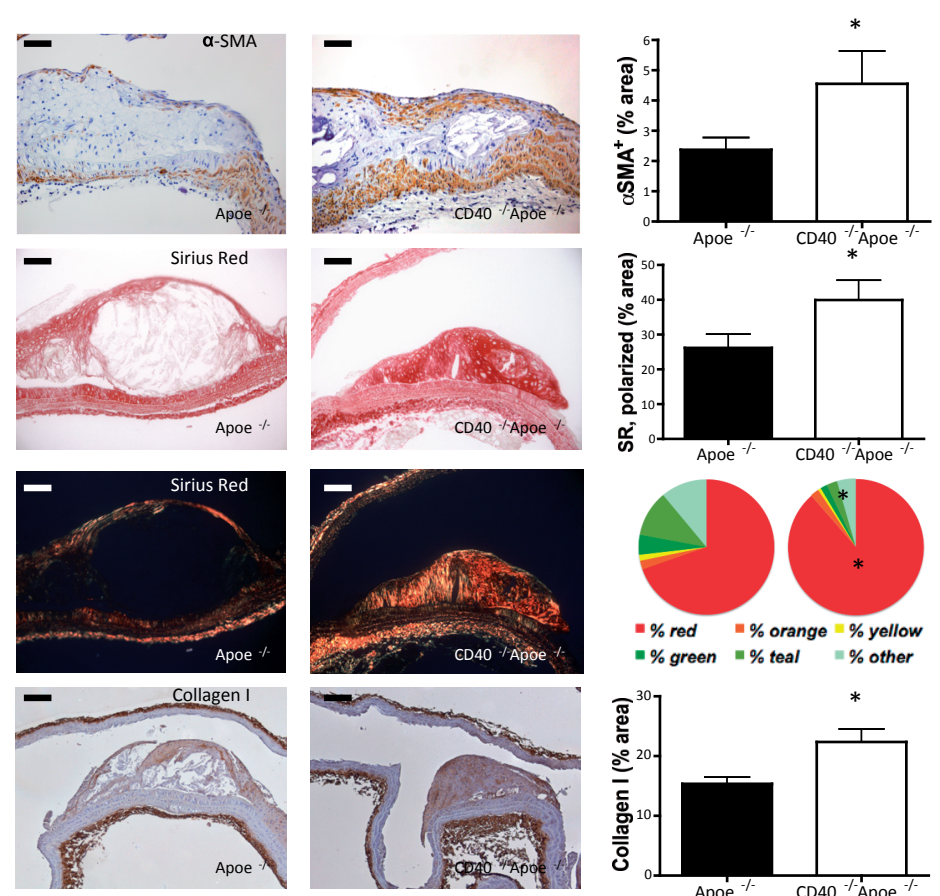

( ${ }^{30}$
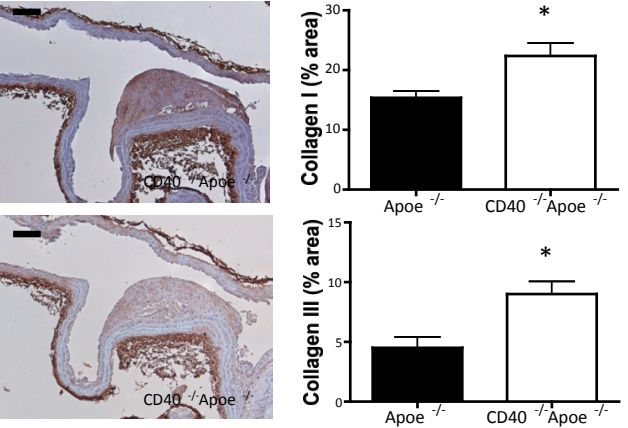

clustering antibody FGK45. We found that gelatinase activity was decreased (suppl. fig. 8.2 c), whereas TIMP-1 levels were increased in CD40-deficient macrophages (suppl. fig. $8.2 d)$.

Leukocyte CD40 Deficiency reduces Atherosclerosis and impairs Macrophage Migration

To unequivocally establish the involvement of leukocyte versus non-leukocyte CD40 in atherosclerosis, we reconstituted lethally irradiated $L D L r^{1-}$ mice with $C D 40 \%$ or wild-type (WT) bone marrow and fed the mice with a high-fat diet for 24 wks. Body weights and plasma cholesterol levels did not differ between the groups (BW: $20.1 \mathrm{~g}$ in $L D L r^{\prime}$-vs 19.7 g, p>0.05; Cholesterol: $368 \mathrm{mg} / \mathrm{dL} L D L r^{\prime-}$ vs $357 \mathrm{mg} / \mathrm{dL}$ ). Chimeric $L D L r^{/-}$mice with $C D 40^{-1}$ bone marrow exhibited markedly reduced atherosclerosis in the aortic arch including its branch points and in the thoraco-abdominal aorta (fig. 8.3 a). Similar to $C D 40^{-1-A p o E^{-1-}}$ mice, atherosclerotic plaques of chimeric $C D 40^{-1-L D L r-}$ mice contained less $\mathrm{Mac}^{+}$macrophages (fig. 8.3 b). In culture, $C D 40 \%$ macrophages showed an impaired migration towards CCL2 (fig. 8.3 c). Moreover, the percentage of CD45 ${ }^{+}$cells and $\mathrm{CD}^{+} \mathrm{T}$-lymphocytes in the plaque was decreased (fig. $\mathbf{8 . 3} \mathbf{~ e )}$. In accordance with this anti-inflammatory profile in the plaque, absence of CD40 strongly decreased the expression of IKB $\alpha$ in FGK45-stimulated macrophages (fig. $\mathbf{8 . 3}$ d), suggesting that the phenotypic effects are mediated by NFkB signaling. Total collagen content (fig. 8.3 f), and smooth muscle cell (SMC) content (fig. 8.3 f) were increased in the plaque in absence of CD40. These data reveal a crucial role for leukocyte-dependent CD40-signaling in atherosclerosis.

Figure 8.2

Deficiency of CD40 induces plaque fibrosis. Sections of the aortic arch and its main branch points (brachiocephalic artery, right and left subclavian artery, right and left carotid artery) of ApOE\% mice (n=19) and CD40\%ApOE ( $n=16)$ mice fed a normal chow diet for 26 wks were stained for smooth muscle actin (aSMA) to detect the content of smooth muscle cells (a, representative sections on the left: scale bars $50 \mathrm{um}$ ), which was quantified as the percentage of aSMA positive plaque area (a, right). Consecutive sections were stained with sirius red to assess the content of collagen in the plaque by light (b) and polarized light (c) microscopy (representative sections on the left, scale bars $50 \mu \mathrm{m}$ ). In addition, the content of collagen was expressed as the percentage of aSMA-positive plaqe area (b, right) and the color spectrum obtained using polarization microscopy was analyzed (c, right). The content of collagen I (d) and collagen III (e) was assessed by immunohistochemistry (representative sections on the left, scale bars $100 \mu \mathrm{m}$ ) and expressed as the percentage of positively stained plaque area (right). ${ }^{*} P<0.05$

Recent studies have identified the involvement of various matrix metalloproteinases in atherosclerotic lesion formation and their contribution to fibrous cap thinning by degrading extracellular matrix. ${ }^{18}$ Interestingly, MMP-2 and MMP-9 expression was decreased in the plaques of $\mathrm{CD} \mathrm{O}^{-1} \mathrm{ApoE} \mathrm{E}^{-}$mice (suppl. fig. $\mathbf{8 . 2} \boldsymbol{a}$-b). To confirm an impairment of proteolytic activity and effects of tissue inhibitor of metalloproteinase (TIMP)-1, we measured gelatinase activity and TIMP-1 mRNA levels in macrophages stimulated with the CD40- 

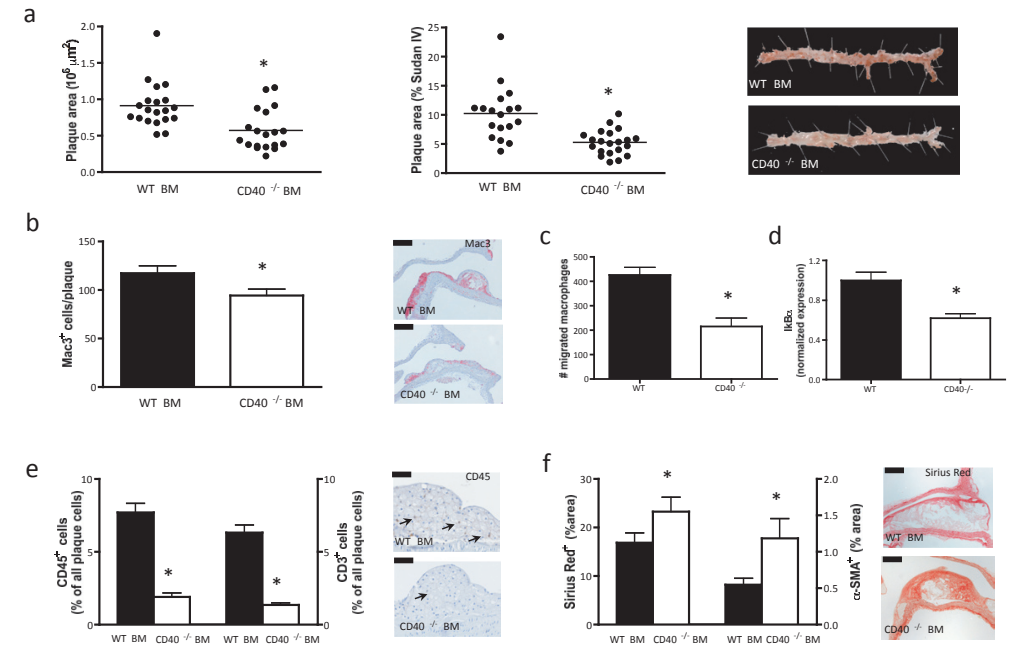

Figure 8.3

Role of haematopoietic cell-derived CD40 in diet-induced atherosclerosis. (a-f) wild-type (WT)>LDLr-chimeras $(n=19)$ were fed a normal chow diet for $26 \mathrm{wks}$ and were compared to $\mathrm{CD} 40^{\circ}>\mathrm{LDLr} /$ bone marrow $(B M)$ chimeras (n=19). Sections of the aortic arch and its main branch points (brachiocephalic artery, right and left subclavian artery, right and left carotid artery) were stained with haematoxylin and eosin and the thoraco-abdominal aorta was stained with Sudan IV (representative examples on the right) to analyze the extent of atherosclerosis (left: plaque area in the arch, middle: plaque area in the thoraco-abdominal aorta) (a) and phenotype (b-f). Macrophage infiltration was expressed as the absolute number of $\mathrm{Mac}^{+}$cells per plaque (scale bars, $\left.100 \mu \mathrm{m}\right)(\mathbf{b})$. Migration of bone marrow-derived macrophages towards CCL2 for 4 hrs was analyzed in a Transwell migration assay ( $n=6$ per group) (c). Levels of $I K B \alpha$ in FGK45-stimulated macrophages were determined by real-time PCR $(n=6)(d) . C D 45$ and $C D 3$ content were expressed as the percentage of $C D 3^{+}$or $C D 45^{+}$cells of all plaque cells (ar-

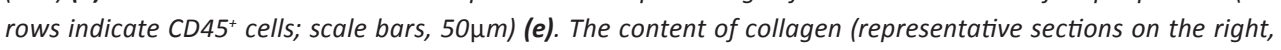

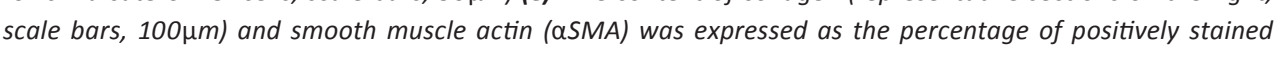
plaque area (f). ${ }^{*} P<0.05$

\section{Deficiency of CD40 polarizes Macrophages towards an M2-Phenotype}

Stimulation of CD40 with the clustering antibody FGK45 in bone marrow-derived macrophages resulted in a significant induction of the pro-inflammatory cytokines interleukin (IL)-12, iNOS (fig. 8.4 a) and CCL-2 (data not shown) and a significant reduction of IL-10 (fig. $8.4 \mathrm{c}$ ) in wild-type (WT) but not in $\mathrm{CD} \mathrm{O}^{-/}$macrophages, indicating that absence of CD40 polarizes macrophages towards an M2 phenotype. ${ }^{19}$

To further differentiate the $\mathrm{M} 2$ subset into 'wound-healing' and 'regulatory' macrophages, ${ }^{20}$ real-time PCR analysis for respective markers was performed in FGK45-stimulated bone marrow-derived macrophages. We observed that CD40-deficiency significantly reduced the inflammatory M1 markers iNOS and IL-12 (fig. 8.4 a) but only slightly reduced the expression of the 'wound healing' macrophage markers YM-1 and RELM $\alpha$, but did not affect the expression of arginase-I, IGF-1 or DCIR (fig. $\mathbf{8 . 4}$ b), suggesting that CD40-signaling is essential for polarization of macrophages towards the M1 subtype but not towards 'woundhealing' macrophages. Moreover, absence of CD40 did not result in an increase in collagen $1 \mathrm{~A} 1 \alpha$ production in these macrophages (fig. $\mathbf{8 . 4}$ b). In contrast, deficiency of CD40 strongly induced the 'regulatory' macrophage marker IL-10, while SPKH1 expression was not affected (fig. $\mathbf{8 . 4}$ c), indicating that CD40 deletion shifts the macrophage phenotype to an anti-inflammatory 'regulatory' signature. 
a

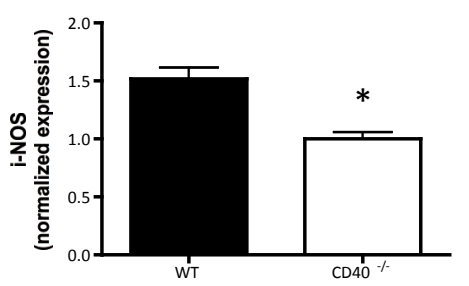

b
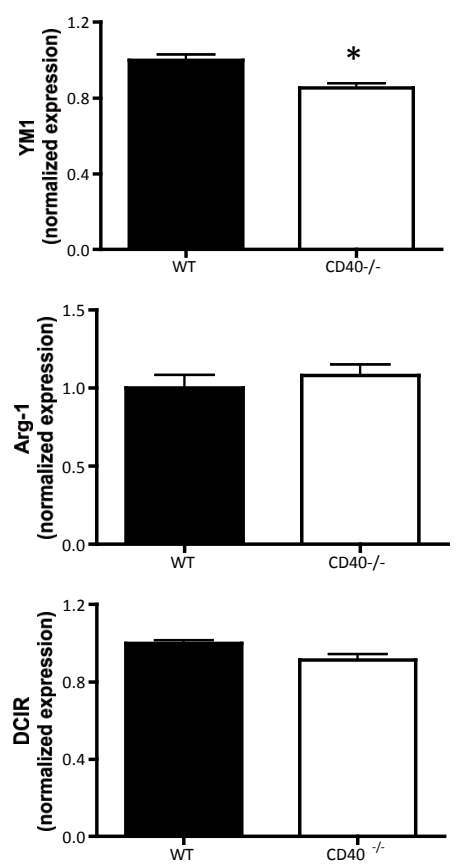

$*$

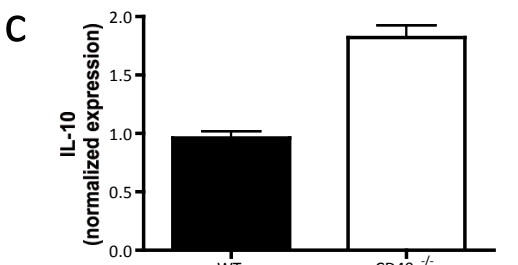

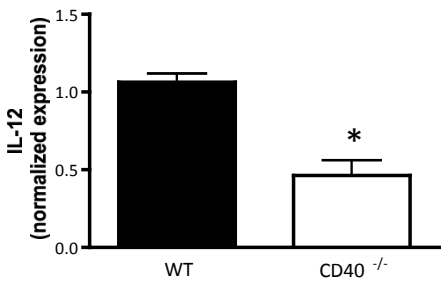
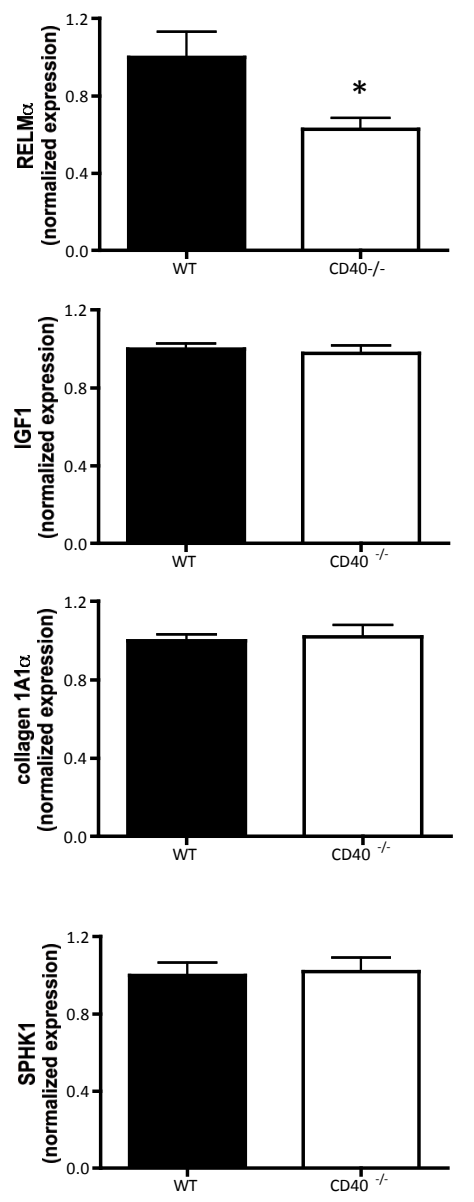

Figure 8.4

Deficiency in CD4O induces polarization of macrophages towards a regulatory M2 macrophage phenotype. Bone marrow-derived macrophages of WT and $\mathrm{CD} 40^{\circ}$ mice were cultured, stimulated with the CD40-clustering antibody FGK45 $(1 \mathrm{\mu g} / \mathrm{ml})$ and analyzed for expression of different $M 1(a)$ and $M 2$ (b) wound-healing macrophages; $c$, regulatory macrophages) subset markers by real-time $P C R ; n=6$ per group. * $P<0.05$.

CD40-Deficiency affects T-cell and DC Phenotype

To elaborate on the immune phenotyping, we performed flow cytometry analysis of blood, spleen and lymph node cells (suppl. fig. 8.3). Consistent with the atherosclerotic phenotype, analysis of the different T-lymphocyte and dendritic cell (DC) subsets revealed an anti-inflammatory profile in $\mathrm{CD}^{-1} \mathrm{ApOE}^{-1}$ versus $\mathrm{APOE}$ - mice. Whereas effector-memory (CD44 ${ }^{\text {high }} \mathrm{CD} 6 \mathrm{~L}^{\text {low }}$ ) $\mathrm{CD} 4^{+}$and $\mathrm{CD} 8^{+} \mathrm{T}$-lymphocytes were decreased, naïve (CD44 ${ }^{\text {low }} \mathrm{CD} 62 \mathrm{~L}-$ high) $\mathrm{CD}^{+}$and $\mathrm{CD} 8^{+}$T-lymphocytes were increased (suppl. fig. 3 a). Moreover, CD11 $\mathrm{C}^{+} \mathrm{CD} 8^{-}$ $\mathrm{CD} 4^{+} \mathrm{DCs}$, a population associated with anti-inflammatory responses was more prominent, whereas $\mathrm{CD} 11 \mathrm{C}^{+} \mathrm{CD} 4 \mathrm{CD}^{-}$and plasmacytoid DCs, populations associated with pro-inflammatory responses, were reduced (suppl. fig. 8.3 b). ${ }^{21}$

\section{CD40-TRAF Signaling in Atherosclerosis}

We next examined which of the $\mathrm{CD} 40$-associated signal transduction pathways was responsible for the phenotype observed in $\mathrm{CD}^{\circ} \mathrm{O}^{-} \mathrm{ApOE} \%$ mice. $\mathrm{CD} 40$ has no intrinsic signaling ability but requires adaptor molecules, TRAFs, to confer signaling. The cytoplasmic tail of CD40 contains 3 binding domains: a proximal domain that binds TRAF6, and two distal domains that bind TRAF1, TRAF2, TRAF3 and, indirectly, TRAF5. ${ }^{7,22,23}$ The separate TRAF binding sites are coupled to divergent signaling pathways involving different CD40 downstream modulators and effectors, ${ }^{7,24,25}$ depending on the target-cell types involved. To unravel the contribution of CD40-TRAF2/3/5 vs. CD40-TRAF6 signaling in $\mathrm{MHClI}^{+}$cells to atherosclerosis, we used $C D 40^{-}$mice expressing a chimeric $\mathrm{CD} 40$ transgene with mutations at the TRAF6 and/or TRAF2/3/5 binding site under control of the major histocompatibility complex (MHC)-II promotor (CD4O-T2/3/5\%, CD4O-T6\% and CD4O-T2/3/5/6 $\%$ mice, respectively) or $C D 40 \%$ mice carrying the transgene without mutations (CD40-Twt mice), ${ }_{16,26}$ and backcrossed them with $A p o E^{-1}$ mice. At 26 wks of age on a normal chow, atherosclerosis was analyzed in the aortic arch including its main branch points and the thoraco-abdominal aorta including the iliac artery bifurcation (data not shown). Body weight, plasma cholesterol level and serum SCD40L level did not differ between the genotypes (table 8.1).

\section{CD40-TRAF2/3/5 signaling does not affect atherosclerosis}

The atherosclerotic plaque area, the plaque phenotype, ${ }^{3}$ the plaque quality, as evident by the content of the lipid core, Mac- $3^{+}$cells, $\mathrm{CD} 45^{+}$cells, $\mathrm{CD} 3^{+} \mathrm{T}$-cells, collagen (I and III), SMCs, cleaved caspase 3 , and macrophage polarization did not differ between CD4OT2/3/5 $\%$ and CD4O-Twt mice, indicating that deficiency in CD40-TRAF2/3/5 signaling does not affect atherosclerosis (fig. 8.5 and fig. 8.6). In fact, $C D 40-T 2 / 3 / 5^{-1}$ mice displayed even higher numbers of $\mathrm{CD} 4^{+}$cells (suppl. fig. 8.4 a), and $\mathrm{CD} 8{ }^{+} \mathrm{CD} 44^{\text {high }} \mathrm{CD}^{2} \mathrm{~L}^{\text {low }}$ effector memory T-lymphocytes in blood, spleen and/or lymph nodes than CD40-Twt mice, and 
elevated CD8 ${ }^{+}$resident DCs (suppl. fig. $8.3 \mathbf{c}$-d), a subtype characterized by increased IL-12 production. This apparently pro-inflammatory profile was counter-balanced by elevated numbers of $\mathrm{CD} 4^{+} \mathrm{CD} 25^{+} \mathrm{FoxP3} 3^{+}$regulatory T-lymphocytes in blood, spleen and lymph nodes of CD4O-T2/3/5 $\%$ mice (suppl. fig. 8.4 b). Treg function had not changed (suppl. fig. 8.4 c), and due to the balanced effector-T-cell and Treg ratio, systemic levels of IFNY, IL-6, TNF $\alpha$, IL-12 or IL-10 were unaltered (data not shown). Notably, the content of $\mathrm{CD} 4^{+} \mathrm{CD} 25^{+} \mathrm{FoxP3}^{+}$ regulatory T-lymphocytes was also increased in the adventitia underlying the plaques, but not in the plaque itself, of CD40-T2/3/5\% mice (suppl. fig. 8.4 d).

\section{Inhibition of CD40-TRAF6 signaling abolishes atherosclerosis}

In a remarkable contrast, deficiency of CD40-TRAF6 signaling almost completely abolished the development of atherosclerosis, as only few intimal xanthomas or fatty-streak lesions (classified according to Virmani et $\mathrm{al}^{3}$ ) were detectable in the aortic arch and its branch points (fig. $8.5 \mathrm{a}$ ), and no plaques were present in the thoraco-abdominal aorta of CD4O$\mathrm{T}^{-}$mice (fig. $\mathbf{8 . 5}$ a). This reduction of atherosclerosis was even more pronounced than in $\mathrm{CD} 4 \mathrm{O}^{-} \mathrm{ApOE} \%$ mice, likely due to effects of residual CD40-TRAF2/3/5 signaling on regulatory T-lymphocytes. Concomitantly, macrophage, $\mathrm{CD} 45^{+}$cell and $\mathrm{CD3}^{+} \mathrm{T}$-lymphocyte infiltration but also collagen (I and III), $\alpha \mathrm{SMA}$, and MMP-2 and MMP-9 content were substantially reduced in the hardly evolved lesions of CD40-T6-/- mice (fig. 8.5 b-c, fig. 8.6 and suppl. fig. 8.5).

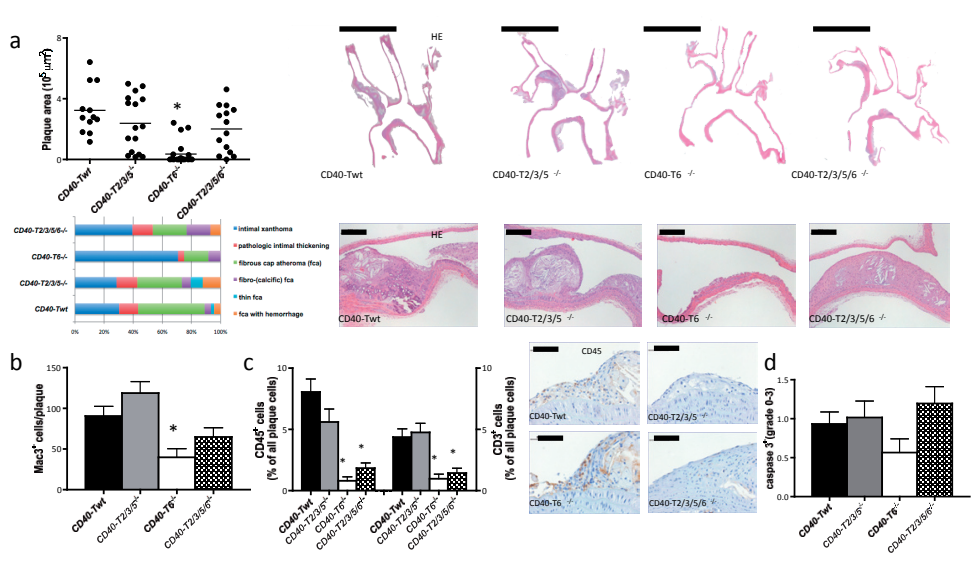

Figure 8.5

Role of CD40-TRAF signaling in atherosclerosis (a-d). CD40-Twt (n=12), CD40-T2/3/5-/ $(n=16)$, CD40-T6- $(n=19)$ and $C D 40-T 2 / 3 / 5 / 6-/-(n=14)$ were backcrosse

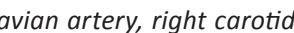
artery, left carotid artery and left subclavian artery) were stained with haematoxylin and eosin (HE) to analyze the extent of atherosclerosis (plaque area) and plaque phenotype (a-d). (a) Plaque area and distribution of mor- phological plaque phenotypes according to the classification by Virmani et al. (3) (left panels). Representative $H E$-stained sections on the right reveal only limited atherosclerosis in absence of CD4O-T6 signaling (scale bars, $2 \mathrm{~mm}$ upper panel, $100 \mathrm{um}$ lower panel). (b-d) CD40-T6-/- mice have small atherosclerotic lesions that contain few macrophages (b), $C D 45^{+}$cells and $C D 3^{+} T$ cells (c). The level of cleaved caspase 3 was determined by grading plaque from $O$ (no expression) to 3 (high expression) (d). ${ }^{*} P<0.05$

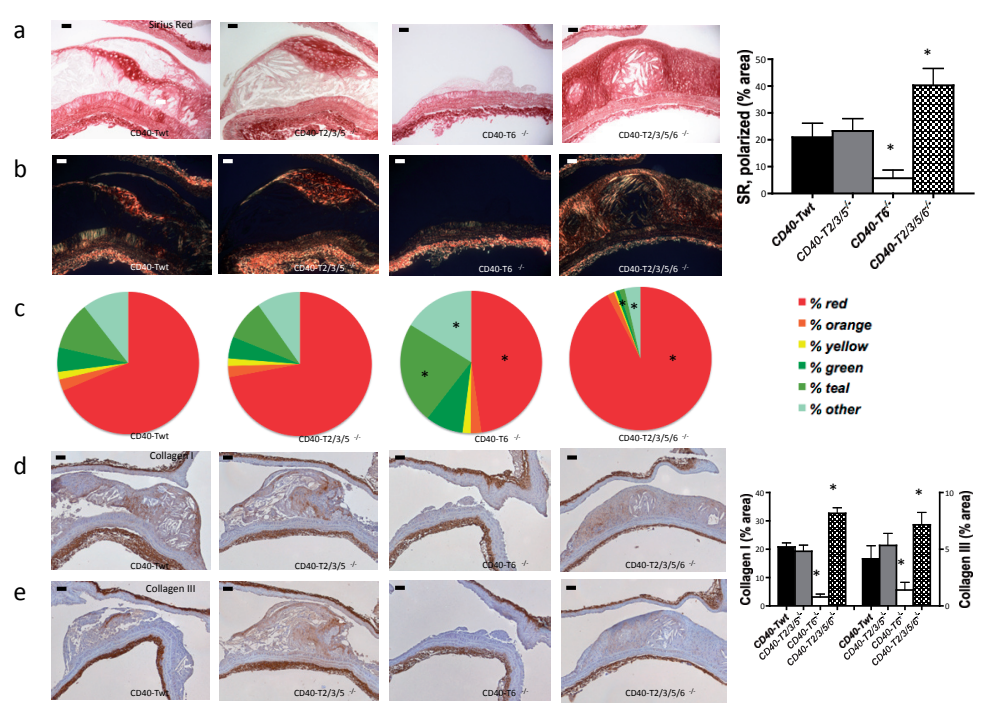

Figure 8.6

Role of CD40-TRAF signaling in plaque fibrosis (a-e). Sirius red-stained sections showed low levels of collagen in the initial plaques of CD4O-T6\% mice, and increased levels in plaques of CD40-T2/3/5/6\% mice (a-c, scale bar 50 $\mu \mathrm{m})$. Collagen content was assessed by light (a) and polarized light (b) microscopy and expressed as the percentage of sirius red-stained plaque area (right). In addition, the color spectrum obtained under polarization microscopy was analyzed (c). The content of collagen I (d) and collagen III (e) was assessed by immunohistochemistry (representative sections on the left, scale bars $100 \mu \mathrm{m}$ ) and expressed as the percentage of positively stained plaque area (right). ${ }^{*} P<0.05$

The population of peripheral blood Ly6 $\mathrm{C}^{\text {high }}$ monocytes was significantly declined (fig. 8.7 a). Moreover, $\mathrm{CD} 40-\mathrm{T6} \%$ macrophages had an impaired capacity to migrate towards CCL2 (fig. 8.7 b). Intravital microscopy showed that the adhesion of circulating leukocytes and in particular that of Ly6C monocytes to carotid arteries was significantly impaired in CD40T6 ${ }^{-1}$ mice (fig. $\left.8.7 c-d\right)$ 
a

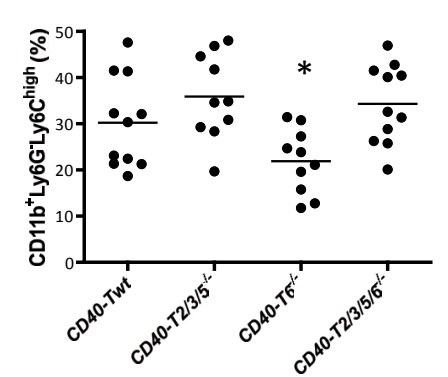

C

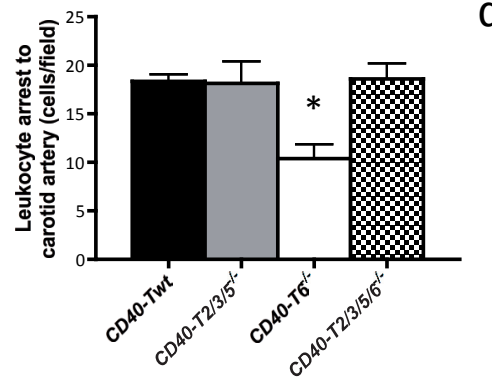

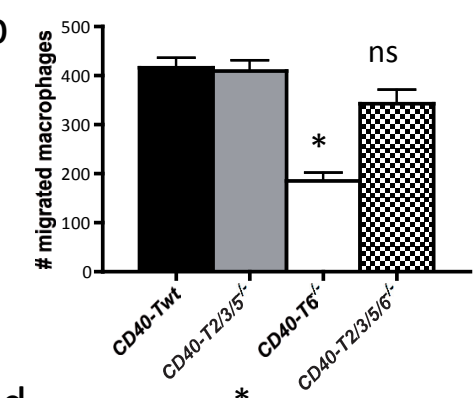

d

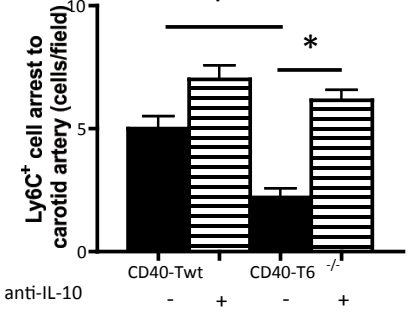

Figure 8.7

CD40-TRAF signaling affects monocyte homeostasis and recruitment (a-d). The percentage of Ly6Chigh monocytes is reduced in the peripheral blood of CD4O-T6*-mice (a). Macrophages deficient in CD4O-TRAF6 signaling have an impaired capacity to migrate towards CCL2 in a Transwell migration assay (b). Accordingly, rhodamine-labeled leukocytes (c) and Ly6C monocytes (d) display an impaired luminal adhesion to the wall of carotid arteries in absence of CD40-T6 interactions in vivo, which is reversed by pretreatment with a blocking antibody to lL-10 (d). $* P<0.05$.

\section{CD40-TRAF6 deficiency polarizes macrophages towards a regulatory M2 phenotype}

Bone marrow-derived macrophages of $\mathrm{CD} 40-\mathrm{T6}^{\%}$ mice stimulated with $\mathrm{FGK} 45$ produced less IL-12 and iNOS but increased amounts of IL-10, (fig. 8.8), indicating that CD40-TRAF6 deficiency skews macrophage polarization towards an anti-inflammatory M2-phenotype. Further subtyping of the M2 macrophages into 'wound-healing' and 'regulatory' macrophages ${ }^{20}$ showed that CD40-TRAF6 interactions did not affect the 'wound-healing' macrophage markers YM-1, RELM $\alpha$, arginase I, IGF1 or DCIR, but markedly dampened the M1 polarization response and rather induced a 'regulatory' macrophage subtype that produces high amounts of IL-10. Importantly, the process of monocyte recruitment driven by CD40-TRAF6 was mediated by IL-10, as treatment of CD40-T6 $\%$ mice with a blocking antibody to IL-10 reversed the protective effect on Ly $6 \mathrm{C}^{+}$cell numbers and adhesion (fig. 8.7 d). The phenotype that occurs in CD40-T6\% mice is likely associated with an impaired NFKB signaling, since IKB $\alpha$ levels in macrophages were markedly decreased (fig. $8.8 \mathrm{~d}$ ). In line with findings in CD40-deficient macrophages, $C D 40-T 6 \%$ macrophages displayed a reduced gelatinolytic activity and increased expression of TIMP-1 (suppl. fig. $8.5 c-d$ ).
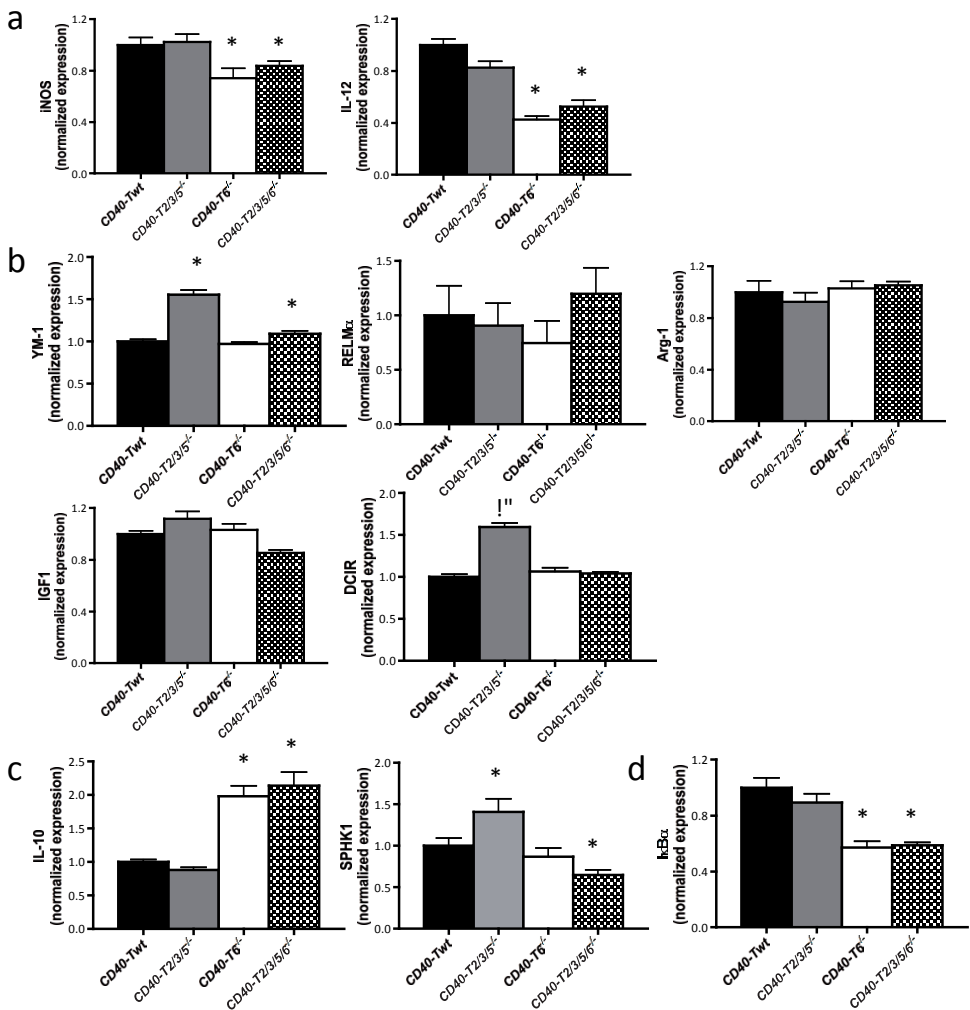

Figure 8.8

Deficiency in CD40-TRAF6 interactions induces polarization of macrophages towards a regulatory M2 macrophage phenotype (a-c). Bone marrow-derived macrophages of CD40-Twt, CD40-T2/3/5 $\%, C D 40-T 6^{-}, C D 40$ $T 2 / 3 / 5 / 6$ mice were cultured, stimulated with the CD4O-clustering antibody FGK45 $(1 \mu \mathrm{g} / \mathrm{ml})$ and analyzed for expression of different $M 1$ ( $a$ ) and $M 2$ ( $b$, wound-healing macrophages; $\boldsymbol{c}$, regulatory macrophages) subset markers by real-time $P C R ; n=6$ per group. The levels of $I K B \alpha$ in $F G K 45$-stimulated macrophages were decreased in bone marrow-derived macrophages of CD40-T6 $\%$ and CD40-T2/3/5/6\% mice $(n=6)(d)$. * $P<0.05$.

Flow cytometry analysis further revealed reduced numbers of $\mathrm{CD} 4{ }^{+} \mathrm{CD} 44^{\text {high }} \mathrm{CD} 62 \mathrm{~L}^{\text {low }}$ promigratory effector-memory T-lymphocytes and plasmacytoid DCs (suppl. fig. 8.3 c-d).

\section{Deficiency of CD40-TRAF2/3/5/6 interactions induces plaque fibrosis}

Of note, mice with a combined deficiency in CD40-TRAF2/3/5 and - 6 binding were characterized by an intermediate phenotype, further supporting counter-curing effects of CD40TRAF2/3/5 and CD40-TRAF6 signaling in atherosclerosis. CD4O-T2/3/5/6\% mice showed only a slight reduction in atherosclerosis (fig. $\mathbf{8 . 5}$ a), but displayed features of atherosclerotic plaque stability (fig. 8.5 a), with an increased number of fibrocalcific plaques containing smaller lipid cores, reduced $\mathrm{CD} 45^{+}$cell and $\mathrm{CD}^{+} \mathrm{T}$-lymphocyte infiltrations. 
Plaques of CD40-T2/3/5/6 - mice exhibited high levels of collagen (fig. 8.6 a-c) and $\alpha$ SMApositive SMCs $(3.1 \pm 0.7$ vs $5.1 \pm 0.9 ; p<0.05)$. Polarized light microscopy on Sirius-Redstained sections further showed that the majority of this collagen consisted of large fibrils, as evident by the high percentage of the 'red' fraction (fig. $\mathbf{8 . 8} c-d$ ). In concordance with this finding, plaque levels of collagen I were significantly increased, whereas collagen III levels were unaffected (fig. 8.6 e-f). Moreover, plaque MMP-2 and MMP-9 levels were significantly reduced in CD40-T2/3/5/6 - mice (suppl. fig. 8.5 a-b), indicating a decreased proteolytic activity in these plaques. Accordingly, bone marrow-derived macrophages of CD40-T2/3/5/6\% mice treated with CD40-clustering antibody FGK45 displayed reduced gelatinolytic activity and elevated levels of TIMP-1 mRNA (suppl. fig. 8.5 c-e).

As in $\mathrm{CD} 40-\mathrm{T6} \%$ mice, macrophages of $\mathrm{CD} 40-\mathrm{T} 2 / 3 / 5 / 6 \%$ mice stimulated with FGK45 exhibited an M2 macrophage profile with decreased IL-12 production and increased production of IL-10, whereas ly $6 \mathrm{C}^{\text {high }}$ monocyte numbers and adhesive function were unaffected (fig. 8.7 and fig. 8.8). CD $40-T 2 / 3 / 5 / 6^{\%}$ mice shared increased CD $8^{+}$effector-memory T lymphocytes with CD4O-T2/3/5\% mice and decreased pDC numbers with CD40-T6\% mice (suppl. fig. $8.3 c-d)$. This indicates that some features, namely reduced inflammatory monocyte arrest, and macrophage polarization are exclusive to $C D 40-T 6 \%$ mice and are not compensated by deficiency of both TRAF binding sites.

\section{Discussion}

In this study, we found a clearly divergent action of the two TRAF binding sites of CD40 in atherosclerosis. Deficiency of CD40-TRAF6 interactions in $\mathrm{MHClI}^{+}$cells nearly abrogated atherosclerosis, an effect more marked than CD40 deletion itself, whereas deficiency of CD40-TRAF2/3/5 interactions did not affect atherosclerosis, but rather showed a tendency to aggravate atherosclerosis. The CD40-TRAF6 interactions appeared to be specifically required for the proatherogenic activity exerted by cells of the myeloid lineage. Deficiency of CD40-TRAF6 interactions limits the subset of Ly6 $\mathrm{C}^{\text {high }}$ inflammatory monocytes, and attenuates their adhesion to and infiltration into the arterial wall, thereby abolishing atherosclerotic plaque formation. The few monocytes that succeed in infiltrating the arterial wall rather differentiate into macrophages with an anti-inflammatory, regulatory M2-signature, thereby preventing plaque inflammation and progression.

Here we provide conclusive evidence for an important role of CD40-TRAF6 interactions in the recruitment and fate of monocytes/macrophages. Diversity and plasticity are a hallmark of the monocyte/macrophage lineage, and their phenotype strongly depends on their microenvironment and the inflammatory signals they perceive. ${ }^{20,27,28}$ We found that CD40TRAF6 signaling affects the homeostasis of both monocyte and macrophage polarization. CD40-T6\% mice showed reduced numbers and reduced arterial recruitment of Ly6Chigh monocytes, the 'inflammatory monocyte' subset that dominates in hyperlipidemia, ${ }^{29,30}$ can easily enter the arterial wall and can differentiate into intimal macrophages. In parallel, CD40-T6\% mice showed a reduction in the classically activated M1 macrophage subset producing iNOS and IL-12, which is involved in clearing intracellular parasites or tumors and eliciting tissue disruption. ${ }^{20,27}$ Macrophages of $\mathrm{CD} 40-\mathrm{T6} \%$ mice were skewed towards the M2 phenotype, and particularly towards the IL-10-producing 'regulatory' subtype. ${ }^{20}$ Interestingly, the reduced recruitment of Ly6 $\mathrm{C}^{\text {high }}$ monocytes in the carotid artery of CD40T6\% mice could be reversed by blocking IL-10, indicating that there could be a link between the IL-10-producing macrophage phenotype and effects on subsequent monocyte recruitment. Surprisingly, markers of the eponymously termed 'wound-healing' macrophages, which contribute to the healing response after tissue destruction, were unaltered in absence of CD40-TRAF6 interactions, although high levels of plaque fibrosis were observed in CD40-T2/3/5/6- mice. However, the relevance of these data has to be further substantiated and validated, since the functional role of different monocyte and macrophage subsets in atherosclerosis remains to be fully elucidated. ${ }^{31,32}$ For now, our data clearly reveal that a deficiency of CD40-T6 interactions confers an immune-regulatory phenotype in the monocyte/macrophage lineage, which reduces atherosclerosis and is capable of inducing plaque stability. 
In vascular pathobiology, only few data are available on the role CD40-TRAF6 interactions. Recently, CD40-TRAF6 interactions in $\mathrm{MHCll}^{+}$cells have also been implicated in neointima formation in a murine ligation model. ${ }^{16}$ Moreover, it has been observed that stimulation with CD40L induces CD40-TRAF6 interactions in endothelial cells but that their disruption surprisingly results in increased expression of CCL2. ${ }^{15}$ More evidence has been gathered regarding the role of CD40-TRAF6 interactions in haematopoietic cell types including cells of the myeloid lineage. In B-cells, effects of CD40-TRAF6 signaling comprise germinal center formation, NFKB activation, IL-6 production and up-regulation of co-stimulatory molecules. ${ }^{26,33,34}$ In monocytes/macrophages, CD40-TRAF6 interactions induce NFKB and ERK activation, as well as the production of TNF $\alpha$ and IL- $6 .{ }^{35}$ In dendritic cells, CD40-TRAF6 signaling is required for MHCII surface expression, IL- 6 and IL-12 production. ${ }^{36}$ Differences in the effector functions of CD40-TRAF6 signaling between the various cell types may be due to context-specific embedding of down-stream pathways.

Our data further show that CD40-TRAF2/3/5 interactions on $\mathrm{MHClI}^{+}$cells appear to be required for maintaining T-lymphocyte homeostasis in atherosclerosis. Absence of CD40-TRAF2/3/5 interactions increased the numbers of $\mathrm{CD}^{+}{ }^{+}$T-cells and pro-migratory $\mathrm{CD} 8^{+} \mathrm{CD} 44^{\text {high }}{ }^{\mathrm{C}} \mathrm{CD} 6 \mathrm{~L}^{\text {low }}$ effector memory T-lymphocytes, which by itself would likely be sufficient to aggravate atherosclerosis. However, the increase in T-cells was compensated by an increase in $\mathrm{CD}^{+} \mathrm{CD}^{2} 5^{+} \mathrm{FoxP}^{+}$regulatory T-lymphocytes, both systemically and in the vasculature. This expansion of regulatory T-cells as an atheroprotective T-cell subtype ${ }^{37}$ may protect $C D 40-T 2 / 3 / 5 \%$ mice against the T-cell induced exacerbation of atherosclerosis.

Data on the role of CD40-T2/3/5 signaling in vascular biology are scarce and not uniform, as the induction of CD40-TRAF2/3/5 signaling yields different outcomes depending on the cell types and pathologies involved. In line with the present study, we did not find an effect on neointima formation after carotid artery ligation in CD40-T2/3/5 $\%$ mice. ${ }^{16}$ However, TRAF2 $\%$ and TRAF5 $\%$ endothelial cells failed to produce IL-6 upon stimulation with CD4OL, whereas CCL2 induction was unaffected..$^{15}$ In areas with high shear stress, TRAF3 expression in endothelial cells covering human atherosclerotic plaques is up-regulated and may act as a feed-back mechanism limiting endothelial activation, as its overexpression prevented CD40-induced proinflammatory cytokine expression. ${ }^{38}$

A clearer picture for the function of CD40-TRAF2/3/5 interactions has emerged in B-cell biology. CD40-TRAF2 signaling is crucial for germinal center formation, induces JNK activation and in particular NFKB2 activation. ${ }^{34,39,40}$ This is accordance with our findings that IKB $\alpha$ mRNA expression was not significantly decreased in CD4O-T2/3/5 $\%$ macrophages. Together with CD40-TRAF5 interactions, which are also required for Ig production, CD40TRAF2 signaling up-regulates co-stimulatory molecules..$^{40}$ In contrast, TRAF3 acts as an inhibitor reducing co-stimulatory molecule expression and IgM production. ${ }^{41}$ In cell types and organs other than B-cells or lymph nodes, however, most of these functions are irrelevant. In line with our data, the overall effect of CD40-TRAF2/3/5 signaling with regards to atherogenesis appears to be balanced.

Our findings may harbor new and interesting therapeutic possibilities. The complete inhibition of CD40-CD40L signaling in atherosclerosis is not therapeutically feasible, since long-term treatment will compromise systemic immune responses and also entails thromboembolic complications. Therefore, inhibition of the TRAF6 binding site on CD40, by using small molecules or an antagonizing CD40 antibody that changes the conformation of the CD40-TRAF binding sites, may be a suitable alternative. It is conceivable that the protection by CD40-TRAF6 blockade is conferred by skewing the immune response to a more anti-inflammatory profile, namely through increased production of IL-10 and its effects on mitigating the relative propensity, the recruitment and differentiation of pro-inflammatory monocytes. Not only could inhibition of the CD40-TRAF6 binding site reduce atherosclerosis more effectively than a complete inhibition of CD40 or CD40L, by avoiding an interference with potentially protective effects by remaining CD40-signaling pathways, it may also leave the normal functions of these pathways unaffected, and would therefore be expected to only cause limited side-effects. However, although our results in the mouse model are promising, caution should be applied when extrapolating these experimental data to the human situation. The effects of such selective targeting strategies will have to be meticulously scrutinized, before being translated into a clinical setting. 
Supplementary figure legends a
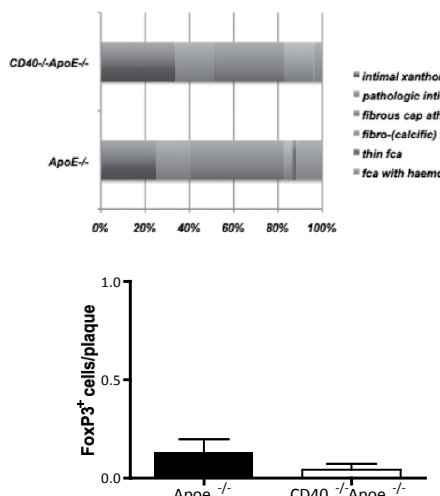

b
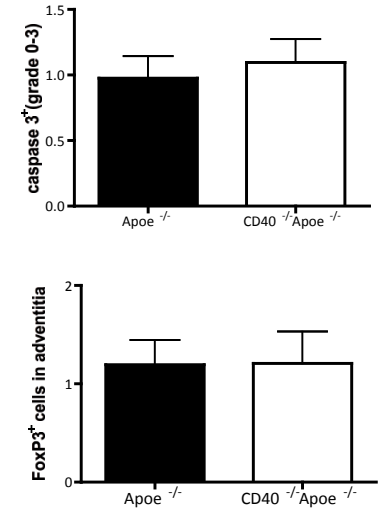

Supplementary figure 8.1

Morphological plaque phenotypes according to Virmani et al (a) show that deficiency of $\mathrm{CD} 40$ results in an increased number of intimal xanthomas and a decrease in the number of fibrous cap atheromata. Moreover, absence of $C D 40$ decreases the amount of vulnerable, thin fibrous cap a theromata. No difference could be observed in the amount of cleaved caspase 3 in the plaque (b) or the number of FoxP3 $3^{+}$regulatory Tlymphocytes in plaque (c) or adventitia (d).

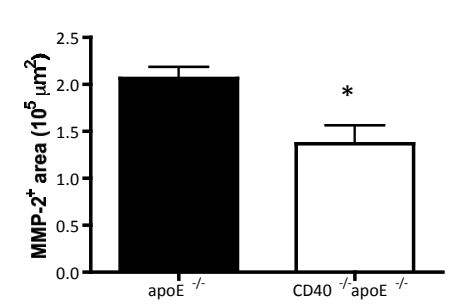

C

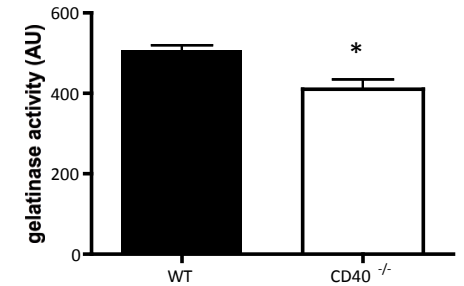

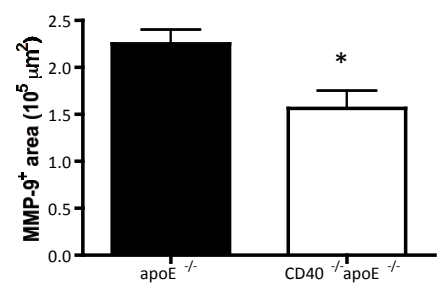

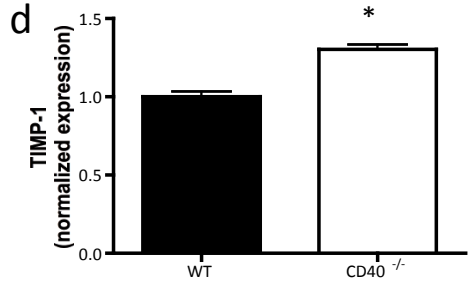

Supplementary figure 8.2

Deficiency of CD40 reduces proteolysis. The content of MMP-2 and MMP-9, expressed as absolute positively stained area per plaque, was reduced in $\mathrm{CD} 40 \%$ ApoE $\%$ mice $(a-b)$. Consistent with these data, gelatinase activity was reduced in bone marrow-derived FGK45-treated macrophages of $\mathrm{CD} 40 \%$ mice (c). The levels of TIMP-1 were increased in $\mathrm{CD} 40^{-}$macrophages (d).
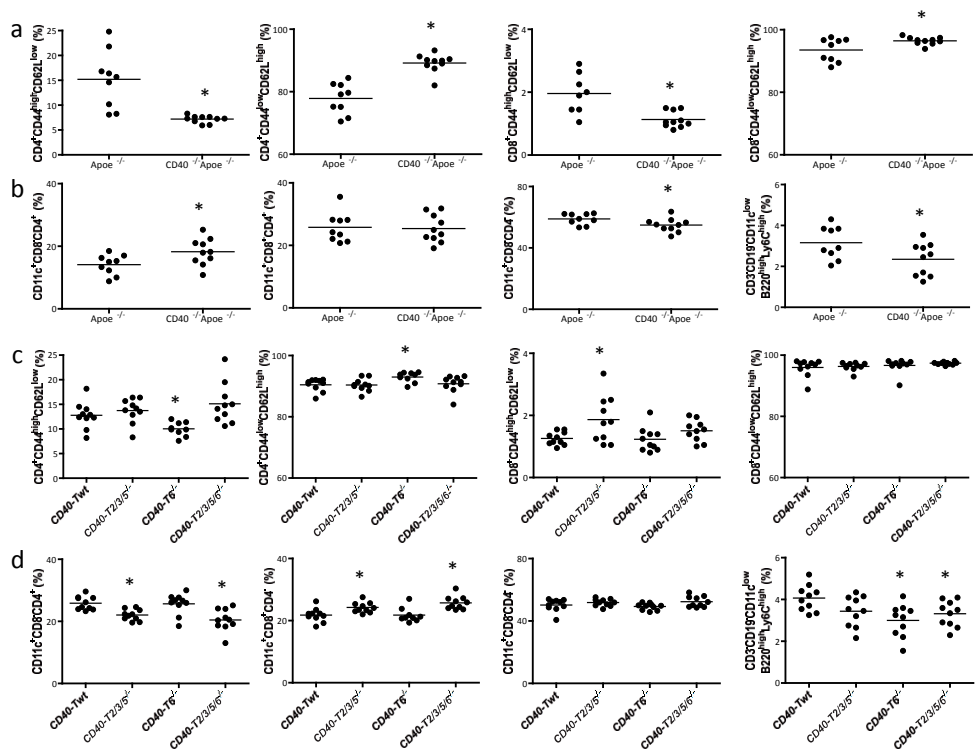

\section{Supplementary figure 8.3}

Immunophenotyping of blood, spleen and lymph node cells. Depicted are the results of FACS experiments of splenic cells from ApoE $\%, C D 40 \% A p o E \%,(a-b), C D 40-T w t, C D 40-T 2 / 3 / 5 \%, C D 40-T 6 \%$, and CD40-T2/3/5/6\% mice (c-d). (a) $\mathrm{CD} 40$ deficiency reduces the fraction of $\mathrm{CD}^{+}$and $\mathrm{CD} 8^{+} \mathrm{CD} 44^{\text {high }} \mathrm{CD} 62 \mathrm{~L}^{\text {low }}$ effector memory $\mathrm{T}$-cells, and increases the fraction of naive T-cells. (b) CD40 deficiency increases the amount of CD8 CD4 $D C$ s and CD8 CD4 DCS, and decreases the fraction of plasmacytoid (CD3-CD19-CD11 ${ }^{\left.\text {low } B 220^{\text {high }} \angle y 6 C^{\text {high }}\right)} D C S$. (c) Deficiency in CD40-T6 signaling reduces the fraction of $C D 4^{+} C D 44^{\text {high }} C D 62 L^{\text {low }}$ effector memory $T$-cells, whereas deficiency in

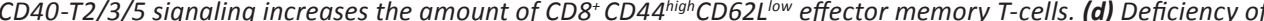
CD4O-T2/3/5 and CD4O-T2/3/5/6 signaling reduces the fraction of CD8 CD4 ${ }^{+} D C s$ and increases the fraction of $C D 8^{+} C D 4 \cdot D C S$, whereas the fraction of plasmacytoid DCs decreases in absence of CD4O-T6 and CD4O-T2/3/5/6 signaling. ${ }^{*} P<0.05$ 

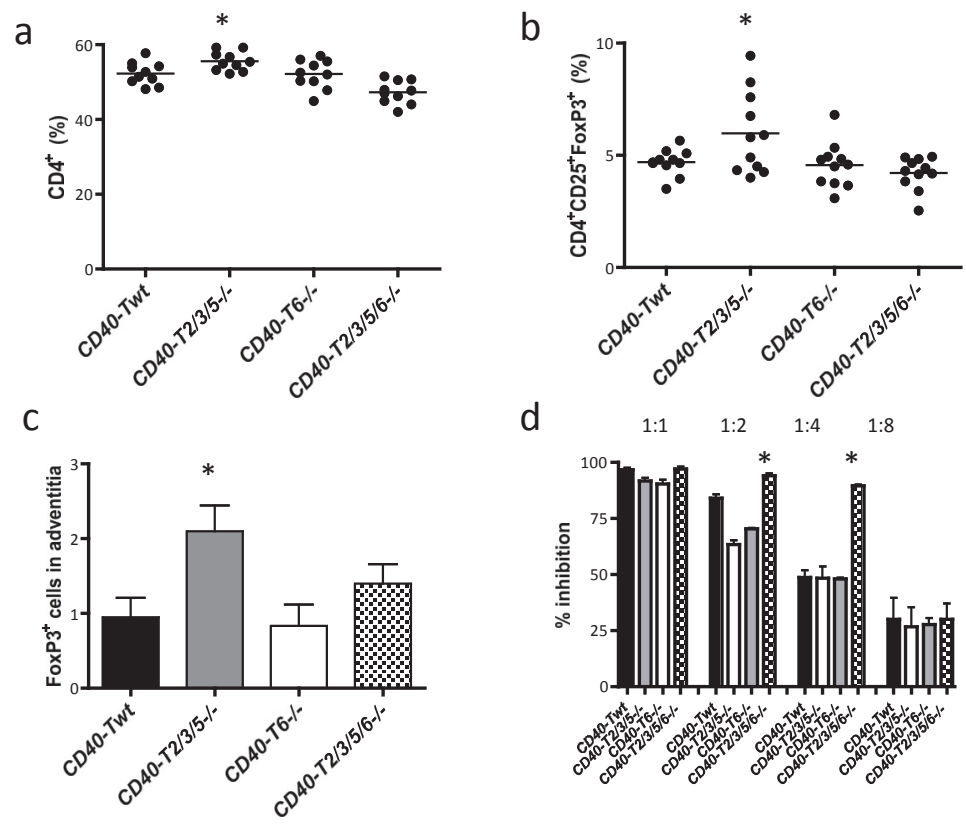

Supplementary figure 8.4

Deficiency of CD4O-TRAF2 signaling results in an increase in $C D 3^{+} C D 4^{+} T$ lymphocytes in spleen (a), blood and lymph nodes (data not shown). This increase in effector-T lymphocytes is compensated by an increase in $C D 4^{+} C D 25^{+} F o x P 3^{+}$regulatory $T$ lymphocytes in spleen (b), blood and lymph nodes (data not shown) and in the adventitia underlying the plaque (c), while Treg function had only significantly changed in the CD40-T2/3/5/6-1 mouse (d). ${ }^{*} P<0.05$. a
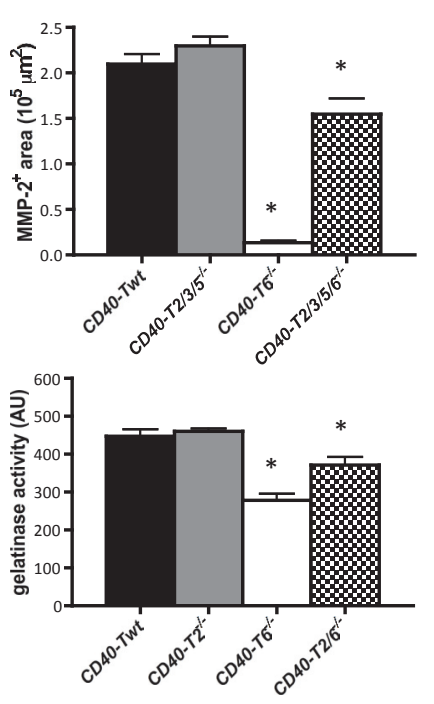
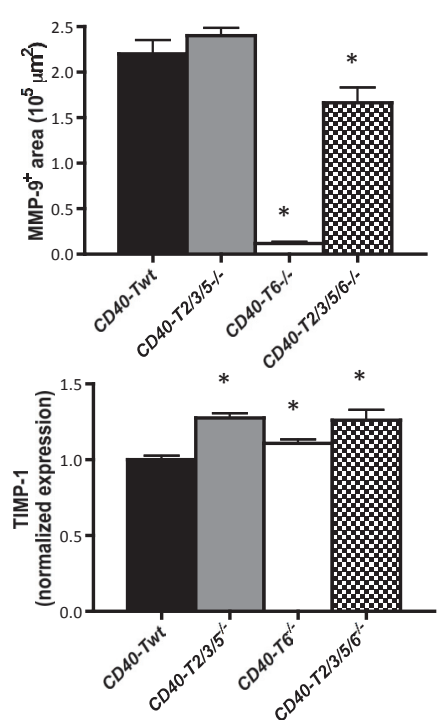

Supplementary figure 8.5

Deficiency of CD40 reduces proteolysis. The content of MMP-2 and MMP-9, expressed as absolute positively stained area per plaque was reduced in CD40-T6\% and CD40-T2/3/5/6\% mice (a-b). Consistent with these data, gelatinase activity was reduced in bone marrow-derived FGK45-treated macrophages of CD40-T6\% and CD4OT2/3/5/6\% mice (c). The levels of TIMP-1 were increased in macrophages of all CD4O-TRAF mouse models (d). 


\section{References}

1. Weber, C., Zernecke, A. \& Libby, P. The multifaceted contributions of leukocyte subsets to atherosclerosis: lessons from mouse models. Nat Rev Immunol 8, 802-815 (2008).

2. Hansson, G.K. Inflammation, atherosclerosis, and coronary artery disease. N Engl J Med 352, 1685-1695 (2005).

3. Virmani, R., Kolodgie, F.D., Burke, A.P., Farb, A. \& Schwartz, S.M. Lessons from sudden coronary death: a comprehensive morphological classification scheme for atherosclerotic lesions. Arterioscler.Thromb.Vasc. Biol. 20, 1262-1275 (2000).

4. Durie, F.H., et al. Prevention of collagen-induced arthritis with an antibody to gp39, the ligand for CD40. Science 261, 1328-1330 (1993).

5. Gerritse, K., et al. CD40-CD40 ligand interactions in experimental allergic encephalomyelitis and multiple sclerosis. Proc Natl Acad Sci U S A 93, 2499-2504 (1996).

6. Vowinkel, T., et al. CD40-CD40 ligand mediates the recruitment of leukocytes and platelets in the inflamed murine colon. Gastroenterology 132, 955-965 (2007).

7. Lutgens, E., Lievens, D., Beckers, L., Donners, M. \& Daemen, M. CD40 and its ligand in atherosclerosis. Trends Cardiovasc Med 17, 118-123 (2007).

8. Lutgens, E., et al. Requirement for CD154 in the progression of atherosclerosis. Nat.Med. 5, 1313-1316 (1999).

9. Lutgens, E., et al. Both early and delayed anti-CD40L antibody treatment induces a stable plaque phenotype. Proc.Natl.Acad.Sci.U.S.A 97, $7464-7469$ (2000).

10. Mach, F., Schonbeck, U., Sukhova, G.K., Atkinson, E. \& Libby, P. Reduction of atherosclerosis in mice by inhibition of CD40 signalling. Nature 394, 200-203 (1998).

11. Schonbeck, U., Sukhova, G.K., Shimizu, K., Mach, F. \& Libby, P. Inhibition of CD40 signaling limits evolution of established atherosclerosis in mice. Proc.Natl.Acad.Sci.U.S.A 97, 7458-7463 (2000).

12. Kawai, T., Andrews, D., Colvin, R.B., Sachs, D.H. \& Cosimi, A.B. Thromboembolic complications after treatment with monoclonal antibody against CD40 ligand. Nat Med 6, 114 (2000).

13. Andre, P., et al. CD40L stabilizes arterial thrombi by a beta3 integrin--dependent mechanism. Nat Med 8 , $247-252$ (2002).

14. Zirlik, A., et al. CD40 ligand mediates inflammation independently of CD40 by interaction with Mac-1. Circulation 115, 1571-1580 (2007).

15. Zirlik, A., et al. TRAF-1, $-2,-3,-5$, and -6 Are Induced in Atherosclerotic Plaques and Differentially Mediate Proinflammatory Functions of CD40L in Endothelial Cells. Arterioscler Thromb Vasc Biol (2007).

16. Donners, M.M., et al. The CD40-TRAF6 axis is the key regulator of the CD40/CD40L system in neointima formation and arterial remodeling. Blood 111, 4596-4604 (2008).

17. Mackenna DA, O.J. A semi-automated method for measuring collagen area fraction and size distribution using picrosirius red. Cardiovasc Pathobiol 1, 104-117 (1996).

18. Hansson, G.K. \& Libby, P. The immune response in atherosclerosis: a double-edged sword. Nat Rev Immunol 6, 508-519 (2006)

19. Martinez, F.O., Helming, L. \& Gordon, S. Alternative Activation of Macrophages: An Immunologic Functional Perspective. Annu Rev Immunol (2008).

20. Mosser, D.M. \& Edwards, J.P. Exploring the full spectrum of macrophage activation. Nat Rev Immunol 8 , 958-969 (2008).

21. Shortman, K. \& Liu, Y.J. Mouse and human dendritic cell subtypes. Nat Rev Immuno/ 2, 151-161 (2002).
22. Zapata, J.M. TNF-receptor-associated factors as targets for drug development. Expert Opin Ther Targets 7, 411-425 (2003).

23. Lu, L.F., et al. The in vivo function of a noncanonical TRAF2-binding domain in the C-terminus of CD40 in driving B-cell growth and differentiation. Blood 110, 193-200 (2007).

24. Lievens, D., Eijgelaar, W.J., Biessen, E.A., Daemen, M.J. \& Lutgens, E. The multi-functionality of CD40L and its receptor CD40 in atherosclerosis. Thromb Haemost 102, 206-214 (2009).

25. Engel, D., et al. The immunobiology of CD154-CD40-TRAF interactions in atherosclerosis. Semin Immunol (2009).

26. Ahonen, C., et al. The CD40-TRAF6 axis controls affinity maturation and the generation of long-lived plasma cells. Nat.Immunol. 3, 451-456 (2002).

27. Gordon, S. Alternative activation of macrophages. Nat Rev Immunol 3, 23-35 (2003).

28. Auffray, C., Sieweke, M.H. \& Geissmann, F. Blood monocytes: development, heterogeneity, and relationship with dendritic cells. Annu Rev Immunol 27, 669-692 (2009).

29. Swirski, F.K., et al. Ly-6Chi monocytes dominate hypercholesterolemia-associated monocytosis and give rise to macrophages in atheromata. J Clin Invest 117, 195-205 (2007).

30. Tacke, F., et al. Monocyte subsets differentially employ CCR2, CCR5, and CX3CR1 to accumulate within atherosclerotic plaques. J Clin Invest 117, 185-194 (2007).

31. Mantovani, A., Garlanda, C. \& Locati, M. Macrophage diversity and polarization in atherosclerosis: a question of balance. Arterioscler Thromb Vasc Biol 29, 1419-1423 (2009).

32. Swirski, F.K., Weissleder, R. \& Pittet, M.J. Heterogeneous in vivo behavior of monocyte subsets in atherosclerosis. Arterioscler Thromb Vasc Biol 29, 1424-1432 (2009).

33. Hostager, B.S. Roles of TRAF6 in CD40 signaling. Immunol Res 39, 105-114 (2007).

34. Tsukamoto, N., Kobayashi, N., Azuma, S., Yamamoto, T. \& Inoue, J. Two differently regulated nuclear factor kappaB activation pathways triggered by the cytoplasmic tail of CD40. Proc Natl Acad Sci U S A 96, 12341239 (1999).

35. Mukundan, L., et al. TNF receptor-associated factor 6 is an essential mediator of CD40-activated proinflammatory pathways in monocytes and macrophages. J Immunol 174, 1081-1090 (2005).

36. Kobayashi, T., et al. TRAF6 is a critical factor for dendritic cell maturation and development. Immunity 19, 353-363 (2003).

37. Ait-Oufella, H., et al. Natural regulatory T cells control the development of atherosclerosis in mice. Nat Med 12, 178-180 (2006).

38. Urbich, C., et al. Upregulation of TRAF-3 by shear stress blocks CD40-mediated endothelial activation. I.Clin.Invest 108, 1451-1458 (2001).

39. Vallabhapurapu, S., et al. Nonredundant and complementary functions of TRAF2 and TRAF3 in a ubiquitination cascade that activates NIK-dependent alternative NF-kappaB signaling. Nat Immuno/ 9, 1364-1370 (2008).

40. Au, P.Y. \& Yeh, W.C. Physiological roles and mechanisms of signaling by TRAF2 and TRAF5. Adv Exp Med Biol 597, 32-47 (2007).

41. Bishop, G.A. \& Xie, P. Multiple roles of TRAF3 signaling in lymphocyte function. Immunol Res 39, 22-32 (2007).

42. Lutgens, E., et al. Disruption of the cathepsin $\mathrm{K}$ gene reduces atherosclerosis progression and induces plaque fibrosis but accelerates macrophage foam cell formation. Circulation 113, 98-107 (2006).

43. Kanters, E., et al. Inhibition of NF-kappaB activation in macrophages increases atherosclerosis in LDL receptor-deficient mice. J Clin Invest 112, 1176-1185 (2003). 
44. Beckers, L., et al. Disruption of hedgehog signalling in ApoE - /- mice reduces plasma lipid levels, but increases atherosclerosis due to enhanced lipid uptake by macrophages. J Pathol 212, 420-428 (2007).

45. Koenen, R.R., et al. Disrupting functional interactions between platelet chemokines inhibits atherosclerosis in hyperlipidemic mice. Nat Med 15, 97-103 (2009).

46. Soehnlein, O., et al. Neutrophil secretion products pave the way for inflammatory monocytes. Blood $\mathbf{1 1 2}$ 1461-1471 (2008). 


\section{DISCUSSION}


The CD40-CD40L dyad is one of the most potent co-stimulatory dyads in atherosclerosis. ${ }^{1,2}$ Genetic CD40L deficiency as well as pharmacological inhibition of CD40L results in the development of a stable atherosclerotic plaque phenotype and protects against aneurysm formation (chapter 4). ${ }^{3-5}$ Postulated mechanisms of this effect on plaque phenotype are the down-regulation of proinflammatory pathways and up-regulation of collagen-promoting factors like transforming growth factor $\beta$ (TGF- $\beta$ ). ${ }^{3}$ This phenotype can even be established when antibody treatment is delayed until advanced plaques have developed. ${ }^{3}$ However, the mechanisms of CD40-CD40L signaling are complex. In atherosclerotic lesions both $\mathrm{CD} 40$ and $\mathrm{CD} 40 \mathrm{~L}$ are expressed on the vast majority of immune and non-immune cells present in the plaque, as well as on monocytes and platelets in the circulation suggesting cell type specific CD40-CD40L interactions. ${ }^{6}$ The contribution of CD40(L) signaling in each of the different cell types towards plaque development has been unknown thus far. In addition, CD40 signal transduction pathways are multiple and depend on the cell-type and pathology involved. In this thesis, we therefore aimed to elucidate cell-type specific CD40-CD40L interactions and to identify the CD40 downstream signaling cascades important in atherogenesis. The main findings of these studies are that:

1. TGF- $\beta$ signaling in cells of the innate immune system is atheroprotective.

2. Activated platelet $\mathrm{CD} 40 \mathrm{~L}$ is pro-atherogenic by mediating leukocyte and endothelial cell activation.

3. Deficiency of leukocyte CD40 reduces atherosclerosis and induces plaque stability.

4. CD40 in atherosclerosis signals through TRAF6. Deficiency of CD40-TRAF6 interactions reduces the adhesion and infiltration of inflammatory monocytes to and into the arterial wall, thereby abolishing atherosclerotic plaque formation.

\section{TGF- $\beta$ signaling in CD11c positive cells is atheroprotective}

TGF- $\beta$ is a potent regulatory cytokine with a wide range of effects on growth, differentiation, extracellular matrix accumulation and the immune system. Besides its prominent role in cancer, TGF- $\beta$ is also involved in cardiovascular disease. Our group and others recognized TGF- $\beta$ in atherosclerosis as an anti-inflammatory and pro-fibrotic cytokine. ${ }^{7,8}$ Interestingly, we also demonstrated that inhibition of CD40L induced increased expression of TGF- $\beta$ in the atherosclerotic lesion. This suggests that upregulation of TGF- $\beta$ might be associated with the CD40L inhibition-induced fibrotic plaque phenotype. ${ }^{8}$ These findings demonstrate the fundamental role of TGF- $\beta$ signaling in regulating atherosclerosis related immune responses.
Robertson et al. studied the effects of TGF- $\beta$ signaling in cells of the adaptive immune system and showed that abrogation of TGF- $\beta$ signaling in T-cells increased atherosclerosis and suggested that TGF- $\beta$ reduces atherosclerosis by dampening T-cell activation. ${ }^{9,10}$ In this thesis we investigated the effects of TGF- $\beta$ signaling in cells of the innate immune system. We found that blocking TGF- $\beta$ signaling in CD11c positive cells accelerated the development of atherosclerosis in ApoE deficient mice and favoured the development of lesions with increased inflammation and decreased collagen content. In addition, a disturbed Tcell homeostasis was observed. These data show that TGF- $\beta$ is an important regulator on the verge of the innate and adaptive immune response in atherosclerosis. TGF- $\beta$ signaling indirectly dampens adaptive immune responses by inhibiting dendritic cells (DC) to prime T-cells towards an effector T-cell phenotype. Agonising TGF- $\beta$ signaling in dendritic cells will therefore decrease T-cell priming and inflammation.

These data significantly contribute to the understanding of TGF- $\beta$ signaling in atherosclerosis and underline the important role of TGF- $\beta$ in regulating immune responses in atherogenesis. Unfortunately, there are a number of obstacles to TGF- $\beta$ therapy. TGF- $\beta$ signaling is highly dependent on the environmental milieu, and can be either beneficial or detrimental. In neoplastic disease, TGF- $\beta$ suppresses the progression of early tumors, but later this effect is lost and cancer cells produce TGF- $\beta$, which then promotes metastasis. ${ }^{11,12}$ Moreover, chronic administration has led to interstitial fibrosis, hepatic fibrosis and several other pathologies. ${ }^{13}$ Targeted induction of TGF- $\beta$ signaling in dendritic cells and T-cells might circumvent these adverse side effects.

\section{Activated platelet CD40L is pro-atherosclerotic}

In chapter 6 we identified, by a cell-transfer approach, platelet CD40L as a powerful leukocyte and endothelial cell activator in atherosclerosis. We identified that platelets, through CD40-CD40L interactions, transactivate their cellular interaction partners, resulting in adhesion, chemotaxis and migration. Injections of activated platelets therefore resulted in an increase in atherosclerotic lesions formation, a process that was not observed when activated platelets, deficient in CD40L, were administered. Even more, through the formation of platelet-leukocyte aggregates, mediated by CD40L-CD40 interactions, platelets and leukocytes "inflame" each other in order to promote vascular inflammation. Thus, not only activated platelets, but also platelet-leukocyte aggregates can be considered to have a specific pro-inflammatory, atherogenic propensity, which is reflected by the increased numbers of platelet-leukocyte-aggregates in the circulation of patients suffering from cardiovascular disease. ${ }^{14}$ 
There is a substantial drawback to anti-platelet CD40L therapy as we showed that CD40L deficient platelets have a defective thrombus formation, causing unstable thrombi. Andre et al. ${ }^{15}$ illustrated that platelet $\mathrm{CD} 40 \mathrm{~L}$ is able to bind to the integrin $\alpha \mathrm{llb} \beta 3$, which is the key adhesion molecule mediating platelet aggregation. ${ }^{16}$ Inhibiting platelet CD40L will therefore cause unstable thrombi. As a potential alternative to platelet CD40L, we targeted in a platelet study platelet CD40. In those preliminary experiments no unstable thrombi were detected, suggesting that deficiency of CD40 in platelets does not affect platelet aggregation. Those experiments also suggest an atherogenic potential of platelet CD40. Compared to mice that were frequently injected with activated wild type platelets, injections of activated platelets deficient in CD40 was even more effective then injections of activated platelets deficient in CD40L (fig. 9.1). Altough the animal model we used in this thesis provided us with novel insights regarding the role of platelet $\mathrm{CD} 40(\mathrm{~L})$ in atherosclerosis we will further explore the exact mechanisms of platelet CD40-CD40L interactions using new research tools, such as conditional knock out models. In fact, we are currently developing a conditional knock-out for CD40 and CD40L using the cre-lox system which will enable us to study platelets in a more physiological setting (PF4cre x CD40LloxP).

\section{From CD40L towards its receptor CD40}

Blockade of CD40L may not be therapeutically feasible, since long-term inhibition will compromise systemic immune responses, and platelets deficient in CD40L can cause thromboembolic events (chapter 6). Antagonising CD40, the receptor of CD40L, or its signaling intermediates provides a sound alternative providing a number of advantages. Of first importance is the fact that we were able to demonstrate that blocking platelet CD40 does not affect platelet aggregation. Second, studying the receptor CD40, enabled us to focus on the different downstream signaling pathways, which could eventually lead towards a more effective, targeted and safe inhibition of atherosclerosis related CD40 pathways. Third, the CD40 receptor is expressed on the majority of the cell-types implicated in atherogenesis, which allows us to determine cell type specific effects of CD40 signaling.

\section{Deficiency of leukocyte CD40 reduces atherosclerosis and induces plaque} stability.

In this thesis we demonstrate that mice, deficient in CD40, were protected from both neointima and atherosclerosis formation. In both models, a decrease in inflammation was observed. CD40 deficiency in leukocytes, obtained by bone marrow transplantation, induced comparable favourable plaque morphology, indicating that leukocyte-CD40 is the responsible cell type. Regarding cell-type specificity, the CD40-related leukocyte effects can be accorded to dendritic cells, macrophages and B-cells. A decrease in both macrophages and T-cells was detected in CD40-/-ApoE-/- animals and in addition, deficiency of CD40 in macrophages induced a polarization towards an anti-inflammatory M2 phenotype. M2 cells tune inflammation and adaptive immunity by secreting various factors, which suppress T-cells and induce Treg recruitment. ${ }^{17,18} \mathrm{M} 2$ cells are also believed to promote tissue remodeling and repair. ${ }^{17}$ These data clearly establish the functional importance of CD40 signaling in macrophages.

Dendritic cells (DC) also express large amounts of CD40. Several studies illustrated the presence of dendritic cells in all stages of atherosclerosis. However, their function in atherosclerosis remains indistinct. Multiple indications point towards an effect of DC-CD40 in our study. CD40 deficiency altered DC phenotype and an increased infiltration of T-cells was seen in the lesions, which is indirectly caused by DCs, since naïve T-cells require priming by DCs before they can enter the lesion. We believe it is appropriate to study the role of DC specific CD40 signaling in atherosclerosis by performing adoptive transfer studies, which will also help to further elucidate the role of DCs in atherosclerosis.

In conclusion, we state that leukocyte CD40 is mandatory in the progression of atherosclerosis. Both macrophage CD40 and dendritic cell CD40 are responsible and open the door towards the exploration of downstream CD40 signaling pathways in these cell-types.

\section{CD40 in atherosclerosis signals through TRAF6}

Since we were able to demonstrate the fundamental effect of leukocyte CD40 in atherosclerosis, we next investigated downstream signaling of CD40 in this cell type. Like other TNF receptor family members, CD40 lacks intrinsic signaling capacity and requires the recruitment of TNF-receptor associated factors (TRAFs), the key-adaptor molecules in CD40 signaling. ${ }^{19-22}$ The interactions between CD40 and the different members of the TRAF family is a highly dynamic process and is dependent on the cell-type where CD40 is expressed and on the function that is required..$^{23}$ TRAF2,3, and 6 are expressed in most cell types, whereas the expression patterns of TRAF1, 4 and 5 are more restricted. ${ }^{19}$ In literature, total TRAF deletion has been extensively described. ${ }^{22}$ The phenotypes of these knock out mice reveal divergent roles for each TRAF molecule. Thus, despite their similarities in signaling pathways, each TRAF protein appears to have a distinct physiological role.

In chapter $\mathbf{7}$ and $\mathbf{8}$ we studied the effects of modulating the different CD40 binding sites in $\mathrm{MHCll}$ expressing leukocytes. We identified that the CD40-TRAF6 binding site is decisive in vascular biology. Both in neointima formation and atherogenesis, TRAF6 appeared to be the principal adaptor molecule for leukocyte CD40-signaling. The reduction in atherosclerosis was even more pronounced than in total CD40-/-ApoE-/- mice suggesting po- 
tential anti-inflammatory effects of the remaining signaling pathways (CD40-TRAF2/3/5). Manipulation of the CD40-TRAF6 by using small molecules against the TRAF6 binding site or against the part of TRAF6 that is crucial for binding CD40, or an antagonizing CD40 antibody that changes the conformation of the CD40 TRAF binding sites may allow selective modulation of proatherogenic functions of CD40L and could therefore improve the outcome of anti-CD40 related therapies. ${ }^{24,25}$

Altogether, these results provide proof of concept that similar approaches could result in the identification of compounds that modulate TRAF6 binding to the CD40 receptor.

\section{Concluding remarks and future perspectives}

The main goal of the studies presented in this thesis was to unravel the mechanisms of CD40-CD40L interactions in atherosclerosis. This thesis provides important insights into the cell-type specificity of CD40-CD40L interactions and on downstream CD40 signaling cascades implicated in the process of atherosclerosis. We recognized that both platelet CD40L and leukocyte CD40 are responsible for the pro-atherosclerotic effects of CD40CD40L interactions. The most important finding of this thesis is that we acknowledge TRAF6 as the key constituent of CD40 signal transduction in atherosclerosis. Blocking the TRAF6 binding site inhibits intracellular signaling pathways aimed at the activation of proinflammatory pathways without interfering with potentially protective effects by the remaining CD40-signaling pathways. These novel concepts on CD40 signaling provide new potential therapeutic targets that will be more efficient and safer than systemic CD40L inhibition.
Figure Legends

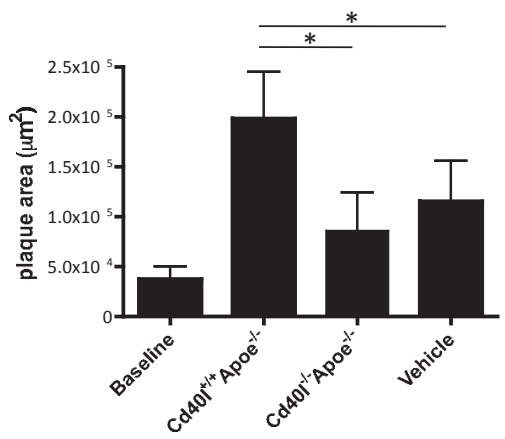

Figure 9.1

Plaque area of 29 wks old ApoE-/- mice injected with activated ApoE-/- or CD40-/-ApoE-/- platelets or PBS (vehicle). Platelets were obtained from donor ApoE-/ of CD4O-/-ApOE-/- mice, activated with thrombin, neutralized with hirudin and injected (3×107 platelets) intravenously once every 5 days in 17 wks old mice during 12 weeks. Baseline animals were ApoE--- mice killed at the start of the experiment (17 wks old) and did not receive any injections. 


\section{References}

1. Engel, D., et al. The immunobiology of CD154-CD40-TRAF interactions in atherosclerosis. Semin Immunol (2009).

2. Lievens, D., Eijgelaar, W.J., Biessen, E.A., Daemen, M.J. \& Lutgens, E. The multi-functionality of CD40L and its receptor CD40 in atherosclerosis. Thromb Haemost 102, 206-214 (2009).

3. Lutgens, E., et al. Both early and delayed anti-CD40L antibody treatment induces a stable plaque phenotype. Proc Natl Acad Sci U S A 97, 7464-7469 (2000).

4. Lutgens, E., et al. Requirement for CD154 in the progression of atherosclerosis. Nat Med 5, 1313-1316 (1999).

5. Mach, F., Schonbeck, U., Sukhova, G.K., Atkinson, E. \& Libby, P. Reduction of atherosclerosis in mice by inhibition of CD40 signalling. Nature 394, 200-203 (1998).

6. Schonbeck, U. \& Libby, P. The CD40/CD154 receptor/ligand dyad. Cell Mol Life Sci 58, 4-43 (2001).

7. Mallat, Z., Gojova, A., Marchiol-Fournigault, C., Esposito, B. \& Kamate, C. Inhibition of transforming growth factor- signaling accelerates atherosclerosis and induces an unstable plaque phenotype in mice. Circ. Res. 89,930 (2001).

8. Lutgens, E., et al. Transforming growth factor-beta mediates balance between inflammation and fibrosis during plaque progression. Arterioscler Thromb Vasc Biol 22, 975-982 (2002).

9. Robertson, A.K., et al. Disruption of TGF- signaling in T cells accelerates atherosclerosis. J. Clin. Invest. 112, 1342 (2003).

10. Robertson, A.K. \& Hansson, G.K. T cells in atherogenesis: for better or for worse? Arterioscler Thromb Vasc Biol 26, 2421-2432 (2006).

11. Li, M.O., Wan, Y.Y., Sanjabi, S., Robertson, A.K. \& Flavell, R.A. Transforming growth factor-beta regulation of immune responses. Annu Rev Immunol 24, 99-146 (2006).

12. Gordon, K.J. \& Blobe, G.C. Role of transforming growth factor-beta superfamily signaling pathways in human disease. Biochim Biophys Acta 1782, 197-228 (2008).

13. Terrell, T.G., Working, P.K., Chow, C.P. \& Green, J.D. Pathology of recombinant human transforming growth factor-beta 1 in rats and rabbits. Int Rev Exp Pathol 34 Pt B, 43-67 (1993).

14. van Gils, J.M., Zwaginga, J.J. \& Hordijk, P.L. Molecular and functional interactions among monocytes, platelets, and endothelial cells and their relevance for cardiovascular diseases. J Leukoc Biol 85, 195-204 (2009).

15. Andre, $\mathrm{P}$. , et al. CD40L stabilizes arterial thrombi by a beta 3 integrin--dependent mechanism. Nat Med 8 , 247-252 (2002).

16. Denis, C.V. \& Wagner, D.D. Platelet adhesion receptors and their ligands in mouse models of thrombosis. Arterioscler Thromb Vasc Biol 27, 728-739 (2007).

17. Martinez, F.O., Helming, L. \& Gordon, S. Alternative activation of macrophages: an immunologic functional perspective. Annu Rev Immunol 27, 451-483 (2009).

18. Ilkovitch, D. \& Lopez, D.M. Immune modulation by melanoma-derived factors. Exp Dermatol 17, 977-985 (2008)

19. Zirlik, A., et al. TRAF-1, $-2,-3,-5$, and -6 are induced in atherosclerotic plaques and differentially mediate proinflammatory functions of CD40L in endothelial cells. Arterioscler Thromb Vasc Biol 27, 1101-1107 (2007).

20. Wajant, H., Henkler, F. \& Scheurich, P. The TNF-receptor-associated factor family: scaffold molecules for cytokine receptors, kinases and their regulators. Cell Signal 13, 389-400 (2001).
21. Lee, S.Y. \& Choi, Y. TRAF-interacting protein (TRIP): a novel component of the tumor necrosis factor receptor (TNFR)- and CD30-TRAF signaling complexes that inhibits TRAF2-mediated NF-kappaB activation. J Exp Med 185, 1275-1285 (1997).

22. Arron, J.R., Walsh, M.C. \& Choi, Y. TRAF-mediated TNFR-family signaling. Curr Protoc Immunol Chapter 11, Unit 11 19D (2002).

23. Harnett, M.M. CD40: a growing cytoplasmic tale. Sci STKE 2004, pe25 (2004).

24. Zapata, J.M., Lefebvre, S. \& Reed, J.C. Targeting TRAfs for therapeutic intervention. Adv Exp Med Biol 597, 188-201 (2007).

25. Fournel, S., et al. C3-symmetric peptide scaffolds are functional mimetics of trimeric CD4OL. Nat Chem Biol 1, 377-382 (2005) 
SUMMARY/SAMENVATTING 
Atherosclerosis is a chronic inflammatory disease of the large arteries that is characterized by the deposition of lipids, inflammatory cells and fibrous material in the arterial wall. Rupture of an atherosclerotic plaque and subsequent thrombus formation is the most important cause of acute cardiovascular incidents, including myocardial infarction and stroke.

A system that has been shown to efficiently modulate plaque stability is the CD40-CD40L dyad. CD40 is a member of the tumor necrosis factor receptor (TNF-R) superfamily that is activated by CD40 ligand (CD40L). In atherosclerotic lesions both CD40 and CD40L are expressed on the majority of immune and non-immune cells. However, the contribution of $C D 40(L)$ signaling in each of these different cell types towards plaque development has been unknown thus far. Therefore, the main goal of the studies presented in this thesis was to unravel the mechanisms of CD40-CD40L interactions in atherosclerosis.

We identified that both platelet $\mathrm{CD} 40 \mathrm{~L}$ and leukocyte $\mathrm{CD} 40$ are responsible for the proatherogenic effects of CD40-CD40L interactions. First, experimental work in this thesis (chapter 6) demonstrated that administration of CD40L expressing platelets exacerbates atherosclerosis by bridging the activation of leukocytes and the endothelium, thereby promoting leukocyte adhesion to the endothelium. Injection of platelets, deficient in CD40L, significantly reduced plaque size, but failed to induce true stable plaques, which can be obtained by total CD40L inhibition. In a different approach (chapter 4), we were able to confirm the inflammatory role of CD40L. Deficiency of CD40L protected against aneurysm formation by reducing the influx and activation of inflammatory cells and by decreasing matrix metalloproteinases (MMP). In addition, previous studies of our group demonstrated that inhibition of CD40L induced TGF- $\beta$ expression. TGF- $\beta$ is an important anti-inflammatory cytokine in vascular biology. However, its function in cells of the innate immune system remains largely unknown. In this thesis (chapter 5) we describe that disrupting TGF- $\beta$ signalling in CD11c positive cells results in a disturbed T-cell homeostasis, thereby accelerating the development of atherosclerosis and inducing a pro-inflammatory plaque phenotype. These data underline the important role of TGF- $\beta$ signaling in CD11c positive cells in regulating immune responses in atherogenesis.

Next, we shifted our research from the CD40 ligand (CD40L) to its receptor, CD40 (chapter 7 and 8). Mice deficient in CD40 were protected from both neointima and atherosclerosis formation. The decrease in atherosclerosis was accompanied by a stable plaque phenotype. Transplanting CD40 deficient bone marrow cells into LDL receptor knock-out animals brought about identical results, demonstrating the importance of leukocyte CD40 in atherogenesis. A decrease in both macrophages and T-cells was detected in CD40-/ApoE-/- animals and in addition, deficiency of CD40 in macrophages induced a polarization towards an anti-inflammatory M2 phenotype.
The next goal of this thesis was to explore CD40 downstream signalling cascades and identify atherosclerosis-associated CD40-TRAF pathways (chapter 7 and 8). This led to a very important finding of this thesis: CD40-TRAF6, but not CD40-TRAF2/3/5 signaling is pivotal in vascular disease TRAF6 as the key constituent of CD40 signal transduction. Blocking the TRAF6 binding site inhibits intracellular signaling pathways aimed at the activation of proinflammatory pathways without interfering with the remaining CD40-signaling pathways.

Finally, we conclude that the novel biological knowledge obtained by the experimental work of this thesis provides important insights into the cell-type specificity of CD40-CD40L interactions and on downstream CD40 signaling pathways implicated in the development of atherosclerosis. 
Atherosclerose (aderverkalking) is een chronische inflammatoire aandoening van de grote arteriën die gekarakteriseerd wordt door de depositie van vet, ontstekingscellen en bindweefsel in de vaatwand. Een atherosclerotische plaque of laesie is opgebouwd uit een necrotische, vetrijke kern die omgeven wordt door een bindweefselrijk kapsel. Complicaties van atherosclerose, zoals het hartinfarct en herseninfarct zijn in de Westerse wereld verantwoordelijk voor de hoogste morbiditeit en mortaliteit en zijn meestal het gevolg van een plaque ruptuur. Hierbij ontstaat een thrombus (bloedstolsel) waardoor de toevoer van bloed wordt afgesneden.

Het CD40-CD40L receptor-ligand systeem is een belangrijk co-stimulatoir systeem, cruciaal in de regulatie en activatie van verschillende celtypes van zowel het aangeboren als het adaptieve immuunsysteem. Uit dierstudies is gebleken dat remming van immunologische CD40-CD40L interacties een vermindering van atherosclerose, alsook stabilisatie van plaques teweeg brengt. Het merendeel van de celtypes aanwezig in atherosclerotische plaques brengen het CD40 en/of CD40L tot expressie op hun celmembraan. Echter, de specifieke functie van het $C D 40(L)$ per celtype in atherosclerosis is nog niet bekend. Daarom hebben we met dit proefschrift de specificiteit van CD40-CD40L interacties in verschillende celtypes onderzocht en het mechanisme van CD40 signalering ontrafelt. Dit proefschrift beschrijft dat zowel CD40L op bloedplaatjes als CD40 op leukocyten verantwoordelijk zijn voor het pro-atherogene effect van CD40-CD40L interacties.

In hoofdstuk 6 beschrijven we dat toediening van geactiveerde bloedplaatjes, die CD40L tot expressie brengen aanleiding geeft, tot versnelde atherogenese. Het plaatjes CD40L fungeert als een brug tussen het endotheel en de witte bloedcel en bevordert hierdoor de influx van inflammatoire cellen in de plaque. Daartegenover staat dat indien we plaatjes injecteren die geen $\mathrm{CD} 40 \mathrm{~L}$ tot expressie brengen de versnelde atherogenese teniet gedaan wordt. In hoofdstuk 4 hebben we tevens kunnen aantonen dat CD40L deficiëntie de frequentie van aneurysma's beduidend verlaagt en gaat gepaard met een verlaagde influx en activatie van ontstekingscellen. Tevens is het reeds beschreven dat inhibitie van CD4OL een inductie van TGF- $\beta$ teweegbrengt. TGF- $\beta$ is een belangrijk en anti-inflammatoir cytokine. Niettemin is de functie van dit cytokine bij immuunreacties van het aangeboren (innate) immuunsysteem nog niet bekend. In hoofdstuk 5 hebben we beschreven dat inhibitie van de TGF- $\beta$ receptor in CD11c positieve cellen resulteert in een verstoorde T-cel homeostase. Dit gaf aanleiding tot een versnelde atherogenese en een verhoogde influx van ontstekingscellen in de plaques. Deze studie benadrukt het belang van de TGF- $\beta$ receptor op CD11c positieve cellen in de regulatie van immuunresponsen in atherosclerose.

In hoofdstuk $\mathbf{7}$ en $\mathbf{8}$ van dit proefschrift hebben we ons onderzoek toegespitst op de receptor van CD40L, namelijk CD40. Muizen, deficiënt in CD40, bieden bescherming tegen zowel neo-intima formatie als de ontwikkeling van atherosclerose. In beide modellen gaat de verminderde atherosclerose gepaard met de vorming van een stabiel plaque fenotype.
CD40 beenmergtransplantaties brachten gelijkaardige resultaten met zich mee, wat het belang van leukocytair CD40 aantoont. Een vermindering in zowel macrofagen als T-cellen was aantoonbaar in de plaques en daarenboven induceert CD40 deficiëntie in macrofagen een polarisatie naar een anti-inflammatoir M2 fenotype. Het volgende doel van deze thesis was om de CD40 downstream pathways te onderzoeken. Dit onderzoek leidde tot een zeer belangrijke bevinding van deze thesis. We hebben namelijk aangetoond dat TRAF6 het belangrijkste signaaltransductie element is in de CD40 signaaltransductie cascade. Inhibitie van de TRAF6 bindingsplaats op CD40 blokkeert namelijk een deel van de ontstekingsprocessen zonder de andere functies van CD40-signaaltransductie teniet te doen.

Tot slot kunnen we concluderen dat de kennis verkregen in dit proefschrift een belangrijke bijdrage levert in de inzichten in de rol van het immuunsysteem, en van CD40-CD40L interacties in het bijzonder, in de pathogenese van atherosclerose. Deze nieuw verworven kennis kan bijdragen tot het ontwikkelen van meer doelgerichte therapeutische agentia tegen atherosclerose. 


\section{CURRICULUM VITAE}




\section{Education history}

\begin{tabular}{|ll}
\hline $2005-2009$ & $\begin{array}{l}\text { University of Maastricht (MAASTRICHT) } \\
\text { Education: PhD student }\end{array}$ \\
\hline $2002-2005$ & $\begin{array}{l}\text { Brussels Free University (BRUSSELS) } \\
\text { Education: Master in Biomedical Sciences }\end{array}$ \\
\hline $1999-2002$ & $\begin{array}{l}\text { Katholieke Hoge School Brugge Oostende (BRUGES) } \\
\text { Education: Bachelor in Medical Laboratory Technology }\end{array}$ \\
\hline $1997-1999$ & $\begin{array}{l}\text { Sint Franciscus Xaverius Instituut (BRUGES) } \\
\text { Secondary scientific education }\end{array}$ \\
\hline $1995-1997$ & Lycée General Leclerc (STRASBOURG) \\
\hline $1992-1995$ & Sint Franciscus Xaverius Instituut (BRUGES)
\end{tabular}

\section{International research}

2008 Research at the Dept. of Pathology, Prof. Dr. D. Wagner, Harvard Medi-
cal School, Boston, MA, USA (4 months)
2007 Research at the Dept. of Molecular Cardiovascular Research and Cardi-
ology, Prof. Dr. C. Weber, RWTH Aachen, Aachen, Germany (1 month)
Research at the Howard Hughes Institute of Immunobiology, Prof. Dr.
R. Flavell, Yale School of Medicine, New Haven, CT, USA (1 month)

\section{Publications}

Loges S, Schmidt T, Tjwa M, Van Geyte K, Lievens $D$, Lutgens E, Vanhoutte $D$, Borgel $D$, Plaisance D, Hoylaerts M, Luttun A, Dewerchin M, Jonckx B, and Carmeliet P. Malignant cells fuel tumor growth by educating infiltrating leukocytes to produce the mitogen Gas6. Blood, Nov 2009; doi:10.1182

Lievens $D$, Eijgelaar W, Biessen $\mathrm{E}$, Daemen M, Lutgens $\mathrm{E}$. The multi-functionality of CD40L and its receptor CD40 in atherosclerosis. Thromb Haemost. 2009 Aug;102:206-14.

Engel D, Seijkens T, Poggi M, Sanati M, Thevissen L, Beckers L, Wijnands E, Lievens D, Lutgens E.The immunobiology of CD154-CD40-TRAF interactions in atherosclerosis. Semin Immunol. 2009 Jul 16 [Epub ahead of print].

Duerschmied D, Canault M, Lievens D, Brill A, Cifuni SM, Bader M, Wagner DD. Serotonin stimulates platelet receptor shedding by tumor necrosis factor-alpha-converting enzyme (ADAM17). J Thromb Haemost. 2009 Jul;7(7):1163-71.

Donners M, Beckers L, Lievens D, Munnix I, Heemskerk J, Janssen B, Ahonen C, Newby $A$, Noelle R, Daemen M, Lutgens E. The CD40-TRAF6 axis is the key regulator of the CD40/CD40L system in neointima formation and arterial remodeling. BLOOD. 2008 May 1;111(9):4596-604.

In't Veld P, Lievens D, De Grijse J, Ling Z, Van der Auwera Bart, Pipeleers-Marichal M, Gorus F, Pipeleers D. Insulitis in autoantibody-positive organ donors. Diabetes. 2007 Sep;56(9):2400-4.

Lutgens E, Lievens D, Beckers L, Donners M, Daemen M. CD40 and its ligand in atherosclerosis. Trends Cardiovasc Med. 2007 May;17(4):118-23.

\section{Grants and awards}

\begin{tabular}{ll}
2009 & $\begin{array}{l}\text { DAS-fellowship for best scientific presentation } \\
\text { Dutch Atherosclerosis Society (DAS) }\end{array}$ \\
\hline 2008 & PhD student travel grant (6 months) \\
& Nederlandse Hartstichting (NHS) \\
& Dr. D Wagner, Harvard Medical School, Boston, USA \\
& Merit award for young investigators \\
& American Heart Association (AHA) council on ATVB
\end{tabular}


DANKWOORD 
Professor Daemen en Dr. Lutgens, beste Mat en Esther, 4 jaar geleden ben ik in mijn beste maatpak naar Maastricht gekomen voor mijn sollicitatiegesprek. Ons gesprek was kort maar krachtig, typerend voor de komende jaren. Jullie hebben me direct het gevoel gegeven dat ik terecht gekomen was in een researchgroep op wereldniveau. Mat, na onze eerste werkbespreking gaf je aan dat ik veel te veel de brave Belg was en meer de assertieve Nederlander moest worden. Of dat gelukt is, laat ik in het midden, maar vandaag, 4 jaar later, ben ik aan het eind gekomen van een fantastische periode. Jullie hebben me vanaf dag 1 ondergedompeld in de fascinerende en boeiende wereld van hart- en vaatziekten. Jullie hebben me niet opgesloten in het lab, maar hebben mij de kans gegeven om een stukje van de wereld te verkennen. Zodoende heb ik meerdere malen mijn koffers gepakt om te proeven van het onderzoeksleven in topinstituten als Yale en Harvard. Geweldige kansen die naast het onderzoek grootse momenten in mijn persoonlijke ontwikkeling geweest zijn. Vandaar dat ik jullie wil danken. Jullie zijn de meest inspirerende mensen die ik in mijn korte carrière ontmoet hebt. Mat, uw "ja" is ja en uw "nee" is nee, "misschien" komt niet in uw woordenschat voor. Bedankt voor de ongelofelijke input, de unieke kansen en de springplank naar de toekomst. Esther, ik weet niet waar te beginnen. Je bent een wetenschapper in hart en nieren. Je visie op research is bewonderenswaardig en je manier van aanpak is dit nog veel meer. Hoe je het allemaal in 24 uur per dag gedaan krijgt, weet ik nog steeds niet. Ik heb ongelofelijk veel van je geleerd. Je hebt me steeds mijn eigen ding laten doen, maar me toch steeds gestuurd, bijgestaan en gesteund. Mijn respect voor jou is oneindig groot.

Professor Biessen, beste Erik. Ongeveer midden in mijn AlO-track ben je naar Maastricht gekomen. Je had de moeilijke taak om het roer van Mat over te nemen en je toplab in Leiden achter te laten. Je hebt dit fantastisch gedaan! Je input als promotor is groot. Vanaf dag 1 was je een volwaardige promotor. Ik kon op ieder moment van de dag bij je binnen springen. Je ideeën zijn oneindig en je loyaliteit immens. Elke dag maak je tijd om bij ieder van ons eens stil te staan en te polsen naar onze progressie. Ik benijd je aanpak en ben je dankbaar voor de gekregen kansen.

Dit boekje is tevens tot stand gekomen door 2 vrienden voor het leven. Lieve Linda, beste Erwin, jullie bijdrage aan dit boekje is onwaarschijnlijk groot. Elke andere AIO benijd me hiervoor. En gelijk hebben ze! Jullie zijn de bouwstenen van het CD40 team, dat zal ieder CD40 lid onder ons met veel plezier toegeven. Maar jullie zijn nog veel meer dan uitstekende analisten. Linda, vanaf dag 1 heb je voor ons gezorgd. Weet je nog de eerste avond dat Erwin en ik langskwamen en dat we op het eind van de avond (waarschijnlijk) onze voornaam niet meer konden uitspreken: "er zit een gat in mijn gitaar waar ik mijn flesjes in bewaar van Jupiler..." Je talloze fantastische kookavonden. Man, man, man, wat hebben Erwin en ik steeds uitgekeken naar je kookkunsten. Kortom, je bent er gewoon altijd, no matter what. Merci meid. Echt! Erwin, we zijn samen begonnen. Je hebt me zover gekregen om een fiets te kopen. Het laatste jaar hebben we niet veel meer samen gefietst (om de eenvoudige reden dat ik niet veel meer fiets) en dat mis ik wel. We moeten zeker de draad weer opnemen. Ooit wil ik die Alpen eens door met mijn "vélo". Tevens ben je het laatste jaar een beetje mijn mental coach geweest. Je wist me steeds te stimuleren, we hebben uren achter het FACS apparaat gezeten en je wetenschappelijke creativiteit is om je vingers van af te likken. Ook heb je die echte Nederlandse assertiviteit waar ik nog niet eens van durf te dromen. Thanks mate! Vandaar dat jullie ook zonder enige twijfel de paranimfen van dit boekje zijn. Besef dat dit evenveel jullie boekje is als het mijne.

Natuurlijk zijn er nog ontelbaar veel mensen van het lab die bijgedragen hebben aan dit boekje. Ten eerste moet ik de AlO/postdoc dames van het eerste uur danken. Judith, Marjo, Natasja, Suus, Kitty en Lili. Als een verlegen jongetje ben ik terechtgekomen in jullie kantoor. Als brave Belg werd ik al snel gebombardeerd tot Chicken little. Bedankt voor de aangename tijd. Judith, samen hebben we een jaar een kantoor gedeeld op de derde verdieping. Bedankt voor alle hulp, tips en trics. Ik wens je veel succes op je nieuwe baan en alvast welkom terug. Ook de andere (nieuwe) AIO/postdocs wil ik danken. Annette, Bea, Brenda, David, Indira, Isabelle, Marjorie, Marco, Timo en Tom, ik wens jullie nog veel succes en geniet vooral van jullie tijd op de pathologie. Ook het analisten team Anique, Ine, Clairy, Mirte, Mathijs, Mat, en Jeffry wil ik bedanken. Barry, dank je voor de ontelbare films, de $20 \mathrm{~kg}$ spiermassa verkregen door al ons sporten en vooral merci voor de leuke vriendschap. Succes met je PhD. Veronica, hola guapa, thanks for all your support, friendship and smartphones! Beste Jack, professor in de kwantimetologie, je hebt me het leven een stuk eenvoudiger gemaakt dankzij je gigantische kennis van morfometriesoftware. Bedankt voor al je hulp. Sylvia, beste Dr. Heeneman, bedankt voor al het verbeterwerk, vragen, interesse of gewoon een babbel.

Maar als ik er eentje in het daglicht wil zetten is het Wouter. We hebben heel wat dagen samen versleten, op elkaars bek gekeken en gebrainstormd. Je bent een groots persoon, een fantastische AlO en vooral een toffe vriend. Veel succes met alles wat je ondernemen gaat en we moeten snel nog eens een whisky tasting organiseren. Cor, Elly, Danielle en alle andere dames van het secretariaat, bedankt voor alle hulp. Benoit en zijn team, bedankt voor de 1000den HE coupes die ik op jullie lab mogen kleuren heb. Robert-Jan en Ruud. Ik heb veel plezier beleefd aan onze golfpartijtjes. Het waren er veel te weinig, maar er zullen er vast nog veel volgen.

Onderzoek bij Esther zonder proefdieren bestaat niet. Rik, Richard, Saskia en het volledige CPV team, bedankt voor jullie flexibiliteit en hulp. Ook de mensen van farmacologie mogen niet ontbreken. Jacques, Peter, Agnieszka en Ben. We hebben jullie lab ettelijke malen platgelopen met onze proefdieren. Sorry voor het ongemak en bedankt voor de gastvrijheid. 
Dankzij het uitgebreide netwerk van Esther, is dit boekje mede tot stand gekomen dankzij vele samenwerkingen. First, I want to thank Prof. Dr. C. Weber. Dear Christian, I'm grateful for the input and many intravital studies but above all special thanks for accepting me as a post-doc in your lab. I'm looking forward to the comming years. Prof. Dr. Flavell, AnnaKarin and Yasmina, thanks for the great time in Yale. Prof. Dr. Wagner, dear Denisa, I want to express my gratitude for the opportunity to perform research in your lab. Daniel, Matthias, Benoit, Steve, Meghan, lan, Tobias and of course dear Carla, thanks for an unforgettable time in Boston. Many memories for life. Hope to see all of you back soon. Dear Dr. Heemskerk, beste Johan, bedankt voor al je bloedplaatjes kennis en voor het grote welkom gevoel in je lab. Dat we maar snel een plaatjes-vervolgstudie opstarten. Prof. Kuiper, beste Johan, meerdere weken heb ik in je lab mogen vertoeven. Dankzij Kim hebben we er mooie resultaten geboekt. Zoals Kim het in haar proefschrift reeds aangeeft: Die België - Nederland samenwerking is "rock sollid". Thanks! Beste Prof. Van Zandvoort, beste Marc en Timo. Bedankt om mij onder te dompelen in de fascinerende wereld van multi-photon. Hopelijk kunnen we nog veel samenwerken en veel nature medicine waardige figuren produceren. Tot slot wil ik nog het labo van Dr. de Winther bedanken. Menno, Marion, Inge, Pieter, Lauran en alle anderen, bedankt voor de leuke samenwerkingen, congressen, muizen-autopsies, atherosclerosis club, vriescoupes, antibodies, buffers, CBA, FACS en noem maar op...

Lieve papa en mama, bedankt voor de oneindige steun en onvoorwaardelijke liefde. Eigenlijk zijn er geen woorden genoeg om jullie te op te hemelen. Alles heb ik aan jullie te danken! Ik weet dat jullie fier zullen zijn met een zoon die Dr. voor zijn naam mag plaatsen. Ik doe mijn uiterste best om jullie in de toekomst nog vele malen fier te maken. Bedankt voor alles! Met veel plezier draag ik dit boekje aan jullie op. Ook Els, lieve zus, bedankt voor je steun en sorry dat ik er de laatste jaren zo weinig was. Ik zal mijn best doen om meer tijd vrij te maken voor Niels.

Last but not least, lieve schat, liefde van mijn leven, dit boekje is vooral voor jou. We hebben samen al heel wat watertjes doorzwommen. Het was niet altijd even gemakkelijk. We moeten elkaar nog steeds veel missen, maar we zijn er onafscheidelijk door geworden. Boekje is af, en huisje (bijna) ook. 


\section{LIST OF ABBREVIATIONS}




\begin{tabular}{|c|c|c|}
\hline " & AAA & aortic abdominal aneurysm \\
\hline " & ACE & angiotensin converting enzyme \\
\hline " & AHA & American Heart Association \\
\hline " & ALK & activin-like kinase \\
\hline " & ANGII & angiotensin II \\
\hline " & APC & antigen presenting cell \\
\hline " & ApoE & apolipoprotein E \\
\hline " & ASMA & -smooth muscle actin \\
\hline$»$ & BCT & brachiocephalic trunk \\
\hline " & BMT & bone marrow transplantation \\
\hline " & CA & carotid artery \\
\hline$"$ & $\mathrm{CCL}$ & CC chemokine ligand \\
\hline " & $C D$ & cluster of differntiation \\
\hline " & CD40L & CD40 ligand \\
\hline " & CVD & cardiovascular disease \\
\hline " & CXCL & chemokine (C-X-C motif) ligand \\
\hline " & CXCR & chemokine (C-X-C motif) receptor \\
\hline " & CDC & conventional dendritic cell \\
\hline " & DAB & 3,3'-diaminobenzidine \\
\hline " & DC & dendritic cell \\
\hline " & dn & dominant negative \\
\hline " & DNR & dominant negative TGF- RII \\
\hline " & DNA & doxyribonucleic acid \\
\hline " & EAE & experimental autoimmune encephalomyelitis \\
\hline " & EC & endothelial cell \\
\hline " & EEL & external elastic lamina \\
\hline » & ELISA & enzyme-linked immunosorbent assay \\
\hline$»$ & EvG & elastin-von-Giesson staining \\
\hline " & FACS & fluorescence-activated cell sorting \\
\hline " & FoxP3 & forkhead box P3 \\
\hline " & Gas6 & growth arrest specific gene 6 \\
\hline$"$ & HE & haematoxilin and eosin \\
\hline » & ICAM-1 & intracellular adhesion molecule 1 \\
\hline 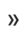 & IEL & internal elastic lamina \\
\hline " & IFN- & interferon gamma \\
\hline " & $\mathrm{IHC}$ & immunohistochemistry \\
\hline " & IL & interleukin \\
\hline " & IT & intimal thickening \\
\hline " & IX & intimal xantoma \\
\hline
\end{tabular}

\begin{tabular}{|c|c|}
\hline JNK & janus kinase \\
\hline LDL-R & low density lipoportein receptor \\
\hline M1 & classically activated macrophage subset \\
\hline M2 & alternatively activated macrophage subset \\
\hline MAPK & mitogen-activated protein kinase \\
\hline MCP-1 & monocyte chemotactic protein 1 \\
\hline M-CSF & macrophage colony-stimulating factor \\
\hline MHC & major histocompatibility complex \\
\hline MIP-1 & macrophage inflammatory protein \\
\hline MMP & matrixmetalloproteinase \\
\hline NFAT & nuclear factor of activated T-cells \\
\hline$N F B$ & nuclear factor kappa B \\
\hline NK cell & natural killer cell \\
\hline OxLDL & oxidized LDL \\
\hline PBS & phosphate buffered saline \\
\hline PCR & polymerase chain reaction \\
\hline $\mathrm{pDC}$ & plasmacytoid dendritic cell \\
\hline PDGF & platelet derived growth factor \\
\hline PF4 & platelet factor 4 \\
\hline $\mathrm{PI} 3$ & phosphoinositide 3-kinase \\
\hline PIT & pathological intimal thickening \\
\hline PLA & platelet-leukocyte aggregate \\
\hline Plt & platelet \\
\hline PSGL-1 & P-selectin glycoprotein ligand-1 \\
\hline RANTES & regulated on activation normal T cell expressed and secreted \\
\hline RNA & ribonucleic acid \\
\hline ROS & reactive oxygen species \\
\hline SCD40L & soluble CD40 ligand \\
\hline SLE & systemic lupus erythematosus \\
\hline SMC & smooth muscle cell \\
\hline TBS & tris buffered saline \\
\hline TFC & thick fibrous cap \\
\hline TGF- & transforming growth factor- \\
\hline TGF RII & transforming growth factor- receptor II \\
\hline Th cell & helper T-lymphocyte \\
\hline TIMP & tissue inhibitor of matrixmetalloproteinases \\
\hline TF & tissue factor \\
\hline TNF & tumor necrosis factor \\
\hline TPLSM & two-photon laser scanning microscopy \\
\hline
\end{tabular}


TNF receptor associated factor regulatory T-cell

vascular cell adhesion molecule

vascular endothelial growth factor

World Health Organization 
